\title{
DEVELOPMENT OF MERCURY AND HYDROGEN CHLORIDE EMISSION MONITORS FOR COAL GASIFIERS
}

\author{
FINAL REPORT \\ to the National Energy Technology Laboratory \\ (Work funded through Work Proposal No. 922-15-1582-01)
}

\author{
Submitted \\ March 9, 2001
}

Glenn A. Norton, David E. Eckels, and

Colin D. Chriswell

Ames Laboratory

Iowa State University

Ames, IA 50011 


\section{TABLE OF CONTENTS}

$\underline{\text { Page }}$

ABSTRACT

EXECUTIVE SUMMARY ii

TABLE OF TABLES viii

TABLE OF FIGURES IX ix

ACKNOWLEDGEMENTS X Xii

INTRODUCTION

OBJECTIVES

BACKGROUND 1

$\begin{array}{ll}\text { APPROACH } & 2\end{array}$

GAS CONDITIONING 4

AMMONIA REMOVAL 4

Copper Reduction Tube $\quad 4$

Platinum Catalyst on Alumina Substrate 4

Platinum Wire Catalyst 6

$\begin{array}{ll}\text { Palladium Wire Catalyst } & 14\end{array}$

Final Design of Catalyst Tube 18

Oxidation Without Catalyst 19

Nafion Tubing 19

$\begin{array}{ll}\text { MOISTURE REMOVAL } & 20\end{array}$

$\begin{array}{ll}\text { TAR REMOVAL } & 20\end{array}$ 


\section{TABLE OF CONTENTS (CONT.)}

$\underline{\text { Page }}$

$\begin{array}{ll}\text { SAMPLING ISSUES } & 21\end{array}$

$\begin{array}{ll}\text { SAMPLE TRANSPORT LINES } & 21\end{array}$

MONITORING FLOW DURING FIELD SAMPLING 23

$\begin{array}{ll}\text { USE OF AN INERTIAL FILTER } & 24\end{array}$

$\begin{array}{ll}\text { MERCURY STUDIES } & 24\end{array}$

SELECTION OF METHODS TO EVALUATE 24

ATOMIC ABSORPTION VS. ATOMIC FLUORESCENCE 25

Overview of Technologies 25

Laboratory Evaluations $\quad 26$

Selection of Analytical Approach $\quad 30$

MERCURY TRANSPORT THROUGH STEEL LINES 31

MERCURY TRANSPORT THROUGH CATALYST BEDS 32

MERCURY TRANSPORT IN NAFION DRYERS 35

GENERAL TRANSPORT AND CONVERSION OF $\mathrm{HgCl}_{2}$

CALIBRATION DEVICES

Elemental Mercury Permeation Tubes $\quad 39$

Mercuric Chloride Permeation Tubes 39

INTERFERENCES IN THE DETERMINATION OF Hg BY AA 40

$\begin{array}{ll}\text { Primary Matrix Gases } & 40\end{array}$

$\begin{array}{ll}\text { Moisture } & 40\end{array}$

Aromatic Hydrocarbons 41

$\mathrm{D}_{2}$ BACKGROUND CORRECTION APPROACH 43

$\begin{array}{ll}\text { Background } & 43\end{array}$

Tests with Optical Breadboard Setup $\quad 44$

Development of Prototype Analyzer 48

Evaluation of Prototype Analyzer $\quad 49$

DESCRIPTION OF Hg ANALYZER AND CEM 57 


\section{TABLE OF CONTENTS (CONT.)}

SELECTION OF METHODS TO EVALUATE 63

GAS FILTER CORRELATION IR 65

$\begin{array}{lc}\text { COLORIMETRIC METHOD } & 68\end{array}$

$\begin{array}{ll}\text { Standard Chemcassette } & 70\end{array}$

Low Level Chemcassette $\quad 71$

$\begin{array}{ll}\text { Discussion } & 73\end{array}$

ION MOBILITY SPECTROSCOPY $\quad 74$

$\begin{array}{ll}\text { Overview of Technology } & 74\end{array}$

$\begin{array}{ll}\text { Laboratory Evaluations } & 75\end{array}$

GENERAL HCl TRANSPORT STUDIES $\quad 79$

HCl TRANSPORT THROUGH CATALYST BEDS 80

$\begin{array}{ll}\mathrm{HCl} \text { TRANSPORT IN NAFION DRYERS } & 81\end{array}$

CALIBRATION DEVICES $\quad 82$

Preliminary Assessment of Permeation Tubes 82

Studies of Different Calibration Systems $\quad 84$

Alternate Calibration Approaches $\quad 93$

$\begin{array}{ll}\text { DESCRIPTION OF CEM } & 94\end{array}$

TESTING OF ENTIRE CEM IN THE LABORATORY 97

$\begin{array}{lr}\text { CONCLUSIONS } & 100\end{array}$

$\begin{array}{ll}\text { REFERENCES } & 101\end{array}$ 


\section{ABSTRACT}

$\mathrm{Hg}$ and $\mathrm{HCl} \mathrm{CEMs}$ for coal gasifiers were developed and tested. The CEMs employ a nonchemical gas conditioning approach using catalytic oxidation of the sample stream. Critical gas conditioning steps include the removal of $\mathrm{NH}_{3}$, tars, aromatic hydrocarbons, and moisture. A commercially available platinum $\left(\mathrm{Pt}\right.$ ) catalyst effectively destroyed $\mathrm{NH}_{3}$, but could not pass $\mathrm{Hg}$ or $\mathrm{HCl}$. Using pure $\mathrm{Pt}$ wire as a catalyst effectively destroyed $\mathrm{NH}_{3}$, tars, and toluene (aromatic hydrocarbon) while passing both $\mathrm{Hg}$ and $\mathrm{HCl}$. A Nafion-based dryer removes moisture after the catalyst. $\mathrm{Hg}$ and $\mathrm{HCl}$ (in air) could be successfully transported through the dryer, although small $\mathrm{Hg}$ losses were observed at extremely low concentrations. The gas conditioning system needs to be simplified and sample transport issues need to be improved before routine use of the CEMs.

Atomic absorption was selected for use in the Hg CEM. Because of spectral overlaps from interfering gases, background corrections are needed. The Hg CEM, which has a detection limit of about $0.1 \mu \mathrm{g} / \mathrm{m}^{3}$, uses a deuterium $\left(\mathrm{D}_{2}\right)$ lamp for broadband background corrections. The $\mathrm{D}_{2}$ system effectively corrected for $\mathrm{SO}_{2}$ interferences when using $\mathrm{Hg}$ concentrations of 9-26 $\mu \mathrm{g} / \mathrm{m}^{3}$. However, a correction factor on the $\mathrm{D}_{2}$ absorption data was needed, and this factor changed slightly with changing $\mathrm{SO}_{2}$ concentration for $\mathrm{SO}_{2}$ levels greater than $0.25 \%$. Tests with the $\mathrm{Hg}$ CEM using $15 \mu \mathrm{g} / \mathrm{m}^{3}$ of elemental $\mathrm{Hg}$ in air indicated that $50 \%$ of the elemental $\mathrm{Hg}$ was lost, apparently from wall losses. Additional losses were observed when $\mathrm{HCl}$ was added, indicating that the pyrolytic converter after the catalyst was not working properly, or that elemental $\mathrm{Hg}$ was reoxidizing in the presence of $\mathrm{HCl}$ after the converter. When using a simulated gasifier stream, background-corrected absorption readings were too erratic to get meaningful $\mathrm{Hg}$ signals. This was apparently related to problems associated with $\mathrm{H}_{2} \mathrm{~S}$ and/or $\mathrm{SO}_{2}$. Sulfates deposited in the sample line between the catalyst tube and Nafion dryer. This is a likely source of $\mathrm{Hg}$ losses. The deposition of sulfate aerosols and the successful conversion of oxidized $\mathrm{Hg}$ back to elemental $\mathrm{Hg}$ (without reoxidation) are issues requiring further study.

Ion mobility spectroscopy (IMS) was selected for use in the $\mathrm{HCl}$ CEM. IMS has a detection limit of about $5 \mathrm{ppb}$ and few interferences, but has a narrow dynamic range. Tests with the CEM using simulated gasifier streams with $1-10 \mathrm{ppm} \mathrm{HCl}$ were generally successful. IMS readings tracked well with changing $\mathrm{HCl}$ concentrations, and changes of $1 \mathrm{ppm}$ in the $\mathrm{HCl}$ concentration could be observed. However, about $20 \%$ of the $\mathrm{HCl}$ appeared to be lost somewhere during sample transport and conditioning. Suitable calibration procedures require investigation, since commercially available systems were not always reliable. 


\section{EXECUTIVE SUMMARY}

Integrated sampling/analysis systems for on-line monitoring of mercury $(\mathrm{Hg})$ and hydrogen chloride $(\mathrm{HCl})$ in advanced coal-based gasification systems were developed. Research efforts focused on 1) identifying and testing suitable analytical approaches, 2) gas conditioning techniques, 3) sample transport, 4) calibration approaches, 4) background correction approaches for $\mathrm{Hg}$ determinations by atomic absorption, and 5) building and testing $\mathrm{Hg}$ and $\mathrm{HCl} \mathrm{CEMs}$ using simulated coal gasification streams. Work performed in this study is summarized below.

\section{GAS CONDITIONING}

Removal of ammonia $\left(\mathrm{NH}_{3}\right)$ is important in view of potential chloride losses during sample transport, plugging of sample lines, or coating of optical components in analytical systems. This could occur from the possible formation and deposition of ammonium chloride as the gases cool. The $\mathrm{NH}_{3}$ can be removed at about $900^{\circ} \mathrm{C}$ without a catalyst, but catalytic oxidation was still used to help ensure complete removal of $\mathrm{NH}_{3}$ under a wide variety of conditions. A commercially available platinum $(\mathrm{Pt})$ catalyst on alumina effectively destroyed $\mathrm{NH}_{3}$ when using air/nitrogen blends. However, work with that catalyst was discontinued because neither $\mathrm{Hg}$ or $\mathrm{HCl}$ could be passed through the catalyst bed. Using pure Pt wire as a catalyst effectively destroyed $\mathrm{NH}_{3}$ while passing both $\mathrm{Hg}$ and $\mathrm{HCl}$ when using air/nitrogen carrier gases. A palladium $(\mathrm{Pd})$ wire catalyst was tested because of its lower cost relative to Pt. Although the Pd wire effectively removed $\mathrm{NH}_{3}$, complete meltdown of the catalyst occurred on several occasions. Therefore, the use of Pd catalysts was discontinued. In tests with simulated gasifier streams, white aerosols were observed exiting the catalyst tube containing Pt wire. Those aerosols appeared to be sulfuric acid mist from the oxidation of $\mathrm{H}_{2} \mathrm{~S}$. The sulfur-bearing aerosols formed very easily in the presence of a catalyst. Also, when using simulated gasifier streams, pulsing flame fronts which migrated upstream from the catalyst (but which quickly dissipated) occurred if the preheat zone immediately upstream from the catalyst was above $700^{\circ} \mathrm{C}$.

Catalytic oxidation is also being used for tar removal. Field studies were performed at a $800 \mathrm{~kW}$ biomass gasifier to confirm whether a Pt wire catalyst could effectively remove tars from a process gas slipstream. For comparative purposes, tests were also performed with $\alpha$ alumina at $900^{\circ} \mathrm{C}$. Although the hot alumina did not remove tars, the tars were completely removed by the Pt catalyst. Due to highly exothermic reactions, localized temperatures appeared to be near the melting point of the quartz tube holding the catalyst. Therefore, caution must be exercised when using catalytic oxidation.

Proper conditioning of coal gasification streams is very complex and does not have simple solutions. This is particularly true in view of the fact that the gas conditioning system must deal with tars, high moisture contents, and problems with $\mathrm{NH}_{3}$ without affecting ppb levels of $\mathrm{Hg}$, ppm (or lower) levels of $\mathrm{HCl}$, or the successful operation of conditioner components and analytical systems. Trying to develop a non-chemical system for gas conditioning was an ambitious task in view of the difficult sampling environment and unique problems associated with coal gasification streams. 


\section{MERCURY STUDIES}

The complexities of sample transport were shown by tests with elemental Hg injections into stainless steel and Teflon lines. Full $\mathrm{Hg}$ recoveries were obtained using air in stainless steel sample lines at room temperature, but recoveries gradually decreased to $20 \%$ as the sample line was heated to $200^{\circ} \mathrm{C}$. When dry, simulated gasifier streams were used in steel lines, no $\mathrm{Hg}$ was detected between 25 and $200^{\circ} \mathrm{C}$. After using the simulated gasifier streams in the steel lines, poor $\mathrm{Hg}$ recoveries were obtained when switching back to dry air and testing at room temperature. Full recoveries could be restored by adding humidity or by purging the lines for several days. The presence of sulfur-containing gases inhibited the transport of elemental $\mathrm{Hg}$ vapors, even in Teflon sample lines. These tests are important because Teflon lines can not be used for much of the sample transport due to the high sampling temperatures anticipated.

Elemental $\mathrm{Hg}$ could not be successfully passed over a commercially available Pt catalyst (on alumina) being used for gas stream oxidation. However, low levels of elemental $\mathrm{Hg}$ in air could be passed over a hot plug of Pt wire. Full $\mathrm{Hg}$ recoveries were still obtained when using a simulated gasifier stream, but $25 \%$ of the $\mathrm{Hg}$ was in the oxidized form when $\mathrm{HCl}$ was present, even when a pyrolytic converter was used after the catalyst. Because an oxidation catalyst is used, there are concerns regarding the $\mathrm{Hg}$ analyses, since the detection system responds to only elemental Hg. Although a high-temperature pyrolysis zone is used downstream from the catalyst, the potential recombination of $\mathrm{Hg}$ and chloride after the pyrolyzer requires further study.

Because of the high moisture content of coal gasifier streams, a Nafion-based dryer is being used. Low levels of elemental $\mathrm{Hg}$ (in air) could be successfully transported through a laboratory-scale Nafion dryer. When using a large Nafion-based dryer intended for process gas streams, elemental $\mathrm{Hg}$ (in air) recoveries of only $80-95 \%$ were obtained. The sample gas flow rate was a very important variable. Tests with the laboratory-scale dryer were also performed with $\mathrm{HgCl}_{2}$ streams. Substantial losses of $\mathrm{HgCl}_{2}$ were observed, but additional work is required to determine the source of the losses. Studies are also required regarding $\mathrm{Hg}$ transport using Nafion in the presence of simulated gasifier streams.

Because of concerns regarding transport of $\mathrm{HgCl}_{2}$ during sampling and the effective conversion of that $\mathrm{Hg}$ species to elemental $\mathrm{Hg}$ (required for detection by atomic absorption), tests were performed on the transport of $\mathrm{HgCl}_{2}$ and on the pyrolytic conversion of $\mathrm{HgCl}_{2}$ to elemental $\mathrm{Hg}$. When using $\mathrm{HgCl}_{2}$ streams in air, the $\mathrm{HgCl}_{2}$ was effectively transported and converted to elemental $\mathrm{Hg}$ without any recombination of the $\mathrm{Hg}$ and $\mathrm{Cl}$ atoms. However, thermodynamic calculations indicated that recombination might be of concern in gas streams with elevated levels of $\mathrm{HCl}$. Testing of this possible problem using mixtures of elemental $\mathrm{Hg}$, $\mathrm{HCl}$, and air flowing over a pyrolyzer at $900^{\circ} \mathrm{C}$ indicated that this could be an area of concern.

Based on available information at the start of the project, the analytical methods considered for our Hg CEM were cold vapor atomic absorption (AA) and cold vapor atomic fluorescence (AF). Two Hg detectors (one each based on AA and AF) were tested in the laboratory. Both instruments were highly sensitive and had minimal base line noise, while the AF detector 
exhibited lower levels of base line drift. The extent of signal quenching from most of the major matrix gases in gasifier streams precluded the possibility of direct gas analysis using AF. The determination of $\mathrm{Hg}$ in gasifier streams by $\mathrm{AF}$ is still possible if collection and preconcentration on gold is used. However, because of possible poisoning of the gold amalgamation devices in gasifier streams, AA was selected for use in our Hg CEM and no gold traps were used.

Because of spectral interferences in AA, background corrections are needed for direct, realtime analyses of $\mathrm{Hg}$ if interfering gases are not removed. Interferences include sulfur-containing gases and aromatic hydrocarbons. The sulfur-containing gases could potentially produce a signal equivalent to that observed for a $100 \mathrm{ppb}_{\mathrm{w}} \mathrm{Hg}$ stream or more, which stresses the importance of the background correction. The assumption was made that aromatic hydrocarbons would be destroyed by the Pt catalyst. Tests indicated that a hot Pt wire catalyst effectively destroyed $2 \%$ toluene (an aromatic hydrocarbon) in air while passing low levels of elemental $\mathrm{Hg}$. Although toluene was not intended to be a model compound for coal gasifiers, it at least provides some data on the removal of aromatic hydrocarbons by the catalyst. For background corrections, the Ames Laboratory Hg CEM uses a broadband background correction technique employing a deuterium $\left(\mathrm{D}_{2}\right)$ lamp. That approach has not been used previously for $\mathrm{Hg}$ CEMs.

The initial design of the $\mathrm{D}_{2}$ module was formulated, assembled on an optical breadboard, and tested. After coupling a commercially available $\mathrm{Hg}$ detector to the $\mathrm{D}_{2}$ unit, the $\mathrm{D}_{2}$ module successfully corrected for background interferences when using $\mathrm{Hg}$ concentrations of 2 to 11 $\mu \mathrm{g} / \mathrm{m}^{3}$ in the presence of up to $0.5 \% \mathrm{SO}_{2}$. However, a correction factor on the $\mathrm{D}_{2}$ channel of the system was needed. In view of those encouraging results, a prototype $\mathrm{Hg}$ CEM containing a $\mathrm{Hg}$ detector and $\mathrm{D}_{2}$ correction system in a single, compact, fully integrated analyzer was built. The prototype $\mathrm{Hg}$ analyzer weighs 50 pounds and is housed in a 26 " by 9" by 18 " case. Up to 48 hours of data can be stored in nonvolatile internal memory. The analyzer can also be operated with an external computer for extended data collection and storage. The analyzer contains tools for data processing, data acquisition, and optical alignments.

The prototype $\mathrm{Hg}$ analyzer was evaluated in the laboratory using streams of air, $\mathrm{SO}_{2}$, and Hg. Levels of base line noise and drift were acceptable. With the Hg channel of the analyzer, excellent calibration curves were obtained, and a detection limit of about $0.1 \mu \mathrm{g} / \mathrm{m}^{3}$ was calculated. Design modifications can improve this considerably. High levels $\left(50 \mu \mathrm{g} / \mathrm{m}^{3}\right)$ of $\mathrm{Hg}$ had no effect on the $\mathrm{D}_{2}$ base line, which is of critical importance for the proper operation of the monitor. As was the case with the optical breadboard system, a $\mathrm{D}_{2}$ correction factor was needed. The correction factor was affected slightly by the $\mathrm{SO}_{2}$ concentration. The $\mathrm{D}_{2}$ system effectively corrected for $\mathrm{SO}_{2}$ interferences when using $\mathrm{Hg}$ concentrations of $9-26 \mu \mathrm{g} / \mathrm{m}^{3}$ and $\mathrm{SO}_{2}$ concentrations up to $0.44 \%$. However, a "sliding" $\mathrm{D}_{2}$ correction factor dependent on the $\mathrm{SO}_{2}$ concentration was needed for $\mathrm{SO}_{2}$ concentrations greater than $0.25 \%$. Background corrected absorbance readings were within $10 \%$ of the theoretical values in $85 \%$ of all cases and were within $5 \%$ of the theoretical values in $50 \%$ of all cases. Modifications in the optics changed the numerical value of the correction factor significantly, but the $\mathrm{SO}_{2}$ concentration still affected the correction factor. Heating the sample cell decreased instrument sensitivity, apparently from defocusing of the optics. However, it is not yet known whether a heated sample cell will be required. The $\mathrm{Hg}$ analyzer with a $\mathrm{D}_{2}$ background correction system is promising, but is not yet fully developed. The primary complicating factor at this time is the fact that the required 
correction factor on the $\mathrm{D}_{2}$ channel of the instrument changes slightly with changing levels of interfering gases. Additional work is required to resolve that issue. Since this analyzer is the first of its kind, it is very probable that the analyzer can be improved substantially.

Tests with the $\mathrm{Hg}$ analyzer and gas conditioning system were performed using a simulated gasifier stream containing $15 \mu \mathrm{g} / \mathrm{m}^{3}$ of elemental $\mathrm{Hg}$. For comparative purposes, $\mathrm{Hg}$ streams in air and nitrogen were passed directly (bypassing the gas conditioner) into the $\mathrm{Hg}$ analyzer. Similarly, tests were performed whereby $\mathrm{Hg}$ in either air or nitrogen was passed through the entire heated gas conditioning system. When using streams of $\mathrm{Hg}$ in air (at room temperature) and bypassing the conditioner, rapid instrument response was observed, and the addition of 50 ppm $\mathrm{HCl}$ resulted in little or no $\mathrm{Hg}$ oxidation. When $\mathrm{Hg}$ in $\mathrm{N}_{2}$ was passed through the heated gas conditioning system, $\mathrm{Hg}$ readings were about $50 \%$ below expected values. Since little or no $\mathrm{Hg}$ oxidation would be anticipated in the $\mathrm{N}_{2}$ stream, this suggests that wall losses in the gas conditioner were substantial. The presence of $50 \mathrm{ppm} \mathrm{HCl}$ in the $\mathrm{N}_{2}$ stream had little effect on the $\mathrm{Hg}$ signals. Similar results were obtained while using streams of air and $\mathrm{Hg}$ without $\mathrm{HCl}$. However, when the air stream contained $50 \mathrm{ppm} \mathrm{HCl}$, the $\mathrm{Hg}$ signals decreased substantially and were only about $15 \%$ of those obtained while bypassing the gas conditioning system. Apparently, either the pyrolyzer is not effectively converting oxidized $\mathrm{Hg}$ (formed when passing over the oxidation catalyst) back to the elemental form, or the pyrolyzer is working as expected, but elemental $\mathrm{Hg}$ is reoxidizing in the presence of chloride as the gases cool.

Attempts were made to pass elemental $\mathrm{Hg}$ in a simulated gasifier stream through the gas conditioning system. When using a simulated gasifier stream and adding oxidation air prior to the catalyst, the background-corrected base line readings from the $\mathrm{Hg}$ detector were too erratic to get meaningful $\mathrm{Hg}$ signals. A variety of possibilities could account for this observation. After using the simulated gasifier stream, the gas stream was switched back to only $\mathrm{N}_{2}$ (no oxidation air) and $\mathrm{Hg}$. However, the $\mathrm{Hg}$ signals were much lower than previously observed when using only $\mathrm{N}_{2}$ to transport the $\mathrm{Hg}$ through the conditioner. Thus, something apparently "poisoned" part of the sample transport and/or gas conditioning system. Sulfur-containing gases are the most likely cause.

After completing the tests, the heat tracing was taken off the Teflon sample line connecting the catalyst tube to the gas dryer. The tube contained numerous spots on the interior walls and was heavily fogged. The spots were crystalline and highly enriched in oxygen and sulfur, and possibly lesser amounts of nitrogen. The spots are apparently sulfate compounds, such as ammonium sulfates and/or ammonium thiosulfates. The presence of the latter compounds was previously shown to exist if $\mathrm{NH}_{3}$ was not completely removed from the gas stream. It is very likely that these sulfur-containing deposits were responsible for at least some of the $\mathrm{Hg}$ losses observed during sample transport. Additional effort would be required to elucidate the mechanisms responsible for the $\mathrm{Hg}$ losses.

Passing low levels of elemental $\mathrm{Hg}$ successfully through the gas conditioning system is very complex. Additional work is required to address sample transport issues through the gas conditioner. Also, the formation and deposition of sulfate aerosols and the successful conversion of oxidized $\mathrm{Hg}$ (formed while passing over the oxidation catalyst) back to the elemental form are 
issues that still require further study. The overall gas conditioning system needs to be simplified to allow for more routine use.

\section{HYDROGEN CHLORIDE STUDIES}

When air streams containing $100 \mathrm{ppm} \mathrm{HCl}$ were passed through a Nafion-based dryer, $\mathrm{HCl}$ recoveries of $80-100 \%$ were obtained, and no $\mathrm{HCl}$ was generally detected in the countercurrent purge gas stream used with the Nafion dryer. However, more work on $\mathrm{HCl}$ transport through Nafion dryers is needed. Tests were also performed on passing $\mathrm{HCl}$ streams through oxidation catalysts. $\mathrm{HCl}$ could not be successfully passed through a commercially available catalyst (Pt on an alumina substrate), but low levels $(10 \mathrm{ppm})$ of $\mathrm{HCl}$ could be passed successfully over a catalyst consisting of pure Pt wire, even when using simulated gasifier streams.

A variety of commercially available $\mathrm{HCl}$ calibration devices were investigated with respect to accuracy and response times while using gas streams containing about $1 \mathrm{ppm} \mathrm{HCl}$. The devices examined included aqueous and anhydrous $\mathrm{HCl}$ permeation tubes, an anhydrous $\mathrm{HCl}$ permeation wafer, and an aqueous $\mathrm{HCl}$ diffusion vial. Each of the calibration devices was used in conjunction with a corresponding calibrator from the respective companies participating in this study. Direct analysis (using IMS) of the span gases from the calibrators indicated that the time required to reach maximum span gas concentrations differed significantly between calibrators, but was reached within several minutes in all cases. In addition, span gases were bubbled into absorbing solutions and analyzed by ion chromatography to calculate actual $\mathrm{HCl}$ emission rates from the calibrators. Actual $\mathrm{HCl}$ emission rates from the calibrators were significantly different from the levels expected based on the certified emission values for the calibration devices. In some cases, minor procedural variables significantly affected $\mathrm{HCl}$ concentrations in the span gases. In follow-up tests with one of the calibration devices, the temperature of the permeation chamber was found to be an important factor. Specifically, $\mathrm{HCl}$ recoveries were $40 \%, 80 \%$, and $90 \%$ of theoretical values at temperatures of $30^{\circ}, 35^{\circ}$, and $70^{\circ} \mathrm{C}$, respectively. It is not known whether this is due primarily to temperature effects or to the elevated $\mathrm{HCl}$ concentrations at higher temperatures (or both). Caution must be exercised if commercially available calibration systems are used, and verification of the $\mathrm{HCl}$ output from such systems at the $\mathrm{HCl}$ concentrations of interest is vital.

Commercially available analyzers employing gas filter correlation IR (GFCIR), dry colorimetry, and ion mobility spectroscopy (IMS) were selected for evaluation in our laboratories. The GFCIR analyzer had extremely stable $\mathrm{HCl}$ readings with base line fluctuations of no more than $0.2 \mathrm{ppm} \mathrm{HCl}$. When using compressed gas cylinders for span gases, calibration curves were linear above $25 \mathrm{ppm} \mathrm{HCl}$, but were somewhat erratic below that. However, when using $\mathrm{HCl}$ permeation tubes to generate gas streams containing 0.2 to $2 \mathrm{ppm}$, linear instrument responses were observed. Methane was a severe interference, but should not be a problem if gas stream oxidation is used.

The dry colorimetric analyzer was based on using continuous, color-indicating detection tapes in the form of "chemcassettes". Chemcassettes for both high and low levels of HCl were tested. For the high level chemcassettes, a calculated detection limit of less than 1 ppm was obtained, and calibration curves were generally linear in the $\mathrm{HCl}$ concentration range studied $(0$ - 
$25 \mathrm{ppm})$. HF and HCN were minor interferences. With the low-level chemcassette, the measured detection limit was about $50 \mathrm{ppb} \mathrm{HCl}$. Good linearity in the calibration curves was observed in the range of 75-400 ppb, but suspected wall effects caused some anomalous readings at lower concentrations. A substantial part of the problem appeared to be due to memory effects within the calibration system itself. HF was a major interference when using the low-level chemcassette, but should not be a problem if the $\mathrm{HCl}$ levels are much greater than the HF levels in the sample gases. HCN was not a significant interference with the low-level chemcassette.

IMS (an atmospheric-pressure, time-of-flight technique) was selected as the analytical method of choice for our $\mathrm{HCl} \mathrm{CEM.} \mathrm{The} \mathrm{detection} \mathrm{system} \mathrm{for} \mathrm{the} \mathrm{HCl} \mathrm{CEM} \mathrm{is} \mathrm{a} \mathrm{commercially}$ available analyzer having programmable high and low alarms, built-in diagnostics, and two analysis ranges (0-20 ppm and 0-200 ppb) which are obtained by changing an internal membrane. Advantages of IMS include minimal zero drift, high sensitivity, little sensitivity to relative humidity, few occurrences of false positives, and real time monitoring capability. However, it has a fairly narrow dynamic range (factor of 200), which would necessitate a dilution system to cover $\mathrm{HCl}$ concentrations in the range of 0 to $100 \mathrm{ppm}$. IMS is sensitive to pulsations in the sample gas flow and the sample gas must be at atmospheric pressure, but those issues are easily dealt with. Evaluation of an IMS analyzer in our laboratories indicated that the instrument response was linear for $\mathrm{HCl}$ concentrations of 1 to $25 \mathrm{ppm}$ and 1 to $200 \mathrm{ppb}$ (after changing membranes). Substantial memory effects were noted when using ppb levels of $\mathrm{HCl}$, but this appeared to be due primarily to the $\mathrm{HCl}$ calibrator. The detection limit was about $5 \mathrm{ppb}$. $\mathrm{HCN}, \mathrm{HF}$, and $\mathrm{H}_{2} \mathrm{~S}$ were not significant analytical interferences. However, $\mathrm{HF}$ could be of concern if $\mathrm{HF}$ levels are at or above the $\mathrm{HCl}$ concentration, which is not expected to be the case.

Laboratory testing was performed with the entire integrated $\mathrm{HCl}$ CEM. Tests were performed with $10 \mathrm{ppm} \mathrm{HCl}$ in air as well as simulated coal gasification streams. When passing those streams through the entire CEM, the IMS readings tracked well with changing $\mathrm{HCl}$ concentrations in the range of 1-10 ppm, and small changes (e.g., 1 ppm or less) in the $\mathrm{HCl}$ concentration could be observed. However, the $\mathrm{HCl}$ concentrations reported by the IMS analyzer were about $20 \%$ lower than those obtained while bypassing the conditioner. A variety of reasons could account for this observation. Unlike the tests with dry air streams through the gas conditioner, rapid response times were observed with the simulated flue gas streams when going from zero air to span gases, which is probably related to a "flushing" effect from the high moisture content of the simulated gasifier stream. Complete removal of $\mathrm{NH}_{3}$ by the oxidation catalyst appeared to be important in order to avoid the formation of ammonium chloride, which in turn can result in decreases in the IMS reading. The tests with $\mathrm{HCl}$ using simulated gasifier streams were successful, but it is clear that additional development is needed before it is ready for field use. As with $\mathrm{Hg}$, additional work on transporting $\mathrm{HCl}$ through the gas conditioning system is required, and the overall gas conditioning system should be simplified. 


\section{TABLE OF TABLES}

$\underline{\text { Table }}$

Table Description

$\underline{\text { Page }}$

1 Anticipated Concentrations of Various Gas Components in Gasifier Streams

2 Summary of Calibration Devices from VICI Metronics and KIN-TEK

Laboratories

3 Measured and Certified (Provided by Manufacturer) $\mathrm{HCl}$ Emission Rates from the $\mathrm{HCl}$ Calibration Systems 


\section{TABLE OF FIGURES}

1 Testing Apparatus Used for Air Toxics Studies

2 Effect of Pd Catalyst Temperature on $\mathrm{NH}_{3}$ Removal

3 Gas Drying System from Perma Pure

4 Thermo Separation Products Model 3200 AA Mercury Detector

5 Tekran Model 2500 AF Mercury Detector

6 Typical AA Signal for $0.5 \mathrm{ppb}_{\mathrm{w}} \mathrm{Hg}$ Stream in Air

7 Quenching Effects for Various Gases vs. Amount of Hg Injected

8 Fluorescence Quenching Effects for 2500-pg Hg Injections into Various Gases

9 Recovery of Elemental $\mathrm{Hg}$ from Steel Lines as a Function of Temperature 31

10 Uncorrected Absorbance Data for Varying Levels of $\mathrm{Hg}$ and $\mathrm{SO}_{2}$

11 Background Corrected Absorbances for Varying Levels of $\mathrm{Hg}$ and $\mathrm{SO}_{2}$

12 Signal Obtained with the CEM for a $0.5 \mu \mathrm{g} / \mathrm{m}^{3} \mathrm{Hg}$ Stream

13 Uncorrected Absorbance Readings Obtained with the CEM for Various Hg Concentrations With and Without $\mathrm{SO}_{2}$ Present

14 Background-Corrected (Fixed $\mathrm{D}_{2}$ Correction Factor) Absorbance Readings Obtained with the CEM for Various Hg Concentrations in the Presence of $0.02-0.06 \% \mathrm{SO}_{2}$

15 Background-Corrected (Fixed $\mathrm{D}_{2}$ Correction Factor) Absorbance Readings Obtained with the CEM for Various Hg Concentrations in the Presence of $0.10-0.25 \% \mathrm{SO}_{2}$

16 Background-Corrected (Sliding $\mathrm{D}_{2}$ Correction Factor) Absorbance Readings Obtained with the CEM for Various $\mathrm{Hg}$ Concentrations with $0.20-0.44 \% \mathrm{SO}_{2}$

17 Background-Corrected Hg Concentration Obtained with the CEM for a Gas 
Stream Containing $9 \mu \mathrm{g} / \mathrm{m}^{3} \mathrm{Hg}$ and $0.2 \% \mathrm{SO}_{2}$

\section{TABLE OF FIGURES (cont.)}

$\underline{\text { Figure }}$

Figure Description

$\underline{\text { Page }}$

18 Mercury Analyzer Employing a $\mathrm{D}_{2}$ Background Correction System 57

19 Simplified Schematic Diagram of the Interior of the Hg Analyzer 58

20 Schematic Diagram of Gas Conditioning System for the Hg CEM 59

21 Thermo Environmental Instruments Model 15 GFCIR HCl Analyzer 65

22 GFCIR Signal Observed for a 170 ppm HCl Stream 66

23 GFCIR Calibration Curve Obtained for $\mathrm{HCl}$ Concentrations of 0 to $150 \mathrm{ppm} \quad 67$

24 GFCIR Calibration Curve Obtained Using Permeation Tubes to Provide Low $\mathrm{HCl}$ Concentrations

25 Effects of Methane on GFCIR Signal $\quad 68$

26 MDA Colorimetric Analyzer for $\mathrm{HCl} \quad 69$

27 Calibration Curve Obtained with the Colorimetric Analyzer While $\begin{array}{ll}\text { Using Blended Gases } & 70\end{array}$

28 Results of HCN Tests with the Standard Chemcassette 71

29 Calibration Curve Obtained with the Low-Level Chemcassette While

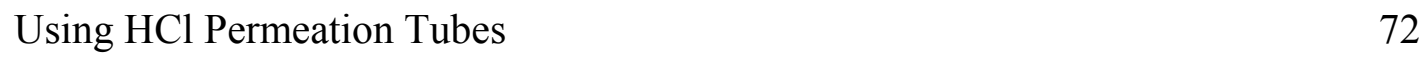

30 Apparent Memory Effects with the VICI Dynacalibrator 72

31 Calibration Curves Obtained with the Low-Level Chemcassette when Increasing and Decreasing the $\mathrm{HCl}$ Concentration 73

32 Ion Mobility Spectrometer for Monitoring $\mathrm{HCl} \quad 76$

33 Calibration Curve Obtained for IMS Unit While Using Blended Gases 76

34 Calibration Curve Obtained Using Permeation Tubes with the IMS Analyzer 77 
35 Signal Responses Vs. Time for 12 and $50 \mathrm{ppb} \mathrm{HCl} \mathrm{Streams}$

36 VICI Metronics Model 340 Dynacalibrator

TABLE OF FIGURES (cont.)

37 KIN-TEK Laboratories Model 491M Gas Standards Generator

38 IMS Readings Versus Time for Different Calibration Devices

39 Effects of Wafer Location on $\mathrm{HCl}$ Output from the Calibrator

40 Effects of Wafer Orientation on $\mathrm{HCl}$ Output from the Calibrator

41 IMS Reading Vs. Calculated Chloride Release Rate from the Calibrators

42 Gas Conditioning System and Analyzer for Monitoring $\mathrm{HCl}$ Emissions

43 Schematic Diagram of Overall Gas Conditioning and Analysis System for $\mathrm{HCl}$ 


\section{ACKNOWLEDGEMENTS}

We greatly appreciate the help from numerous Ames Laboratory research assistants throughout this study, including Laura Clifford, Tim Eickman, Rachel Peters, Amy Gensch, and Josh O’Donnell. In addition, we thank Susan Joines, Donald Krastman, Tom Brown, and most recently Richard Read, who served as the NETL Contracting Officer's Representative for this project.

For equipment loans, we thank Zellweger Analytics for the loan of an MDA Model 7100 Toxic Gas Monitor, Frank Schaedlich for the loan of a Tekran Model 2500 CVAFS Mercury Detector, Thermo Environmental Instruments for the loan of a GFCIR analyzer, and Steve Schelwat of WESLINE Company for arranging the GFCIR instrument loan.

This work was performed with funds provided by the U.S. Department of Energy through the National Energy Technology Laboratory under Contract 93MC30024.000 (NETL) with Ames Laboratory, Iowa State University. Ames Laboratory is operated for the U.S. D.O.E. by Iowa State University under Contract No. W-7405-Eng-82. 


\section{INTRODUCTION}

\section{OBJECTIVES}

The goal of this work was to develop integrated sampling and analysis systems suitable for on-line monitoring of mercury $(\mathrm{Hg})$ and hydrogen chloride $(\mathrm{HCl})$ in advanced coal-based gasification systems. Specific objectives of the study were to 1) identify and test analytical approaches which may be suitable for determining $\mathrm{Hg}$ and $\mathrm{HCl}$ in high-temperature, highpressure process gas streams, 2) study the necessary gas conditioning and sample transport considerations, and 3) produce reliable on-line monitors which are adaptable to plant-scale diagnostics and process control applications. Although the focus of this work involved developing $\mathrm{Hg}$ and $\mathrm{HCl}$ continuous emission monitors (CEMs) for coal gasification applications, much of this work is also applicable to coal combustion units and waste incinerators. Sampling combustors and incinerators is less problematic than sampling gasifiers because the gas matrices and sampling environments at such facilities are more conducive to sampling with available analytical instrumentation.

\section{BACKGROUND}

In the 1990 Amendments to the Clean Air Act, 189 compounds and elements are listed as hazardous air pollutants (i.e., air toxics). Among those air toxics, $\mathrm{Hg}$ and $\mathrm{HCl}$ are produced during coal combustion or gasification. In coal gasifiers, concentrations of $\mathrm{Hg}$ are anticipated to be in the range of $0.1-100 \mu \mathrm{g} / \mathrm{m}^{3}$ in the raw gas streams. Concentrations of $\mathrm{HCl}$ are anticipated to be in the range of $50-500 \mathrm{ppm}_{\mathrm{v}}$ in the raw gas and less than $1 \mathrm{ppm}$ after the flue gas is treated to remove acid vapors (1-3). For fuel cell applications, there is interest in monitoring $\mathrm{HCl}$ levels in the ppb range, since $\mathrm{HCl}$ can lead to catalyst poisoning in such systems. On-line monitoring for $\mathrm{Hg}$ and $\mathrm{HCl}$ in high-temperature, high-pressure power-producing systems is of interest in view of environmental and technological considerations. However, instrumentation designed for performing those analyses in the specified environments have not been available. Although commercially available CEMs were not available for such applications, we believed that suitable detection systems existed that could potentially be adapted, with proper gas stream conditioning, for analyzing the gas streams of interest.

Even in conventional combustion systems, difficulties are often encountered in sampling and analysis of those compounds because of uncertainties pertaining to collection efficiencies, chemical interferences, and maintaining sample integrity. This is particularly true for $\mathrm{Hg}$. Sampling and analysis of gasifier streams is even more problematic due to the high-temperature (up to $500^{\circ} \mathrm{C}$ ) and high-pressure (up to $300 \mathrm{psi}$ ) streams that are present, as well as the unique gas chemistry and high moisture contents involved. However, by devising an integrated sampling and analysis system for the analytes of interest (i.e., $\mathrm{Hg}$ and $\mathrm{HCl}$ ), process control for coal gasifiers can be improved and concentrations of air toxics in the effluent streams can be minimized. 


\section{APPROACH}

Initial work in this project involved reviewing and evaluating commercially available instrumentation suitable for the monitoring applications of interest. About 150 companies who market air emission monitoring and sampling equipment were contacted to determine the availability of equipment suitable for monitoring $\mathrm{Hg}$ or $\mathrm{HCl}$ in hot gases from NETL power producing systems. In addition, pertinent literature was assessed to obtain additional information on analytical methodologies that could potentially be used. The relevant literature items were obtained after performing computerized on-line searches of appropriate technical databases.

After reviewing the pertinent literature, analytical approaches which appeared to have the most potential for our monitoring applications were identified. Using this as a basis for our work, we decided to modify existing analytical methodologies rather than try to devise new analytical technologies, since this was viewed by Ames Laboratory and NETL personnel as being the most economical approach overall. In order to help attain our end goal, extensive studies were performed in a variety of critical areas. These were 1) testing and evaluation of commercially available detectors and monitors, 2) calibration approaches, 3) sample conditioning, and 4) background correction approaches for determining $\mathrm{Hg}$ by atomic absorption (AA).

Testing of commercially available instrumentation was necessary for this work in order to confirm vendor claims and to gain operating experience with instruments that were candidates for use in the CEMs. This avoided purchasing expensive instrumentation that would be unsuitable for the end task. Also, because of the unique sampling environments, instrument manufacturers were often uncertain about the suitability of their instruments for our application. As an integral part of our development of $\mathrm{Hg}$ and $\mathrm{HCl} \mathrm{CEMs}$, commercially available calibration devices were also examined. This was considered to be a crucial part of our work since accurate CEMs require accurate calibration systems. Sample conditioning is a critical step in the development of $\mathrm{Hg}$ and $\mathrm{HCl} \mathrm{CEMs,} \mathrm{and} \mathrm{a} \mathrm{major} \mathrm{thrust} \mathrm{of} \mathrm{our} \mathrm{development} \mathrm{work} \mathrm{was} \mathrm{performed}$ in this area. The most crucial areas of gas stream conditioning are the removal of moisture, tars, and ammonia gases. Finally, considerable effort was devoted to the development of a background correction approach for the $\mathrm{Hg}$ analyses. This was necessary because the detection method selected for the CEM was known to have a variety of spectral interferences from gases that will be present in the sample streams.

A system was designed and constructed in order to blend, heat, and deliver gases that would simulate coal gasifier streams. Cylinders of compressed gases were used for $\mathrm{CH}_{4}, \mathrm{CO}$, $\mathrm{CO}_{2}, \mathrm{COS}, \mathrm{H}_{2}, \mathrm{HCl}, \mathrm{HCN}, \mathrm{H}_{2} \mathrm{~S}, \mathrm{~N}_{2}$, and $\mathrm{NH}_{3}$. For our work, we assumed that gasifier streams contained concentrations of individual gas components as shown in Table 1. The basic design of the testing apparatus consists of a Teflon gas mixer for blending metered gases, a gas heating system, a steam generator, toxic gas traps (to be used after the detector), and a gas burner for burning flammable gases and destroying toxic gases not collected by the traps. The tubing from the $\mathrm{HCl}$ gas cylinder is made of Teflon, while all other gas lines are made of stainless steel. A schematic diagram of the apparatus is shown in Figure 1. That system was used to test a variety 
of analytical instruments, sample transport considerations, and gas stream conditioning approaches.

Table 1. Anticipated Concentrations of Various Gas Components in Gasifier Streams.

\begin{tabular}{|l|c|}
\hline GASEOUS SPECIES & CONCENTRATION \\
\hline Ammonia & $0-0.5 \%$ \\
\hline Carbon Dioxide & $5-20 \%$ \\
\hline Carbon Monoxide & $10-60 \%$ \\
\hline Carbonyl Sulfide & $0-0.1 \%$ \\
\hline Hydrogen & $15-30 \%$ \\
\hline Hydrogen Chloride & $1-300 \mathrm{ppm}$ \\
\hline Hydrogen Sulfide & $0-0.5 \%$ \\
\hline Mercury & $0.1-100 \mu \mathrm{g} / \mathrm{m}^{3}$ \\
\hline Methane & $2-15 \%$ \\
\hline Nitrogen & $0-50 \%$ \\
\hline Water Vapor & $5-50 \%$ \\
\hline
\end{tabular}

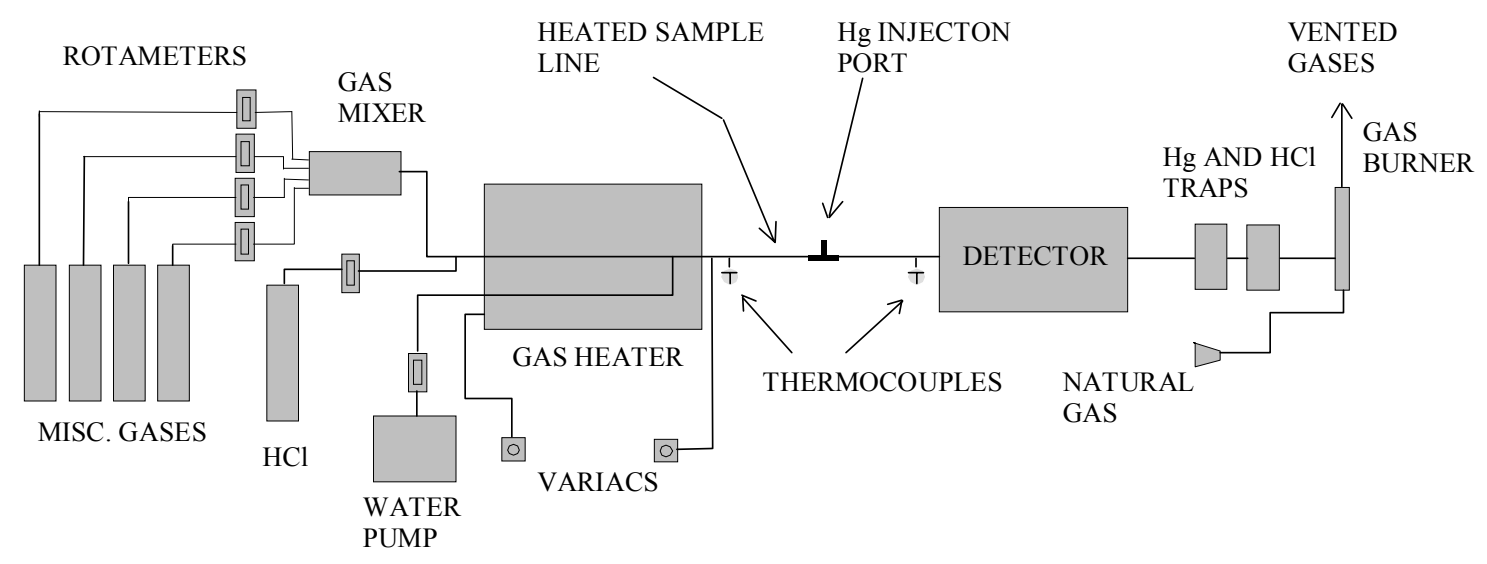

Figure 1. Testing Apparatus Used for Air Toxics Studies.

After assessing the overall operation of the initial system, modifications in the steam generation, gas heating, and gas burner components were made. Some of those changes included replacing a gas chromatography oven with a hot sand bath to heat the gases. In the latter approach, the blended gases are heated by passing them into a stainless steel coil immersed in the sand bath. To achieve a gas temperature of about $200^{\circ} \mathrm{C}$, the sand bath is maintained at $300-400^{\circ} \mathrm{C}$. In addition, an external steam generation vessel was replaced with a pump from a liquid chromatograph. That pump provides a precise, adjustable water flow in the proper range to give the desired moisture content in the sample gas mixtures. The water is pumped into a separate stainless steel coil in the hot sand bath. The water is vaporized in the steam coil and is introduced into the sample gas stream just before the sample gases exit the sand bath. This 
approach for adding moisture worked well and eliminated problems in regulating and metering the steam flow in the initial approach. 


\title{
GAS CONDITIONING
}

\author{
AMMONIA REMOVAL
}

In the presence of ammonia $\left(\mathrm{NH}_{3}\right)$, chloride losses can occur during sample transport due to the formation and deposition of solid ammonium chloride $\left(\mathrm{NH}_{4} \mathrm{Cl}\right)$. This compound can be kept in the vapor phase during sample transport by heating the sample lines. However, since most of the $\mathrm{HCl}$ monitors being considered operate at temperatures of less than $100^{\circ} \mathrm{C}$ and require the chloride to be present as $\mathrm{HCl}$ rather than $\mathrm{NH}_{4} \mathrm{Cl}$, the presence of $\mathrm{NH}_{3}$ gases in the sample stream presents a problem. Consequently, it is desirable to remove the $\mathrm{NH}_{3}$ from the gasifier stream in order to avoid the formation of $\mathrm{NH}_{4} \mathrm{Cl}$ prior to determining $\mathrm{HCl}$. Aside from the problems related to $\mathrm{HCl}$ analyses, it is best to avoid the formation of $\mathrm{NH}_{4} \mathrm{Cl}$ since it could quickly plug sample lines if not sufficiently heated, or it could potentially cause problems by coating optical components of the analytical systems. Work on the removal of $\mathrm{NH}_{3}$ from gas streams is discussed below.

\section{COPPER REDUCTION TUBE}

Tests were performed to determine whether a commercially available copper reduction tube could be used to effectively remove $\mathrm{NH}_{3}$. The reduction tube consisted of a heated quartz tube containing about $100 \mathrm{~mL}$ of granular (minus $20 \mathrm{mesh}$ ) copper. Experiments were performed using $1 \%$ and $5 \% \mathrm{NH}_{3}$, total gas flow rates of $25-1000 \mathrm{~mL} / \mathrm{min}$, and temperatures of $25-1000^{\circ} \mathrm{C}$. Results of those tests indicated that $95 \%$ or more of a $1 \% \mathrm{NH}_{3}$ stream (in nitrogen) could be removed from a gas stream flowing at $1000 \mathrm{~mL} / \mathrm{min}$ over a hot copper reduction tube. Temperatures of at least $900^{\circ} \mathrm{C}$ were needed for effective $\mathrm{NH}_{3}$ removal, which may reflect nothing more than simple thermal cracking. Tests with a $300 \mathrm{ppm} \mathrm{HCl}$ stream indicated that less than $50 \%$ of the $\mathrm{HCl}$ could be successfully passed through the reduction tube at temperatures above $500^{\circ} \mathrm{C}$. Therefore, this approach for removing $\mathrm{NH}_{3}$ was not studied further.

\section{PLATINUM CATALYST ON ALUMINA SUBSTRATE}

Tests were performed with a beaded (1/8-inch) catalyst containing $1 \%$ platinum $(\mathrm{Pt})$ on an alumina substrate (catalyst G-97B from United Catalysts, Louisville, KY) to determine how effectively it removes $\mathrm{NH}_{3}$ gases. For these tests, $3 \%(\mathrm{v} / \mathrm{v}) \mathrm{NH}_{3}$ in a given carrier gas stream was passed through $100 \mathrm{cc}$ of catalyst using a total gas flow rate of about $1 \mathrm{~L} / \mathrm{min}$. The temperature of the catalyst was varied from ambient to $400^{\circ} \mathrm{C}$, and a given temperature was maintained to within $5^{\circ} \mathrm{C}$ for 30 minutes before obtaining semiquantitative measurements of the $\mathrm{NH}_{3}$ concentration exiting the catalyst tube. Those measurements were performed using colorindicating paper sensitive to $\mathrm{NH}_{3}$. In base line tests with blends of nitrogen and $\mathrm{NH}_{3}$, little or no $\mathrm{NH}_{3}$ was removed as the temperature was increased to $400^{\circ} \mathrm{C}$. When the $\mathrm{NH}_{3}$ was blended with air rather than nitrogen, virtually no $\mathrm{NH}_{3}$ was removed at temperatures below about $250^{\circ} \mathrm{C}$. However, as the temperature was increased to about $250^{\circ} \mathrm{C}$, exothermic reactions began 
occurring, which made it more difficult to maintain the desired temperature. Also, the formation of water was evident (condensation was observed after exiting the catalyst tube) and no $\mathrm{NH}_{3}$ was detected with the color-indicating paper. After heating the catalyst tube outlet to avoid condensed water, a Sensidyne pump and color-indicating tubes (accurate to within 25\%) were used to help determine the $\mathrm{NH}_{3}$ concentration exiting the catalyst tube at $300^{\circ} \mathrm{C}$. Results indicated that the $\mathrm{NH}_{3}$ concentration was less than $1 \mathrm{ppm}_{\mathrm{v}}$. Thus, it appears that nearly $100 \%$ of the $\mathrm{NH}_{3}$ was removed at only $300^{\circ} \mathrm{C}$. Also, it is interesting to note that when the temperature of the catalyst tube was ramped back down to near room temperature, no $\mathrm{NH}_{3}$ could be detected at the outlet of the catalyst tube, even after several hours at $100^{\circ} \mathrm{C}$ or less. After purging the catalyst tube over night with air only, the catalyst was once again unable to remove $\mathrm{NH}_{3}$ at temperatures below $250^{\circ} \mathrm{C}$ within 30 minutes at a given temperature.

The water formed during the catalytic oxidation of $\mathrm{NH}_{3}$ was very acidic $(\mathrm{pH}<1)$ and was probably nitric acid. The acid caused considerable corrosion of the stainless steel thermocouple sheath. When the catalyst tube was at $300^{\circ} \mathrm{C}$ and the outlet of the tube was heated to avoid condensation, gases exiting the tube were bubbled into deionized water for several minutes. Analysis of this water sample by ion chromatography (IC) indicated that it had a lot of nitrate and a considerable amount of an unidentified compound, which is believed to be a nitric acid precursor. Nitric acid is often commercially made by the catalytic oxidation of $\mathrm{NH}_{3}$ using the Ostwald process, as shown below:

$$
\begin{aligned}
& 4 \mathrm{NH}_{3}(\mathrm{~g})+5 \mathrm{O}_{2}(\mathrm{~g}) \rightarrow \mathrm{Pt} \rightarrow 4 \mathrm{NO}(\mathrm{g})+6 \mathrm{H}_{2} \mathrm{O}(\mathrm{g}) \\
& 2 \mathrm{NO}(\mathrm{g})+\mathrm{O}_{2}(\mathrm{~g}) \rightarrow 2 \mathrm{NO}_{2}(\mathrm{~g}) \\
& 3 \mathrm{NO}_{2}(\mathrm{~g})+\mathrm{H}_{2} \mathrm{O}(\mathrm{g}) \rightarrow 2 \mathrm{H}^{+}+2 \mathrm{NO}_{3}{ }^{-}+\mathrm{NO}(\mathrm{g})
\end{aligned}
$$

Attempts were made to maintain the oxidation of $\mathrm{NH}_{3}$ without promoting the subsequent formation of nitric acid by initially activating the catalyst at about $250^{\circ} \mathrm{C}$ and then subsequently decreasing the temperature. As the temperature was gradually decreased, it was held at each desired temperature for periods ranging from 2 to 12 hours. The $\mathrm{NH}_{3}$ was completely removed and acidic water was noted regardless of temperature. This was true even after 12 hours at $60^{\circ} \mathrm{C}$, which was the minimum temperature attained with no external heat supplied to the catalyst. The catalytic oxidation reactions were disrupted only after terminating the $\mathrm{NH}_{3}$ flow and purging the catalyst tube with either air or nitrogen. After doing so, the catalyst tube was heated to $200^{\circ} \mathrm{C}$ and the $\mathrm{NH}_{3}$ flow was resumed. $\mathrm{No} \mathrm{NH}_{3}$ removal was observed and no moisture was formed, even after 7 hours at that temperature. Apparently, a minimum activation energy is required in order to initiate the catalytic oxidation of $\mathrm{NH}_{3}$. Also, these results indicate that lowering the reaction temperature after initial activation of the catalyst is not a viable approach for preventing acid formation when using air containing $3 \% \mathrm{NH}_{3}$.

Attempts were made to avoid nitric acid formation by decreasing the oxygen content of the gas stream by blending the air with additional nitrogen. In doing so, it was hoped that there would be sufficient oxygen for oxidizing the $\mathrm{NH}_{3}$, but not for the subsequent oxidation of the 
$\mathrm{NO}$ byproduct to nitric acid precursors. Calculations indicated that a gas stream with $3 \% \mathrm{NH}_{3}$ would require $4 \%$ oxygen as the stoichiometric amount of oxygen necessary for reacting with the $\mathrm{NH}_{3}$. A gas stream containing about $5 \%$ oxygen would contain $25 \%$ excess oxygen for the oxidation of $\mathrm{NH}_{3}$, but would be well short of the oxygen needed for subsequent reactions leading to the formation of nitric acid. For our initial tests, $3 \% \mathrm{NH}_{3}$ in an air/nitrogen blend containing the stoichiometric amount of oxygen necessary for reacting with the $\mathrm{NH}_{3}$ was passed through the catalyst at a rate of $1000 \mathrm{~mL} /$ minute while heating the catalyst to $300^{\circ} \mathrm{C}$. After several hours at that temperature, some water was being formed, suggesting that some $\mathrm{NH}_{3}$ decomposition was occurring. However, no major decrease in the $\mathrm{NH}_{3}$ concentration was noted using colorindicating paper sensitive to $\mathrm{NH}_{3}$. At $5 \%$ excess oxygen, the condensate was slightly basic, and most (but not all) of the $\mathrm{NH}_{3}$ was being removed after operating over night. After increasing the air flow to give $10 \%$ excess oxygen, nearly all of the $\mathrm{NH}_{3}$ was being removed, but the condensate was very acidic. These results suggest that it would be difficult to adjust the oxygento- $\mathrm{NH}_{3}$ ratio in order to completely remove $\mathrm{NH}_{3}$ at $300^{\circ} \mathrm{C}$ without forming acid.

In subsequent tests, $3 \% \mathrm{NH}_{3}$ in an air/nitrogen stream containing $10 \%$ excess oxygen was passed through the catalyst tube at $270^{\circ} \mathrm{C}$. After one hour at that temperature, the $\mathrm{pH}$ of the condensate was neutral and nearly all of the $\mathrm{NH}_{3}$ was being removed. Readings obtained using a Sensidyne gas sampling pump with color-indicating tubes indicated that there was about $25 \mathrm{ppm}$ $\mathrm{NH}_{3}$ exiting the catalyst tube at this point. The temperature of the catalyst tube was then gradually decreased. Within several hours, no $\mathrm{NH}_{3}$ was detected using the color-indicating tubes, and the $\mathrm{pH}$ of the condensate was still neutral. This held true down to $150^{\circ} \mathrm{C}$. However, at $100^{\circ} \mathrm{C}$, the $\mathrm{pH}$ of the condensate became basic and $\mathrm{NH}_{3}$ removal was minimal. These results suggest that it may be possible to remove all of the $\mathrm{NH}_{3}$ without forming acid through the proper selection of both temperature and oxygen concentration.

This work showed that the catalyst being studied could effectively remove $\mathrm{NH}_{3}$ and could potentially do so without excessive oxidation of the gas stream. Because of these encouraging results, tests were performed to determine whether $\mathrm{Hg}$ and $\mathrm{HCl}$ could be passed through this catalyst material. Unfortunately, problems were encountered for both $\mathrm{Hg}$ and $\mathrm{HCl}$. Results of experiments involving $\mathrm{Hg}$ and $\mathrm{HCl}$ with this catalyst material are discussed later in the respective sections of the report entitled "Mercury Studies" and "Hydrogen Chloride Studies."

\section{PLATINUM WIRE CATALYST}

\section{$\underline{\text { Ammonia Removal Efficiencies }}$}

Preliminary tests with a stream containing $2 \mu \mathrm{g} / \mathrm{m}^{3}$ elemental $\mathrm{Hg}$ in air indicated that the $\mathrm{Hg}$ could be successfully passed over a hot Pt wire. Therefore, we investigated whether a catalyst bed made of pure $\mathrm{Pt}$ wire could effectively remove $\mathrm{NH}_{3}$. A Pt wire plug was prepared by compressing about 10 feet of 0.010 -inch diameter Pt wire into the interior of a 1/4-inch OD quartz tube. The tube was heated by applying current to a piece of nickel-chromium wire wrapped around the tube. A total gas flow rate of about $850 \mathrm{~mL} / \mathrm{min}$ was used with $\mathrm{NH}_{3}$ concentrations of $5 \%$ in a nitrogen/air blend. The ratio of air to nitrogen was adjusted to provide 
about $15 \%$ excess oxygen for the oxidation of $\mathrm{NH}_{3}$. At a bulk bed temperature of only $200^{\circ} \mathrm{C}$, the Pt wire reduced $\mathrm{NH}_{3}$ levels to about $1 \mathrm{ppm}$ based on semiquantitative analyses of the gases using colorimetric detection tubes. The water formed from the oxidation reactions had a neutral $\mathrm{pH}$. After 16 hours at that temperature, the $\mathrm{pH}$ of the condensate was still neutral. At a temperature of $400^{\circ} \mathrm{C}$, no $\mathrm{NH}_{3}(<0.5 \mathrm{ppm})$ could be detected in the gases exiting the catalyst tube. Thus, at that temperature, essentially all of the $\mathrm{NH}_{3}$ appeared to be destroyed in the air/nitrogen $/ \mathrm{NH}_{3}$ blends when that detection method was used.

With continued testing, it was apparent that the color-indicating tubes were not always entirely reliable for measuring residual (trace levels) of $\mathrm{NH}_{3}$ in gases downstream from the catalyst. This may be due to the high humidity in the gas stream when $\mathrm{NH}_{3}$ is oxidized. Also, the measurements may be inaccurate at low levels in the gas matrices involved, particularly when using a simulated gasifier stream. Therefore, we switched to the use of IC to determine low levels of $\mathrm{NH}_{3}$ gases. This was a more reliable measure of low $\mathrm{NH}_{3}$ concentrations. In that approach, gases were typically bubbled through a 1/8-inch OD Teflon tube into $100 \mathrm{~mL}$ of deionized water in a $125-\mathrm{mL}$ Erlenmeyer flask, which was subsequently analyzed by IC. Backup water traps were occasionally used to check for breakthrough from the first trap, which was determined not to be a problem at the gas flow rates normally used for testing.

Based on IC analyses of absorbing solutions, it was found that $\mathrm{NH}_{3}$ removals by the catalyst were not consistent. This indicated that methods to improve $\mathrm{NH}_{3}$ removal efficiencies, such as lowering gas flow rates, using higher catalyst temperatures, or using greater catalyst surface areas, needed to be explored further. With continued testing, we were able to consistently obtain excellent $\mathrm{NH}_{3}$ removal efficiencies by doubling the size of the catalyst bed and by adding a preheat zone just upstream from the catalyst. For the preheat zone, a 6-inch section of the $1 / 4$-inch OD quartz tube housing the catalyst was heated to roughly $900^{\circ} \mathrm{C}$ using a nickel-chromium wire. The enlarged catalyst bed contained 20-25 feet of 0.010-inch diameter Pt wire. For tests performed in the absence of $\mathrm{CH}_{4}, \mathrm{CO}$, and $\mathrm{H}_{2}$, the catalyst was maintained at a temperature of roughly $900^{\circ} \mathrm{C}$. With the changes noted above, $99.99 \%$ or more of the $\mathrm{NH}_{3}$ was removed from gas streams consisting of $\mathrm{NH}_{3}, \mathrm{H}_{2} \mathrm{~S}, \mathrm{~N}_{2}$, and air. In particular, for $\mathrm{NH}_{3}$ concentrations of $1.5 \%$ in the initial (before adding air for oxidation) gas stream, $\mathrm{NH}_{3}$ levels were consistently reduced to less than $1 \mathrm{ppm}$.

Additional tests were performed using a Pt catalyst with $\mathrm{NH}_{3}$ and $\mathrm{H}_{2} \mathrm{~S}$ streams blended with air/nitrogen mixtures. For those tests, a total gas flow rate of $1000 \mathrm{~mL} / \mathrm{min}$ was used with a catalyst temperature of about $900^{\circ} \mathrm{C}$. The $\mathrm{NH}_{3}$ and $\mathrm{H}_{2} \mathrm{~S}$ concentrations were held constant at $1 \%$, while the ratio of nitrogen to air was varied to investigate excess air requirements. Initially, $800 \mathrm{~mL} / \mathrm{min}$ of air and $200 \mathrm{~mL} / \mathrm{min}$ of nitrogen were used. The nitrogen flow was then increased in increments of $100 \mathrm{~mL} / \mathrm{min}$ while the air flow was decreased in increments of $100 \mathrm{~mL} / \mathrm{min}$. Gases exiting the catalyst tube were bubbled into deionized water and then analyzed for ammonium ion by IC. Results of those analyses indicated that $\mathrm{NH}_{3}$ removals were complete until the air flow was only $200 \mathrm{~mL} / \mathrm{min}$ (added to $800 \mathrm{~mL} / \mathrm{min}$ of nitrogen). At that point, small amounts of $\mathrm{NH}_{3}$ began getting through the catalyst and a white, solid aerosol began to deposit on the tube downstream from the catalyst. The implications of this work are that the excess air requirements are rather high (greater than 200\%) in order to attain complete removal of $\mathrm{NH}_{3}$. For an actual gasifier stream, which contains a variety of other oxidizable gases such as $\mathrm{CO}$, 
$\mathrm{CH}_{4}$, and $\mathrm{H}_{2}$, this would require an air stream flowing at several $\mathrm{L} / \mathrm{min}$ for every $1 \mathrm{~L} / \mathrm{min}$ of sample gas. When some of the tests were repeated at a total (sample gas plus added air) gas flow rate of $2.5 \mathrm{~L} / \mathrm{min}$, significant amounts of $\mathrm{NH}_{3}$ began to get through. Results of these tests suggest that a fairly low sample gas flow rate may be required in order to keep the total gas flow rate at an acceptable level.

Additional tests with a Pt catalyst were performed to study excess air requirements. In these tests, $500 \mathrm{~mL} / \mathrm{min}$ of a simulated gasifier stream consisting of $50 \% \mathrm{CO}, 15 \% \mathrm{CO}_{2}, 25 \% \mathrm{H}_{2}$, $8 \% \mathrm{CH}_{4}, 2 \% \mathrm{H}_{2} \mathrm{~S}$, and $1 \% \mathrm{NH}_{3}$ was blended with $3000 \mathrm{~mL} / \mathrm{min}$ of air and passed over a hot $\left(900^{\circ} \mathrm{C}\right) \mathrm{Pt}$ wire catalyst. Also, a $900^{\circ} \mathrm{C}$ "preheat" zone was used to increase the gas temperature prior to entering the catalyst. These tests differ from the previous tests in that 1) a simulated gasifier stream was used instead of using a blend of only $\mathrm{N}_{2}, \mathrm{NH}_{3}$, and $\mathrm{H}_{2} \mathrm{~S}$, and 2) a more realistic $\mathrm{NH}_{3}$ concentration in the final blended (after addition of air) gas stream was used. Gases exiting the catalyst tube were bubbled into water to quantitatively collect the $\mathrm{NH}_{3}$. IC analyses on the water indicated that the $\mathrm{NH}_{3}$ removal was complete. When the air flow was decreased to $1000 \mathrm{~mL} / \mathrm{min}$, the removal of $\mathrm{NH}_{3}$ was still complete. Trace amounts of $\mathrm{NH}_{3}$ began to appear when the air flow was decreased to $500 \mathrm{~mL} / \mathrm{min}$. Results of these tests with a simulated gasifier stream indicate that excess air requirements for complete oxidation of the simulated gasifier stream are only on the order of $50 \%$ (assuming that the $\mathrm{NH}_{3}$ and $\mathrm{H}_{2} \mathrm{~S}$ are not preferentially oxidized). It appears that higher sample gas flow rates can be used without exceeding the desired total (after diluting with air) gas flow rate of several liters/minute. As an additional note, it was observed that brownish deposits formed on the interior walls of the quartz tube housing the catalyst, both in the actual catalyst zone and the empty "preheat" zone prior to the catalyst. Analysis of the residue by scanning electron microscopy with energy-dispersive $\mathrm{x}$ ray analysis (SEM-EDX) indicated that it consisted mostly of nickel and iron, which may or may not be present as oxides.

Next, tests were performed using a nitrogen stream flowing at $400 \mathrm{~mL} / \mathrm{min}$ and containing $3 \% \mathrm{NH}_{3}$ and $2 \% \mathrm{H}_{2} \mathrm{~S}$. This gas stream was blended with air flowing at $600 \mathrm{~mL} / \mathrm{min}$. Thus, $\mathrm{NH}_{3}$ concentrations in the final blended gas stream were about $1.5 \%$. For these tests, a catalyst $(20$ feet of $\mathrm{Pt}$ wire) temperature of $900^{\circ} \mathrm{C}$ was maintained, and a gas preheat zone maintained at that temperature was also used. Gases exiting the catalyst tube were bubbled into water and analyzed by IC to determine the amount of residual $\mathrm{NH}_{3}$ in the gas stream. Results of the IC analyses indicated that residual $\mathrm{NH}_{3}$ levels in the gas stream after the catalyst were only about $50 \mathrm{ppb}$. Thus, this $\mathrm{NH}_{3}$ removal approach can be highly effective.

In all of the tests where $\mathrm{NH}_{3}$ removal was effective, liquid condensate was observed downstream from the catalyst. Some of the liquid condensate was analyzed by IC to see if it contained any ammonium ion, which would indicate that some $\mathrm{NH}_{3}$ was actually getting through the catalyst. Although small amounts of ammonium ion were found in the condensate, this equated to a residual $\mathrm{NH}_{3}$ level in the blended gases of only several ppm (starting concentration was $1 \%$ ). The $\mathrm{NH}_{3}$ was probably not detected in the gases exiting the catalyst tube because of the very low levels involved and because of the substantial dilution that occurred while bubbling the sample into the collection solution. 
A new version of the catalyst module was also tested in a simulated gasifier stream for its ability to remove $\mathrm{NH}_{3}$. The new catalyst module consisted of $\mathrm{Pt}$ wire at $900^{\circ} \mathrm{C}$ which was placed in between two alumina beds at $900^{\circ} \mathrm{C}$. The simulated gasifier stream consisted of $50 \% \mathrm{CO}$, $15 \% \mathrm{CO}_{2}, 25 \% \mathrm{H}_{2}, 8 \% \mathrm{CH}_{4}, 2 \% \mathrm{NH}_{3}$, and $2 \% \mathrm{H}_{2} \mathrm{~S}$. For these tests, $0.5 \mathrm{~L} / \mathrm{min}$ of simulated gasifier stream was blended with $1.0 \mathrm{~L} / \mathrm{min}$ of air. Gases exiting the catalyst tube were bubbled into deionized water to collect any $\mathrm{NH}_{3}$ passing through the catalyst. The water samples were then analyzed for ammonium ion using IC. Results of the analyses indicated that more than $99.9 \%$ of the $\mathrm{NH}_{3}$ was removed using this alternative catalyst unit.

\section{$\underline{\text { Effects of } \mathrm{HCl}}$}

A series of tests were performed in which $\mathrm{HCl}$ was added (prior to air injection) to a simulated gasifier stream to give a concentration on the order of $1 \mathrm{ppm}_{\mathrm{v}}$. Flow rates of simulated gasifier stream and air were 0.5 and $1.0 \mathrm{~L} / \mathrm{min}$, respectively. A catalyst temperature of $900^{\circ} \mathrm{C}$ was used for these tests, and no gas preheat zone was used. Gases exiting the catalyst tube were bubbled into deionized water to collect any $\mathrm{NH}_{3}$ exiting the tube. Results of IC analyses on the water indicated that $\mathrm{NH}_{3}$ removals decreased significantly in the presence of $\mathrm{HCl}$. Those tests were repeated multiple times with the same results. It was speculated that $\mathrm{HCl}$ was rapidly combining with the $\mathrm{NH}_{3}$ to form ammonium chloride, which may not be destroyed as effectively by the catalyst as $\mathrm{NH}_{3}$. Heating the gases to $200^{\circ} \mathrm{C}$ prior to the catalyst and prior to the air injection point did not help the problem and, in fact, caused an additional problem of carbonaceous deposits forming on the inside of the quartz tube. Relocating the $\mathrm{HCl}$ injection point downstream from the air injection port also did not help restore the $\mathrm{NH}_{3}$ removal efficiencies to the desired levels. However, $\mathrm{NH}_{3}$ removal efficiencies were fully restored in the presence of $\mathrm{HCl}$ by increasing the air flow rate to $1.5 \mathrm{~L} / \mathrm{min}$.

Because of the possible effects of $\mathrm{HCl}$ on $\mathrm{NH}_{3}$ removal, the tests were repeated using a higher $\mathrm{HCl}$ content. For those tests, about $0.5 \mathrm{~L} / \mathrm{min}$ of the simulated gasifier stream was used, except the $\mathrm{HCl}$ content was increased to about $150 \mathrm{ppm}_{\mathrm{v}}$. In addition, a $600^{\circ} \mathrm{C}$ preheat zone was used prior to the catalyst, since we anticipate heating sample gases to that temperature up to the catalyst entry point. The $\mathrm{NH}_{3}$ was first blended at room temperature with the simulated gasifier stream, followed by injection of $\mathrm{HCl}$ further downstream. About $1 \mathrm{~L} / \mathrm{min}$ of air was added to the gasifier stream. The $600^{\circ} \mathrm{C}$ preheat zone immediately followed the air injection point. With this design, virtually all of the $\mathrm{NH}_{3}$ was removed. The $\mathrm{NH}_{3}$ concentrations were reduced from about $1 \%$ to less than $0.5 \mathrm{ppm}$. The tests were repeated using $1 \mathrm{~L} / \mathrm{min}$ of simulated gasifier stream plus $2 \mathrm{~L} / \mathrm{min}$ of air, and the same high $\mathrm{NH}_{3}$ removal efficiencies were observed.

\section{$\underline{\text { Aerosols and Condensates }}$}

Tests were performed with a simulated gasifier stream consisting of $46 \% \mathrm{CO}, 16 \% \mathrm{CO}_{2}$, $12 \% \mathrm{CH}_{4}, 21 \% \mathrm{H}_{2}, 1.5 \% \mathrm{H}_{2} \mathrm{~S}$, and $3.0 \% \mathrm{NH}_{3}$ by volume. Each of those gases was metered into the gas stream individually. The total gas flow rate prior to mixing with air was about 500 $\mathrm{mL} / \mathrm{min}$. Prior to the Pt catalyst, this gas stream was blended with air flowing at about 1.5 $\mathrm{L} / \mathrm{min}$, which gave an excess oxygen concentration of about $15 \%$ for complete oxidation of the simulated gasifier stream. The $\mathrm{NH}_{3}$ concentration at the exit of the catalyst tube didn't change 
until the Pt was heated to a temperature of about $350^{\circ} \mathrm{C}$. When that temperature was reached, the temperature increased rapidly due to exothermic oxidation reactions, and the $\mathrm{Pt}$ wire began to glow red hot. At that point, the external heat was turned off. In this initial test with the simulated gasifier stream, the sample transport line downstream from the catalyst tube quickly (within an hour) plugged up with unknown, water soluble deposits that were white to pale yellow in color. In addition, little or no water condensation in unheated portions of the sample line downstream from the catalyst was observed. Considerable amounts of water should be produced if the anticipated oxidation reactions go to completion. Analysis of the deposits by SEM-EDX indicated that the oxygen-to-sulfur ratio was less than $2: 1$, suggesting that oxidation of the simulated gasifier stream was not complete. It was speculated that these deposits were some type of ammonium/sulfur compound (most of which are water soluble) from the reaction of $\mathrm{NH}_{3}$ with $\mathrm{H}_{2} \mathrm{~S}$.

The experiments with the simulated gasifier stream were repeated, except the air flow was increased by $25 \%$. However, this did not solve the deposition problem. During the tests, it was noted that only about $25 \%$ of the Pt wire was glowing red hot. This hot zone was on the end of the catalyst furthest downstream, which led to concerns that the gas residence time over sufficiently heated portions of the Pt was not adequate for completing the desired reactions. Therefore, external heat was supplied by applying current to the nickel-chromium wire wrapped around the quartz tube containing the catalyst. When this was performed, over $75 \%$ of the Pt was glowing red hot. At this point, considerable amounts of water were produced, virtually all of the $\mathrm{NH}_{3}$ was removed, and no solids deposited in the sample transport lines downstream from the catalyst. However, small amounts of white aerosol could still be seen exiting the tube. When the liquid condensate (mostly water) was allowed to evaporate, considerable quantities of solids remained. X-ray diffraction (XRD) analyses indicated that the solid material was composed primarily of ammonium sulfate with substantial amounts of ammonium thiosulfate. Therefore, trace amounts of $\mathrm{NH}_{3}$ apparently passed through the catalyst without being oxidized, which may be responsible for the aerosols observed. It is possible that some $\mathrm{NH}_{3}$ passed through the catalyst before the catalyst attained the proper temperature, which could have resulted in considerable contamination in the downstream sample lines.

The hypothesis was made that the aerosol was a result of incomplete oxidation of $\mathrm{NH}_{3}$ and $\mathrm{H}_{2} \mathrm{~S}$, and that none of the other gases in the simulated gas mixture were involved. To test this hypothesis, a series of tests were performed with only $\mathrm{NH}_{3}, \mathrm{H}_{2} \mathrm{~S}$, and $\mathrm{N}_{2}$ in the gas stream. Air was still mixed with the gas stream before being passed over the heated $\mathrm{Pt}$ wire. The composition of the gas stream after the addition of the air was about $1 \% \mathrm{NH}_{3}, 0.5 \% \mathrm{H}_{2} \mathrm{~S}$, and $12 \% \mathrm{O}_{2}$, with $\mathrm{N}_{2}$ comprising the balance. The length of the catalyst heater was increased from 2 " to 6" to provide temperature uniformity of the hot Pt catalyst and of the gases flowing across the catalyst. With the $\mathrm{Pt}$ catalyst at room temperature, no deposits were formed and high concentrations of $\mathrm{NH}_{3}$ were still present in gases exiting the catalyst tube. When the Pt was heated to only a few hundred degrees Celsius, a thick pale yellow aerosol was formed that quickly deposited on the walls of the exit tubing. These deposits could be avoided by heating the tubing to roughly $100^{\circ} \mathrm{C}$. When the Pt temperature was increased until it glowed a dull red, most of the aerosol formation disappeared. However, a slight amount remained, even after an hour at those conditions. The aerosol was found to be highly acidic by placing a piece of wet $\mathrm{pH}$ paper in contact with the aerosol exiting the catalyst tube. Also, upon closer examination of the end of 
the quartz tube, a small amount of a viscous liquid could be seen. A drop of the liquid was allowed to sit in an open petri dish over night in air. The liquid did not evaporate, and touching it with litmus paper indicated that it was very acidic. Analysis of the liquid by IC indicated that it contained large amounts of sulfate ion. These results indicate that the liquid was probably sulfuric acid, which probably formed by the catalytic oxidation of $\mathrm{H}_{2} \mathrm{~S}$ to form sulfur trioxide, which then dissolved in the condensate to form sulfuric acid. The aerosol appears to be acid mist from the oxidation of the $\mathrm{H}_{2} \mathrm{~S}$.

In related tests, a mixture of $\mathrm{H}_{2} \mathrm{~S}$ and $\mathrm{N}_{2}$ was blended with air and passed over the $\mathrm{Pt}$ catalyst in the absence of $\mathrm{NH}_{3}$. When the catalyst was at room temperature, no deposits were formed downstream from the catalyst. However, deposits did begin to form downstream from the catalyst even with minimal heating (several hundred degrees Celsius or less). When the catalyst was heated to the normal operating temperature of about $900^{\circ} \mathrm{C}$, no deposits were observed. Thus, the heavy deposits that had formed initially (catalyst temperature of only several hundred degrees Celsius) on the quartz tube disappeared as the catalyst was heated to higher temperatures. These results indicate that sulfur aerosols can form and deposit very easily, even in the absence of $\mathrm{NH}_{3}$ (i.e., these particular deposits are not ammonium sulfates).

Additional tests were performed with a stream of $\mathrm{NH}_{3}, \mathrm{H}_{2} \mathrm{~S}$, and $\mathrm{N}_{2}$, which was then blended with air prior to the catalyst such that there was $200 \%$ excess oxygen for the oxidation of both the $\mathrm{NH}_{3}$ and $\mathrm{H}_{2} \mathrm{~S}$. Total gas flow rates of $1 \mathrm{~L} /$ min were used. The Pt catalyst was heated and maintained at $700-900^{\circ} \mathrm{C}$ before adding the $\mathrm{NH}_{3}$ and $\mathrm{H}_{2} \mathrm{~S}$ to ensure that the downstream tubing did not become contaminated by undesirable gases passing through the catalyst before it had attained the desired temperature. Also, the downstream lines were rinsed thoroughly with deionized water prior to the tests to remove any residual compounds from previous tests. With a constant $\mathrm{NH}_{3}$ concentration of about $1.5 \%$, the $\mathrm{H}_{2} \mathrm{~S}$ concentration was gradually increased to about $1 \%$. A white aerosol formed in the gas stream and the concentration of the aerosol in the gas stream increased as the $\mathrm{H}_{2} \mathrm{~S}$ concentration increased, which adds additional support for the belief that the aerosol being formed is primarily from sulfur compounds and not from $\mathrm{NH}_{3}$. However, no solid deposits formed on the quartz tube downstream from the catalyst, even after an hour of operation. Thus, the deposition of solid aerosols near the catalyst can be avoided by ensuring efficient oxidation of the gas stream. In addition to the white aerosol that was observed, small amounts of liquid condensate appeared downstream from the catalyst. Some of the condensate was collected in a beaker and analyzed by IC. Results of those analyses showed that it contained over 95\% sulfate. This further supports the belief that the white aerosol is a result of the catalytic oxidation of $\mathrm{H}_{2} \mathrm{~S}$ to form sulfuric acid mist. It is believed that complete destruction of the $\mathrm{NH}_{3}$ will result in liquids (containing no dissolved solids) condensing in downstream portions of the catalyst tube, while no dry solids will deposit anywhere in the tube.

Similar tests were run in which $\mathrm{NH}_{3}, \mathrm{H}_{2} \mathrm{~S}$, and $\mathrm{N}_{2}$ were passed over a hot Pt catalyst. However, in these tests, the amount of air used was approximately stoichiometric for the complete oxidation of the gas stream. These tests were performed to determine if $\mathrm{NH}_{3}$ would be preferentially oxidized relative to $\mathrm{H}_{2} \mathrm{~S}$. In the absence of $\mathrm{H}_{2} \mathrm{~S}$, no $\mathrm{NH}_{3}$ could be detected with color-indicating paper. The sensitivity of the paper to $\mathrm{NH}_{3}$ was sufficient to conclude that at least the large majority of $\mathrm{NH}_{3}$ was being oxidized. With the addition of $\mathrm{H}_{2} \mathrm{~S}$, a considerable amount of solid deposits formed at the end of the quartz tube containing the catalyst. In 
addition, a small amount of liquid condensate was observed in the Teflon line farther downstream. A portion of the solid was analyzed by XRD, while another portion was dissolved in water (sample was completely water soluble) and analyzed for ammonium and sulfate ions by IC. In addition, the liquid condensate was rinsed out with deionized water and analyzed by IC. The XRD analyses indicated that the solid condensates were largely ammonium sulfate, which was also confirmed by the IC analyses. The condensate was also high in ammonium and sulfate ions. In the absence of $\mathrm{HCl}$, residual $\mathrm{NH}_{3}$ in the gas stream after the catalyst readily combines with the oxidation products of $\mathrm{H}_{2} \mathrm{~S}$. Although much of the $\mathrm{NH}_{3}$ was oxidized, there is not a high degree (if any) of preferential oxidation of $\mathrm{NH}_{3}$ relative to $\mathrm{H}_{2} \mathrm{~S}$.

In another series of tests, various mixtures of air, $\mathrm{N}_{2}, \mathrm{NH}_{3}$, and $\mathrm{H}_{2} \mathrm{~S}$ were used. For the tests involving $\mathrm{NH}_{3}$ or $\mathrm{H}_{2} \mathrm{~S}$, concentrations of each of those compounds were about $2 \%$, and roughly $200 \%$ excess air was present for the oxidation reactions. In addition to collecting the liquid condensate at the end of the quartz tube after each test, gases exiting the catalyst tube were bubbled into deionized water for a period of 30 minutes to collect water soluble species. In all the tests where the gas stream contained $\mathrm{H}_{2} \mathrm{~S}$, a fine white aerosol was observed above the water as the gases were being bubbled into it. Analyses of the collection solutions and liquid condensates by IC indicated that there was no ammonium ion in the solutions, regardless of whether $\mathrm{H}_{2} \mathrm{~S}$ was present or not. Nitrate ion was present in the collection solutions when $\mathrm{NH}_{3}$ was used in the absence of $\mathrm{H}_{2} \mathrm{~S}$, but not when $\mathrm{H}_{2} \mathrm{~S}$ was present along with the $\mathrm{NH}_{3}$. The reasons for this are not known, but it was not deemed necessary to pursue this issue further. As with previous tests, at least $99.9 \%$ of the $\mathrm{NH}_{3}$ was removed.

It will be difficult to avoid the formation of a sulfuric acid aerosol during the catalytic oxidation of gasifier streams. This in turn may necessitate the use of a heated sample cell for the determination of $\mathrm{Hg}$. Results suggest that a temperature of at least $100^{\circ} \mathrm{C}$ will be required to prevent the condensation of the oxidation products. Also, precautions in the operation of the gas conditioner are advisable to ensure that the catalyst remains at the desired temperature during sampling. If this is not done, there is a significant risk of completely plugging the sample lines, resulting in pressure buildup that could damage portions of the CEM. The problem associated with the fine white aerosols is of less concern for $\mathrm{HCl}$ analyses using ion mobility spectroscopy, since large gas stream dilutions are required for that technique in order to maintain a fairly constant gas matrix composition.

The liquids formed during gas stream oxidation will probably need to kept in the vapor phase during sample transport. Based on tests with $\mathrm{N}_{2} / \mathrm{NH}_{3} / \mathrm{H}_{2} \mathrm{~S}$ mixtures blended with air, the liquid condensate downstream from the catalyst was found to have a high boiling point of 250$275^{\circ} \mathrm{C}$. This was of concern because the Teflon lines connected to the catalyst tube could not be maintained at such temperatures, and the accumulation of large amounts of liquid condensate was undesirable for a CEM. In view of this concern, tests were performed with a simulated gasifier stream consisting of $50 \% \mathrm{CO}, 15 \% \mathrm{CO}_{2}, 25 \% \mathrm{H}_{2}, 8 \% \mathrm{CH}_{4}, 2 \% \mathrm{H}_{2} \mathrm{~S}$, and $1 \% \mathrm{NH}_{3}$. In those streams, it was noted that the temperature necessary to keep the liquid in the vapor phase was only about 150 to $170^{\circ} \mathrm{C}$, which is much more desirable and will allow the use of Teflon fittings downstream from the catalyst. In the initial tests (using only $\mathrm{N}_{2} / \mathrm{NH}_{3} / \mathrm{H}_{2} \mathrm{~S}$ mixtures blended with air), the high boiling points for the liquids were probably due to the condensate being a strong acid. With the simulated gasifier stream, greater amounts of water were formed 
downstream from the catalyst due to the oxidation of other gases such as $\mathrm{H}_{2}$ and $\mathrm{CH}_{4}$. Thus, the liquid condensate would be less acidic and would therefore have a lower boiling point.

Although exit temperatures of 150 to $170^{\circ} \mathrm{C}$ would allow the use of Teflon downstream from the catalyst, there were still concerns about passing those gases directly into a Nafionbased drying system. The maximum allowable temperature of the gas stream entering the dryer is approximately $150^{\circ} \mathrm{C}$. Also, drying efficiency decreases as the gas temperature increases, so a temperature of $150^{\circ} \mathrm{C}$ is undesirable from a drying standpoint. Therefore, tests with the simulated gasifier stream were repeated, with the exception that the oxidation air blended with the simulated gasifier stream was humidified by bubbling it through deionized water. Because actual gasifier streams will have substantial amounts of moisture prior to gas stream oxidation, this more closely simulated field conditions. With the added humidity, the temperature required to keep the liquid in the vapor phase decreased to only $120-130^{\circ} \mathrm{C}$, which would allow us to pass the gases directly into the Perma Pure dryer without exceeding temperature limitations. This is believed to be due to a further decrease in acid concentration, which in turn would reduce the boiling point of the liquid. When sampling actual gasifier streams, the elevated levels of moisture in the raw gases will probably result in further decreases in the temperature required to keep the liquids downstream from the catalyst from condensing.

\section{$\underline{\text { Flame Formation }}$}

During tests on the removal of $\mathrm{NH}_{3}$ from simulated gasifier streams, a periodic problem was noted related to flames forming in the quartz catalyst tube and migrating slightly upstream before extinguishing. This is sometimes called a "cool flame." There is enough energy for a flame to form, but the temperature is below the flashpoint of the gases and the flame quickly extinguishes since there is not enough energy for combustion. This occurred both in the presence of a Pt catalyst and in empty tubes heated to $900^{\circ} \mathrm{C}$. Numerous tests were performed to circumvent this problem. While using an empty tube heated to $900^{\circ} \mathrm{C}$, tests were performed with a simulated gasifier stream (preblended in a single compressed gas cylinder) in which $0.5 \mathrm{~L} / \mathrm{min}$ of gasifier stream was blended with $1.0 \mathrm{~L} / \mathrm{min}$ of air. A flame occurred in those tests. As the air flow was increased to $1.5 \mathrm{~L} / \mathrm{min}$, the flame moved upstream and overheated a Teflon fitting that was connected to the upstream end of the quartz tube. With further increases in the air flow rate ( $2 \mathrm{~L} / \mathrm{min}$ or more), the gas flow had sufficient pressure to push the head of the flame back towards the catalyst, although the pulsing flame still extended upstream from the catalyst somewhat.

Tests were also performed with a simulated gasifier stream in the presence of a Pt catalyst heated to $900^{\circ} \mathrm{C}$. Approaches that were examined to eliminate the flame included 1) increasing the ratio of the dilution air to gasifier stream in order to lower combustible gas concentrations, and 2) decreasing the ratio of dilution air to gasifier stream in order to hopefully suppress flame formation through decreased oxygen content. Those approaches did not help eliminate the formation of the flame. However, it was discovered that the flame occurred only if a preheat zone was used just prior to the $900^{\circ} \mathrm{C}$ catalyst region. Tests indicated that lowering the temperature of the preheat zone (normally at about $900^{\circ} \mathrm{C}$ ) eliminated the flame. Specifically, the flame did not form until a temperature of roughly $750^{\circ} \mathrm{C}$ was attained in the preheat zone. 
Based on the results noted above, tests were performed with a simulated gasifier stream in which the temperature of the preheat zone was maintained at $600^{\circ} \mathrm{C}$, which is the sample line temperature upstream from the catalyst we anticipate using in actual sampling operations. The preheated gases passed over a hot $\left(900^{\circ} \mathrm{C}\right) \mathrm{Pt}$ catalyst bed. In addition, an alumina bed heated to $900^{\circ} \mathrm{C}$ was added immediately downstream from the catalyst to serve as a polisher. A simulated gasifier stream containing approximately $50 \% \mathrm{CO}, 15 \% \mathrm{CO}_{2}, 25 \% \mathrm{H}_{2}, 8 \% \mathrm{CH}_{4}, 2 \% \mathrm{H}_{2} \mathrm{~S}$, and $1 \% \mathrm{NH}_{3}$ was then passed through the catalyst tube. In that gas stream, all of the individual gas components were individually metered and blended together. Initial tests involved using 0.5 $\mathrm{L} / \mathrm{min}$ of simulated gasifier stream blended with $1.0 \mathrm{~L} / \mathrm{min}$ of air. The concentrations of $\mathrm{CH}_{4}$ and $\mathrm{H}_{2}$ were varied to provide a wide range of combustible gas concentrations. No flames formed in those tests. However, as was the case before, the flame appeared if the temperature of the preheat zone was heated to $750^{\circ} \mathrm{C}$ or more. The tests with the $600^{\circ} \mathrm{C}$ preheat temperature prior to the catalyst were repeated using $1 \mathrm{~L} / \mathrm{min}$ of simulated gasifier stream blended with 2 $\mathrm{L} / \mathrm{min}$ of air. No flame was observed, and $\mathrm{NH}_{3}$ levels were reduced to less than $0.5 \mathrm{ppm}$. These results indicate that excess air requirements for effective $\mathrm{NH}_{3}$ removal can be substantially reduced and the flame can be avoided by using a $600^{\circ} \mathrm{C}$ preheat zone, followed by a Pt catalyst at $900^{\circ} \mathrm{C}$. After about 24 hours of operation using simulated gasifier streams, no physical degradation of the catalyst was noted, and no decrease in $\mathrm{NH}_{3}$ removal efficiencies was observed.

\section{$\underline{\text { Miscellaneous }}$}

Tests were performed using a single compressed gas cylinder containing a simulated gasifier stream. The simulated gasifier stream consisted of $50 \% \mathrm{CO}, 15 \% \mathrm{CO}_{2}, 25 \% \mathrm{H}_{2}, 8 \%$ $\mathrm{CH}_{4}$, and $2 \% \mathrm{H}_{2} \mathrm{~S}$. This gas stream was blended with $\mathrm{NH}_{3}$ to provide a final $\mathrm{NH}_{3}$ concentration of $1 \%$. During testing, the catalyst began to plug up, which caused excessive backpressure on the system and prevented continued operation. The restricted flow was due to greenish deposits in the upstream portion of the catalyst. Analysis of the greenish material by SEM-EDX indicated that it was nickel oxide. It is possible that the nickel was initially present as another compound, such as nickel carbonyl, and was later converted to the oxide form. All of the nickel deposits could easily be dissolved in hot $10 \% \mathrm{HNO}_{3}$. Analysis of the interior of the stainless steel sample transport line by SEM-EDX indicated that the interior surfaces were badly pitted and corroded. Thus, the stainless steel tubing is the likely source of the nickel, even though the vendor of the compressed gas cylinder containing the simulated gasifier stream believed that the stainless steel should hold up well with this gas blend. The interior walls of a brand new piece of stainless steel tubing was also examined by SEM-EDX. No pitting or grain boundary attack was noted. However, the interior surfaces were very rough, which would make it more subject to chemical attack in view of the increased surface area. The problem was eliminated by going to Teflon lines upstream from the catalyst. This suffices for laboratory testing, but can not be used in the field when the sample transport lines will be heated to temperatures that Teflon could not withstand. For field use, another type of sample transport line is needed.

\section{PALLADIUM WIRE CATALYST}




\section{Ammonia Removal Efficiencies}

The use of a palladium (Pd) catalyst was tested as a possible alternative to $\mathrm{Pt}$ in view of its lower cost relative to $\mathrm{Pt}$ and because of its known lower catalytic activity, which in turn could result in effective $\mathrm{NH}_{3}$ removal without the formation of acid byproducts and aerosols. The Pd catalyst consisted of about 10 feet of 0.010 -inch diameter Pd wire, which was placed in a $1 / 4$-inch OD quartz tube. In the initial tests, a total gas flow of about $1000 \mathrm{~mL} / \mathrm{min}$ was passed over a hot (700-900 ${ }^{\circ} \mathrm{C}$ ) catalyst using various mixtures of $\mathrm{N}_{2}$, air, $\mathrm{NH}_{3}$, and $\mathrm{H}_{2} \mathrm{~S}$. For the tests involving $\mathrm{NH}_{3}$ and $\mathrm{H}_{2} \mathrm{~S}$, about $200 \%$ excess air was present for the oxidation reactions to go to completion. During testing, the gases which had passed over the catalyst were bubbled into deionized water collection solutions for a period of 30 minutes. In addition, the liquid condensate which formed at the end of the quartz tube containing the catalyst was collected. Results of IC analyses on those samples showed that no ammonium ion was present in the collection solutions or the liquid condensate, indicating that the $\mathrm{NH}_{3}$ removal was $99.9 \%$ or greater, regardless of whether $\mathrm{H}_{2} \mathrm{~S}$ was present or not. Thus, for these test conditions, the effectiveness of the catalyst was the same for both $\mathrm{Pt}$ and $\mathrm{Pd}$. As with the tests using $\mathrm{Pt}$, nitrate was present in the collection solutions after testing when $\mathrm{NH}_{3}$ was used in the absence of $\mathrm{H}_{2} \mathrm{~S}$, but no nitrate was detected when $\mathrm{H}_{2} \mathrm{~S}$ was present.

Because the decomposition of $\mathrm{NH}_{3}$ is a critical sample conditioning step in our overall analytical scheme, tests were performed to study the range of acceptable conditions for the complete removal of $\mathrm{NH}_{3}$ using a $\mathrm{Pd}$ catalyst. Initial tests involved using an air stream flowing at $1000 \mathrm{~mL} / \mathrm{min}$ blended with $20 \mathrm{~mL} / \mathrm{min}$ of $\mathrm{NH}_{3}$ to give a final $\mathrm{NH}_{3}$ concentration of $2 \%(\mathrm{v} / \mathrm{v})$ and an excess air concentration of roughly 500\%. Further tests were also done with proportionally increased $\mathrm{NH}_{3}$ and air flows, which increased the total gas flow rate over the catalyst while maintaining a constant $\mathrm{NH}_{3}$ concentration and a constant ratio of excess air to $\mathrm{NH}_{3}$. The gas streams, with total gas flow rates ranging from about 1000 to $4000 \mathrm{~mL} / \mathrm{min}$, were then passed over a heated $\mathrm{Pd}$ catalyst. The amount of $\mathrm{NH}_{3}$ in the gases downstream from the catalyst was determined by bubbling the gases into absorbing solutions (water) which were contained in a series of two $125-\mathrm{mL}$ Erlenmeyer flasks. Results of IC analyses on the solutions indicated that little or no $\mathrm{NH}_{3}$ passed through the catalyst when using a total gas flow rate of $1000 \mathrm{~mL} / \mathrm{min}$, which is consistent with results obtained previously. However, at a total gas flow rate of $2000 \mathrm{~mL} / \mathrm{min}$, small amounts (less than $0.05 \%$ of the initial $\mathrm{NH}_{3}$ concentration) of the $\mathrm{NH}_{3}$ began getting through. In addition, the initial water trap collected only about $90 \%$ of the $\mathrm{NH}_{3}$ exiting the catalyst tube at the higher gas flow rate (normally the first solution collects $100 \%$ of the $\mathrm{NH}_{3}$ exiting the catalyst tube). At a total gas flow rate of $3000 \mathrm{~mL} / \mathrm{min}$, the $\mathrm{NH}_{3}$ removal efficiency decreased substantially, and the first water trap was ineffective at collecting the $\mathrm{NH}_{3}$. The results from these tests indicate that our $\mathrm{NH}_{3}$ collection procedure may need to be modified when performing tests with gas streams involving total gas flow rates of $2000 \mathrm{~mL} / \mathrm{min}$ or more.

Similar tests were performed with the exception that Sensidyne color-indicating tubes were used to directly measure $\mathrm{NH}_{3}$ in the gas stream rather than using absorbing solutions to capture the $\mathrm{NH}_{3}$ for subsequent IC analyses. The color-indicating tubes have an accuracy of about $25 \%$ according to the manufacturer, although this was not experimentally verified using our gas matrix. Unlike the tests with the absorbing solutions, results of these tests indicated that no (less 
than $1 \mathrm{ppm}) \mathrm{NH}_{3}$ was getting through the catalyst, even at total gas flow rates of up to 4000 $\mathrm{mL} / \mathrm{min}$ with $2 \% \mathrm{NH}_{3}$. One possible reason for this discrepancy is that small amounts of $\mathrm{NH}_{3}$ are getting through the catalyst and then subsequently reacting with $\mathrm{HNO}_{3}$ vapor (produced from the oxidation of $\mathrm{NH}_{3}$ ), which could then form some sort of ammonium nitrate compound that would not be detectable with the color-indicating tubes. As noted earlier in the discussion of work with a Pt catalyst, the IC results appear to be more trustworthy than the color-indicating detection tubes for trace levels of $\mathrm{NH}_{3}$. Despite this, the colorimetric tubes were still sometimes used for information on general trends in $\mathrm{NH}_{3}$ concentration as an experimental variable was adjusted.

The percent excess air necessary for complete removal of $\mathrm{NH}_{3}$ was also examined. A gas stream consisting of $20 \mathrm{~mL} / \mathrm{min}$ of $\mathrm{NH}_{3}$ and $1000 \mathrm{~mL} / \mathrm{min}$ of air was initially used. This constitutes about $500 \%$ excess air for the complete oxidation of $\mathrm{NH}_{3}$ to $\mathrm{NO}_{2}$. Measurements for $\mathrm{NH}_{3}$ using the semiquantitative color-indicating tubes downstream from the catalyst indicated that the majority of the $\mathrm{NH}_{3}$ was removed under those conditions. While maintaining a constant $\mathrm{NH}_{3}$ flow, the air flow was gradually decreased to determine how low of an air: $\mathrm{NH}_{3}$ ratio could be used while still effectively removing the $\mathrm{NH}_{3}$. It was determined that an air flow of only 400 $\mathrm{mL} / \mathrm{min}$ was sufficient to remove the $\mathrm{NH}_{3}$, but lowering the air flow below this rate resulted in low (few tenths of one percent) concentrations of $\mathrm{NH}_{3}$ being detected downstream from the catalyst. Therefore, these results indicate that about $200 \%$ excess air should be used for the complete removal of $\mathrm{NH}_{3}$ under these conditions. However, it should be pointed out that total gas flow rates decreased as the percent excess air decreased, which in turn increased residence times in the catalyst zone. Therefore, this excess air percentage should only be considered as an approximation since the excess air requirements are likely to change as the total gas flow rate changes. Also, as noted previously, the detection tubes used to determine $\mathrm{NH}_{3}$ concentrations are only semiquantitative. Nonetheless, these results provide ballpark figures for excess air requirements under the experimental conditions studied.

Next, tests were performed with a constant air flow of $1000 \mathrm{~mL} / \mathrm{min}$ and $\mathrm{NH}_{3}$ flows ranging from 20 to $200 \mathrm{~mL} / \mathrm{min}$ to further study excess air requirements. The approximate $\mathrm{NH}_{3}$ concentrations in the gases downstream from the Pd catalyst were determined using colorindicating tubes. As the $\mathrm{NH}_{3}$ concentration was gradually increased, no $\mathrm{NH}_{3}$ was detected downstream from the catalyst until the $\mathrm{NH}_{3}$ flow at the catalyst tube inlet was about 175 $\mathrm{mL} / \mathrm{min}$, which resulted in a reading of about $1 \mathrm{ppm} \mathrm{NH} 3$ in the gases downstream from the catalyst. Results of these tests suggest that only about $75 \%$ excess air may be required for complete removal of $\mathrm{NH}_{3}$. In other tests, a constant $\mathrm{NH}_{3}$ flow of $20 \mathrm{~mL} / \mathrm{min}$ was blended with air flowing at 1000 to $2500 \mathrm{~mL} / \mathrm{min}$ and then passed over the hot Pd catalyst. The gases exiting the catalyst tube were bubbled into absorbing solutions, which were subsequently analyzed for ammonium ion using IC. Results of the IC analyses indicated that there was complete removal of $\mathrm{NH}_{3}$ for the flow rates tested. These tests are more indicative of actual field sampling operations in that we intend to use a gasifier stream flowing at about $1000 \mathrm{~mL} / \mathrm{min}$ and then blend it with air as needed. Therefore, although tests were performed previously which involved $2 \% \mathrm{NH}_{3}$ flowing over the catalyst, the $\mathrm{NH}_{3}$ concentration in the blended gas stream will never be as high as $2 \%$ since the $\mathrm{NH}_{3}$ concentrations in raw gasifier streams will probably start at $1 \%$ or less and will then be blended with air before passing over the catalyst. 
Next, tests were performed to investigate the Pd catalyst temperatures required for the complete removal of $\mathrm{NH}_{3}$. For these tests, $400 \mathrm{~mL} / \mathrm{min}$ of a nitrogen stream containing $3 \% \mathrm{NH}_{3}$ and $2 \% \mathrm{H}_{2} \mathrm{~S}$ was blended with air flowing at $600 \mathrm{~mL} / \mathrm{min}$. Thus, $\mathrm{NH}_{3}$ concentrations in the final blended gas stream were about $1.5 \%$. Gases exiting the catalyst tube were bubbled into water and analyzed by $\mathrm{IC}$ to determine the amount of residual $\mathrm{NH}_{3}$ in the gas stream. Results of those analyses are shown in Figure 2. Excellent $\mathrm{NH}_{3}$ removal efficiencies were observed at catalyst temperatures in the range of $700-900^{\circ} \mathrm{C}$, but were particularly high at temperatures of about $900^{\circ} \mathrm{C}$. At temperatures near $900^{\circ} \mathrm{C}, \mathrm{NH}_{3}$ levels were reduced from $1.5 \%$ to less than $0.5 \mathrm{ppm}$. When the gas flows were increased by factors of 1.5, 2.0, and 2.5 while maintaining a catalyst temperature of $900^{\circ} \mathrm{C}$, residual $\mathrm{NH}_{3}$ in the blended gas stream gradually increased from 0.3 to $30 \mathrm{ppm}$. Thus, using total gas flow rates greater than about $1 \mathrm{~L} / \mathrm{min}$ did not effectively destroy the $\mathrm{NH}_{3}$ in the gas stream under the conditions used.

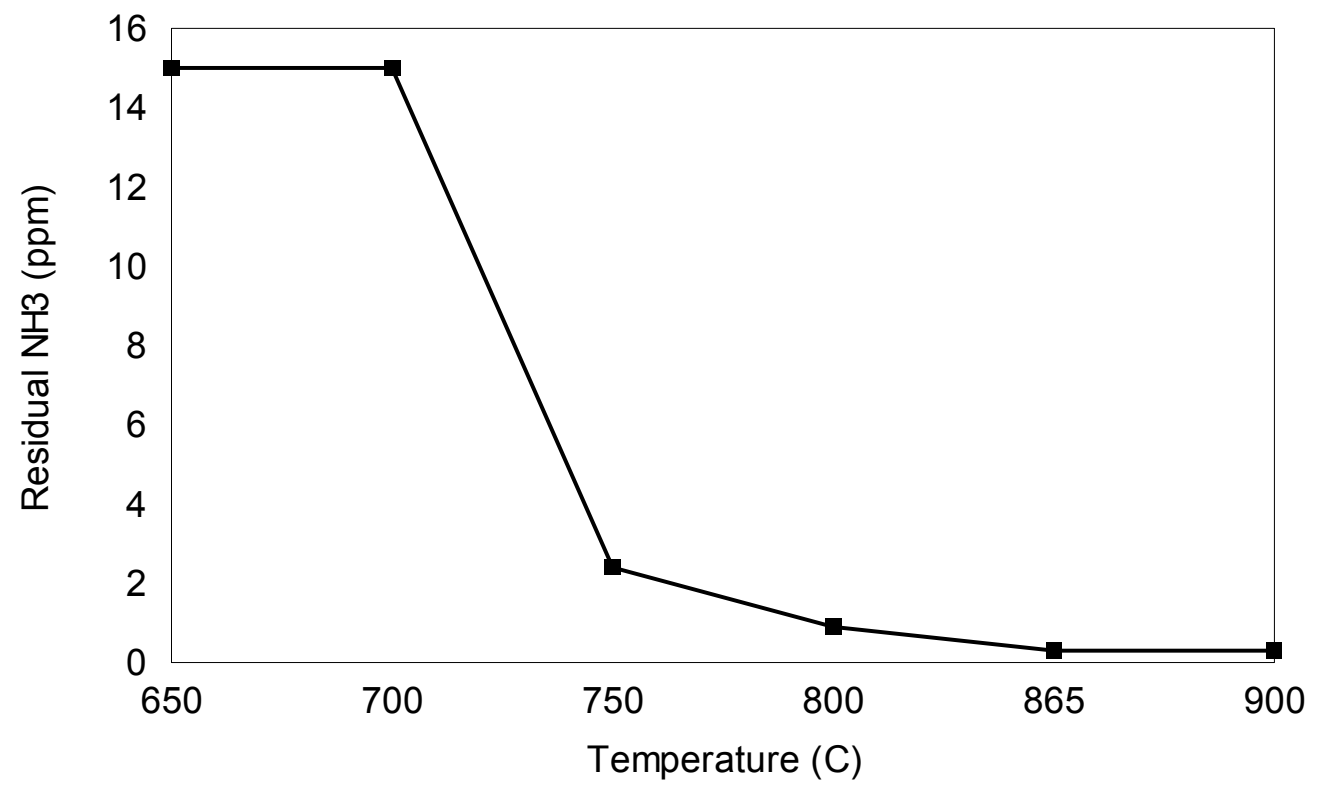

Figure 2. Effect of Pd Catalyst Temperature on $\mathrm{NH}_{3}$ Removal.

$\underline{\text { Aerosols and Condensates }}$

Tests were performed to investigate the proper temperature needed downstream from the catalyst to prevent the condensation of gases into solid deposits. This work was complicated by difficulties in removing all of the $\mathrm{NH}_{3}$ from the gas streams, which substantially affected results on aerosol condensation. Through continued testing, it was determined that small amounts $(<1 \%$ of the initial concentration) of the $\mathrm{NH}_{3}$ were still passing over the catalyst unaffected. Efforts were then focused on removing these trace levels of $\mathrm{NH}_{3}$. The amount of Pd catalyst was increased from 10 feet to 20 feet of wire, the gas preheat zone upstream from the catalyst was lengthened, and the packing characteristics of the catalyst in the quartz tube were improved. With these changes, $\mathrm{NH}_{3}$ was completely removed from the gas streams. However, because of problems noted in the "Miscellaneous" section below, the use of a Pd catalyst was discontinued. 


\section{$\underline{\text { Miscellaneous }}$}

For tests performed at a total gas flow rate of $3000 \mathrm{~mL} / \mathrm{min}$ or higher, the $1 / 4$-inch OD quartz tube downstream from the catalyst overheated. Consequently, the Teflon line connected to the downstream end of the quartz tube (about 12 inches from the catalyst) also overheated and burned through the Teflon. For effective sample transport, we prefer to couple Teflon lines to the exit of the catalyst tube. Therefore, tests were performed to study approaches for cooling the gases sufficiently to enable the use of Teflon lines downstream from the catalyst tube without extending the length of the quartz tube or using costly or cumbersome cooling devices. While using air, a total gas flow rate of $3 \mathrm{~L} / \mathrm{min}$ was passed through the 1/4-inch OD quartz tube. The $\mathrm{Pd}$ catalyst in the tube was heated at $900^{\circ} \mathrm{C}$. Directing a fan on the downstream portions of the catalyst tube had little effect on the temperature of the gases exiting the tube. Next, a 2-inch long chromel coil was placed inside the quartz tube downstream from the catalyst. The coil consisted of about 12 inches of a wire 0.02 inches in diameter. The coil improved cooling by causing turbulence and increased the degree of contact between the tube walls and the hot gases. Using this internal coil decreased the exit gas temperature from about $260^{\circ} \mathrm{C}$ to $180^{\circ} \mathrm{C}$, which was now in a suitable range for PTFE Teflon. In actual practice, a chromel wire would not be placed inside the catalyst tube. However, it is anticipated that substituting chromel for $\mathrm{Pd}$ or $\mathrm{Pt}$ would still provide effective cooling.

Using quartz cooling coils at the downstream end of the catalyst tube was also investigated as a method for cooling the gases to the point where Teflon fittings could be used. When a quartz cooling coil was used, gas temperatures at the exit of the tube were reduced to $30^{\circ} \mathrm{C}$ when using air flow rates of 3 and $5 \mathrm{~L} / \mathrm{min}$. The quartz coil consisted of 30 inches of quartz tube formed into a coil 10 inches long and one inch in diameter When the length of the coil was reduced by $50 \%$, the gas temperature was about $90^{\circ} \mathrm{C}$ at a flow rate of $3 \mathrm{~L} / \mathrm{min}$. In other work, it was later found that increasing the diameter of the quartz tube (housing the catalyst) to $3 / 8$ " provided a number of benefits, including reduction of backpressure upstream from the catalyst. Therefore, the 1/4" diameter quartz tube was permanently replaced with a $3 / 8$ " diameter quartz tube. With the larger diameter tube, the linear velocity of the gases decreased considerably, and the gases were sufficiently cooled by the time they exited the tube. Therefore, the addition of a cooling coil was no longer needed.

While performing tests on $\mathrm{NH}_{3}$ removal with a $\mathrm{Pd}$ catalyst, an overall bulk bed temperature of about $900^{\circ} \mathrm{C}$ was generally maintained. However, due to localized heating of the catalyst surface, complete meltdown of the catalyst was encountered on several occasions. At a minimum, fusion of pieces of the catalyst to one another was routinely observed. This in turn resulted in decreased $\mathrm{NH}_{3}$ removal efficiencies due to decreased available surface area. Because of these problems, we discontinued the use of a Pd catalyst for oxidizing the sample gas streams. Because the melting point of Pt is several hundred degrees Celsius higher than that of $\mathrm{Pd}$, using Pt expands the "temperature window" at which the catalyst can operate to effectively remove $\mathrm{NH}_{3}$ without melting or fusing the catalyst. In the work with Pt catalysts, which was discussed earlier, no melting or fusion problems were noted with extended use. 


\section{FINAL DESIGN OF CATALYST TUBE}

A sample transport temperature (prior to the catalyst) of $600^{\circ} \mathrm{C}$ will probably be used. The sample gases will enter a 3/8-inch OD quartz catalyst tube. The hot sample gases will first be passed over a bed (about $11 / 2$ inches long) of granular (-6 to +12 mesh) alumina at $900^{\circ} \mathrm{C}$ or higher, which will oxidize most of the gas stream. This will be followed immediately by a 1inch zone of $\mathrm{Pt}$ catalyst (pieces of $\mathrm{Pt}$ wire) to serve as a polisher to remove residual traces of $\mathrm{NH}_{3}$ or other unwanted compounds (e.g., hydrocarbons) from the gas stream. Finally, the gases will pass through a pyrolysis zone at about $900^{\circ} \mathrm{C}$ in order to convert $\mathrm{Hg}$ to the elemental form prior to the detector.

\section{OXIDATION WITHOUT CATALYST}

Tests were performed using a simulated gasifier stream $\left(50 \% \mathrm{CO}, 15 \% \mathrm{CO}_{2}, 25 \% \mathrm{H}_{2}, 8 \%\right.$ $\mathrm{CH}_{4}, 2 \% \mathrm{H}_{2} \mathrm{~S}$, and $1 \% \mathrm{NH}_{3}$ ) flowing at $0.5 \mathrm{~L} / \mathrm{min}$ through empty quartz tubes with outer diameters of $1 / 4$ " and $3 / 8$ ". The simulated gasifier stream was blended with $1.5 \mathrm{~L} / \mathrm{min}$ of air prior to the quartz tube. The portion of the quartz tube that would normally house the catalyst was heated to $900^{\circ} \mathrm{C}$. In addition, a preheat zone at $900^{\circ} \mathrm{C}$ was used immediately prior to the catalyst. In those tests, virtually all of the $\mathrm{NH}_{3}$ was removed, even with no catalyst. Thus, the catalyst is not of critical importance for the removal of $\mathrm{NH}_{3}$. However, because aromatic hydrocarbons (a strong interference in the determination of $\mathrm{Hg}$ by $\mathrm{AA}$ ) are much more difficult to thermally decompose, an oxidation catalyst will still be used. In addition, the catalyst will be helpful to remove tars, since heating at $900^{\circ} \mathrm{C}$ is not expected to destroy those compounds. Finally, using a catalyst will help ensure complete removal of $\mathrm{NH}_{3}$ under a wide variety of conditions in the field.

\section{NAFION TUBING}

The use of Nafion-based dryers to remove $\mathrm{NH}_{3}$ gases from sample streams was investigated. The sample gas is transported in the Nafion tubing while passing a countercurrent purge gas stream over that tubing. According to literature provided by the manufacturer (Perma Pure), this drying system may result in some losses of $\mathrm{NH}_{3}$ into the purge gas. The magnitude of such losses were unknown. However, if the losses were considerable, it could potentially be used to remove $\mathrm{NH}_{3}$ from gasifier streams. Also, it could potentially be used as a polishing step after the use of an oxidation catalyst. To evaluate the use of Nafion dryers for this purpose, we used a dry sample stream containing $5 \% \mathrm{NH}_{3}$ in air flowing at $500 \mathrm{~mL} / \mathrm{min}$. Countercurrent purge gas flow rates of 1000 and $2500 \mathrm{~mL} / \mathrm{min}$ were used, which provided purge:sample gas flow ratios of 2:1 and 5:1. The sample gases and purge gases were bubbled into deionized water absorbing solutions, which were subsequently analyzed for ammonium ion concentrations by IC. Results of the IC analyses indicated that at least $95 \%$ of the $\mathrm{NH}_{3}$ was retained in the sample gas stream, regardless of whether a $2: 1$ or 5:1 purge:sample flow ratio was used. Therefore, this approach did not appear to have potential for removal of $\mathrm{NH}_{3}$ from sample gases. However, it was later learned that the presence of moisture is required in order for $\mathrm{NH}_{3}$ losses to occur $\left(\mathrm{NH}_{3}\right.$ is reportedly captured by water vapor and is removed along with the moisture as ammonium 
hydroxide). Unfortunately, in the presence of sulfur-bearing gases under oxidizing conditions, ammonium sulfates are anticipated to form, which are expected to quickly plug the openings in the Nafion membranes.

\section{MOISTURE REMOVAL}

The potentially high moisture content (up to $50 \%$ by volume) of coal gasification streams requires that most of the moisture be removed from the gas stream prior to entering the analytical detection systems. For this purpose, a gas drying system from Perm Pure was selected for use in the overall CEM design. This unit, shown in Figure 3 below, is a Perma Pure GASS ${ }^{\text {TM }}$ (Gas Analysis Sampling System) dryer designed to handle a 1-2 L/min gas flow with up to 50\% moisture. That system contains two Perma Pure PD-1000-24AFS dryers with Nafion tubes as well as an internal Model FF-250-FG Filter Coalescer. By properly adjusting the temperature of the coalescer, it may also be possible to remove some of the acid gases without condensing water. This dryer is one of the key components to the gas conditioning system used for both the $\mathrm{Hg}$ and $\mathrm{HCl}$ determinations.

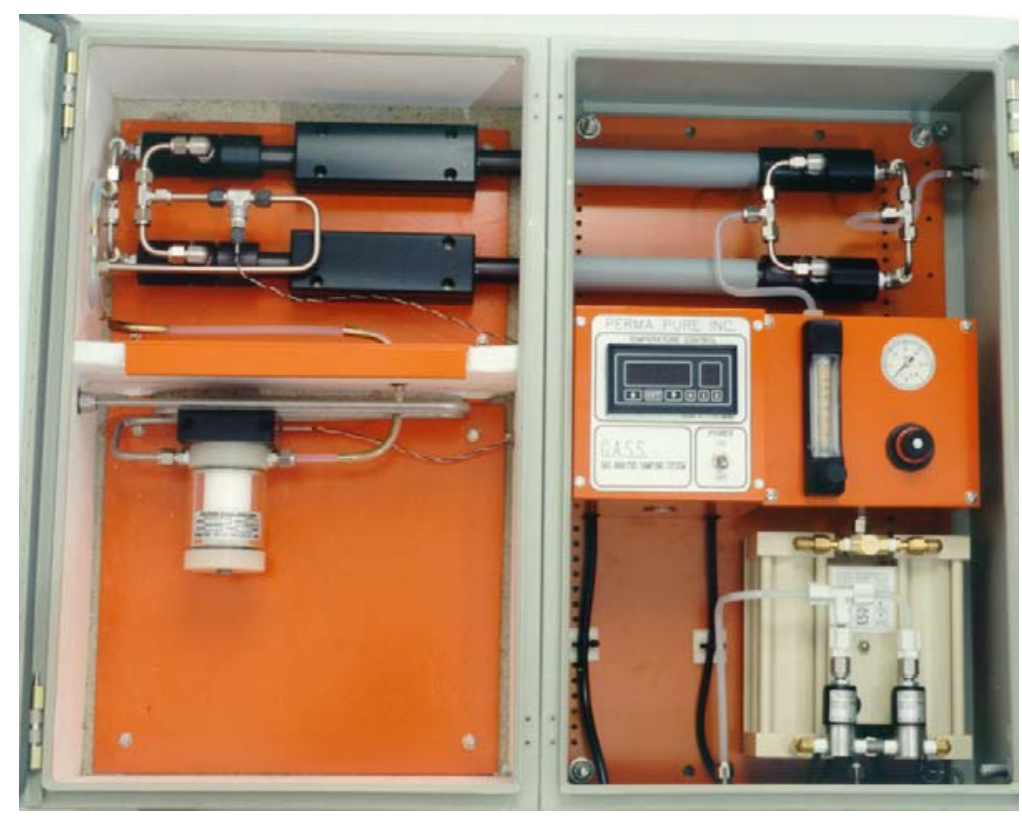

Figure 3. Gas Drying System from Perma Pure.

\section{TAR REMOVAL}

Studies were performed at a $800 \mathrm{~kW}$ (thermal input) biomass gasifier to determine whether a Pt catalyst could effectively remove tars from the gas stream. Tar removal is needed prior to 
analyzing $\mathrm{Hg}$ or $\mathrm{HCl}$ in coal gasifier streams. About $1 \mathrm{~L} / \mathrm{min}$ of gasifier stream was blended with $2 \mathrm{~L} / \mathrm{min}$ of air and passed over a hot Pt catalyst in a quartz tube. The quartz tube was long enough so that the downstream end of the tube was at $50^{\circ} \mathrm{C}$ or less, thereby making it easy to see whether tars were depositing. The catalyst zone was initially heated to $900^{\circ} \mathrm{C}$ to activate the reactions. The catalyst tube contained three zones. The first zone consisted of $\alpha$-alumina to oxidize the combustible gases such as $\mathrm{CH}_{4}, \mathrm{CO}$, and $\mathrm{H}_{2}$. This would help prevent overheating of the Pt catalyst zone by oxidizing the portion of the gas stream where a catalyst was not required. The second zone contained Pt wire to serve as a catalyst for oxidizing tars and other organic compounds that were not oxidized in the alumina zone. The third zone contained a commercially available Pt catalyst on an alumina substrate. That catalyst material has an extremely high surface area relative to the wire and served as a backup catalyst in case the first catalyst zone did not sufficiently oxidize the gas stream. For comparative purposes, tests were also performed with hot $\left(900^{\circ} \mathrm{C}\right) \alpha$-alumina alone (no catalyst) to see if the tars could be oxidized in this manner.

When using an empty catalyst tube, tars quickly deposited in the quartz tube and the deposits became very heavy within just a few minutes. Using alumina at $900^{\circ} \mathrm{C}$ did not prevent tar buildup. However, when using the Pt catalyst, the tars were completely removed. The catalyst was initially heated to $900^{\circ} \mathrm{C}$ to start the reactions. After the reactions (highly exothermic) began, the external heat source was decreased but not turned off. Sampling was performed for 30 minutes with no tars getting through the catalyst. At that time, sampling was discontinued. After the sampling system was taken back to the laboratory and examined, it was noted that a quartz wool plug that was used in the catalyst tube had become partially fused. In addition, there was some pitting and other indicators in the quartz tube itself that suggested temperatures in the $\mathrm{Pt}$ zone were near the melting point of quartz (about $1600^{\circ} \mathrm{C}$ ). Therefore, precautions should be used to keep the temperature from reaching such extremes. Turning down the external heat source further would be one option for decreasing the overall temperature of the catalyst bed.

\section{SAMPLING ISSUES}

\section{SAMPLE TRANSPORT LINES}

Consideration was given to the type of sample transport tubing to use between the gasifier and the catalyst. Stainless steel was considered as one option, but the composition is inherently reactive with the gas matrix involved. Therefore, additional options were considered, including the possible use of Hastelloy B, Hastelloy X, alloy C-276, and Ni-200 .

A metallurgical engineer suggested that alloy C-276 would be the best choice for the given conditions of temperature and gas matrix composition. It was noted that Ni-200 will be quickly pitted by $\mathrm{HCl}$ in the gasifier stream. Hastelloy-B will be limited to lower temperatures because of the corrosive nature of the gasifier streams. Hastelloy- $\mathrm{X}$ is generally used in oxidizing conditions and is high in iron content, which will be degraded by the corrosive gases. The C-276 
is high in Mo (15-17\%) content and will help decrease the effect of the corrosive gases. Also, that alloy is expected to hold up under the sample transport temperatures of $600^{\circ} \mathrm{C}$ that are anticipated, although this is approaching its upper temperature limit. Haynes $242^{\mathrm{TM}}$ alloy, which had not been previously considered, was suggested as a better option. The higher Mo (24\%) content of that alloy is expected to result in better performance (in terms of corrosion) than the C-276 alloy. Unfortunately, after contacting numerous vendors who stock the 242 alloy, we were unable to locate a vendor who manufactures any tubing out of that material. Some vendors who manufactured C-276 tubing in the desired size (3/8-inch OD) were located. However, with that vendor, a 20 -foot section selling for $\$ 650$ must be purchased. In addition, the necessary fittings in upstream sections of the sample transport system would cost an additional $\$ 600$ if made of the C-276 alloy. Consequently, the total cost of the tubing plus the fittings would come to over $\$ 1200$, which was too costly in view of budget constraints.

Because of cost considerations with alloy C-276, the use of electropolished 316 stainless steel was reconsidered. There could be some tradeoffs with respect to reactivity of the metals to gasifier streams. Although stainless steel is expected to be inherently more reactive to the sample gases than C-276 alloy, the reactivity of the stainless steel can be substantially diminished by electropolishing. The C-276 alloy, on the other hand, is inherently less reactive but can not be electropolished nearly as efficiently at the 300 series stainless steels. Therefore, it is possible that the reactivity of electropolished stainless steel could be comparable to the C-276 alloy that is not electropolished. Also, as opposed to a cost of over \$1200 for C-276 tubing and fittings, getting electropolished stainless steel tubing and fittings will cost only about $\$ 350$. For the electropolished stainless steel, the overall reactivity of the metal is diminished in part because of the reduced ( $90 \%$ or more) surface area on the interior of the tube. Electropolishing is superior to mechanical polishing, with friction coefficients 3 to 4 times lower than those typically obtained by mechanical polishing. Also, during the electropolishing operations, a chromium-enriched surface is typically produced due to preferential removal of $\mathrm{Ni}$ and $\mathrm{Fe}$. This further improves corrosion resistance. In view of cost considerations, the electropolished steel may be an attractive sample transport option. In the future, it may be desirable to test the C-276 alloy and compare it to electropolished type 316 stainless steel during prolonged use.

Next, because of potential problems associated with contacting metals with corrosive gases, we considered using silica-coated stainless steel (sold as Silcosteel ${ }^{\circledR}$ by Restek Corporation). Silcosteel has a fused layer of silica of uniform thickness. Depending on consumer preferences, the thickness can range from 100 to 5000 angstroms. However, we were concerned about the differences in thermal expansion coefficients between the silica and the steel, which could potentially result in the silica flaking off as the tubing is repeatedly heated and cooled. Therefore, we took a small piece of Silcosteel having roughly 1000 angstroms of silica and subjected it to 10 heating (to $600^{\circ} \mathrm{C}$ ) and cooling cycles in a muffle furnace. The tubing was maintained at $600^{\circ} \mathrm{C}$ for only a few minutes for each cycle. The interior of the tubing, as well as a fresh piece of tubing, were then examined by SEM-EDX for physical appearance and chemical composition. Results of the analyses showed that the silica was still evenly distributed (on a macro scale) after heating, and there was no evidence of any flaking or other degradation. However, a color change was noted after heating. The fresh tube was bluish in color, while the heated tube was purple. Personnel at Restek noted that a color change from blue to purple can indicate that the thickness of the silica layer decreased. Although they have made similar 
observations when heating their tubing in a muffle furnace, the mechanism for the possible silica "loss" is unknown. In view of this, we performed additional tests to determine whether the thickness of the silica layer would continue to decrease with repeated heating (to $600^{\circ} \mathrm{C}$ ) and cooling cycles. Fresh Silcosteel was subjected to 10, 20, and 30 heating cycles. In addition, a fresh sample was heated in air at $600^{\circ} \mathrm{C}$ overnight. Visually, there was a color change from sample to sample, which could possibly indicate a change in the thickness of the silica layer. However, analyses of the interiors of the tubes by SEM-EDX showed uniform silica coatings for every sample, and there were no signs of any flaking or pitting. Based on this information, personnel at Restek now believe that we are not losing silica, and that the color changes are probably due to a changing index of refraction as the sample is heated. Therefore, Silcosteel appears to be a viable sample transport material for our purposes. An area of concern at the anticipated sampling temperatures is that the temperatures are starting to approach the point at which solid state diffusion of carbon in the steel may occur, in which case the silica could start to flake off. However, if the Silcosteel degrades with prolonged use, it will not be costly to periodically replace necessary sections of the sample tubing. Alternatively, it may be advisable to go to silica-coated super alloys that will be able to withstand the sampling environments better. Although this would initially be more costly, it might be the least expensive approach in the long run.

\section{MONITORING FLOW DURING FIELD SAMPLING}

Consideration was given to monitoring sample gas flow rates during field sampling operations. The heated gases can not be run into a flow meter prior to gas stream oxidation because of potential problems with analyte losses and because of problems from tars. One possibility for measuring flows is to use an orifice plate. The pressure drop across the plate would be monitored and the magnitude of the pressure drop would be correlated with volumetric gas flows. Similarly, in the Ames Laboratory alkali monitoring system, the sample flow is monitored by a differential pressure flow cell. In that system, the flow element consists of a 1/4inch OD stainless steel rod that is $1 \frac{1 / 4}{4}$ " long with a $1 / 8$ " hole in it. The differential pressure generated by the flow of the sample through the steel tube is then monitored and correlated to volumetric flows. In any event, because of effects of gas densities among the gases present, knowledge of the composition of the gasifier stream is required in order to obtain accurate flow calculations. The situation is even more complex when gas stream oxidation is used and gas flow readings are taken after the oxidation occurs. This is because some of the primary matrix gases are converted to gaseous species with completely different gas densities, and some of the gases are converted entirely to water which will subsequently be removed by the gas conditioning system.

The $\mathrm{Hg}$ and $\mathrm{HCl}$ CEMs have not yet been field tested. Problems may be encountered in the field which will require modification of some of the gas conditioning components. Therefore, until the overall technology (combined analytical and sampling systems) is proven in the field, work focused on whether the system will track changes in analyte concentrations at a given flow rate, and an emphasis was not placed on uncertainties in the sample flow rate at this time. The total dry gas flow rate (after gas stream conditioning) and the flow rate of the dilution/oxidation air will both be monitored. The approximate flow rate of the gasifier stream 
will then be calculated by difference. Using this approach, the calculated flow rate of the gasifier stream should be accurate to within $50 \%$, which is adequate for our purposes at this stage in the development of the CEMs.

\section{USE OF AN INERTIAL FILTER}

Although an inertial filter was not field tested in this work, such a filter was considered for sampling gasifier streams. A Model 7611 IGS (inertial gas sampling) cross-flow filter with an eductor from Mott Corporation was purchased from other funding sources and would be available for short-term use to test its suitability for sampling gasifier streams. With this filter, a high velocity gas enters the eductor to develop a high-velocity axial flow through the filter tube. The high axial velocity prevents particulate buildup in the filter. A clean sample flow develops radially through the porous tube wall at a very low face velocity. The porous length of the filter is 12 inches, allowing for a maximum clean sample flow rate of $2 \mathrm{~L} / \mathrm{min}$. The cut point for this particular filter is about 0.5 microns. The unit is constructed of type 316 stainless steel porous media, type 316 stainless steel housing and connector, and type 300 stainless steel eductor. For prolonged gasifier sampling, other materials of construction (much more costly) would be preferred once the utility of this filtering approach has been demonstrated.

\section{MERCURY STUDIES}

\section{SELECTION OF METHODS TO EVALUATE}

The goal of our work was to adapt conventional technologies to the monitoring application of interest rather than trying to develop new analytical technologies which would, in all likelihood, take many years of development. At the time this work was started, there was very little available to choose from in terms of relatively inexpensive $\mathrm{Hg}$ CEMs. Based on available information at the time, the analytical methods considered for use in our Hg CEM included cold vapor atomic absorption (CVAA, or AA), cold vapor atomic fluorescence (CVAF, or AF), and gold amalgamation devices using resistivity measurements. After weighing the pros and cons of those methods for our applications, we selected AA and AF for further consideration. AA is one of the most common laboratory methods for determining $\mathrm{Hg}$, while $\mathrm{AF}$ has been gaining in popularity in recent years. We decided not to use the gold amalgamation device ("Jerome" analyzer sold by Arizona Instruments) for a variety of reasons. Company representatives informed us that the instrument must be returned to the manufacturer every 6-12 months for electronic calibration (cost of about \$400) and sensor replacement (cost of about \$600) when used intermittently. For the continuous operation desired, the unit may have to be sent in for recalibration and sensor replacement every 2 to 4 weeks. Because of the calibration logistics, calibration frequency, and probable frequent replacement of the sensor, that unit was not considered further for on-line analysis of coal gasifier streams. At the time this decision was made, the problems associated with using gold films in the presence of $\mathrm{NO}_{\mathrm{x}}$ (which would be formed during gas stream oxidation) and acid gases were not yet known. 
The following sections discuss our work on the development of a Hg CEM. For the purposes of our work, concentration units of $\mathrm{ppb}_{\mathrm{w}}$ and $\mu \mathrm{g} / \mathrm{m}^{3}$ are used synonymously, even though they are slightly different. Since testing typically involved observing trends or observing relative concentrations between tests, small uncertainties in the exact $\mathrm{Hg}$ concentrations were not important for data evaluation.

\section{ATOMIC ABSORPTION VS. ATOMIC FLUORESCENCE}

\section{OVERVIEW OF TECHNOLOGIES}

Atomic absorption spectroscopy (AA) involves free neutral ground-state atoms absorbing light energy that is characteristic of that particular element. As light is absorbed by the analyte in the sample cell, a decrease in the transmitted light intensity will result. The transmitted intensity, $I_{t}$, is related to the incident intensity, $I_{0}$, by the Beer-Lambert Law (Eq. 1), where "a" is the absorbtivity of the analyte, " $\mathrm{b}$ " is the path length of absorption, and "c" is the concentration of the analyte. The absorbance, "A", of the analyte is given by Eq. 2 .

$$
\begin{aligned}
& I_{t}=I_{o} 10^{-a b c} \\
& A=-\log I_{t} / I_{o}=a b c
\end{aligned}
$$

The absorbance is expressed in terms of "absorbance units" (AUs) and is linear with analyte concentration. At low absorbance values, milliabsorbance units (mAU) are usually used. A Hg lamp is usually employed to generate the characteristic radiation for $\mathrm{Hg}$. The most common wavelength to use for analysis is $254 \mathrm{~nm}$, since absorption is strongest at that wavelength. Many $\mathrm{Hg}$ detectors use both a sample beam and reference beam. The radiation intensity passing through the analyte-free reference cell represents the incident intensity, while the radiation intensity passing through the sample cell represents the transmitted intensity. For the measurement of $\mathrm{Hg}$, the $\mathrm{Hg}$ must be present in the elemental vapor phase and not combined with other elements in a molecular form. Problems of special concern for AA include spectral interferences from molecules such as hydrocarbons, $\mathrm{H}_{2} \mathrm{~S}$, and $\mathrm{SO}_{2}$.

AF employs a type of photoluminescence similar to that in AA in that both involve the absorption of light energy that is characteristic of a particular element by a free neutral groundstate atom. However, the desired signal for AF is the emitted or luminesced light energy from the excited atom and not the transmitted light. If the luminesced radiation is the same frequency as the absorbed light, then resonance fluorescence occurs. The AF detector used in this study measures the resonance fluorescence of elemental $\mathrm{Hg}$ at $254 \mathrm{~nm}$. The fluorescence light intensity, $\mathrm{I}_{\mathrm{f}}$, is directly proportional to the absorbed light using Eq. 3, where " $\mathrm{K}$ " is a constant of proportionality which depends on the element and its environment. If a substitution is made for the transmitted intensity, $\mathrm{I}_{\mathrm{t}}$, then Eq. 4 results.

$$
\begin{aligned}
& I_{f}=K\left(I_{o}-I_{t}\right) \\
& I_{f}=K I_{o}\left(1-10^{-a b c}\right)
\end{aligned}
$$


Deviations of the fluorescence signal from Eq. 4 can be due to primary or secondary absorption effects. The primary absorption effect is absorption of the incident radiation before it reaches the portion of the sample cell observed by the detector. The secondary absorption effect is absorption of the fluorescence signal before reaching the detector and is usually due to selfabsorption by the analyte. Combining Eq. 4 with the absorption effects gives Eq. 5, where "p" and "s" are the path lengths for the primary and secondary absorption effects, respectively. For small absorbencies (abc $<0.01$ with $\mathrm{p}+\mathrm{s}<\mathrm{b}$ ), Eq. 5 can be approximated by using Eq. 6, and the fluorescence intensity is directly proportional to the concentration of the analyte.

$$
\begin{aligned}
& \mathrm{I}_{\mathrm{f}}=\mathrm{KI}_{\mathrm{o}} 10^{-\mathrm{apc}}\left(1-10^{-\mathrm{abc}}\right) 10^{-\mathrm{asc}} \\
& \mathrm{I}_{\mathrm{f}}=2.303 \mathrm{KI}_{\mathrm{o}} \mathrm{abc}
\end{aligned}
$$

In addition to absorption effects, the intensity of the fluorescence signal can be decreased significantly due to "quenching" of the signal from certain other gaseous species in the sample. Quenching occurs when the excited analyte atoms transfer their excitation energy via collisions with other molecules. To avoid this problem, $\mathrm{Hg}$ is normally collected on gold and then thermally desorbed into an argon (Ar) carrier gas. Because even trace amounts of impurity gases can decrease sensitivity, ultra high purity Ar is preferred. Compared to AA, where numerous compounds interfere at the absorbing wavelength, $\mathrm{AF}$ is less subject to false positives.

\section{LABORATORY EVALUATIONS}

Two extremely sensitive mercury detectors were tested in the laboratory to demonstrate general analytical capabilities and to investigate their potential use for on-line analysis of $\mathrm{Hg}$ at coal gasification facilities. Specifically, a Thermo Separation Products Model 3200 Cold Vapor Atomic Absorption Mercury Detector and a Tekran Model 2500 Cold Vapor Atomic Fluorescence Mercury Detector were investigated. The Thermo Separation Products detector, which is equipped with a 10-cm cell, later became the workhorse for the bulk of our $\mathrm{Hg}$ work. The AA and AF units investigated in our work are shown in Figures 4 and 5, respectively. 


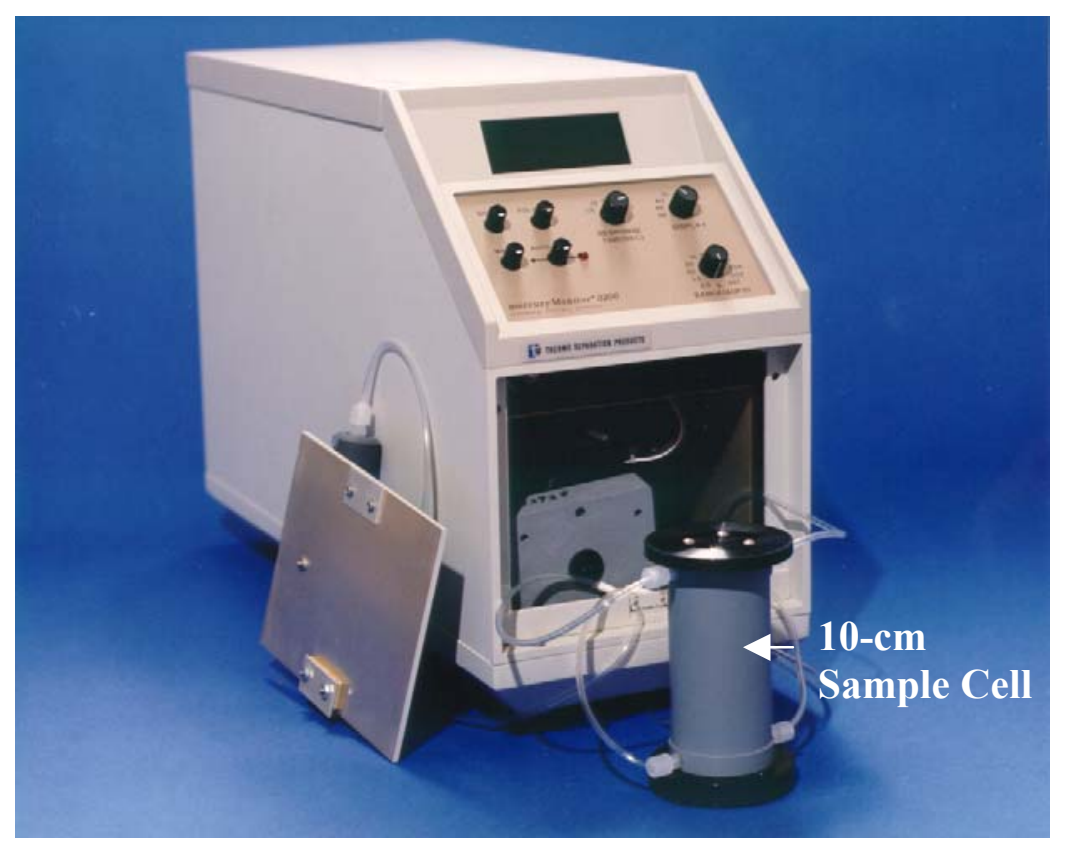

Figure 4. Thermo Separation Products Model 3200 AA Mercury Detector.

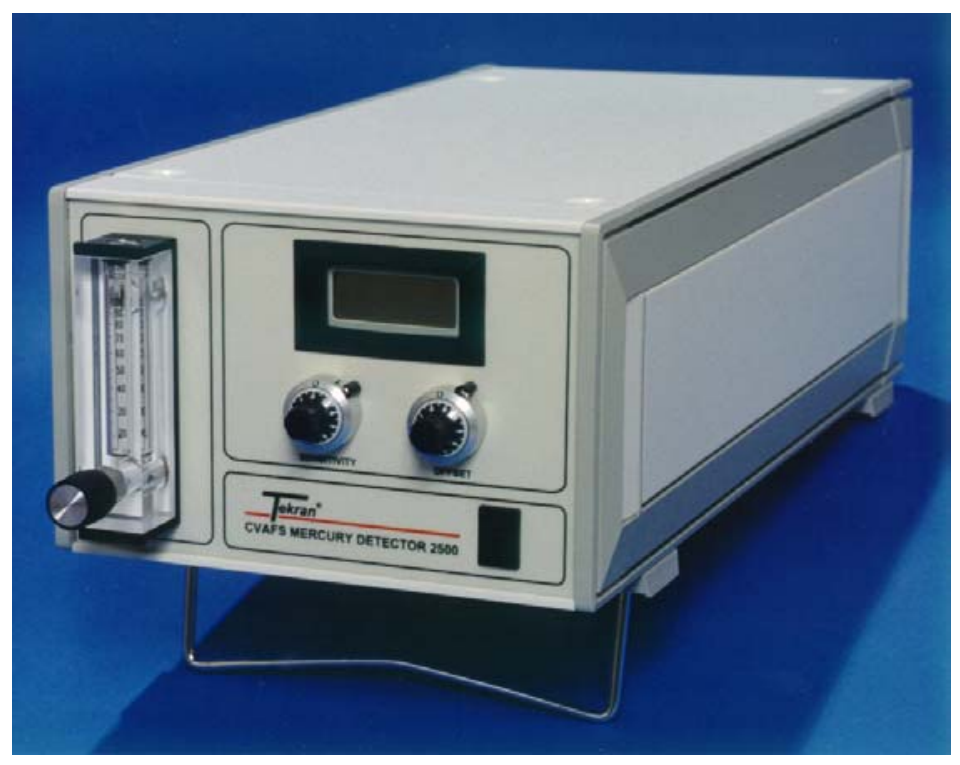

Figure 5. Tekran Model 2500 AF Mercury Detector.

Known amounts of vapor phase elemental $\mathrm{Hg}$ ranging from 3 to 50,000 picograms (pg) were collected with gas-tight syringes by withdrawing $\mathrm{Hg}$-saturated air above a pool of $\mathrm{Hg}$ in an Erlenmeyer flask fitted with a septum. At known temperature and pressure, the $\mathrm{Hg}$ concentration in air was calculated from known $\mathrm{Hg}$ vapor pressure parameters. The smallest injection volume that could be reliably withdrawn was about $0.2 \mu \mathrm{L}$ of $\mathrm{Hg}$-saturated air, which corresponds to about $3 \mathrm{pg}$ of $\mathrm{Hg}$ at room temperature. For comparative purposes, a series of 
injections were performed with the $\mathrm{AF}$ detector in which $\mathrm{Hg}$ vapor was collected from the flask containing an Ar atmosphere rather than air, thereby eliminating any potential quenching effects from the air being injected along with the $\mathrm{Hg}$.

Gases entering the detectors were spiked by injecting the $\mathrm{Hg}$ into the carrier gas upstream from the detector. For a given injection volume, three to six injections were made and the average peak intensities and relative standard deviations (RSDs) were calculated. In addition to manual injections of $\mathrm{Hg}$ vapor into the carrier gas, a VICI Metronics Model 340 Dynacalibrator with elemental $\mathrm{Hg}$ permeation tubes was used to provide a continuous flow of gases containing 0.1 to $960 \mathrm{ppb}_{\mathrm{w}} \mathrm{Hg}$ in air. For the $\mathrm{AA}$ and $\mathrm{AF}$ tests using continuous $\mathrm{Hg}$ streams, three sequential signals at each $\mathrm{Hg}$ concentration were recorded, and averages and RSDs were then calculated from those data. For both the injections and continuous $\mathrm{Hg}$ streams, instrument responses were obtained by measuring peak heights on a strip chart recorder.

For the AA work, the carrier gas was zero air, except for one series of tests in which research grade Ar was used to allow for better comparisons with the AF data. Unless otherwise noted, research grade Ar was used as the carrier gas for the AF tests in order to avoid possible fluorescence quenching effects from molecular gases. However, a series of tests was performed with the $\mathrm{AF}$ detector in which a variety of other carrier gases were used in place of Ar. Those gases, which included $\mathrm{CH}_{4}, \mathrm{CO}, \mathrm{CO}_{2}, \mathrm{O}_{2}, \mathrm{H}_{2}$, and $\mathrm{N}_{2}$, were used to study the fluorescence quenching effects to determine whether it might be possible to pass conditioned sample gases directly into the detection cell for analysis. It should be noted that the AF instrument is not intended to be operated with carrier gases other than Ar, and that passing other gases through the detector is an aberration from specified procedures in the instrument manual. Flow rates for the carrier gases were typically $100-200 \mathrm{~mL} / \mathrm{min}$ for AA, and was $115 \mathrm{~mL} / \mathrm{min}$ for AF unless otherwise noted.

For the AA tests, base line drift was typically about $0.05 \mathrm{mAU} / \mathrm{hr}$ and was always less than $0.1 \mathrm{mAU} / \mathrm{hr}$. A mAU reading of 0.1 is roughly equivalent to a $\mathrm{Hg}$ concentration of about 0.5 $\mathrm{ppb}_{\mathrm{w}}$ in air or an injection of several pg of Hg. Minimal base line noise was observed even for flows up to $1000 \mathrm{~mL} / \mathrm{min}$.

Results from the $\mathrm{Hg}$ injections into the AA unit indicated that the detector could easily detect less than $3 \mathrm{pg} \mathrm{Hg}$. A theoretical detection limit of $0.3 \mathrm{pg} \mathrm{Hg}$ was calculated from the recorder data. The instrument response showed good linearity in the range of 3 to $50,000 \mathrm{pg}$. RSDs were typically $\pm 1-5 \%$ for injections of $25 \mathrm{pg}$ or more and were typically $\pm 10-15 \%$ for injections of lesser amounts.

For the tests with continuous $\mathrm{Hg}$ streams into the $\mathrm{Hg}$ detector, the dynamic range was spanned at least four orders of magnitude in $\mathrm{Hg}$ concentration. A typical signal for a $\mathrm{Hg}$ concentration of $0.5 \mathrm{ppb}_{\mathrm{w}}$ is shown in Figure 6. As can be seen, an excellent signal is obtained at that concentration. The amount of base line drift over a period of 15 minutes was negligible relative to the magnitude of the signal. When a $0.1 \mathrm{ppb}_{\mathrm{w}}\left(0.01 \mathrm{ppb}_{\mathrm{v}}\right) \mathrm{Hg}$ stream (near the minimum detectable concentration) was passed through the detector, a distinct signal was observed. The RSDs were $\pm 5 \%$ or better for $\mathrm{Hg}$ concentrations of 0.1 to $1000 \mathrm{ppb}_{\mathrm{w}}$, and did not exceed $\pm 2 \%$ for concentrations above $10 \mathrm{ppb}_{\mathrm{w}}$. 


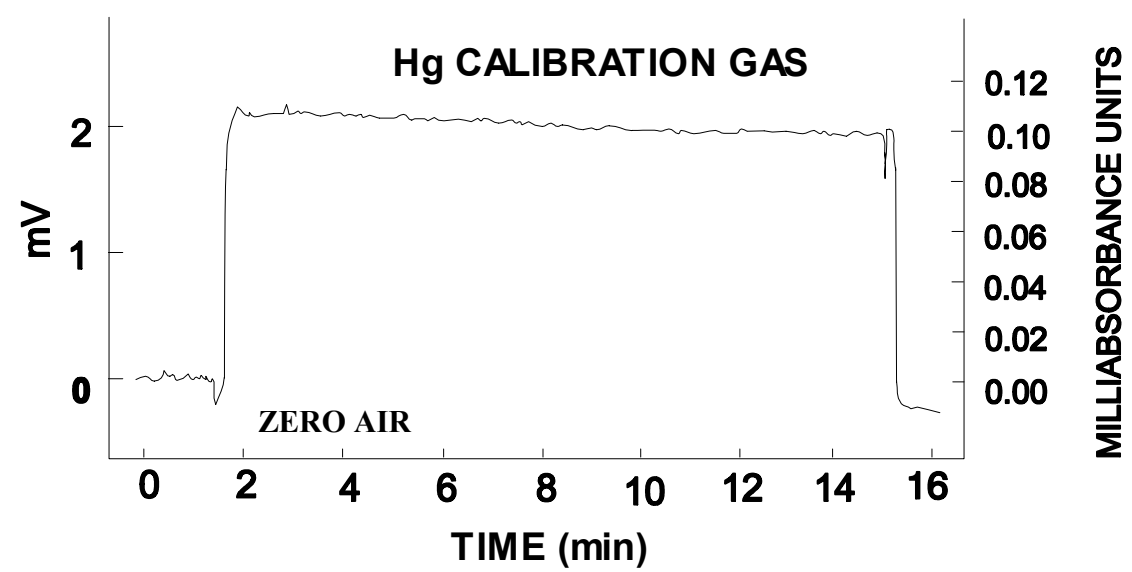

Figure 6. Typical AA Signal for $0.5 \mathrm{ppb}_{\mathrm{w}} \mathrm{Hg}$ Stream in Air.

In the tests using $\mathrm{Hg}$ (collected in air) injections into the $\mathrm{AF}$ unit, the base line drift was typically on the order of $0.5 \mathrm{mV} / \mathrm{hr}$, which is roughly equivalent to a signal produced from injecting about $1 \mathrm{pg} \mathrm{Hg}$. Flow rate changes in the range of $10-1000 \mathrm{~mL} / \mathrm{min}$ did not affect the base line signal level or base line noise. The instrument response showed good linearity over at least two orders of magnitude in the amount of $\mathrm{Hg}$ injected. Over a wider range, some degree of non-linearity resulted from quenching effects related to the increased amount of oxygen associated with the increasing amount of $\mathrm{Hg}$ (collected in air) injected into the detector. Collecting the $\mathrm{Hg}$ vapor in an Ar atmosphere rather than in air did not significantly affect peak heights for injections of less than $300 \mathrm{pg} \mathrm{Hg}$. However, for injections of 300 to $5000 \mathrm{pg} \mathrm{Hg}$, peak heights for a given amount of $\mathrm{Hg}$ increased by up to $40 \%$, which greatly improved the linearity of the calibration curve over a wide range. A theoretical detection limit of $0.1 \mathrm{pg}$ was calculated from these tests. RSDs were $\leq 5 \%$ for injections of $25-5,000 \mathrm{pg}$ and $5-25 \%$ for injections of 2-25 pg. Using peak areas rather than peak heights would probably have improved precision, even at these low levels of $\mathrm{Hg}$. When continuous $\mathrm{Hg}$ streams were passed into the $\mathrm{AF}$ detector, a $\mathrm{Hg}$ concentration of $0.1 \mathrm{ng} / \mathrm{L}$ in Ar could easily be detected.

When $\mathrm{Hg}$ was injected into different carrier gases flowing into the AF detector, no quenching effects were observed for $\mathrm{CH}_{4}$, substantial quenching was observed for $\mathrm{N}_{2}$, and severe quenching was observed for $\mathrm{O}_{2}, \mathrm{H}_{2}, \mathrm{CO}$, and $\mathrm{CO}_{2}$. For the latter gases, a signal reduction (compared to signal levels observed with Ar as the carrier gas) of $95 \%$ or more was observed for $\mathrm{Hg}$ injections of $2500 \mathrm{pg}$ or less. For $\mathrm{Hg}$ injections of $500 \mathrm{pg}$ or less, the decrease in signal strength was roughly $75 \%$ for $\mathrm{N}_{2}$ and was $99 \%$ or more for $\mathrm{O}_{2}, \mathrm{CO}_{2}, \mathrm{CO}$, and $\mathrm{H}_{2}$. The most severe quenching was observed for $\mathrm{O}_{2}$. The degree of quenching generally appeared to decrease as the amount of $\mathrm{Hg}$ injected increased in the range of 2 to $5,000 \mathrm{pg}$. This is shown in Figure 7 below. For emphasis, the results obtained for 2500-pg injections of $\mathrm{Hg}$ are shown in graph form in Figure 8. 


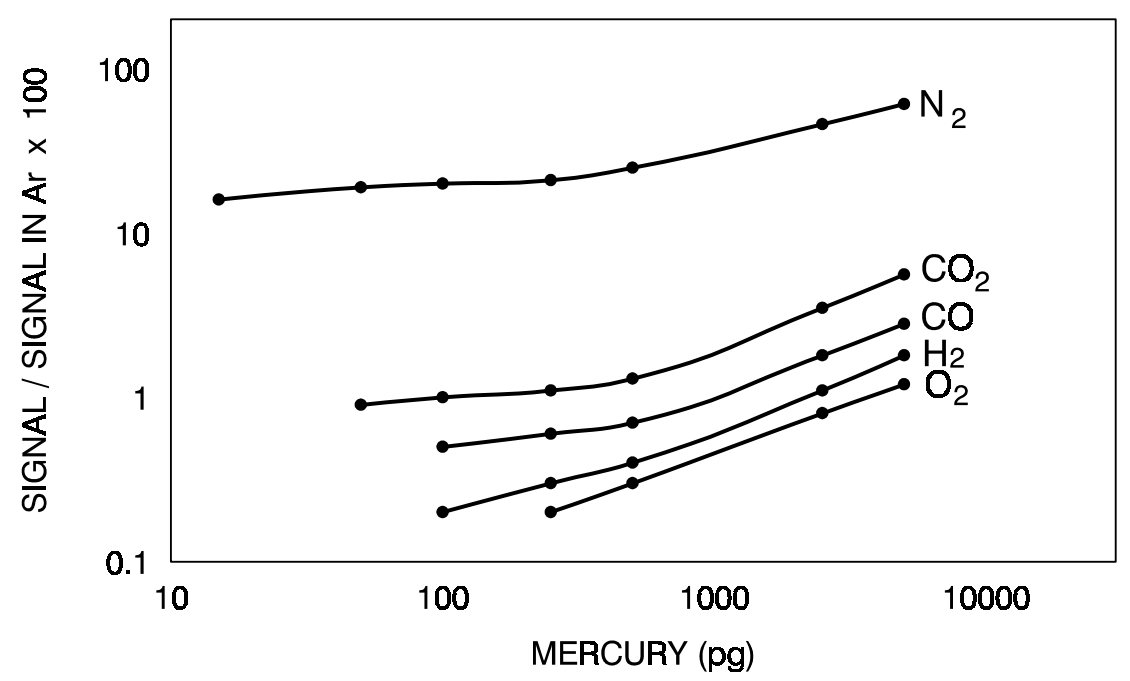

Figure 7. Quenching Effects for Various Gases vs. Amount of Hg Injected.

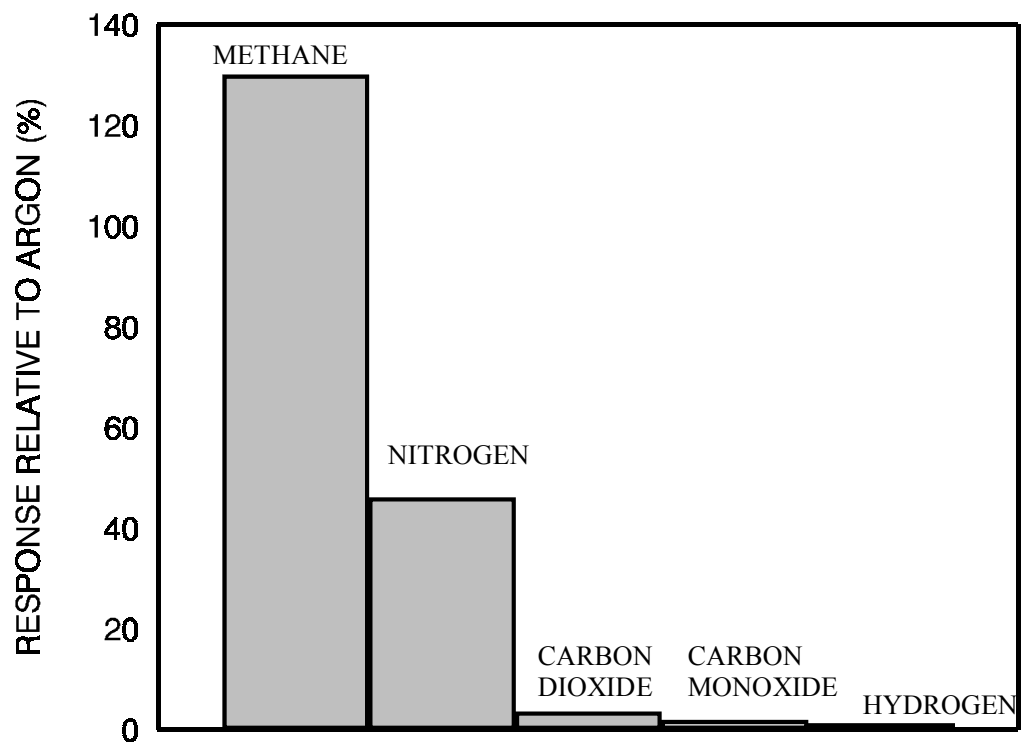

Figure 8. Fluorescence Quenching Effects for 2500-pg Hg Injections into Various Gases.

\section{SELECTION OF ANALYTICAL APPROACH}

Both $\mathrm{Hg}$ detectors investigated are compact, have minimal base line noise, and offer rapid analysis, low cost, and simplicity. In addition, they both have sufficient sensitivity to determine vapor phase $\mathrm{Hg}$ in coal gasification effluents. The AF unit exhibited less base line drift than the 
AA unit, although the amount of drift in the AA base line was still acceptable in view of the concentrations of $\mathrm{Hg}$ anticipated to be present in coal gasification streams.

An advantage of using AA is the potential for passing conditioned effluent gases directly into the absorption cell, although extensive gas conditioning will be needed. Disadvantages of using AA include interferences from hydrocarbons and other molecular gases, including $\mathrm{SO}_{2}$ and $\mathrm{H}_{2} \mathrm{~S}$. For passing gases directly into the AA cell, background corrections for those gases will be required if they can not be selectively removed. The possibility existed that extensively conditioned effluent gases could be directly analyzed by passing those gases into the AF detection cell. Unfortunately, the extent of the quenching from most of the major gases in a combustor or gasifier stream precludes the possibility of direct gas analysis at the anticipated $\mathrm{Hg}$ concentrations. However, AF can still potentially be used for effluent monitoring if the $\mathrm{Hg}$ is first collected by gold amalgamation or other suitable collection material and then released into a high purity Ar stream, which is the normal operating procedure with that instrument. That approach avoids interfering gases and also concentrates the $\mathrm{Hg}$ prior to evolution and detection. Early in the project, there were concerns that there may be problems associated with using gold cartridges in some process gas streams. It appears that suitable gas conditioning approaches are now available to circumvent those problems (4). However, at the time our work began and a selection of a suitable technology was needed, the necessary sample conditioning technology had not yet been made. Therefore, AA was selected for use in our Hg CEM after weighing the considerations noted above. At this point, the Thermo Separation Products $\mathrm{Hg}$ detector was intended to be part of the Hg CEM being developed, which is why it was thoroughly evaluated in the laboratory.

\section{MERCURY TRANSPORT THROUGH STEEL LINES}

Recoveries of elemental Hg through stainless steel (Type 304) sample lines were studied as a function of temperature and carrier gas composition. For these tests, 100-pg injections of elemental $\mathrm{Hg}$ vapor were made into the gas streams. Peak heights obtained for injections into zero air when using Teflon lines were used as the reference representing 100\% recovery. Full $\mathrm{Hg}$ recoveries were obtained using zero air in stainless steel sample lines at room temperature, but recoveries decreased to only $20 \%$ as the sample line was heated to $200^{\circ} \mathrm{C}$ (see Figure 9 below). When simulated gasifier streams (mixtures of $\mathrm{CO}, \mathrm{CO}_{2}, \mathrm{CH}_{4}, \mathrm{COS}, \mathrm{H}_{2}$, and $\mathrm{H}_{2} \mathrm{~S}$ ) were used without added moisture, no $\mathrm{Hg}$ was detected at any temperature between 25 and $200^{\circ} \mathrm{C}$. After using the simulated flue gases, poor $\mathrm{Hg}$ recoveries were obtained using zero air in stainless steel lines at room temperature. Several days of purging the sample line with zero air were required before full $\mathrm{Hg}$ recoveries could once again be obtained at room temperature. 


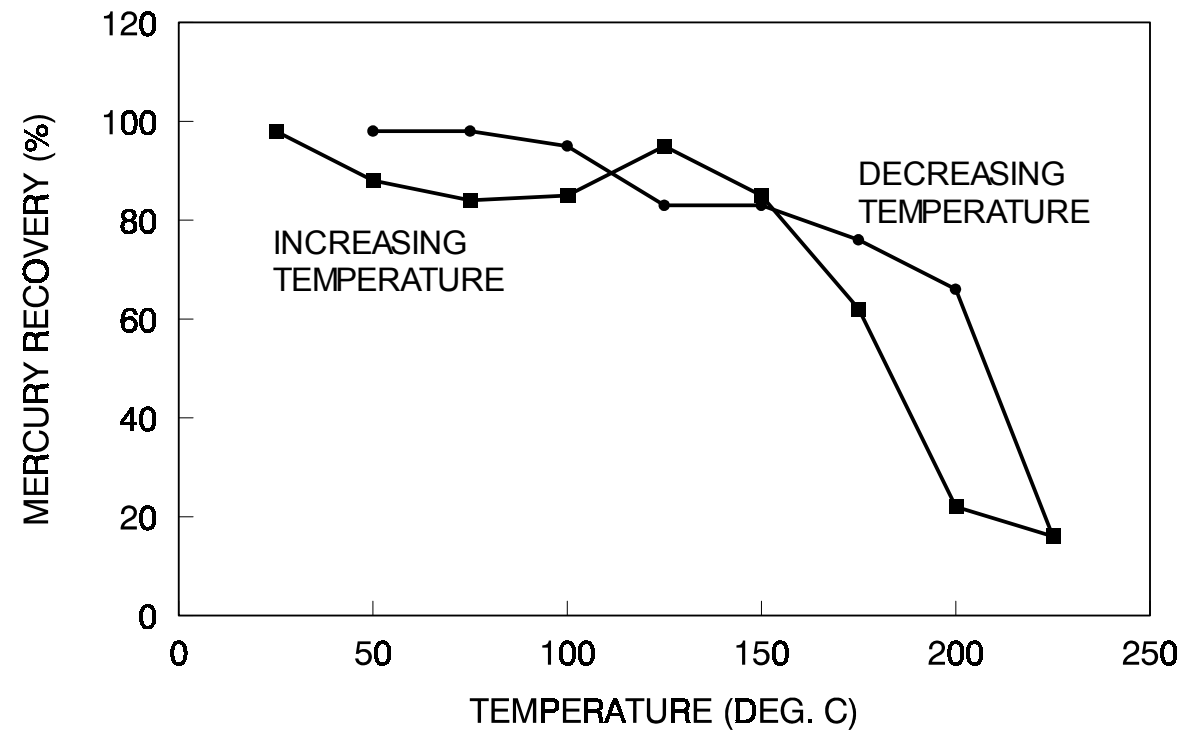

Figure 9. Recovery of Elemental Hg from Steel Lines as a Function of Temperature.

Next, 100-pg injections of elemental $\mathrm{Hg}$ vapor were made into Teflon sample lines containing simulated gasifier streams flowing at $1000 \mathrm{~mL} / \mathrm{min}$. Full $\mathrm{Hg}$ recoveries were obtained when the carrier gas contained mixtures of only $\mathrm{H}_{2}, \mathrm{CO}, \mathrm{CO}_{2}$, and $\mathrm{CH}_{4}$, while recoveries decreased to about $75 \%$ when the carrier gas also contained either $1 \% \mathrm{H}_{2} \mathrm{~S}$ or $0.5 \%$ COS. Because the majority of the $\mathrm{Hg}$ was recovered using the simulated gasifier streams, even in the presence of sulfur-containing gases, chemical interactions between $\mathrm{Hg}$ and the other gases present are not believed to be the primary cause of the poor $\mathrm{Hg}$ recoveries observed previously using the same gas mixtures in steel sample lines. The steel may be catalyzing gas stream reactions with the $\mathrm{Hg}$ or wall losses may be occurring directly with the steel after the simulated gasifier effluents have altered the steel surface chemistry.

Recoveries of Hg were also examined by injecting $100 \mathrm{pg}$ of elemental $\mathrm{Hg}$ vapor into zero air and nitrogen carrier gases in Teflon and stainless steel lines. Full Hg recoveries were obtained using both steel and Teflon lines (previously exposed to simulated gasifier streams) when using zero air with ambient humidity. However, when the air was dried with magnesium perchlorate prior to the $\mathrm{Hg}$ injections, $\mathrm{Hg}$ recoveries were very low when using steel lines relative to the recoveries observed when using the Teflon lines. In similar tests with nitrogen, $\mathrm{Hg}$ recoveries were much higher when using Teflon lines than steel lines when dry nitrogen was used, and $\mathrm{Hg}$ recoveries through the steel lines improved greatly when the nitrogen was humidified prior to the $\mathrm{Hg}$ injections. Although these results indicate that the moisture content of the carrier gas affects $\mathrm{Hg}$ recovery from steel sample lines, it is important to note that this factor was only important after simulated gasifier effluents were passed through the steel lines. Prior to using the simulated gasifier streams, full $\mathrm{Hg}$ recoveries could be obtained through steel lines even when using dry carrier gases.

MERCURY TRANSPORT THROUGH CATALYST BEDS 
In work discussed later in this report, a commercially available catalyst (G-97B from United Catalysts) effectively removed toluene at elevated temperatures. That catalyst also effectively removed $\mathrm{NH}_{3}$ from gas streams. In view of this, tests were performed to determine whether low concentrations of $\mathrm{Hg}$ could be passed through that catalyst. An air stream containing $2 \mathrm{ppb}_{\mathrm{w}} \mathrm{Hg}$ was passed through about $100 \mathrm{~cm}^{3}$ of the catalyst at $450^{\circ} \mathrm{C}$ using a gas flow rate of $1000 \mathrm{~mL} / \mathrm{min}$, and the gases exiting the catalyst tube were then analyzed continuously by AA. No $\mathrm{Hg}$ signal was observed, even after 48 hours of operation. In addition, excessive base line drift was observed throughout the experiment, although the magnitude of the drift was not sufficient to mask any $\mathrm{Hg}$ signal. When the catalyst tube was bypassed, a strong $\mathrm{Hg}$ signal was observed and the base line drift was greatly reduced. The Hg concentration was then increased to $10 \mathrm{ppb}$ and once again passed through the catalyst. No $\mathrm{Hg}$ was detected exiting the catalyst tube even after 8 hours of operation.

It was possible that the $\mathrm{Hg}$ was exiting the tube in an oxidized form, which would render it undetectable by AA. To help confirm the absence of $\mathrm{Hg}$ emitted from the catalyst tube, those gases were passed over a gold trap, since gold will collect both elemental and oxidized forms of Hg. The gold trap was then heated to $900^{\circ} \mathrm{C}$ while under an argon purge. This theoretically should release any $\mathrm{Hg}$ (as elemental $\mathrm{Hg}$ ) that was collected, and the evolved $\mathrm{Hg}$ was passed into an atomic fluorescence $\mathrm{Hg}$ detector. As a check, $2 \mathrm{ng}$ of elemental $\mathrm{Hg}$ was injected into the gas stream and collected by the gold trap. When the $\mathrm{Hg}$ was thermally evolved (in Ar), the $\mathrm{Hg}$ that was released gave a strong signal on the AF unit. However, when $3 \mathrm{ng}$ of $\mathrm{Hg}$ was injected into the catalyst tube while the gases exiting the tube were being passed over a gold trap, little or no response was observed with the AF unit during subsequent heating of the gold. Therefore, the use of this particular catalyst does not seem well suited for conditioning gasifier streams prior to $\mathrm{Hg}$ analysis.

Next, we investigated whether the $\mathrm{Hg}$ retention by the catalyst was due to the alumina substrate or the Pt on the substrate surface. A 9-mm ID quartz tube was packed with about $2 \mathrm{~cm}$ of catalyst or catalyst substrate. The catalyst substrate was received from United Catalysts and was identical to the substrate material in the Pt catalyst used in the tests discussed above. Initial tests involved injecting $200 \mathrm{pg}$ of elemental $\mathrm{Hg}$ into the catalyst substrate using a carrier stream of air flowing at $500 \mathrm{~mL} / \mathrm{min}$. Gases exiting the quartz tube were then analyzed for $\mathrm{Hg}$ using AA. Full $\mathrm{Hg}$ recoveries were obtained both at room temperature and at $450^{\circ} \mathrm{C}$ (the temperature necessary for destroying toluene) when using the substrate material. However, no $\mathrm{Hg}$ was detected at any temperature in the range of 25 to $600^{\circ} \mathrm{C}$ when the Pt catalyst was used. When follow-up tests were performed in a hydrogen atmosphere (i.e., a reducing environment), the same results were obtained. Although conclusions are not conclusive, it currently does not appear that $\mathrm{Hg}$ oxidation is the explanation for the lack of Hg signals. Additional experimental work would be required to verify this.

Because of the possibility that the $\mathrm{Hg}$ retention by the catalyst was due to some physical or chemical properties inherent in the manufacturing of the catalyst, additional tests were performed to determine whether pure Pt retains $\mathrm{Hg}$ at $450^{\circ} \mathrm{C}$. Instead of using the commercially available catalyst, a Pt trap was prepared by pressing $60^{\prime \prime}$ of pure Pt wire into a 1-inch section of a 1/4-inch OD quartz tube. Injections (about $5 \mathrm{ng}$ ) of elemental $\mathrm{Hg}$ were made into carrier gases 
upstream from the trap. The carrier gas flow rate was about $300 \mathrm{~mL} / \mathrm{min}$, and the trap was maintained at $450^{\circ} \mathrm{C}$ by a small tube furnace. Tests were performed by 1 ) injecting the $\mathrm{Hg}$ into high purity argon with subsequent $\mathrm{Hg}$ detection by $\mathrm{AF}$, and 2) injecting the $\mathrm{Hg}$ into air streams with subsequent $\mathrm{Hg}$ detection by AA. Thus, tests were performed both in oxidizing and nonoxidizing atmospheres. Results of the tests indicated that little or no $\mathrm{Hg}$ was retained by the heated $\mathrm{Pt}$ wire in either atmosphere. In order to ensure that the lack of $\mathrm{Hg}$ retention by the $\mathrm{Pt}$ wire was not a result of $\mathrm{Hg}$ simply bypassing the trap due to insufficient contact time, a test was performed whereby the same Pt trap was used at room temperature downstream from the tube furnace. In that test, the $\mathrm{Hg}$ was quantitatively collected, as evidenced by the peak areas observed during subsequent thermal evolution of the $\mathrm{Hg}$ at $900^{\circ} \mathrm{C}$, followed by AA detection of the evolved $\mathrm{Hg}$. Therefore, the hot Pt wire does not retain trace amounts of elemental $\mathrm{Hg}$, and the lack of $\mathrm{Hg}$ retention at $450^{\circ} \mathrm{C}$ is due to the temperature and not to inadequate residence times.

At first glance, there might appear to be a discrepancy between the results obtained when using the commercially available Pt catalyst versus the Pt wire. The catalyst substrate did not retain $\mathrm{Hg}$, while the Pt catalyst on that substrate did retain $\mathrm{Hg}$, implying that the Pt component of the catalyst was responsible for the $\mathrm{Hg}$ retention. On the other hand, the pure Pt wire retained little or no $\mathrm{Hg}$. One possibility is that there may be a minute amount of $\mathrm{Hg}$ retained per unit surface area of $\mathrm{Pt}$ for each injection. The loss could be undetectable when the Pt wire is used because of the low surface area (about $12 \mathrm{~cm}^{2}$ ) of the wire plug. If, on the other hand, the commercially available catalyst had a large surface area of $\mathrm{Pt}$ relative to the $\mathrm{Pt}$ wire, the retention of even small amounts of $\mathrm{Hg}$ per unit surface area of Pt could result in major $\mathrm{Hg}$ losses. Based on information provided by United Catalysts, the porosity of a catalyst pellet (about 1/8 inch diameter) is about $30 \%$, which is considerable. By using information on bulk density and surface area per gram of catalyst, it was calculated that $2 \mathrm{~cm}^{3}$ of catalyst has a Pt surface area roughly 25,000 times that of the Pt wire plug that was used. This value takes into account the fact that the Pt coverage on the catalyst substrate is only about $10 \%$. Therefore, it is possible that a small percentage of the $\mathrm{Hg}$ is retained by each $\mathrm{cm}^{2}$ of $\mathrm{Pt}$, even at high temperatures. The $\mathrm{Hg}$ loss could be undetectable with the Pt wire due to the relatively low surface area, while total retention of the $\mathrm{Hg}$ may be observed when using the commercially available catalyst because of its extremely high surface area.

In the tests discussed earlier, little or no $\mathrm{Hg}$ was retained by the Pt wire when $5 \mathrm{ng}$ of $\mathrm{Hg}$ was injected into an air stream flowing over the wire (contained in a quartz tube) at a rate of 300 $\mathrm{mL} / \mathrm{min}$. Since some tests on the removal of toluene (discussed later in this report) involved using a gas flow rate of $1 \mathrm{~L} / \mathrm{min}$, additional tests were performed to study the effect of the Pt wire on $\mathrm{Hg}$ in a gas stream flowing at that rate. A $2 \mathrm{ppb}_{\mathrm{w}} \mathrm{Hg}$ stream was passed over the Pt wire at a flow rate of $1 \mathrm{~L} / \mathrm{min}$ while heating the $\mathrm{Pt}$ at $450^{\circ} \mathrm{C}$. As before, gases exiting the catalyst tube were analyzed continuously for $\mathrm{Hg}$ using AA. The signal observed with the $\mathrm{Hg}$ detector was about $80 \%$ of that observed when heating the quartz tube in the absence of the Pt wire. Diminished AA signals were also observed when the $\mathrm{Pt}$ was heated at $500^{\circ}$ and $550^{\circ} \mathrm{C}$. However, when the Pt temperature was held at $600^{\circ} \mathrm{C}$, the signal from the $\mathrm{Hg}$ detector was the same as that observed when passing the gases through an empty tube at that temperature.

Tests were also performed to determine if low levels of elemental $\mathrm{Hg}$ vapor could be passed over the catalyst in the presence of a simulated gasifier stream. The catalyst consisted of 
Pt wire and was followed immediately by a bed of alumina, both of which were heated to about $900^{\circ} \mathrm{C}$. A $5 \mathrm{ppb}_{\mathrm{w}} \mathrm{Hg}$ stream in a simulated gasifier matrix was passed through the catalyst tube and the gases exiting the tube were bubbled into an aqueous $\mathrm{KCl}$ trap (for oxidized $\mathrm{Hg}$ ) followed by an acidified $\mathrm{KMnO}_{4}$ solution (for elemental $\mathrm{Hg}$ ). Difficulties were encountered because backpressure began to increase in the catalyst tube during testing. This resulted in difficulties in regulating gas flows and also resulted in small flame pulses (which quickly dissipated) shooting upstream at regular intervals. It was also noted that, after several days of operation, portions of the catalyst tube (including the alumina bed immediately downstream from the catalyst) turned a dark red in color. The alumina was analyzed by SEM-EDX. Results of those analyses clearly showed that the alumina was heavily coated with iron oxides. The source of iron is not known, but it appears to have contributed to the backpressure problem by coating the alumina and inhibiting gas flow. The gases upstream from the flowmeters pass through stainless steel lines, but the gases are dry and at room temperature. The gases are not heated until after they enter the quartz catalyst tube. It is hard to imagine that iron is picked up from the stainless steel lines when dry gases are flowing at room temperature. The gas manufacturers did not believe any contaminants of this nature are present in their gases, and corrosion resistant regulators specifically recommended for the gases being used were installed. The source of the iron was not investigated further, but it is clear that the catalyst tube will need to be watched carefully during prolonged use.

The iron-contaminated alumina and the quartz tube were leached with hot $\mathrm{HCl}$ to remove the iron oxides, and the tests with $\mathrm{Hg}$ in a simulated gasifier stream were repeated. However, unlike the previous test in which the gases were individually blended, these tests used a single compressed gas cylinder containing $50 \% \mathrm{CO}, 15 \% \mathrm{CO}_{2}, 25 \% \mathrm{H}_{2}, 8 \% \mathrm{CH}_{4}$, and $2 \% \mathrm{H}_{2} \mathrm{~S}$. Results of these tests showed that only partial $(50 \%) \mathrm{Hg}$ recoveries were being obtained downstream from the catalyst. In view of this, several modifications were made to the catalyst module.

A new design was tested which consisted of $\mathrm{Pt}$ wire at $900^{\circ} \mathrm{C}$ in between two alumina beds at $900^{\circ} \mathrm{C}$. Initial tests with this catalyst system were performed to determine whether we could pass $\mathrm{Hg}$ through the catalyst unit while using only air. In those tests, a $20 \mathrm{ppb}_{\mathrm{w}} \mathrm{Hg}$ stream in air was passed through the catalyst at a flow rate of $0.5 \mathrm{~L} / \mathrm{min}$. The gases exiting the catalyst tube were continuously analyzed in the gas phase by AA. The same $\mathrm{Hg}$ signals were obtained when the gases were passing through the catalyst tube as when they were bypassing the catalyst tube. Thus, for gas streams consisting of $\mathrm{Hg}$ in only air, $100 \% \mathrm{Hg}$ recoveries were obtained while passing the gases through the redesigned catalyst unit.

Next, tests were performed with $\mathrm{Hg}$ in a simulated flue gas stream consisting of $50 \% \mathrm{CO}$, $15 \% \mathrm{CO}_{2}, 25 \% \mathrm{H}_{2}, 8 \% \mathrm{CH}_{4}, 2 \% \mathrm{H}_{2} \mathrm{~S}$, and $20 \mathrm{ppb}_{\mathrm{w}} \mathrm{Hg}$. About $0.5 \mathrm{~L} / \mathrm{min}$ of simulated gasifier stream was blended with $1.0 \mathrm{~L} / \mathrm{min}$ of air and passed through the catalyst module. Gases exiting the catalyst tube were bubbled into $40-50 \mathrm{~mL}$ each of $\mathrm{KCl}$ solution followed by acidified $\mathrm{KMnO}_{4}$ solution. This mimics the Ontario Hydro sampling approach. Although a collection solution for removing $\mathrm{SO}_{2}$ prior to the $\mathrm{KMnO}_{4}$ was not used, a strong purple color persisted in the $\mathrm{KMnO} 4$ solution throughout the tests. For comparative purposes, the calibration gases containing the $\mathrm{Hg}$ were bubbled directly into the absorbing solutions (i.e., they were not blended with the gasifier matrix stream and were not passed through the catalyst tube). All of the solutions were analyzed by conventional CVAA spectroscopy. Results of the analyses indicated that full $\mathrm{Hg}$ recoveries 
were obtained through the catalyst tube and that all of the $\mathrm{Hg}$ was present as elemental $\mathrm{Hg}$, even when using the simulated gasifier stream.

After that success, the tests were repeated with the exception that the $\mathrm{Hg}$ concentration was lowered to $5 \mathrm{ppb}_{\mathrm{w}}$ and $\mathrm{HCl}$ was added to the simulated gasifier stream to provide an $\mathrm{HCl}$ concentration of about $125 \mathrm{ppm}$. Results of the solution analyses for those tests indicated once again that full $\mathrm{Hg}$ recoveries were being obtained through the catalyst tube. However, with the addition of the $\mathrm{HCl}$, about $25 \%$ of the $\mathrm{Hg}$ was now oxidized. Numerous additional tests were performed with modified catalyst designs in an attempt to pass all of the $\mathrm{Hg}$ over the catalyst and subsequently convert all of the $\mathrm{Hg}$ to elemental form. The complexity and difficulty of this gas conditioning step became evident, and this portion of the gas conditioning system remains an area of concern. Additional modifications in the catalyst system may be required to avoid any oxidized $\mathrm{Hg}$ in the gas stream entering the $\mathrm{Hg}$ detector while using simulated gasifier streams.

\section{MERCURY TRANSPORT IN NAFION DRYERS}

Because of the high moisture content of coal gasifiers, most of the water needs to be removed from the sample gas without affecting the $\mathrm{Hg}$ content. As one potential approach for doing this, a chemically selective membrane (Nafion) was investigated as a possible gas conditioning approach for moisture removal prior to the $\mathrm{Hg}$ determinations. The drying system is based on transporting the sample gas with Nafion tubing and running a countercurrent purge gas over that tubing. Little information was available on whether low levels of elemental $\mathrm{Hg}$ could be successfully transported with Nafion tubing. Specifically, the issue is whether or not some of the $\mathrm{Hg}$ will be pulled into the purge gas stream and constitute a loss in the analyte. To investigate this possibility, tests were performed in the laboratory using a small Nafion-based dryer (Perma Pure Model MD-110-48F) intended for bench-top use. If the Hg could not be successfully transported with this simple dryer, then it would certainly not be possible to transport it with a more complex and scaled up system based on the Nafion technology.

For our tests, elemental $\mathrm{Hg}$ streams (in air) were transported with the Nafion tubing while the purge gas stream (dry compressed air) flowed countercurrent to the sample gas flow. Specific conditions used were $\mathrm{Hg}$ concentrations of $1.6,3.1,6.2$, and $18 \mu \mathrm{g} / \mathrm{m}^{3}$; sample gas flow rates of 500,1000 , and $2000 \mathrm{~mL} / \mathrm{min}$; and ratios of $2,5,10$, and 20 for the relative flow rates of the purge gas to sample gas. The $\mathrm{Hg}$ in the sample gas stream was determined continuously using a CVAA Hg detector. For comparison, tests were also performed through the Nafion with no purge gas flow. Similarly, for comparative purposes, tests were performed whereby the $\mathrm{Hg}$ streams bypassed the dryer and passed immediately into the $\mathrm{Hg}$ detector. In order to determine whether there might be some loss of analyte when using Nafion, absorption signals obtained for all of the tests with Nafion were compared to those obtained while bypassing the Nafion. The signals obtained while bypassing the Nafion were taken to represent full (100\%) signals. All other data were compared to those values and the data were reported as a percentage of the full signal values. All tests were performed in triplicate and the results obtained for a given set of experimental conditions were averaged. Results of the tests indicated that low levels of $\mathrm{Hg}$ could be successfully transported with the Nafion-based drying system under all of the conditions tested. In other words, losses (if any) of $\mathrm{Hg}$ into the purge gas stream or from surface 
adsorption were negligible in all cases. Specifically, any losses were $2 \%$ or less of the input $\mathrm{Hg}$ stream.

Next, follow-up tests were performed using the large dryer incorporated into the CEM. This dryer was a Perma Pure Gas Analysis Sampling System designed to handle a 1-2 L/min gas flow with up to $50 \%$ (volumetric) moisture. As was the case with the laboratory Nafion dryer, dry compressed air was used for the purge gas stream. At low flow rates of less than 200 $\mathrm{mL} / \mathrm{min}$, signal rise times were 20-30 minutes, which is clearly unacceptable. Signal rise times were decreased to several minutes when using a gas flow rate of $500 \mathrm{~mL} / \mathrm{min}$, even though the $\mathrm{Hg}$ concentration at this flow rate was substantially lower than that at the lower flow rate. Thus, it is clear that low gas flow rates must be avoided. Flow rates of $0.5,1.0$, and $2.0 \mathrm{~L} / \mathrm{min}$ were tested, which corresponded to $\mathrm{Hg}$ concentrations of $6.2,3.1$, and $1.6 \mu \mathrm{g} / \mathrm{m}^{3}$, respectively. The results of those tests were very interesting. Relative to the $\mathrm{Hg}$ signals observed when bypassing the dryer, the $\mathrm{Hg}$ signals were 81,89 , and $93 \%$ for $\mathrm{Hg}$ concentrations of $6.2,3.1$, and $1.6 \mu \mathrm{g} / \mathrm{m}^{3}$, respectively. Thus, $\mathrm{Hg}$ recoveries were the highest when the $\mathrm{Hg}$ concentrations were the lowest, which is also when higher gas flow rates were used. Once again, the critical importance of gas flow rate is seen. Studies on transporting elemental $\mathrm{Hg}$ through Nafion-based dryers in the presence of simulated gasifier streams is still required.

The situation was much more complex when similar tests were performed using a humidified nitrogen stream containing about $20 \mu \mathrm{g} / \mathrm{m}^{3} \mathrm{HgCl}_{2}$. For these tests, only a single sample flow rate was used with a purge gas flow rate twice that of the sample gas flow rate. The gas stream was humidified to minimize sorption of the $\mathrm{HgCl}_{2}$ onto the walls of the sample transport system. For those tests, a pyrolyzer was used just prior to the $\mathrm{Hg}$ detector to convert the $\mathrm{HgCl}_{2}$ to elemental $\mathrm{Hg}$, which is required for detection by AA. Also, because of the humidified gases, a magnesium perchlorate trap was used as a drying agent after the pyrolyzer (used to convert $\mathrm{HgCl}_{2}$ to elemental $\mathrm{Hg}$ ) and before the $\mathrm{Hg}$ detector. When the sample gas was passed into the Nafion dryer, the signal on the $\mathrm{Hg}$ detector was only about $25 \%$ of that observed when the sample gas bypassed the dryer. Initially, this seemed to indicate that Nafion was probably removing $75 \%$ of the $\mathrm{HgCl}_{2}$. However, different results were obtained when the sample and purge gases were bubbled into $\mathrm{KMnO}_{4}$ absorbing solutions, which were subsequently analyzed by AA. Results of the solution analyses indicated that $50 \%$ or more of the $\mathrm{HgCl}_{2}$ was remaining in the sample gas when going through the Nafion dryer, and that less than $25 \%$ of the $\mathrm{Hg}$ was going into the purge gas stream. The remaining $25 \%$ of the $\mathrm{HgCl}_{2} \mathrm{was}$ not accounted for. This could be due to retention of the $\mathrm{HgCl}_{2}$ on (or in) the Nafion walls. The results from the solution analyses are believed to be the most indicative of what is actually happening to the $\mathrm{HgCl}_{2}$. The AA readings for the direct gas analysis may have been deceptively low when the sample gases exited the Nafion dryer. Since virtually all of the humidity was being removed by the Nafion, humidified gas was being transported to the $\mathrm{Hg}$ detector when the sample gas bypassed the Nafion, but dry gas was being transported to the detector when the sample gas went through the Nafion drying system. Therefore, because of the difficulties in transporting $\mathrm{HgCl}_{2}$, there may be a sample transport issue related to gas humidity levels. Additional work in this area is required.

\section{GENERAL TRANSPORT AND CONVERSION OF $\mathrm{HgCl}_{2}$}


Because of concerns regarding transport of $\mathrm{HgCl}_{2}$ during sampling and the effective conversion of that $\mathrm{Hg}$ species to elemental $\mathrm{Hg}$ (required for detection by $\mathrm{AA}$ ), a variety of tests were performed on the transport of $\mathrm{HgCl}_{2}$ and on the conversion of the $\mathrm{HgCl}_{2}$ to elemental $\mathrm{Hg}$ using a pyrolyzer. For generating $\mathrm{HgCl}_{2}$ gases, a $\mathrm{HgCl}_{2}$ permeation tube from VICI Metronics was used. The permeation tube was housed in a VICI Metronics U-tube, which in turn was placed in an oil bath in a convection oven maintained at a temperature of $100^{\circ} \mathrm{C}$. Dry nitrogen was used for the carrier gas in these tests. The $\mathrm{HgCl}_{2}$ stream from the oven, which had a nominal $\mathrm{Hg}$ concentration of about $15 \mathrm{ppb}_{\mathrm{w}}$, was passed through a pyrolyzer heated to $900^{\circ} \mathrm{C}$ to convert $\mathrm{Hg}$ to the elemental form. Gases exiting the pyrolyzer were then analyzed directly for elemental $\mathrm{Hg}$ by $\mathrm{AA}$. In addition, gases were bubbled into acidified $\mathrm{KMnO}_{4}$ solutions to collect $\mathrm{Hg}$ at various points in the apparatus to study the effectiveness of $\mathrm{HgCl}_{2}$ transport. Sample collection points included the oven outlet, pyrolyzer inlet, and detector inlet. Also, gases at the detector inlet were bubbled into a double-trap system where the first trap collected ionic $\mathrm{Hg}$ and the second trap collected elemental $\mathrm{Hg}$. This test was done to determine whether there was any recombination of $\mathrm{Hg}$ and chloride after the pyrolyzer, which would render that $\mathrm{Hg}$ undetectable by AA. All solutions were subsequently analyzed by conventional CVAA.

Results from the solution analyses indicated that all of the $\mathrm{Hg}$ coming out of the oven was being successfully transported to the pyrolyzer and subsequently to the $\mathrm{Hg}$ detector. In addition, results from the tests with the double-trap system showed that all of the $\mathrm{Hg}$ at the detector inlet was elemental $\mathrm{Hg}$. This indicates that the pyrolyzer was successfully converting all of the $\mathrm{HgCl}_{2}$ to elemental $\mathrm{Hg}$ and that the elemental $\mathrm{Hg}$ was not re-combining with chloride downstream from the pyrolyzer. As additional support for these observations, the absorbance reading obtained for the direct gas analysis with the $\mathrm{Hg}$ detector was precisely what it should be for the amount of $\mathrm{Hg}$ reaching the detector, which again indicates that virtually all of the $\mathrm{Hg}$ remained in the elemental form downstream from the pyrolyzer.

As noted earlier, oxidized forms of $\mathrm{Hg}$ need to be reduced to elemental $\mathrm{Hg}$ in order to be detected by AA. One potential method for doing this is to use a pyrolyzer to convert oxidized $\mathrm{Hg}$ species to elemental $\mathrm{Hg}$. However, the recombination of elemental mercury with chloride ions after the pyrolyzer is of potential concern. Although the tests discussed above indicated that there was no recombination under the conditions studied, the effects of added $\mathrm{HCl}$ (among other variables) were not included. Thermodynamic calculations were performed to determine whether complete pyrolysis of $\mathrm{HgCl}_{2}$ can be expected for the concentrations of $\mathrm{Hg}$ anticipated to be present in gasifier streams. Results of those calculations indicated that, for a given pyrolyzer temperature, pyrolysis efficiency would be expected to decrease with increased $\mathrm{HgCl}_{2}$ concentration. However, for the $\mathrm{Hg}$ concentrations that would typically be found in gasifier streams, complete pyrolysis of the $\mathrm{HgCl}_{2}$ at $900^{\circ} \mathrm{C}$ should not be a problem if the $\mathrm{HCl}$ content is low (e.g., $1 \mathrm{ppm}$ ). For high concentrations of $\mathrm{HCl}$ (e.g., $100 \mathrm{ppm}$ or more), the calculations indicated that the pyrolysis efficiency might be significantly decreased. This requires experimental verification.

Tests were performed to determine whether the recombination of $\mathrm{Hg}$ and $\mathrm{Cl}$ to form $\mathrm{HgCl}_{2}$ between the pyrolyzer and detector is of concern when using elevated levels of $\mathrm{HCl}$. For these tests, about $100 \mathrm{pg}$ of elemental $\mathrm{Hg}$ were injected into a gas stream at room temperature flowing 
at $500 \mathrm{~mL} / \mathrm{min}$. The gas stream consisted of either room air or a mixture of room air with a blend of $\mathrm{HCl}$ and nitrogen. For the gas stream containing $\mathrm{HCl}$, the gases were blended such that the final $\mathrm{HCl}$ concentration was about $400 \mathrm{ppm}_{\mathrm{v}}$. Results of the tests showed that the $\mathrm{Hg}$ signal (using peak height) from the AA decreased by about $10 \%$ when $\mathrm{HCl}$ was present. However, this magnitude of change can be attributable to uncertainties in total gas flow rates when combining the two gas streams. These tests were repeated, except the gas stream was first passed through a pyrolyzer prior to the $\mathrm{Hg}$ detector. The pyrolyzer consisted of a 1/4" OD quartz tube (about 20" long) packed with a 1 -inch plug of quartz wool that was maintained at $1000^{\circ} \mathrm{C}$ by a tube furnace. When $\mathrm{HCl}$ was present in the gas stream, the magnitude of the $\mathrm{Hg}$ signal was reduced by $65 \%$. It is not known whether similar results would be observed in actual gasifier streams. However, this is a problem that should probably be watched carefully, even though $\mathrm{HCl}$ levels in gasifier streams would seldom be as high as those tested.

As a sample transport consideration, dry $\mathrm{HgCl}_{2}$ streams were passed through virgin PFA, PTFE, and FEP Teflon lines to determine whether one form of Teflon may be most suitable for transporting cooled gasifier streams to the detector. For these tests, the $\mathrm{Hg}$ concentration was about $20 \mathrm{ppb}_{\mathrm{w}}$ (in air) and the total gas flow rate was about $400 \mathrm{~mL} / \mathrm{min} . \mathrm{A} \mathrm{HgCl}_{2}$ permeation tube from VICI Metronics was used. The permeation device was housed in a U-tube, which was placed in an oven maintained at $100^{\circ} \mathrm{C}$. The gases containing $\mathrm{HgCl}_{2}$ were passed through a pyrolyzer at $900^{\circ} \mathrm{C}$ before entering an $\mathrm{AA} \mathrm{Hg}$ detector. After equilibrating the piece of Teflon tubing attached to the exit of the permeation tube holder for at least a day, 4-ft sections of each type of 1/8" OD Teflon tubing were attached to the sample transport line at the exit of the oven just prior to the pyrolyzer. Only one type of Teflon was tested at a time. The maximum reading on the $\mathrm{Hg}$ detector was observed and the amount of time needed to reach that value was noted. Test results indicated that there was no significant difference in $\mathrm{Hg}$ levels or equilibration times when using the different types of Teflon. Therefore, for the purposes of our work, the type of Teflon used to transport cooled sample gases does not appear to be an important issue.

Similar tests were performed with the exception that a Teflon cartridge (volume of $8 \mathrm{~cm}^{3}$ ) containing various materials was put in the $\mathrm{HgCl}_{2}$ stream just prior to the pyrolyzer. The materials put in the cartridge were $1 / 8$ " in diameter and included PTFE Teflon, Pyrex glass, soda lime glass, quartz, and boron nitride. These tests were performed to help determine the effects of various materials on $\mathrm{HgCl}_{2}$ transport at temperatures near room temperature. Gases containing a nominal $20 \mathrm{ppb}_{\mathrm{w}}$ of $\mathrm{Hg}$ as $\mathrm{HgCl}_{2}$ were passed through a pyrolyzer at $900^{\circ} \mathrm{C}$ before passing into an $\mathrm{AA} \mathrm{Hg}$ detector. Tests were performed both with dry and humidified nitrogen. For the tests with humidified nitrogen, a magnesium perchlorate trap was inserted after the pyrolyzer and just prior to the $\mathrm{Hg}$ detector. The system was first equilibrated by passing the span gases through the sample lines and pyrolyzer until a steady $\mathrm{Hg}$ signal was obtained. Then, the Teflon cartridge was added just prior to the pyrolyzer while zero air was flowing through the lines. The gas stream was immediately switched to span gases and the signal profile for the $\mathrm{Hg}$ reading as a function of time was observed. The magnitude of the $\mathrm{Hg}$ signal observed after obtaining a constant signal was also recorded. Several span gas/zero air cycles were performed to ensure experimental consistency, and results were observed to be very consistent from cycle to cycle. Under the experimental conditions tested, it appears that the different materials all equilibrated quickly. Also, the same $\mathrm{Hg}$ signals were obtained regardless of the material in the cartridge and regardless of whether the gases were humidified or not. 


\section{CALIBRATION DEVICES}

\section{ELEMENTAL MERCURY PERMEATION TUBES}

For much of our $\mathrm{Hg}$ work, elemental $\mathrm{Hg}$ permeation tubes supplied by VICI Metronics were used. No other calibration devices for elemental $\mathrm{Hg}$ vapor were commercially available. Through the course of this work, it was discovered that some of the permeation tubes did not meet the vendor's specifications listed on the tubes. This was discovered after sending one of the uncertified permeation tubes to the vendor for certification. Although the uncertified tube was reportedly accurate to within $25 \%$, the certified value for that tube was only within $50 \%$ of the uncertified value. Such inconsistencies have a significant impact on much of our research with Hg. After discussing these problems with the vendor, they revised the emission rates and uncertainties for all of our uncertified permeation tubes. This emphasizes why checks on equipment vendors is an integral part of our research from a quality control standpoint.

\section{MERCURIC CHLORIDE PERMEATION TUBES}

After receiving a new $\mathrm{HgCl}_{2}$ permeation tube from VICI Metronics, some unusual readings were obtained while performing tests to ensure that the $\mathrm{HgCl}_{2}$ was being transported effectively. Therefore, a series of absorbing solutions was used to determine the $\mathrm{Hg}$ species being emitted from the permeation tube. It was determined that the $\mathrm{Hg}$ coming from the permeation tube was $15 \%$ elemental and $85 \%$ oxidized. In view of this, four other $\mathrm{HgCl}_{2}$ permeation tubes were checked and were found to be putting out significant amounts of elemental $\mathrm{Hg}$. Most of the tests were performed with the permeation tubes heated (in a convection oven) at $100^{\circ} \mathrm{C}$. Based on results from blank runs performed without the permeation tubes present, the carrier gases being used did not appear to be contaminated with elemental $\mathrm{Hg}$, nor did the sample lines appear to be contaminated. It is of further interest to note that the ratio of elemental $\mathrm{Hg}$ to $\mathrm{HgCl}_{2}$ decreased to near zero with continued testing, but it took at least several days before the elemental $\mathrm{Hg}$ contaminants diminished to trace levels. It is possible that elemental $\mathrm{Hg}$ somehow forms and builds up during storage of the tubes, and is then emitted when the tube is heated. Alternatively, some researchers from other institutions believe that elemental $\mathrm{Hg}$ is commonly a contaminant in the $\mathrm{HgCl}_{2}$ from the beginning. With regard to $\mathrm{HgCl}_{2}$ permeation tubes, it is worth noting that there are currently no certified calibration devices for $\mathrm{HgCl}_{2}$ that are commercially available.

\section{INTERFERENCES IN THE DETERMINATION OF Hg BY AA}

\section{PRIMARY MATRIX GASES}

The magnitude of potential interferences in the determination of $\mathrm{Hg}$ using CVAA was examined by using continuous streams of various gases which passed directly into an $\mathrm{AA} \mathrm{Hg}$ 
detector (Thermo Separation Products, Model 3200). This was done for confirmation of published absorbance values, as a check on equipment calibration, and to provide useful information related to the background correction approach that was being considered. For these tests, diluted streams of $\mathrm{CH}_{4}, \mathrm{CO}_{2}, \mathrm{CO}, \mathrm{COS}, \mathrm{H}_{2} \mathrm{~S}, \mathrm{SO}_{2}, \mathrm{O}_{2}$, and $\mathrm{H}_{2}$ were examined by blending $10 \mathrm{~mL} / \mathrm{min}$ of a given gas with $1000 \mathrm{~mL} / \mathrm{min}$ of the nitrogen carrier gas stream. This provided $1 \%$ concentrations for each gas of interest. The $\mathrm{SO}_{2}$ and $\mathrm{O}_{2}$ were included since some of the gas conditioning approaches being considered involved oxidation of the gas stream. Experimental absorbance readings were in good agreement with published values for a given gas. As expected, the strongest interferences were for the sulfur-containing gases. The absorbance produced by COS was comparable to that produced by $\mathrm{H}_{2} \mathrm{~S}$, although $\mathrm{H}_{2} \mathrm{~S}$ is of much greater concern because it will be present in gasifier streams at much higher concentrations than COS. By using published absorbtivity values and our own experimental data, we determined that about $500 \mathrm{ppm}_{\mathrm{v}} \mathrm{H}_{2} \mathrm{~S}$ will produce a signal equivalent in magnitude to the signal from a $1 \mathrm{ppb}_{\mathrm{w}} \mathrm{Hg}$ stream. Based on the anticipated $\mathrm{H}_{2} \mathrm{~S}$ levels in coal gasification effluents, the interference from $\mathrm{H}_{2} \mathrm{~S}$ could produce an absorption value equivalent to that observed for a $10 \mathrm{ppb}_{\mathrm{w}} \mathrm{Hg}$ stream. This interference is severe enough that either background corrections must be made or else the $\mathrm{H}_{2} \mathrm{~S}$ must be eliminated before the sample gas enters the detection cell. During gas stream oxidation, $\mathrm{SO}_{2}$ would be formed, which interferes 30 times more strongly than $\mathrm{H}_{2} \mathrm{~S}$. In addition to those interferences, a substantial absorbance was noted for gases from the $\mathrm{CO}$ cylinder. However, this was found to be due to impurities in the $\mathrm{CO}$ rather than to the $\mathrm{CO}$ itself.

\section{MOISTURE}

Water vapor is another gas that was considered as a possibility for causing spectral interferences. Discrepancies in the literature and disagreements among analytical chemists were noted on whether non-condensed moisture is an analytical interference in the determination of $\mathrm{Hg}$ by AA. Results of our own tests indicated that non-condensed moisture is indeed an interference. A nitrogen gas stream with about $100 \%$ relative humidity at room temperature gave a reading of about 0.06 absorbance units, which is equivalent to a reading obtained from a gas stream containing several hundred ppb $\mathrm{Hg}$. Tests were also performed at reduced relative humidity levels to ensure that erroneous readings were not being obtained due to moisture possibly condensing in the sample cell. Data from those tests corroborated the initial results. If a sample gas stream can be delivered to the $\mathrm{Hg}$ detector at $1 \%$ relative humidity at room temperature, the magnitude of the absorbance reading due to moisture would be equivalent to the reading from a $\mathrm{Hg}$ concentration of about $3 \mathrm{ppb}$ by weight. It is clear that the performance of the background correction unit is of critical importance. The ability of the Perma Pure gas drying system to remove moisture without affecting $\mathrm{Hg}$ is therefore a critical issue.

\section{AROMATIC HYDROCARBONS}

The catalytic oxidation of toluene was investigated since aromatic hydrocarbons absorb strongly at the wavelength $(254 \mathrm{~nm})$ being used for $\mathrm{Hg}$ analyses and therefore constitute a significant analytical interference. The commercially available Pt catalyst (G-97B from United Catalysts) was tested as a potential method for destroying vapor-phase aromatic hydrocarbons 
prior to $\mathrm{Hg}$ analysis. If a specific vapor-phase hydrocarbon such as toluene can be readily removed with the catalyst, it is anticipated that the catalyst will also be effective in destroying many other aromatic hydrocarbons in the vapor phase that may be present in the gas stream. Therefore, for our purposes, the catalytic oxidation of toluene (a benzene ring with a methyl group attached) was investigated.

An air stream was blended with toluene to give a toluene concentration of about $2 \%$. The blended gases were passed through $100 \mathrm{~cm}^{3}$ of the catalyst at a rate of $1000 \mathrm{~mL} / \mathrm{min}$ while the temperature was slowly increased. Grab samples of the gases exiting the catalyst tube were collected and analyzed for toluene by UV spectroscopy and for $\mathrm{CO}_{2}$ (a byproduct of toluene decomposition) by gas chromatography. Results of the tests indicated that little or no toluene was removed by the catalyst below $440^{\circ} \mathrm{C}$. At temperatures of $440-460^{\circ} \mathrm{C}$, water vapor (another byproduct of toluene decomposition) began to be observed. In addition, no hydrocarbons were detected in the gases exiting the catalyst tube and the $\mathrm{CO}_{2}$ concentration corresponded to the amount anticipated with the quantitative destruction of the toluene. Therefore, this catalyst showed good potential for effectively removing vapor-phase aromatic hydrocarbons.

Although the commercially available catalyst effectively removed toluene, it was later learned that low concentrations of $\mathrm{Hg}$ could not be successfully passed through the catalyst. Therefore, an alternate catalyst was needed. In this regard, tests were performed to determine whether toluene could be effectively destroyed using a Pt wire bed. A stream of $2 \%$ toluene in air was passed over the Pt wire plug at various temperatures using a total gas flow rate of 1000 $\mathrm{ml} / \mathrm{min}$. The desired temperatures were maintained by using a small tube furnace to heat the quartz tube containing the Pt. There was little visual evidence of toluene oxidation (e.g., water formation) as the temperature of the $\mathrm{Pt}$ was increased from $450^{\circ}$ to $600^{\circ} \mathrm{C}$. Also, UV spectrophotometric analysis of the gases exiting the tube containing the Pt indicated that little or no toluene was removed at those temperatures. However, when the temperature of the tube furnace was increased to $650^{\circ} \mathrm{C}$, water condensation was observed downstream from the Pt and the analyses of the gases exiting the tube indicated that most of the toluene was being destroyed. In order to quantify the magnitude of the toluene removal, a gas-tight syringe was used to withdraw $200 \mu \mathrm{L}$ of gas both upstream and downstream from the Pt. The $200-\mu \mathrm{L}$ gas samples were then injected into an AA Hg detector. The absorbance readings obtained with the AA for the gases entering and exiting the catalyst tube indicated that more than $99 \%$ of the toluene was being removed.

Highly exothermic reactions were involved with the toluene removal. After initiating the catalytic oxidation reactions by using the tube furnace to provide external heat, the exothermic reactions were sufficient to maintain a high Pt temperature without using the furnace. At that point, the portion of the quartz tube containing the $\mathrm{Pt}$ was removed from the furnace. Based on the color of the $\mathrm{Pt}$, it was estimated that a temperature greater than $900^{\circ} \mathrm{C}$ was being sustained without any external heat source. These tests indicate that a $\mathrm{Pt}$ wire plug can probably be used to effectively remove aromatic hydrocarbons from gas streams. However, because of the highly exothermic reactions, some concern arose as to whether the oxidation of actual gasifier streams could result in excessive temperatures for the sample transport lines. Based on the composition of a typical gasifier stream and possible reactions during oxidation of the gases, thermodynamic calculations indicated that oxidation of the gas stream would result in temperatures sufficient for 
the removal of aromatic hydrocarbons. By adjusting gas flows and the degree of sample line insulation, it is anticipated that excessive sample line temperatures can be avoided.

It was possible that the exothermic reactions could be self-sustaining even in the absence of a catalyst. Therefore, tests were performed to determine whether the catalyst was actually needed by repeating the tests with toluene. However, in these tests, the Pt wire plug was placed between two quartz wool plugs. The oxidation reactions were initiated by heating to $600-700^{\circ} \mathrm{C}$ as before, and the Pt and quartz wool plugs were then completely removed from the external heat source. The Pt plug glowed red hot, while the quartz wool plugs at each end of the Pt did not glow at all. Therefore, this is truly a catalytic reaction rather than just a self-sustaining set of exothermic reactions that do not require a catalyst once initiated.

Next, an air stream containing both $2 \%$ toluene and $2 \mathrm{ppb}_{\mathrm{w}}$ elemental $\mathrm{Hg}$ was passed through a heated $\mathrm{Pt}$ wire cartridge to see if the $\mathrm{Hg}$ could successfully pass through the cartridge while effectively destroying the toluene. Initially, only toluene was added to the air stream. The oxidation reactions were initiated by heating the $\mathrm{Pt}$ to about $650^{\circ} \mathrm{C}$ in a tube furnace. Once the reactions were underway, the portion of the tube containing the $\mathrm{Pt}$ was removed from the tube furnace, since the exothermic reactions (in the presence of a catalyst) were sufficient to maintain a high enough temperature for the Pt to glow red hot. In order to determine the degree of toluene removal, $200 \mu \mathrm{L}$ of gas were withdrawn before and after the Pt. Those samples were then injected into a clean (air only) carrier gas stream and analyzed by AA. Results of those tests indicated that $98 \%$ of the toluene was being removed. Next, elemental $\mathrm{Hg}$ was added continuously (using a permeation tube) to the toluene stream and the gases exiting the $\mathrm{Pt}$ cartridge were passed directly into an AA $\mathrm{Hg}$ detector. However, results on the amount of elemental $\mathrm{Hg}$ passing through the heated Pt cartridge were inconclusive because of erratic data obtained with the AA when attempting to analyze the gases exiting the Pt cartridge directly. The erratic signals were observed even in the absence of $\mathrm{Hg}$. This could be related to problems from the moisture produced from the oxidation of toluene, even though a magnesium perchlorate drying trap was used prior to the $\mathrm{Hg}$ detector. In other words, the drying trap may not have been completely effective. Another possibility relates to the small amounts of toluene that were able to pass through the Pt cartridge unaffected. Because toluene is a strong interference with the determination of $\mathrm{Hg}$ by $\mathrm{AA}$ at $254 \mathrm{~nm}$, even small fluctuations in the amount of toluene passing through the Pt cartridge will result in an erratic AA signal.

The tests with toluene and $\mathrm{Hg}$ were repeated. However, the experimental setup was modified by 1) placing a water knockout bottle (in an ice bath) between the catalyst and the magnesium perchlorate trap, and 2) using 10-ng injections of elemental $\mathrm{Hg}$ rather than continuous $\mathrm{Hg}$ streams. In order to determine the degree of toluene removal, $100 \mu \mathrm{L}$ of gas were withdrawn before and after the Pt catalyst. Those samples were then injected into a clean (air only) carrier gas stream and analyzed by AA. Results of those tests indicated that more than $99 \%$ of the toluene was being removed. Next, elemental $\mathrm{Hg}$ was injected (performed in triplicate) into the toluene stream, and the gases exiting the Pt cartridge were passed directly into an $\mathrm{AA} \mathrm{Hg}$ detector for analysis. When $\mathrm{Hg}$ was injected into an air/toluene stream prior to the catalyst, the average peak areas for the $\mathrm{Hg}$ signals were within $1 \%$ of those obtained when using air only. Therefore, it appears that the catalyst can effectively remove volatile aromatic hydrocarbons without affecting low levels of $\mathrm{Hg}$. 


\section{$\mathrm{D}_{2}$ BACKGROUND CORRECTION APPROACH}

\section{BACKGROUND}

As discussed earlier, AA was selected as the method of choice for monitoring $\mathrm{Hg}$ in coal gasification streams after carefully evaluating two commercially available $\mathrm{Hg}$ detectors (one each based on AA and AF). However, interferences from sulfur-containing gases and aromatic hydrocarbons are of concern in AA. Based on the anticipated $\mathrm{H}_{2} \mathrm{~S}$ levels in coal gasification effluents, the interference from $\mathrm{H}_{2} \mathrm{~S}$ could produce an absorption value equivalent to that observed for a $10 \mathrm{ppb}_{\mathrm{w}} \mathrm{Hg}$ stream. Since gas stream oxidation will be used to remove tars and $\mathrm{NH}_{3}$, the $\mathrm{H}_{2} \mathrm{~S}$ will be converted mostly to $\mathrm{SO}_{2}$, which absorbs even more strongly than $\mathrm{H}_{2} \mathrm{~S}$ at the wavelength being used for the $\mathrm{Hg}$ determination. This necessitates either background corrections or the elimination of $\mathrm{H}_{2} \mathrm{~S}$ before the sample gas enters the detection cell.

Since our work began, a number of Hg CEMs employing AA have been developed, some of which use a Zeeman-modulated background correction approach (5). Although that background correction approach appears to have good potential for the application of interest, we chose to investigate an alternate approach for performing the background corrections. Specifically, the effectiveness of using a broadband spectral correction approach employing a deuterium $\left(\mathrm{D}_{2}\right)$ lamp as the broadband radiation source was tested. No Hg CEMs currently employ this background correction method. Both the Zeeman modulation and broadband correction approaches are commonly used in laboratory AA instruments. Therefore, the decision was made to explore the merits of using the latter background correction method for $\mathrm{Hg}$ monitoring in process gas streams.

The Ames Laboratory Hg CEM uses two UV lamps. One is a Hg lamp and the other is a $\mathrm{D}_{2}$ lamp. The principle of operation for the background corrections is based on the fact that the Hg UV lamp emits mostly in a very narrow spectral line at $254 \mathrm{~nm}$, while the $\mathrm{D}_{2}$ lamp emits in a relatively broad band over the same spectral region. The $\mathrm{Hg}$ channel of the analyzer responds to both $\mathrm{Hg}$ and interfering gases at $254 \mathrm{~nm}$, while the $\mathrm{D}_{2}$ channel of the analyzer responds only to gases which absorb over a much broader spectral region. The absorption region for $\mathrm{Hg}$ is so narrow compared to the broad band associated with the $\mathrm{D}_{2}$ lamp that $\mathrm{Hg}$ should not be detected with the $\mathrm{D}_{2}$ system. Therefore, the $\mathrm{Hg}$ content of a gas stream can theoretically be determined by subtracting the signal from the $\mathrm{D}_{2}$ channel (absorption due to interfering gases only) from that of the $\mathrm{Hg}$ channel (absorption from both $\mathrm{Hg}$ and interfering gases).

In addition to using a $\mathrm{D}_{2}$ lamp for background corrections, using such a lamp for both the background correction and source lamp for the $\mathrm{Hg}$ determination was considered. However, after performing a variety of tests, it appears that the resolution necessary for the determination of $\mathrm{Hg}$ with that approach would be inadequate for the sensitivity required. For background corrections, the possibility of using a commercially available AA instrument with an internal $\mathrm{D}_{2}$ background correction system was investigated. Based on data provided by two manufacturers 
of such instruments (Perkin-Elmer and ATI), blank readings had too much base line variability for determining $\mathrm{Hg}$ in gasifier streams at the anticipated $\mathrm{Hg}$ concentrations.

Catalytic oxidation of the sample gas stream will be used to remove tars (as well as other hydrocarbons) prior to analysis, and $\mathrm{H}_{2} \mathrm{~S}$ will be converted to $\mathrm{SO}_{2}$. The oxidized sample stream will then be passed over a high temperature pyrolyzer and subsequently dried using a Nafionbased drying system prior to entering the $\mathrm{Hg}$ detector. Therefore, for our purposes in evaluating the basic principles involved with our Hg CEM, it was assumed that hydrocarbons and moisture will be absent from the gas streams entering the $\mathrm{Hg}$ detection system. Consequently, spectral interferences from $\mathrm{SO}_{2}$ are expected to be the primary issue during sample analysis by AA. All subsequent laboratory tests with the $\mathrm{D}_{2}$ background subtraction approach were performed based on that assumption.

\section{TESTS WITH OPTICAL BREADBOARD SETUP}

After obtaining encouraging preliminary results on the base line stability with a $\mathrm{D}_{2}$ lamp, the decision was made to build our own $\mathrm{Hg}$ analyzer employing a $\mathrm{D}_{2}$ background subtraction approach. The initial design of the $\mathrm{D}_{2}$ background correction module was formulated, assembled on an optical breadboard, and tested using a single photo diode. Experimental results indicated that the use of photo diodes in conjunction with the $\mathrm{D}_{2}$ lamp should not add significant analytical uncertainties in the determination of $\mathrm{Hg}$ at the $\mathrm{ppb}$ level. The signal strength from the photo diode was excellent. The optical system was later modified to include a reference beam measurement of the $\mathrm{D}_{2}$ lamp emission using a second photo diode. A holder for the photo diodes was constructed to stabilize their positions. Excellent results were obtained with the stabilized photo diodes. The amount of base line drift over a period of 8 minutes was nearly zero and the absorbance standard deviation of the base line signal (i.e., noise) was only about $24 \times 10^{-6}$. An absorbance standard deviation of less than $100 \times 10^{-6}$ for background measurement would have no significant impact on the accuracy of the $\mathrm{Hg}$ determination.

Tests on the stability of the ratio of the photo diode signals measured simultaneously from the sample and reference beams indicated that this ratio was excellent for our purposes. Next, a $1000 \mathrm{ppm} \mathrm{SO}_{2}$ stream in nitrogen was passed through the cell in order to determine the accuracy of the readings. The absorbance value obtained with the background correction module agreed with literature values, and the noise level observed while using the $\mathrm{SO}_{2}$ stream was very low.

Tests were performed with the Thermo Separation Products $\mathrm{Hg}$ detector and the $\mathrm{D}_{2}$ module operating in series. A drift of about $1 \mathrm{mAU} / \mathrm{hr}$ was observed with the $\mathrm{D}_{2}$ module, which was higher than desired. The drift was primarily due to the $\mathrm{D}_{2}$ lamp and/or power supply rather than the light-measuring electronics of the $\mathrm{D}_{2}$ module. This was not of immediate concern since it is likely that more stable $\mathrm{D}_{2}$ lamps are commercially available. Nonetheless, the optics were modified to help reduce the drift resulting from lamp and/or power supply instabilities. Also, the $\mathrm{D}_{2}$ module was enclosed to help minimize the potential presence of interfering gases in the optical path. 
A second series of tests was performed with the AA $\mathrm{Hg}$ detector and $\mathrm{D}_{2}$ module operating in series. For these tests, $\mathrm{SO}_{2}$ was used as an interfering gas since gas stream oxidation will be used. A $2 \% \mathrm{SO}_{2}$ (in nitrogen) gas stream was blended with air to give a final $\mathrm{SO}_{2}$ concentration of about $0.05 \%$. When elemental $\mathrm{Hg}$ was introduced to the carrier gas, the final $\mathrm{Hg}$ concentration was about $20 \mathrm{ppb}_{\mathrm{w}}$. Excellent signals were obtained with the $\mathrm{Hg}$ detector for $\mathrm{SO}_{2}$, $\mathrm{Hg}$, and $\mathrm{SO}_{2} / \mathrm{Hg}$ blends. Response times were very rapid and memory effects were minimal. However, a disadvantage of having $\mathrm{SO}_{2}$ in the sample stream is that $\mathrm{SO}_{2}$ absorbs about 30 times more strongly than $\mathrm{H}_{2} \mathrm{~S}$ at the wavelength $(254 \mathrm{~nm})$ being used for determining $\mathrm{Hg}$. Therefore, oxidizing the sample stream could increase the detection limit of the monitor for $\mathrm{Hg}$ due to the formation of $\mathrm{SO}_{2}$. On the other hand, the presence of aromatic hydrocarbons (strong absorbers at $254 \mathrm{~nm}$ ) in an unoxidized gasifier stream would also have the same effect. Whether or not the magnitude of the interferences is better or worse with gas stream oxidation depends on the relative levels of aromatic hydrocarbons and sulfur-containing gases, which will probably vary from gasifier to gasifier.

The $\mathrm{D}_{2}$ module gave the same background reading for $\mathrm{SO}_{2}$ as it did for the $\mathrm{SO}_{2} / \mathrm{Hg}$ blend. This is of critical importance and indicates that the $\mathrm{D}_{2}$ module was operating correctly. However, the observation was made that the absorbance reading from the $\mathrm{D}_{2}$ module was about $30 \%$ larger than the value expected for the $\mathrm{SO}_{2}$ concentration being used. A variety of tests indicated that this phenomenon was not being caused by the electronics or optics of the system. It is possible that the deviation from the expected value is being caused by $\mathrm{SO}_{2}$ spectral complexities in the wavelength region being used for analysis by the $\mathrm{D}_{2}$ module. The ratio of the absorbance reading from the $\mathrm{Hg}$ detector to that from the $\mathrm{D}_{2}$ module was fairly constant (about 0.78 ) for $\mathrm{SO}_{2}$ concentrations ranging from $0.02 \%$ to $0.5 \%$. Therefore, the need for a spectral correction factor was not considered to be of concern, since a correction factor can be applied to give accurate background readings. This correction factor should be accurate as long as $\mathrm{SO}_{2}$ is the interfering gas with the greatest absorbance. This situation is expected to be the case when oxidizing the gas stream.

Additional work was done with the $\mathrm{D}_{2}$ background correction module coupled in series to the Thermo Separation Products $\mathrm{Hg}$ detector. For these tests, $0-300 \mathrm{~mL} / \mathrm{min}$ of $2 \% \mathrm{SO}_{2}$ were blended with room air flowing at $900-2000 \mathrm{~mL} / \mathrm{min}$ in order to confirm that the ratio of the absorbance reading from the $\mathrm{Hg}$ detector to that of the $\mathrm{D}_{2}$ module remained constant, as should theoretically be the case. However, it was observed that the ratio increased by $10-15 \%$ as the total flow of the dilution air and $\mathrm{SO}_{2}$ increased from 900 to $2000 \mathrm{~mL} / \mathrm{min}$. Detailed analysis of the data indicated that the mAU readings from the $\mathrm{Hg}$ detector and $\mathrm{D}_{2}$ module tracked well with each other as the $\mathrm{SO}_{2}$ concentration was varied, as long as the total gas flow rate was unchanged. However, the mAU values did not track as well with each other when the total gas flow rate was changed by altering the dilution flow and keeping a constant $\mathrm{SO}_{2}$ flow. Also, the $\mathrm{D}_{2}$ readings tracked better with the changing $\mathrm{SO}_{2}$ concentrations that the readings from the $\mathrm{Hg}$ detector did, suggesting that changing total gas flow rates may somehow cause inaccuracies in the mAU readings from the $\mathrm{Hg}$ detector. This caused some concern about whether a single correction factor independent of gas flow rate could be used.

Experiments were performed with the $\mathrm{D}_{2}$ background correction module coupled to the AA $\mathrm{Hg}$ detector to demonstrate the accuracy of determining low levels of $\mathrm{Hg}$ in gas streams 
containing high levels of $\mathrm{SO}_{2}$. This represents a worst case scenario. For these tests, gas streams containing $2 \mathrm{ppb}_{\mathrm{w}}\left(0.2 \mathrm{ppb}_{\mathrm{v}}\right)$ elemental $\mathrm{Hg}$ and $0.3 \% \mathrm{SO}_{2}$ were used. The total gas flow rate was about $1000 \mathrm{~mL} / \mathrm{min}$. The absorption signal from $\mathrm{SO}_{2}$ in the $\mathrm{Hg}$ detector was about 100 times higher than that from the $\mathrm{Hg}$. In addition, tests were performed using $4 \mathrm{ppb}_{\mathrm{w}}$ elemental $\mathrm{Hg}$ and $0.4 \% \mathrm{SO}_{2}$ at a total gas flow rate of $500 \mathrm{~mL} / \mathrm{min}$.

A calibration curve ( $\mathrm{Hg}$ concentration versus mAU reading) was prepared using the Thermo Separation Products $\mathrm{Hg}$ detector for $\mathrm{Hg}$ concentrations ranging from $0.1-5 \mathrm{ppb}_{\mathrm{w}}$ in the absence of $\mathrm{SO}_{2}$. For the tests involving low levels of $\mathrm{Hg}$ with high concentrations of $\mathrm{SO}_{2}$, the background reading (in $\mathrm{mAU}$ ) from the $\mathrm{D}_{2}$ module was used to correct the readings from the $\mathrm{Hg}$ detector to give a background-corrected mAU value. These background-corrected mAU values were then compared to the calibration curve to give a background-corrected $\mathrm{Hg}$ concentration. For the tests using $2 \mathrm{ppb}$ and $4 \mathrm{ppb}$ elemental $\mathrm{Hg}$ with high concentrations of $\mathrm{SO}_{2}$, backgroundcorrected $\mathrm{Hg}$ concentrations of 3.5 and $5 \mathrm{ppb}$ were obtained, respectively. In view of the low $\mathrm{Hg}$ concentrations involved and the fact that the interfering gas gave absorption values up to 100 times higher than the $\mathrm{Hg}$ did, these results were considered to be encouraging in this worst-case scenario.

After making several refinements in the experimental design, additional tests with $\mathrm{Hg}$ in the presence of varying concentrations of $\mathrm{SO}_{2}$ were performed. For these tests, $\mathrm{Hg}$ concentrations ranged from 2 to $12 \mathrm{ppb}_{\mathrm{w}}$ and $\mathrm{SO}_{2}$ concentrations ranged from 0.02 to $0.5 \%(\mathrm{v} / \mathrm{v})$. Using these gas stream concentrations of $\mathrm{Hg}$ and $\mathrm{SO}_{2}$, the absorbance due to $\mathrm{SO}_{2}$ was ten to thirty times higher than the absorbance due to $\mathrm{Hg}$. The total absorbance of the $\mathrm{Hg}$ and $\mathrm{SO}_{2}$ stream was measured with the $\mathrm{Hg}$ detector. Figure 10 shows the absorbance data from the $\mathrm{Hg}$ detector (i.e., the data are not background corrected) for various $\mathrm{Hg}$ concentrations in the presence of $\mathrm{SO}_{2}$ and in the absence of $\mathrm{SO}_{2}$. This shows the large magnitude of the absorbance from the interfering gas $\left(\mathrm{SO}_{2}\right)$ and demonstrates the importance of the background correction. Figure 11 is a plot of the net absorbance as a function of the $\mathrm{Hg}$ concentration for varying concentrations of $\mathrm{SO}_{2}$. The net absorbance is the total absorption measured by the $\mathrm{Hg}$ detector minus the absorbance measured by the $\mathrm{D}_{2}$ system (i.e., the background from the interfering gas). The background corrected values were typically within $5 \%$ of the values obtained for a given $\mathrm{Hg}$ concentration in the absence of $\mathrm{SO}_{2}$. These data demonstrate that using a $\mathrm{D}_{2}$ lamp is a viable approach for correcting for $\mathrm{SO}_{2}$ interferences in gasification streams and that low levels of $\mathrm{Hg}$ can be measured in gas streams containing high levels of $\mathrm{SO}_{2}$ using this method. 


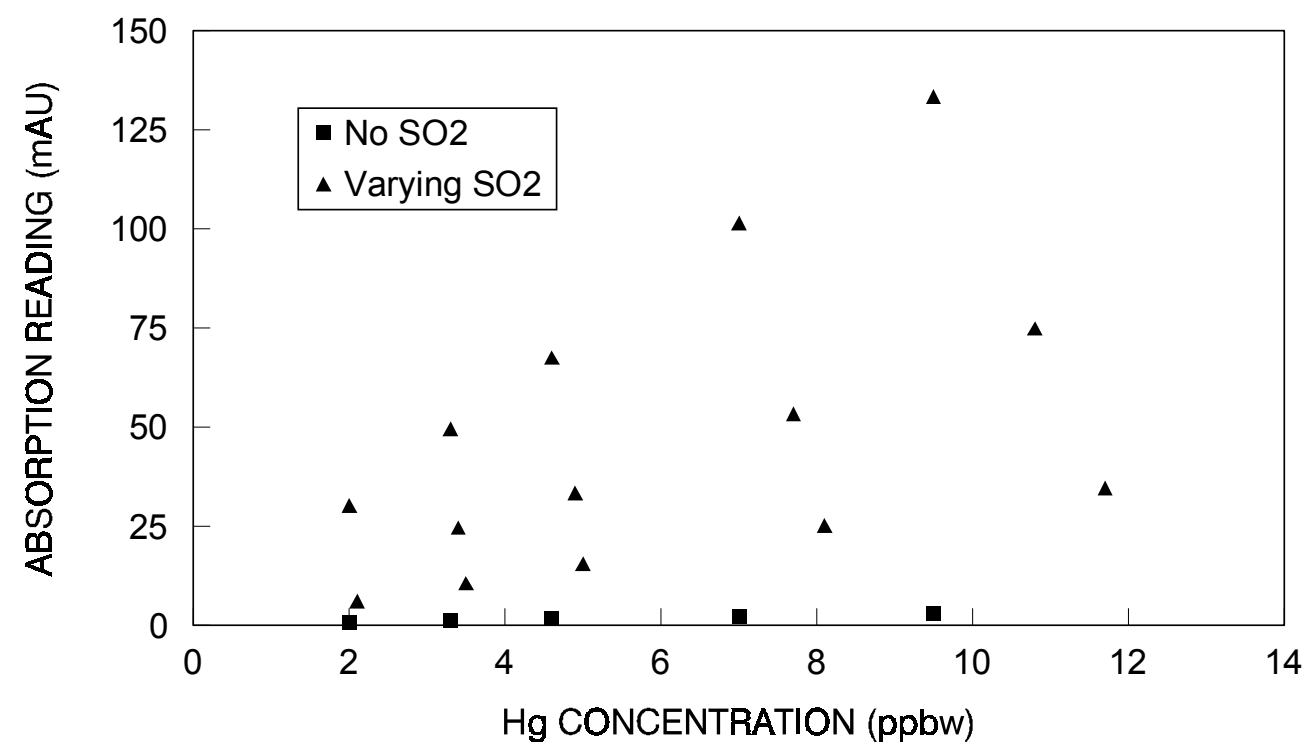

Figure 10. Uncorrected Absorbance Data for Varying Levels of $\mathrm{Hg}$ and $\mathrm{SO}_{2}$.

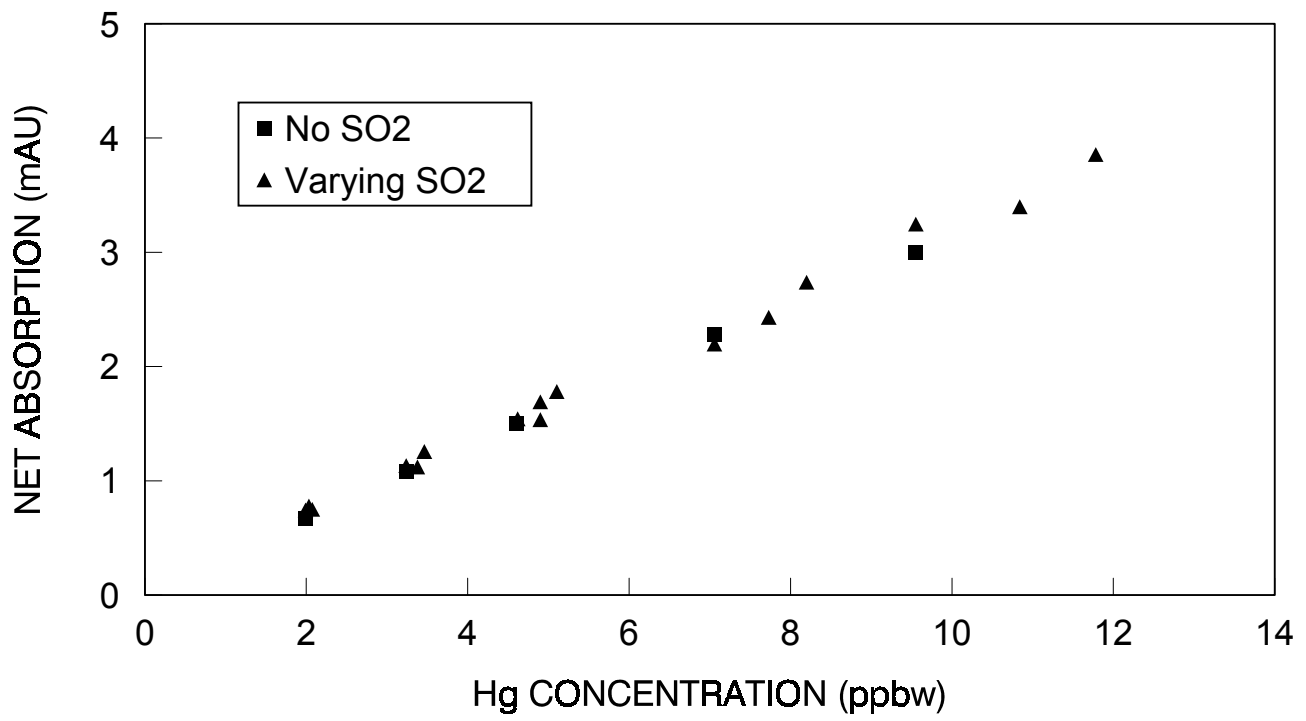

Figure 11. Background Corrected Absorbances for Varying Levels of $\mathrm{Hg}$ and $\mathrm{SO}_{2}$.

A new $\mathrm{D}_{2}$ lamp and power supply was purchased, and the overall stability of the lamp/power supply combination was much better than the old one. For the new $\mathrm{D}_{2}$ system, the short term (10 minutes) signal variation with the dual photo diode optical setup was about 30 $\mu \mathrm{AU}$ after subtracting the signal drift. The long term drift was about $2 \mathrm{mAU} / \mathrm{hr}$, which is comparable to that of the old $\mathrm{D}_{2}$ system. A reading of $2 \mathrm{mAU}$ is roughly equivalent to the signal from a $8 \mathrm{ppb}_{\mathrm{w}} \mathrm{Hg}$ stream. Since on-line $\mathrm{Hg}$ measurements would be performed over a period of only about 5 minutes, the magnitude of the observed drift is acceptable. However, smaller iris sizes and alternate data processing methods were investigated in an attempt to reduce the amount 
of drift. After reducing the iris sizes in the optical setup, the drift was reduced to about 1 $\mathrm{mAU} / \mathrm{hr}$. With further testing, it was discovered that the drift was primarily from the reference channel of the system rather than from the lamp or the sample channel. Consequently, the optics were simplified (removed mirrors, etc.) in order to help identify the source of the problem. A careful realignment of the optics was also performed. After these refinements, excellent results were obtained for the long-term drift. Over a period of about 20 hours, the drift was only about $0.1 \mathrm{mAU} / \mathrm{hr}$. A reading of $0.1 \mathrm{mAU}$ is roughly equivalent to the signal from a $0.5 \mathrm{ppb}_{\mathrm{w}} \mathrm{Hg}$ stream. Therefore, the lamp, power supply, and measuring electronics have excellent stability, and the previous problem with drift appears to be from an optical alignment problem.

\section{DEVELOPMENT OF PROTOTYPE ANALYZER}

Although excellent results were obtained when using a $\mathrm{Hg}$ detector and a breadboard $\mathrm{D}_{2}$ module in series, the $\mathrm{Hg}$ detector was a commercially available unit that was discontinued by the vendor. In addition, the $\mathrm{Hg}$ detector and breadboard $\mathrm{D}_{2}$ module were operated as separate units. Therefore, the decision was made to proceed directly to the design and construction of an instrument that would incorporate a $\mathrm{Hg}$ detector and $\mathrm{D}_{2}$ correction module into a single, compact, fully integrated system. DMK Engineering (Palos Verdes, CA) was subcontracted to build the prototype analyzer. During the development of that analyzer, numerous design modifications were made. A variety of different design options for the integrated $\mathrm{Hg}$ analyzer were considered, with particular attention being paid to stray light in the optical set up, light intensity, instrumental sensitivity, and effects of solarization of optical components during extended use. The overall optical design that minimized or eliminated problems in those areas was selected.

At an intermediate stage of development, we received the optical/mechanical components of the $\mathrm{Hg}$ analyzer. Although the unit was not fully assembled at this time, we wanted to test the basic optical design before proceeding to the final construction stages. Those tests yielded very positive results. A detection limit of $1 \mu \mathrm{g} / \mathrm{m}^{3}$ was observed and the linearity of the instrument response was excellent in the $1-20 \mu \mathrm{g} / \mathrm{m}^{3}$ range. This represented a worst case situation, since a variety of features for stabilizing the signals (e.g., use of a reference beam) had not yet been applied to the system. After adding the signal stabilization features, it was estimated that the detection limit would be lowered by a factor of 10 .

After completing the initial construction of the instrument, problems with excess noise and drift were encountered. It was discovered that the reference channel photodetector had a cracked window, which in turn was causing much of the noise. Both reference and sample photodetectors were replaced with new ones that had larger active areas for improved light collection. Eliminating the cracked window and using the larger active areas greatly reduced the noise levels. Some machining problems related to a shutter in the instrument were also noted. Because of this, the shutter was not in its optimum position and the light beams were being slightly clipped. The shutter was remachined to eliminate clipping of the beams. This further reduced the noise levels. The reason for the excessive drift was also explored. Testing indicated that the drift was probably electronic rather than optical in nature. A redesigned preamplifier was built in an attempt to reduce the amount of drift without significantly increasing noise. This 
greatly reduced the drift for the $\mathrm{Hg}$ channel. Next, the $\mathrm{Hg}$ channel was integrated with the $\mathrm{D}_{2}$ background correction channel. Numerous additional modifications were made in the electronics and the shutter mechanism. With these changes, initial results indicated that the noise was reduced to only $0.1 \mathrm{mAU}$ and the drift was reduced to $0.1 \mathrm{mAU} / \mathrm{hr}$. The magnitude of noise and drift now met the design goals for the instrument.

As part of the development of the prototype analyzer, response times obtained with a 10$\mathrm{cm}$ quartz sample cell (to be used in the final instrument) were tested using a $2 \mu \mathrm{g} / \mathrm{m}^{3}$ elemental $\mathrm{Hg}$ stream flowing at $1 \mathrm{~L} / \mathrm{min}$. In particular, the time necessary to achieve a steady $\mathrm{Hg}$ signal after switching from zero air to span gases was examined, as well as the time necessary to return to the base line after switching from span gases to zero air. Analysis of the gas streams was performed using a Thermo Separation Products AA Hg detector. For comparative purposes, tests were also performed using a Teflon cell fitted with quartz windows. Tests were performed at both room temperature and at about $200^{\circ} \mathrm{C}$ for the quartz cell, while the Teflon cell was tested only at room temperature. There was essentially no difference in response times at room temperature between a $10-\mathrm{cm}$ quartz cell and a $10-\mathrm{cm}$ Teflon cell. In both cases, it took about 60 s for the signal to equilibrate after switching to span gases, and it took about 10s for the signal to return to the original base line after switching back to zero air. The relatively long time necessary to achieve a steady signal when switching to span gases appears to be due to a "pressure pulse" in the VICI Metronics calibration system that was used to generate the elemental $\mathrm{Hg}$ streams. This causes a temporary excessive rise in the mAU reading before the signal falls and steadies out at a constant value. Heating the quartz cell improved response times only slightly.

\section{EVALUATION OF PROTOTYPE ANALYZER}

\section{Original Optics}

The prototype $\mathrm{Hg}$ CEM employing a $\mathrm{D}_{2}$ broadband correction feature was tested in our laboratories to asses its overall performance as well as its strengths and limitations. Air streams containing known concentrations of elemental $\mathrm{Hg}$ were generated with a VICI Metronics Model 340 Dynacalibrator in conjunction with an uncertified elemental $\mathrm{Hg}$ permeation tube from VICI Metronics. These gases were then blended with either $\mathrm{N}_{2}$ or $\mathrm{SO}_{2}$ and were subsequently passed directly into the analyzer via unheated Teflon lines. As with the tests with the breadboard optical setup, tests were performed only with dry gases. Also, unless otherwise noted, a heated sample cell was not used.

The possibility of flow rate effects on base line drift or noise was checked by passing air into the analyzer at various gas flow rates. Specifically, air flow rates of 500, 1000, and 2000 $\mathrm{mL} / \mathrm{min}$ were used consecutively while the analyzer was running continuously. About 5 minutes of testing was performed at each gas flow rate before going to the next flow rate. Within the range of air flow rates tested, there was no effect on either the $\mathrm{Hg}$ or $\mathrm{D}_{2}$ base lines. This was true for both base line noise and drift. Therefore, the sample flow rate in this range is not of concern. 
Levels of base line noise and drift were assessed for both the $\mathrm{Hg}$ and $\mathrm{D}_{2}$ channels in the analyzer. In the $\mathrm{Hg}$ channel of the instrument, base line noise was typically about $0.02 \mathrm{mAU}$ and the base line drift varied from 0.1 to $0.4 \mathrm{mAU} / \mathrm{hr}$. For the $\mathrm{D}_{2}$ channel, noise levels were typically 0.2 to $0.3 \mathrm{mAU}$ and base line drift was typically about $0.3 \mathrm{mAU} / \mathrm{hr}$. Thus, the $\mathrm{D}_{2}$ channel was substantially noisier than the $\mathrm{Hg}$ channel. The $\mathrm{D}_{2}$ channel was expected to be less noisy than the $\mathrm{Hg}$ channel, and the noise in the $\mathrm{D}_{2}$ channel is currently one of the limiting factors affecting detection limits and the accuracy of the analyzer when using high concentrations of interfering gases. It may be possible to obtain a quieter lamp and power supply combination than the one currently used in the instrument. Also, some of the problem could possibly be related to the peripheral electronics, which can also be improved upon if needed. In addition, since noise and drift are affected by lamp and optics alignments, the possibility can not be ruled out than more precise alignment is necessary.

While using only the $\mathrm{Hg}$ channel of the analyzer, calibration curves were obtained for air streams (no $\mathrm{SO}_{2}$ ) containing $\mathrm{Hg}$ concentrations of $0.5-50 \mu \mathrm{g} / \mathrm{m}^{3}$. These tests were performed to assess detection limits and the linearity of the calibration curves. Excellent calibration curves were obtained with the $\mathrm{Hg}$ channel of the detector. For the entire calibration range, the linear

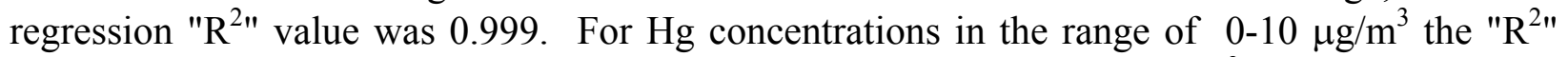
value was 0.993 . The signal observed for a $\mathrm{Hg}$ concentration of $0.5 \mu \mathrm{g} / \mathrm{m}^{3}$ is shown in Figure 12. Based on the raw absorption readings from the $\mathrm{Hg}$ channel, a detection limit of about 0.1 $\mu \mathrm{g} / \mathrm{m}^{3}$ was calculated. It must be emphasized that the analyzer uses only a $10-\mathrm{cm}$ sample cell, yet attained a detection limit on the order of $0.1 \mu \mathrm{g} / \mathrm{m}^{3}$. The detection limit could be reduced by about a factor of 10 by using a $100-\mathrm{cm}$ sample cell. The tradeoff is that the overall analyzer would be substantially larger and less portable. Lesser improvements could probably be made in the detection limit by keeping the 10-cm cell and modifying the electronics and/or signal processing routines. By using the latter approach, the detection limit could probably be lowered to $0.05 \mu \mathrm{g} / \mathrm{m}^{3} \mathrm{Hg}$ or less.

When $\mathrm{Hg}$ was added to an air stream such that the final $\mathrm{Hg}$ concentration was $50 \mu \mathrm{g} / \mathrm{m}^{3}$, the $\mathrm{D}_{2}$ base line was unaffected. Since this $\mathrm{Hg}$ concentration is much higher than that anticipated for gaseous effluents from coal-based power generation, it is clear that the $\mathrm{D}_{2}$ base line will not be affected by $\mathrm{Hg}$ in the gas stream. This is critical to the application of the $\mathrm{D}_{2}$ based background correction approach.

Because of the observation that a $\mathrm{D}_{2}$ correction factor was needed in the tests with the breadboard optical setup, a variety of tests were performed with the prototype CEM using various concentrations of $\mathrm{SO}_{2}$ without any $\mathrm{Hg}$ present. In one series of tests, $2.0 \% \mathrm{SO}_{2}$ (in a $\mathrm{N}_{2}$ balance) was blended with air and then passed into the $\mathrm{Hg}$ analyzer. Total gas flow rates of 500, 700,1000 , and $1500 \mathrm{~mL} / \mathrm{min}$ were used, while the flow rate of the $2 \% \mathrm{SO}_{2}$ was varied from 50 $300 \mathrm{~mL} / \mathrm{min}$. For a given total gas flow rate, the air flow was proportionally decreased as the $\mathrm{SO}_{2}$ flow increased in order to keep the total gas flow rate the same. This provided $\mathrm{SO}_{2}$ concentrations of $0.1-0.9 \%$ in the final gas stream. The raw mAU readings from the $\mathrm{Hg}$ channel and the $\mathrm{D}_{2}$ channel were both measured and recorded. For each total gas flow rate and $\mathrm{SO}_{2}$ concentration, the ratio of the mAU value from the $\mathrm{Hg}$ channel to that of the $\mathrm{D}_{2}$ channel was calculated. This ratio is the $\mathrm{D}_{2}$ correction factor. The $\mathrm{D}_{2}$ correction factors were also calculated 
when passing a stream of $1000 \mathrm{ppm} \mathrm{SO}_{2}\left(\right.$ in $\mathrm{N}_{2}$ ) directly into the analyzer at flow rates of 100 , $250,500,750$, and $1000 \mathrm{~mL} / \mathrm{min}$. For those tests, no dilution of the gas stream was used.

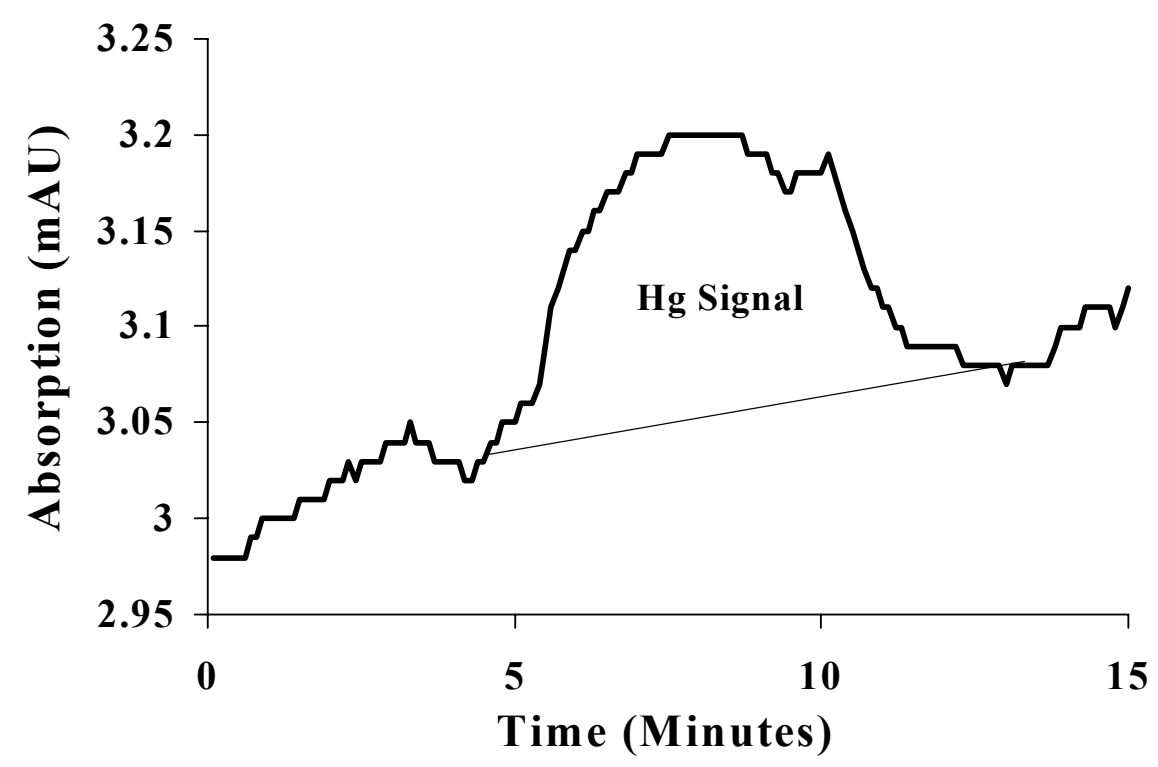

Figure 12. Signal Obtained with the CEM for a $0.5 \mu \mathrm{g} / \mathrm{m}^{3} \mathrm{Hg}$ Stream.

Results of the tests with $\mathrm{SO}_{2}$ (no $\mathrm{Hg}$ present) indicated that the absorbance from the $\mathrm{D}_{2}$ channel was significantly higher than that observed in the $\mathrm{Hg}$ channel. This is in agreement with the observations made with the breadboard optical design and may reflect the relatively complex $\mathrm{SO}_{2}$ absorption spectrum in the wavelength region being used for analysis. For a given $\mathrm{SO}_{2}$ concentration, the $\mathrm{Hg} / \mathrm{D}_{2}$ absorption values (i.e., the $\mathrm{D}_{2}$ correction factor) was not affected by the total gas flow rate. Similarly, when a $1000 \mathrm{ppm} \mathrm{SO}$ stream entered the analyzer at flow rates of $100-1000 \mathrm{~mL} / \mathrm{min}$, no flow rate effects on the $\mathrm{D}_{2}$ correction factor were observed. Although the $\mathrm{D}_{2}$ correction factor for a given $\mathrm{SO}_{2}$ concentration was not affected by the total gas flow rate while using $2 \% \mathrm{SO}_{2}$ blended with air, it was affected slightly by the $\mathrm{SO}_{2}$ concentration. The $\mathrm{Hg} / \mathrm{D}_{2} \mathrm{mAU}$ ratio increased from 0.82 to 0.85 as the $\mathrm{SO}_{2}$ concentration was increased from 0.1 to $0.6 \%$, respectively. Although this is a narrow range, the differences can have a considerable impact on the background-corrected mAU readings when using blends of $\mathrm{Hg}$ and $\mathrm{SO}_{2}$ in the concentration ranges of interest. The $\mathrm{Hg} / \mathrm{D}_{2}$ ratio appeared to be constant for $\mathrm{SO}_{2}$ concentrations of less than about $0.3 \%$. Despite the current need for a $\mathrm{D}_{2}$ correction factor, it is possible that this need can be diminished or even eliminated through modifications in the instrument design. This is particularly important since it is undesirable to have a correction factor that is somewhat dependent on the concentration of the primary interfering gas in the sample stream.

Tests were also performed using blends of $\mathrm{Hg}$ and $\mathrm{SO}_{2}$. For these tests, an uncertified $\mathrm{Hg}$ permeation tube (VICI Metronics) with a nominal $\mathrm{Hg}$ emission rate of $10 \mathrm{ng} / \mathrm{min}$ at $30^{\circ} \mathrm{C}$ was used. Tests were performed to determine the actual $\mathrm{Hg}$ emission rate. To do this, span gases from the calibrator were bubbled into $\mathrm{KMnO}_{4}$ absorbing solutions and then analyzed by CVAA. 
Results of those analyses indicated that the actual $\mathrm{Hg}$ emission rate was $11.0 \pm 0.5 \mathrm{ng} / \mathrm{min}$. Therefore, a value of $11 \mathrm{ng} / \mathrm{min}$ was used as the actual emission rate from the tube. This provided $\mathrm{Hg}$ concentrations of $9-26 \mu \mathrm{g} / \mathrm{m}^{3}$ while using total gas flow rates ranging from 360$1020 \mathrm{~mL} / \mathrm{min}$. Although $\mathrm{Hg}$ concentrations of $1-10 \mu \mathrm{g} / \mathrm{m}^{3}$ may be more typical of gaseous effluents from coal-based power generation, the higher $\mathrm{Hg}$ concentrations were used at this point in order to begin with more favorable conditions for the initial assessments of the CEM in the presence of interfering gases. The $\mathrm{Hg}$ calibration streams were blended with $2.0 \% \mathrm{SO}_{2}\left(\right.$ in $\left.\mathrm{N}_{2}\right)$. The $\mathrm{SO}_{2}$ concentration in the final blended gas stream was varied from $0.02-0.44 \%$ by adjusting the $\mathrm{SO}_{2}$ flow rate. For these tests, the absorbance at $254 \mathrm{~nm}$ due to $\mathrm{SO}_{2}$ was 15 to 35 times higher than the signal due to $\mathrm{Hg}$. For each $\mathrm{SO}_{2}$ flow rate, corresponding $\mathrm{Hg}$ calibration curves were prepared in the absence of $\mathrm{SO}_{2}$ by blending the span gases from the calibrator with dry $\mathrm{N}_{2}$ and measuring raw absorption values with the $\mathrm{Hg}$ channel of the analyzer.

Results of the tests with the $\mathrm{Hg}$ and $\mathrm{SO}_{2}$ blends are shown in Figures 13 through 16 . In Figure 13, the raw (uncorrected) mAU values obtained for various $\mathrm{Hg}$ concentrations with and without $\mathrm{SO}_{2}$ present are shown. As with the tests with the breadboard optical unit, the severity of the $\mathrm{SO}_{2}$ interference is clearly shown. In Figures 14 through 16, the background-corrected absorption values are shown and compared with a calibration curve obtained for $\mathrm{Hg}$ in the absence of $\mathrm{SO}_{2}$. In Figures 14 and 15, in which $\mathrm{SO}_{2}$ concentrations varied from 0.02 to $0.25 \%$, a fixed value was used for the $\mathrm{D}_{2}$ correction factor. However, a "sliding" $\mathrm{D}_{2}$ correction factor was needed at higher $\mathrm{SO}_{2}$ concentrations in order to effectively correct for the $\mathrm{SO}_{2}$ interference. To do this, the $\mathrm{D}_{2}$ correction factors were bracketed along with the $\mathrm{SO}_{2}$ concentrations in order to provide a "sliding" correction factor dependent on the $\mathrm{SO}_{2}$ concentration. In other words, as the $\mathrm{SO}_{2}$ concentration changed, the correction factor for the $\mathrm{D}_{2}$ channel changed slightly. A sliding $\mathrm{D}_{2}$ correction factor based on the $\mathrm{SO}_{2}$ concentration was used for the data shown in Figure 16. The linear regression " $\mathrm{R}^{2}$ " values for the $\mathrm{Hg}$ calibration curves were all about 0.999 . The $\mathrm{D}_{2}$ background correction approach generally did a good job at correcting for the $\mathrm{SO}_{2}$ interference. This is particularly true for $\mathrm{SO}_{2}$ concentrations of less than $0.25 \%$ in which a fixed $\mathrm{D}_{2}$ correction factor was applied. Although the mAU readings due to $\mathrm{SO}_{2}$ were 15 to 35 times higher than those due to $\mathrm{Hg}$, the background-corrected mAU readings were generally ( $85 \%$ of all cases) within $10 \%$ of the theoretical $\mathrm{Hg} \mathrm{mAU}$ values (i.e., the absorption due only to $\mathrm{Hg}$ ). In fact, the corrected values were within $5 \%$ of the theoretical $\mathrm{mAU}$ values in about $50 \%$ of all cases.

In Figure 17, the results are shown for a $9 \mu \mathrm{g} / \mathrm{m}^{3} \mathrm{Hg}$ stream containing $0.2 \% \mathrm{SO}_{2}$. The data are not only corrected for the $\mathrm{SO}_{2}$ interference using the $\mathrm{D}_{2}$ data, but are also automatically correlated with a $\mathrm{Hg}$ calibration curve prepared in the absence of $\mathrm{SO}_{2}$. To obtain this readout, a $\mathrm{Hg}$ calibration coefficient is simply input into the analyzer. The $\mathrm{D}_{2}$ background correction did an excellent job at correcting for the $\mathrm{SO}_{2}$ and correlating the corrected readings to an actual $\mathrm{Hg}$ concentration. It can also be seen that the signals are slightly noisier when integrating the readings from the $\mathrm{Hg}$ and $\mathrm{D}_{2}$ channels, rather than taking readings from the $\mathrm{Hg}$ channel alone while analyzing $\mathrm{Hg}$ streams in the absence of $\mathrm{SO}_{2}$. This is to be expected since the $\mathrm{D}_{2}$ channel is significantly noisier than the $\mathrm{Hg}$ channel. 


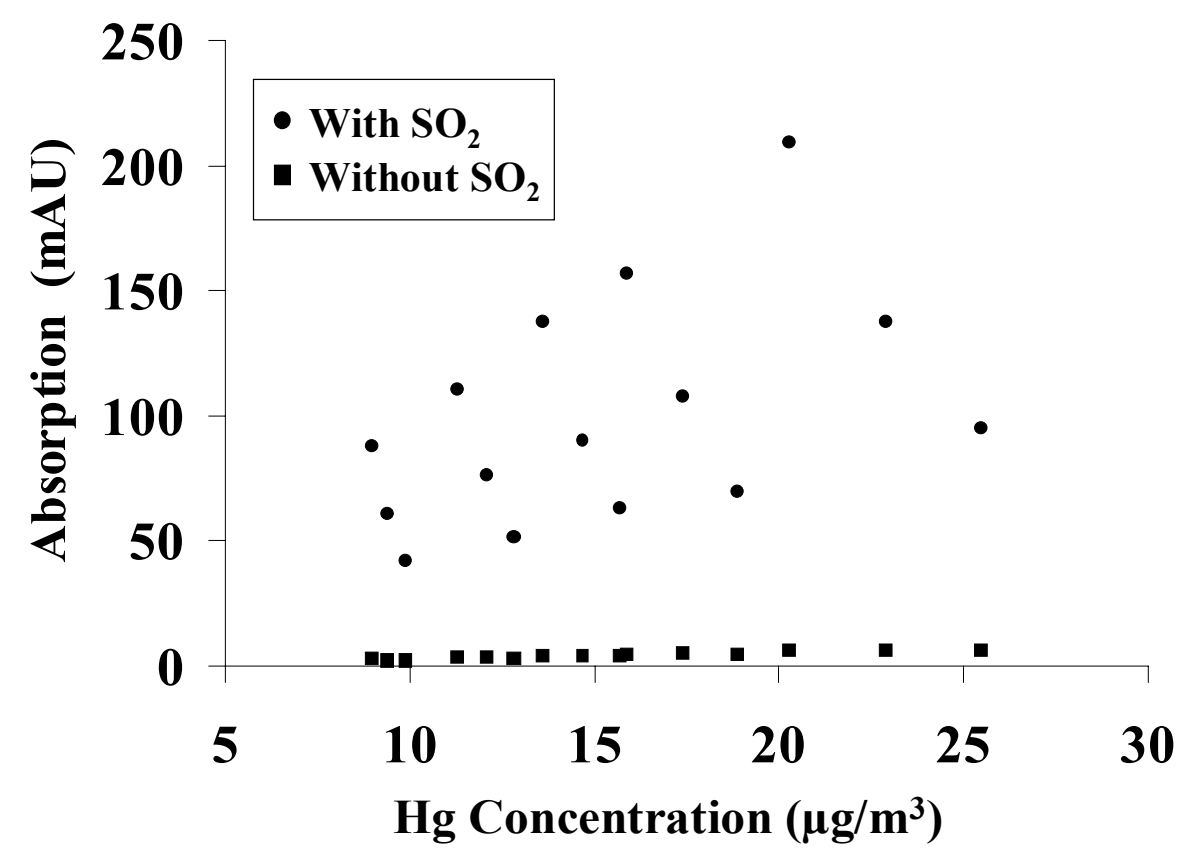

Figure 13. Uncorrected Absorbance Readings Obtained with the CEM for Various $\mathrm{Hg}$ Concentrations With and Without $\mathrm{SO}_{2}$ Present.

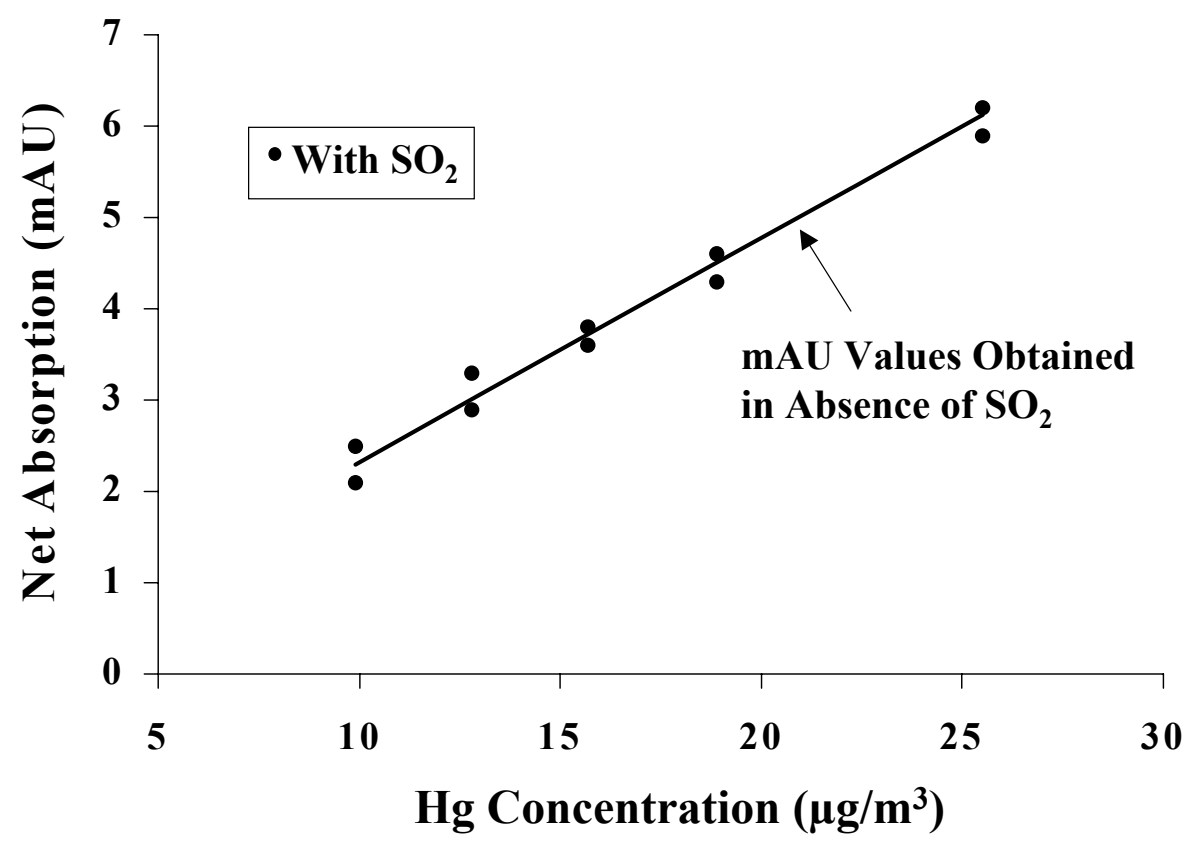

Figure 14. Background-Corrected (Fixed $\mathrm{D}_{2}$ Correction Factor) Absorbance Readings Obtained with the CEM for Various Hg Concentrations in the Presence of $0.02-0.06 \% \mathrm{SO}_{2}$. 


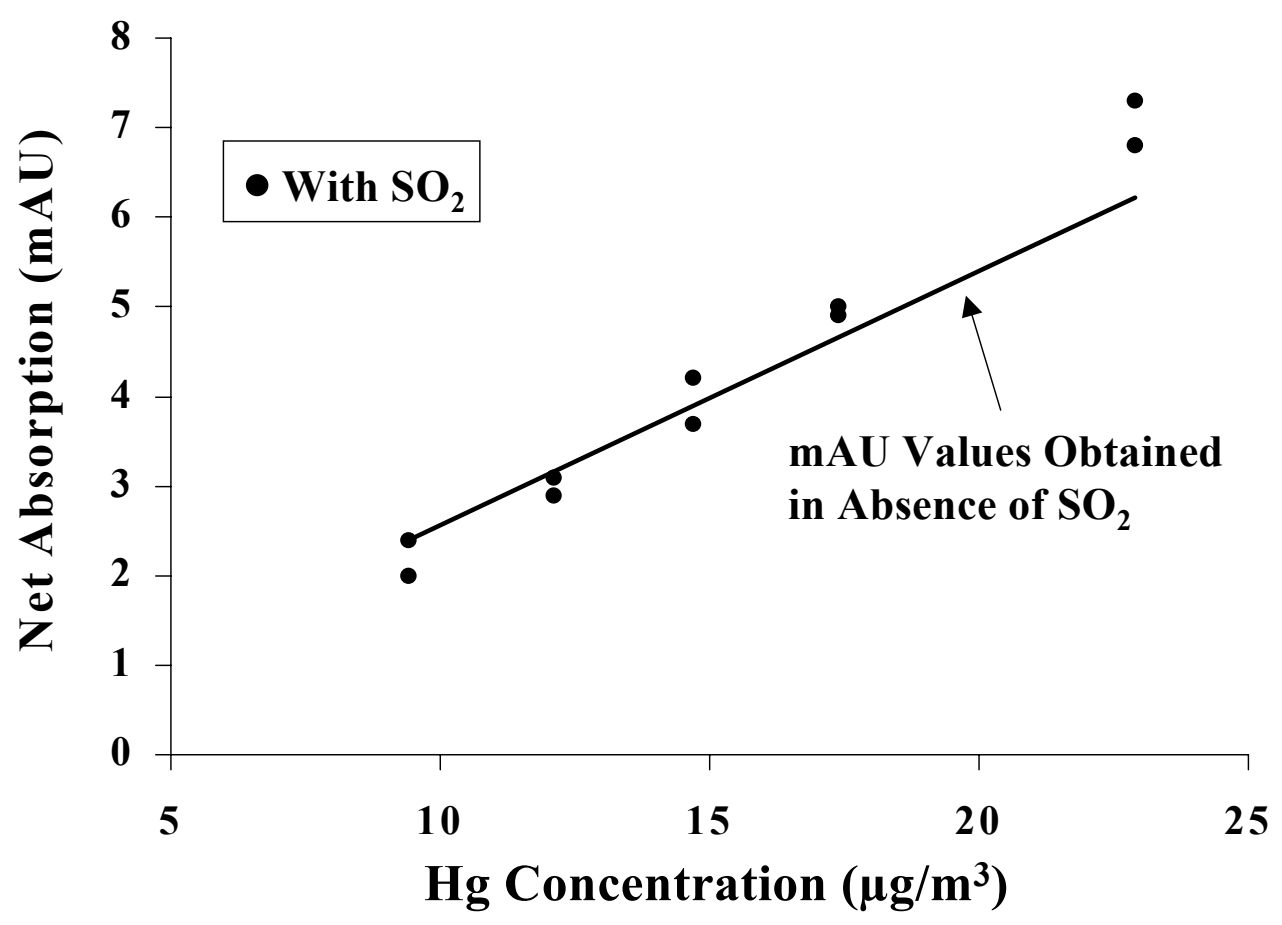

Figure 15. Background-Corrected (Fixed $\mathrm{D}_{2}$ Correction Factor) Absorbance Readings Obtained with the CEM for Various Hg Concentrations in the Presence of $0.10-0.25 \% \mathrm{SO}_{2}$.

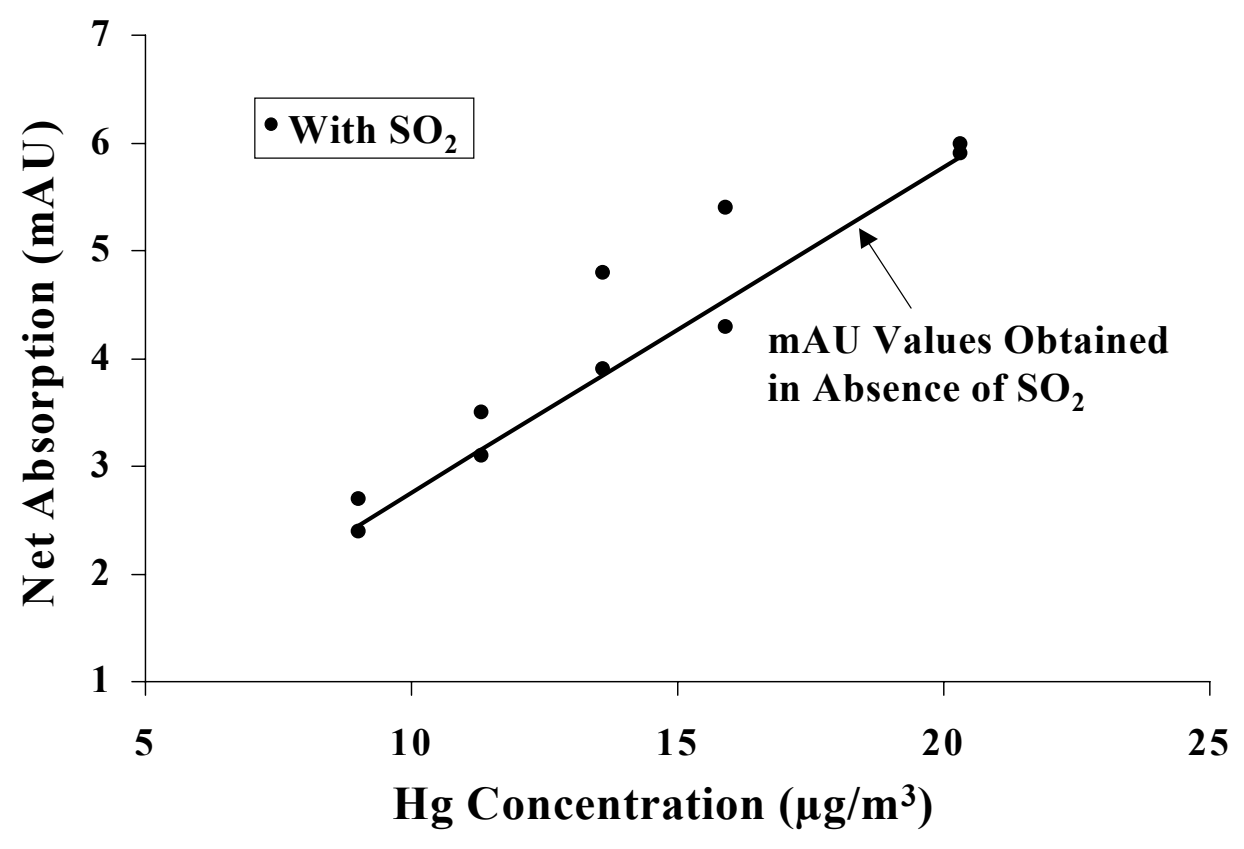

Figure 16. Background-Corrected (Sliding $\mathrm{D}_{2}$ Correction Factor) Absorbance Readings Obtained with the CEM for Various $\mathrm{Hg}$ Concentrations with $0.20-0.44 \% \mathrm{SO}_{2}$. 


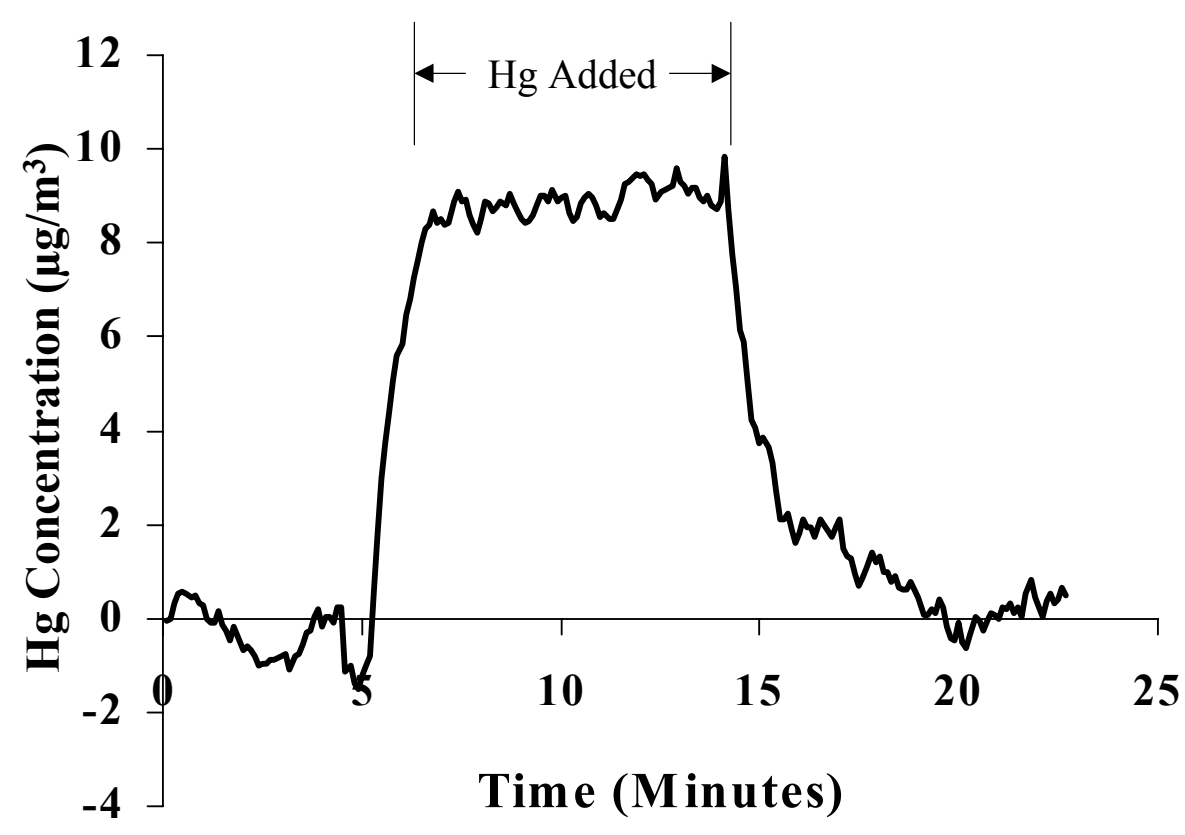

Figure 17. Background-Corrected $\mathrm{Hg}$ Concentration Obtained with the CEM for a Gas Stream Containing $9 \mu \mathrm{g} / \mathrm{m}^{3} \mathrm{Hg}$ and $0.2 \% \mathrm{SO}_{2}$.

A limited number of tests were performed with a heated sample cell. While performing those tests, a prominent cyclic noise problem was noted. The cycles had an amplitude of about $0.2 \mathrm{mAU}$ and a frequency that varied from 10-60 seconds, depending on the cell temperature. This precluded seeing $\mathrm{Hg}$ concentrations below about $2 \mu \mathrm{g} / \mathrm{m}^{3}$ while using a heated cell. The cyclic base line was thought to be due to the temperature controller for the cell heater. In particular, it could be caused by unshielded wires connected to the controller relay. The cyclic noise could also be caused by inadequate line regulation of the power supply such that when the heater switches on, the line voltage drops and causes a drop in the DC power supply, which in turn causes a drop in the power to the Hg lamp. Still another possibility is that the cyclic nature of the base line with a heated cell is related to thermal effects because of the low thermal mass of the detection cell. Tests were performed to determine if the cyclic base line could be avoided with a heated sample cell by using an alternate heating approach. To do this, the sample cell was heavily insulated and the cell heater was turned off. However, the sample line into the cell was heat traced and connected to a Variac for temperature control. Thus, the gas entering the cell was heated in this manner. The heavily insulated sample cell heated up due to the hot gases entering the cell and quickly reached a temperature equilibrium. Testing was performed with the sample line heated to 50,100 , and $200^{\circ} \mathrm{C}$. Results of those tests indicated that the cyclic base line was eliminated by this approach. Therefore, the problem was indeed related to the cell heater cycling on and off. Furthermore, the base line noise (about $0.02 \mathrm{mAU}$ ) was not affected by increases in temperature. Simple design modifications should allow the sample cell to be heated directly without causing the cyclic base line problem. 
Aside from the cyclic nature of the base line observed with a heated sample cell, the instrument sensitivity decreased when the cell was heated. This was not due to the cyclic nature of the base line, but rather from a decreased instrument response for a given $\mathrm{Hg}$ concentration. As the cell temperature increased from ambient to $200^{\circ} \mathrm{C}$, the magnitude of the $\mathrm{Hg}$ signal decreased by about $50 \%$. The $\mathrm{Hg}$ signal decreased incrementally with each increase in temperature in that temperature range. One of the possibilities is that there was defocusing of the optics when the cell is heated. If so, the problem could be potentially alleviated by providing better insulation at the ends of the sample cell in order to decrease temperature variations in the cell windows. To see if improved insulation at the ends of the cell would help regain instrument sensitivity, the entire sample cell was heavily insulated and the cell was heated indirectly by heating the sample gases entering the cell (as done earlier to study the cyclic base line problem). However, this did not alleviate the problem of lower instrument response with increased cell temperature. Therefore, apparent defocusing of the optics remains a problem that would have to be dealt with if a heated sample cell is desired.

Although the use of a heated sample cell was investigated, using a heated sample cell may not offer many advantages over a cell at closer to room temperature. The $10-\mathrm{cm}$ sample cell provided very high sensitivity and rapid response. Response times were compared at various temperatures in the range of $25-200^{\circ} \mathrm{C}$, and no differences were observed in the rise and fall times (when switching back and forth between zero air and span gases) as the temperature was varied. Therefore, heating the cell did not significantly decrease sorption of $\mathrm{Hg}$ onto the cell walls and provide improved instrument response. Unless condensable aerosols are found to be a problem with the cell at room temperature, heating of the sample cell will probably not be necessary.

\section{$\underline{\text { Modified Optics }}$}

Because of the observation that the $\mathrm{D}_{2}$ correction factor changes slightly with varying $\mathrm{SO}_{2}$ concentration, thereby complicating the analytical determinations, the optics in the instrument were modified in an attempt to eliminate the need for the $\mathrm{D}_{2}$ correction factor or at least reduce its importance. After the optical modifications, tests were performed whereby gas streams containing $\mathrm{SO}_{2}$ concentrations of 0.1 to $0.6 \%$ (in air) were passed into the analyzer at a total gas flow rate of $1000 \mathrm{~mL} / \mathrm{min}$. The $\mathrm{D}_{2}$ correction factor (ratio of the $\mathrm{mAU}$ reading from the $\mathrm{Hg}$ channel to that from the $\mathrm{D}_{2}$ channel) was determined at each $\mathrm{SO}_{2}$ concentration. These tests had been performed earlier with the initial optics. As before, the $\mathrm{D}_{2}$ correction factor increased slightly as the $\mathrm{SO}_{2}$ concentration increased. Whereas the correction factor with the initial optics was about 0.8 , the correction factor with the new optics was about 1.1. Thus, modifying the optics changed this correction factor considerably. However, the actual value of the correction factor is not the primary issue. Rather, the most important issue is the varying $\mathrm{D}_{2}$ correction factor with changing $\mathrm{SO}_{2}$ concentration, and that phenomenon was still observed after installation of the new optical components. Therefore, when tests were performed using $\mathrm{Hg}$ concentrations of $10-20 \mu \mathrm{g} / \mathrm{m}^{3}$ in the presence of $0.2-0.44 \% \mathrm{SO}_{2}$, a fixed $\mathrm{D}_{2}$ correction factor was still inadequate for accurately performing the background corrections at those high $\mathrm{SO}_{2}$ levels. In fact, results were very similar to those obtained under the same experimental conditions but while using the original optics. Therefore, the problem with the correction factor 
changing slightly with changing $\mathrm{SO}_{2}$ concentration still remains, and accurate background corrections could only be made with a "sliding" $\mathrm{D}_{2}$ correction factor when $\mathrm{SO}_{2}$ concentrations were above about $0.25 \%$.

\section{DESCRIPTION OF Hg ANALYZER AND CEM}

The Hg analysis component (i.e., detection system) of the Hg CEM is shown in Figure 18, and a simplified schematic diagram of the interior of the analyzer is shown in Figure 19. The $\mathrm{Hg}$ analyzer weighs roughly 50 pounds and is housed in a 26 " by 9 " by $18^{\prime \prime}$ case equipped with a carrying handle. The case opens up like a suitcase to provide easy access to all optical and electrical components. A $10-\mathrm{cm}$ quartz cell (volume of about $18 \mathrm{~cm}^{3}$ ) that can be heated from $30-225^{\circ} \mathrm{C}$ is used. The cell temperature is selected with a thumbwheel on the instrument cover.

The analyzer contains a temperature-controlled, low-pressure, non-ozone Hg lamp for measuring total absorbance at $254 \mathrm{~nm}$, and a 40 -watt $\mathrm{D}_{2}$ lamp for measuring the background in that region. A single beam splitter is used with a shutter mechanism to alternately switch the beams from the $\mathrm{Hg}$ and $\mathrm{D}_{2}$ lamps through the sample cell to the photo diode detector. A reference beam is used to reduce base line noise and drift by compensating for fluctuations in lamp intensity and other instrumental variables. This is accomplished by sending a portion of each beam to a reference photo diode detector.

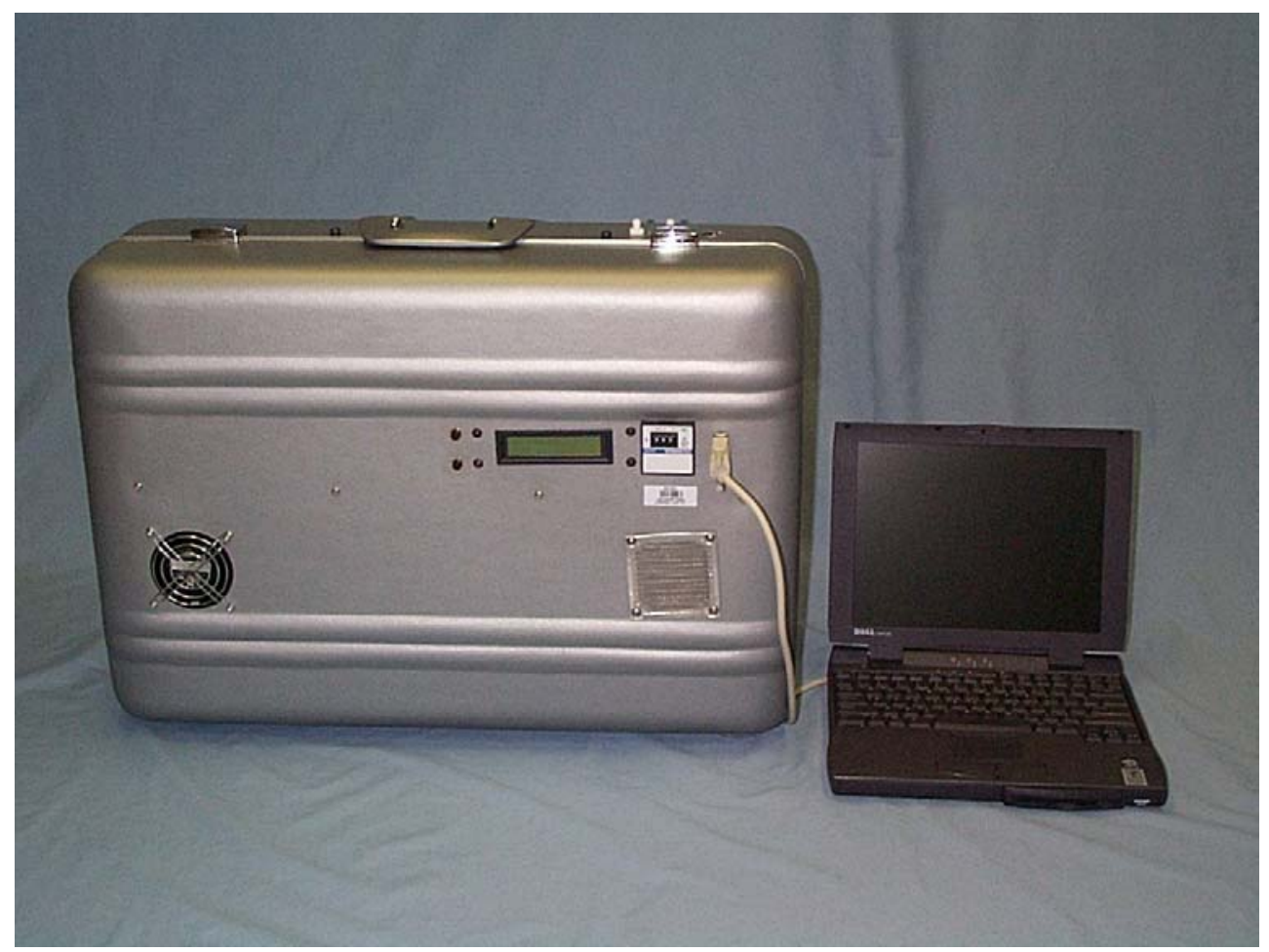

Figure 18. Mercury Analyzer Employing a $\mathrm{D}_{2}$ Background Correction System. 


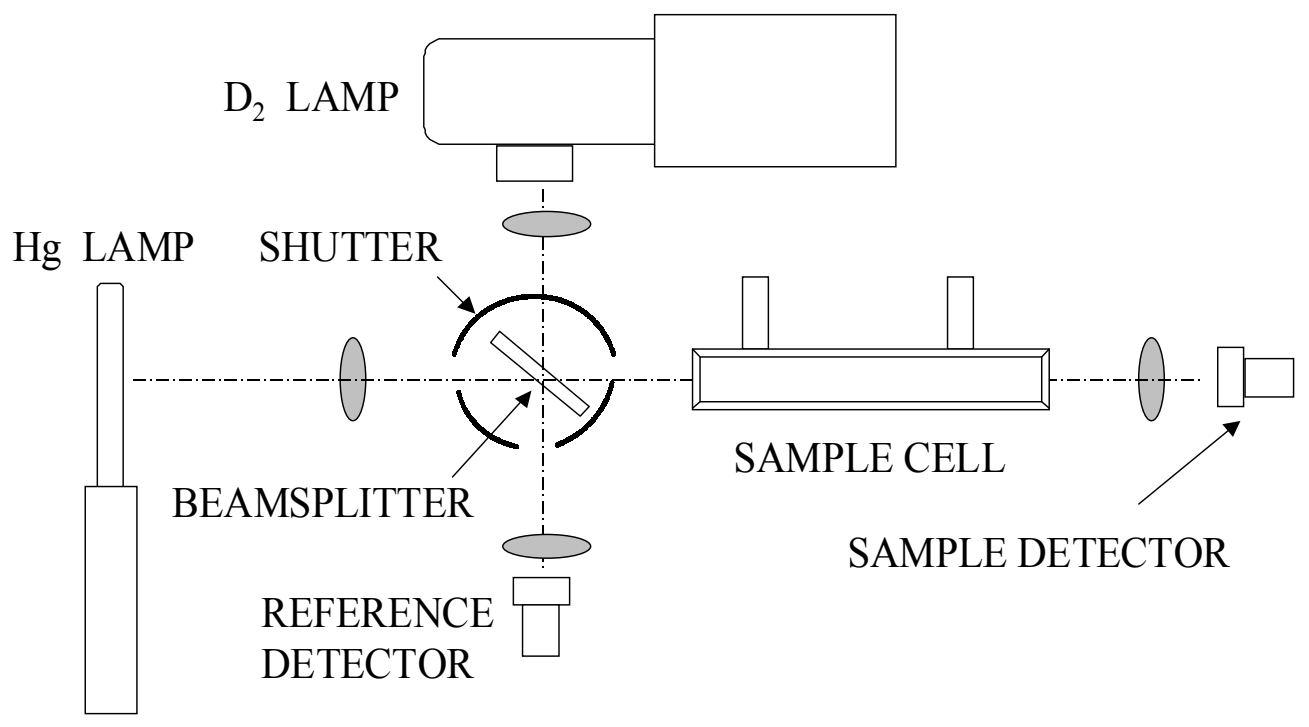

Figure 19. Simplified Schematic Diagram of the Interior of the Hg Analyzer.

A small panel mounted in the cover displays a reading about every three seconds, and up to 48 hours of data can be stored in nonvolatile internal memory. Those data can later be downloaded onto a laptop computer or a PC. By using the panel display, the instrument can be zeroed, data acquisition into the internal memory buffer can be initiated, and one of two data display modes can be selected. The analyzer can also be operated continuously with an external laptop computer or PC through a DB-9 connector. With an external computer hooked up to the analyzer, one of six data display modes can be selected. In addition, there are diagnostic tools, adjustments for data processing parameters, instrument zeroing capabilities, and optical alignment features which can be used if desired. Data smoothing is accomplished with an adjustable digital filter. With the digital filter, there is a tradeoff between signal smoothing and instrument response time. In other words, as the signal is smoothed to a greater degree, the instrument takes longer to respond and reach a steady reading. To simplify the analyzer, the number of detectors was reduced from 4 to 2 , and a single beamsplitter with a chopper mechanism was used. This has the advantage of eliminating cross-talk interference between the sources and improves stability since any degradation in the optics and/or detectors will occur equally in both signals.

The discussion above pertains only to the detection portion of the overall CEM and does not include the gas conditioning components required for sampling gasifier streams. Because funds were not available to duplicate the entire gas conditioning system, the $\mathrm{Hg}$ analyzer would be connected to the same gas conditioning system used for the HCl CEM. A schematic diagram of the overall gas conditioning and analysis system when sampling for $\mathrm{Hg}$ is shown in Figure 20. As noted above, this is basically the same gas conditioning that is used for monitoring $\mathrm{HCl}$ (see description of $\mathrm{HCl} \mathrm{CEM}$ in latter portions of this report). However, when being used for $\mathrm{Hg}$, several modifications are necessary. Specifically, the soda lime scrubber that is used for $\mathrm{HCl}$ is 
replaced with an activated carbon scrubber, the sample gases bypass the $\mathrm{HCl}$ analyzer and enter the $\mathrm{Hg}$ analyzer instead, and no instrument air is required for the $\mathrm{Hg}$ detector. The $\mathrm{Hg}$ scrubber consists of four Model 300 Hydrocarbon Traps (in parallel) from Chromatography Research Supplies. These scrubbers are to ensure that the air stream added to the sample gas prior to the oxidation catalyst is free from $\mathrm{Hg}$ contaminants. For more details on the gas conditioning system, refer to the CEM description in the "Hydrogen Chloride Studies" section of this report.

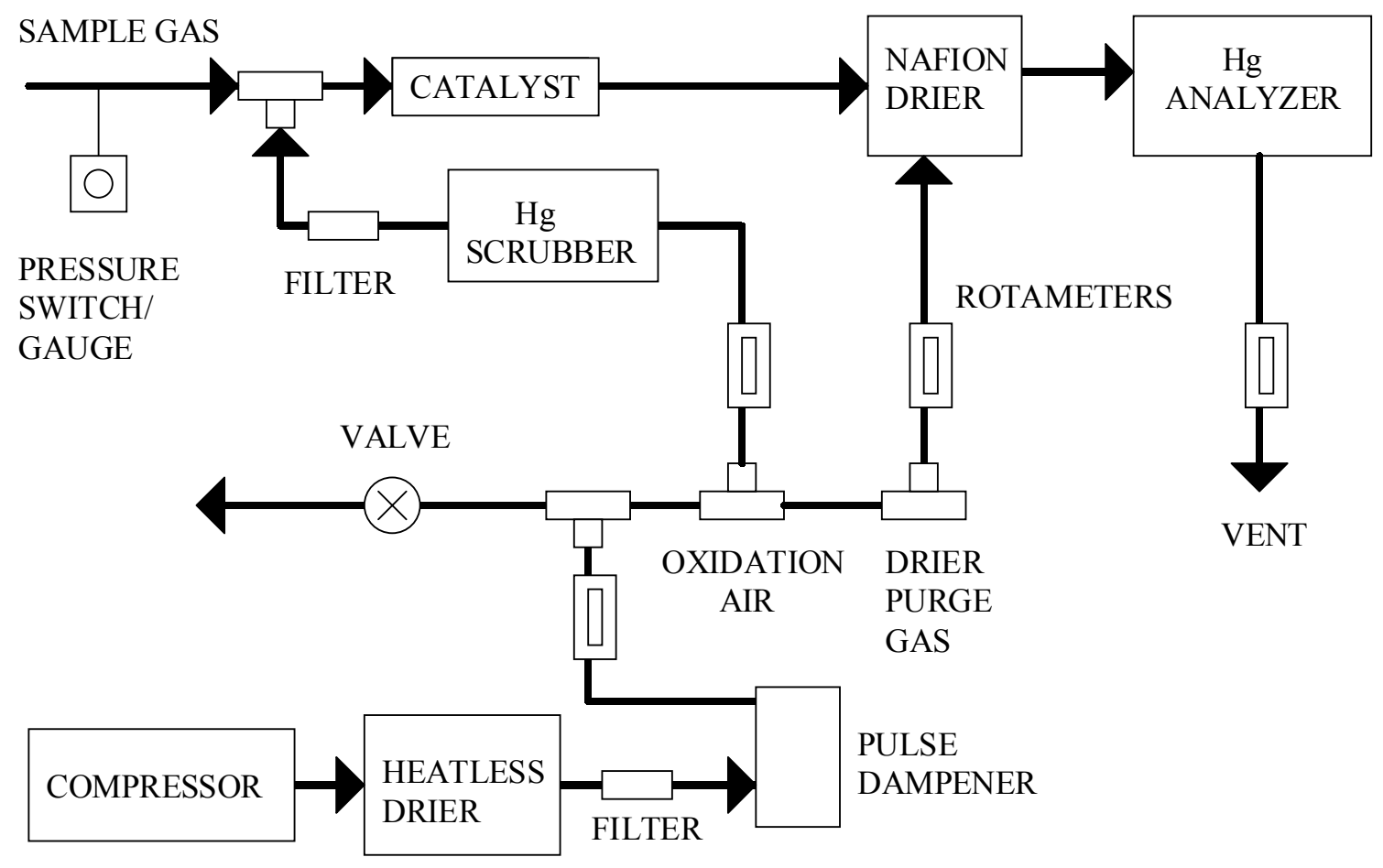

Figure 20. Schematic Diagram of Gas Conditioning System for the Hg CEM.

The use of an oxidation catalyst raises some concerns regarding the $\mathrm{Hg}$ analyses, since the detection system responds to only elemental $\mathrm{Hg}$ and not oxidized $\mathrm{Hg}$. Therefore, the catalyst module contains a catalyst zone for removing $\mathrm{NH}_{3}$ and tars, followed by a high-temperature $\left(900-950^{\circ} \mathrm{C}\right)$ pyrolysis zone intended to convert all of the $\mathrm{Hg}$ to elemental form prior to entering the $\mathrm{Hg}$ analyzer. Even if the pyrolysis zone effectively converts all the $\mathrm{Hg}$ to the elemental form, the possible recombination of $\mathrm{Hg}$ and chloride as the gases are in transit to the analyzer remains an issue which requires further study.

The operation of the overall CEM is based on the assumption that a properly filtered gas stream is available. Thus, particle filtration is not performed as part of the gas conditioning system in the CEM, but should be performed upstream from the CEM using an inertial filter, standard metal filter, or other suitable filtering device. Also, calibrations are nonautomated and are done "off line" whereby the instrument is calibrated with elemental $\mathrm{Hg}$ while bypassing the 
gas conditioning system. The off-line calibrations will help ensure that the instrument is properly calibrated. Accurate analyses will then hinge on sample transport issues. However, the calibration issues have not been fully resolved in view of the difficult sampling and gas conditioning problems involved. Although it is often preferred to pass span gases through the entire analytical and gas conditioning system in order to perform calibrations, an issue of concern with that approach is that the calibration gases are in a drastically different gas matrix than the sample gases are in. This is of concern because sample transport difficulties and analyte losses typically vary as the gas matrix is changed. In addition to performing off-line calibrations to ensure proper instrument calibration, elemental $\mathrm{Hg}$ spikes into the gasifier streams would be desirable to gain confidence in sample transport issues.

\section{TESTING OF ENTIRE CEM IN THE LABORATORY}

After integrating the prototype $\mathrm{Hg}$ analyzer with the gas conditioning system, the fully integrated $\mathrm{Hg}$ CEM was evaluated in the laboratory using a simulated gasifier stream. The simulated gasifier stream (dry basis) consisted of $22 \% \mathrm{H}_{2}, 13 \% \mathrm{CO}_{2}, 7 \% \mathrm{CH}_{4}, 1.7 \% \mathrm{H}_{2} \mathrm{~S}, 44 \%$ $\mathrm{CO}, 0.25 \% \mathrm{NH}_{3}, 50 \mathrm{ppm} \mathrm{HCl}, 15 \mu \mathrm{g} / \mathrm{m}^{3}$ elemental $\mathrm{Hg}$, and a balance of $\mathrm{N}_{2}$. Also, moisture was added to give a water content of $20 \%$. A single compressed gas cylinder containing blended $\mathrm{H}_{2}$, $\mathrm{CO}_{2}, \mathrm{CH}_{4}, \mathrm{H}_{2} \mathrm{~S}$, and $\mathrm{CO}$ was used. The $\mathrm{NH}_{3}, \mathrm{H}_{2} \mathrm{O}, \mathrm{HCl}$, and $\mathrm{Hg}$ were each added separately to the sample line just prior to the inlet of the gas conditioner. Compressed gas cylinders were used for the $\mathrm{NH}_{3}$ and $\mathrm{HCl}$, while known amounts of water were fed into the gas stream by using a peristaltic pump. Elemental $\mathrm{Hg}$ vapors were added to the sample gas stream by using a VICI Metronics Model 120 Field Calibrator in conjunction with a certified elemental $\mathrm{Hg}$ permeation tube. The sample line (316 stainless steel) into the gas conditioner was heated and maintained at $600^{\circ} \mathrm{C}$, and the $\mathrm{NH}_{3}, \mathrm{H}_{2} \mathrm{O}, \mathrm{HCl}$, and $\mathrm{Hg}$ were added to the gasifier stream via union tees in the $600^{\circ} \mathrm{C}$ sample line. Type 316 stainless steel would not be the preferred choice of materials during prolonged testing, but was used because of its low cost relative to other options and because extended testing of the CEM was not to be performed. Sections (about 8" each) of the $\mathrm{NH}_{3}, \mathrm{H}_{2} \mathrm{O}, \mathrm{HCl}$, and $\mathrm{Hg}$ lines connected to the union tees in the main sample line were heavily insulated to provide preheating prior to entering the gasifier stream.

For tests with the simulated gasifier stream, about $1 \mathrm{~L} / \mathrm{min}$ (dry basis) of gasifier stream was blended with $2 \mathrm{~L} / \mathrm{min}$ of oxidation air, which was preheated to $600^{\circ} \mathrm{C}$ and added to the simulated gasifier stream just prior to the oxidation catalyst. For comparative purposes, $\mathrm{Hg}$ streams $\left(15 \mu \mathrm{g} / \mathrm{m}^{3}\right)$ in air and nitrogen were passed directly (bypassing the gas conditioner) into the $\mathrm{Hg}$ analyzer. Similarly, tests were performed in which the $\mathrm{Hg}$ streams in either air or nitrogen were passed through the heated gas conditioning system. Operating the entire gas conditioning/analytical system was complex and required a substantial amount of experience with the systems.

When using streams of only $\mathrm{Hg}$ in air flowing at $1 \mathrm{~L} / \mathrm{min}$ and bypassing the conditioner, full signals were obtained with the $\mathrm{Hg}$ analyzer within about a minute when switching from zero air to span gases. When the air stream contained $50 \mathrm{ppm} \mathrm{HCl}$, the reading on the $\mathrm{Hg}$ analyzer was within $3 \%$ of that observed in the absence of $\mathrm{HCl}$. Since the detector responds to $\mathrm{Hg}$ only in 
the elemental (reduced) form, these results show that little or no oxidation of $\mathrm{Hg}$ occurred in the presence of $\mathrm{HCl}$ at room temperature. When switching from span gases back to zero air, the $\mathrm{Hg}$ in the analyzer was purged out in less than a minute.

Next, a stream of $\mathrm{Hg}$ in $\mathrm{N}_{2}$ flowing at $1 \mathrm{~L} / \mathrm{min}$ was passed through the heated gas conditioning system prior to entering the $\mathrm{Hg}$ analyzer. No air was added prior to the catalyst for these tests, which were performed with and without $50 \mathrm{ppm} \mathrm{HCl}$ in the gas stream. When $\mathrm{HCl}$ was absent, the $\mathrm{Hg}$ readings were about $50 \%$ below expected values. This suggests that wall losses in the gas conditioner were substantial, since little or no $\mathrm{Hg}$ oxidation would be anticipated in the $\mathrm{N}_{2}$ stream. However, it is possible that there were residual traces of oxygen in the system from previous tests. In that event, either the pyrolyzer (at $900^{\circ} \mathrm{C}$ ) downstream from the oxidation catalyst was not effectively converting any oxidized $\mathrm{Hg}$ back to the elemental form, or else the pyrolyzer was working as intended and some of the elemental $\mathrm{Hg}$ was oxidizing as the gases cooled after exiting the pyrolyzer. When the tests were repeated while bypassing the Nafion dryer, the $\mathrm{Hg}$ signals increased by $40-50 \%$ (relative), but were still well below the values obtained while bypassing the entire gas conditioner. This shows that the Nafion (or the inlet tubing to the dryer) is one source, but not the only source, of $\mathrm{Hg}$ losses when going through the entire gas conditioner. When the tests through the entire gas conditioning system were repeated with $50 \mathrm{ppm} \mathrm{HCl}$ in the gas stream, the $\mathrm{Hg}$ signals decreased by about $10 \%$ relative to those obtained in the absence of $\mathrm{HCl}$. However, this magnitude of decrease is not beyond experimental uncertainties, including uncertainties in the flow meter readings.

During the tests with $\mathrm{Hg}$ in $\mathrm{N}_{2}$ through the conditioner, a quartz wool pad at the upstream end of the catalyst tube began turning brown. Analysis of the brownish material by scanning electron microscopy with energy dispersive x-ray analysis (SEM-EDX) indicated that the material was highly enriched in iron and nickel. This material, which presumably came from the steel sampling line entering the catalyst tube, is undesirable because transfer of those metals downstream could catalyze the oxidation of $\mathrm{Hg}$ or could result in sorption of $\mathrm{Hg}$ vapors. Also, continued buildup on the quartz wool would eventually lead to gas flow restrictions. Careful consideration will need to be given to the type of material used in the sample lines.

Subsequent tests were performed with streams of air (as opposed to $\mathrm{N}_{2}$ ) and $\mathrm{Hg}$ flowing through the heated conditioner at $1 \mathrm{~L} / \mathrm{min}$. The $\mathrm{Hg}$ signals obtained in those tests were comparable to those obtained while using streams of $\mathrm{Hg}, \mathrm{HCl}$, and $\mathrm{N}_{2}$ through the conditioner. When the tests with air and $\mathrm{Hg}$ were repeated, but in the presence of $50 \mathrm{ppm} \mathrm{HCl}$, the elemental $\mathrm{Hg}$ signals decreased substantially (as was feared) and were only about $15 \%$ of those obtained while bypassing the gas conditioning system. Also, when testing with $\mathrm{Hg}$ in streams of air and $\mathrm{HCl}$, the $\mathrm{Hg}$ signals were considerably more erratic than in previous tests. As discussed above, it appears that either the pyrolyzer is not effectively converting oxidized $\mathrm{Hg}$ back to the elemental form, or that the pyrolyzer is working as expected, but elemental $\mathrm{Hg}$ downstream from the pyrolyzer is oxidizing in the presence of chloride as the gases cool. Although a larger pyrolyzer would effectively circumvent the first potential problem, it would do little good if the $\mathrm{Hg}$ is reoxidizing in the cool-down zone after the pyrolyzer. A number of $\mathrm{Hg}$ researchers believe that Hg oxidation occurs in the cool-down zone in a coal combustor, and this could well be what is occurring downstream from the pyrolyzer in the gas conditioning system. This issue was always a concern with the gas conditioning approach being used, but insufficient information was 
available on the pyrolytic conversion approach to adequately assess its utility for this application. The tests so far indicate that $\mathrm{Hg}$ transport through the gas conditioning system is problematic and requires further study to minimize wall effects and to ensure that all the $\mathrm{Hg}$ after the pyrolyzer is (and stays) in the elemental form.

Next, attempts were made to pass elemental $\mathrm{Hg}$ in a simulated gasifier stream through the heated gas conditioner. When using $1 \mathrm{~L} / \mathrm{min}$ of simulated gasifier stream (including $\mathrm{H}_{2} \mathrm{O}$ ) and adding $2 \mathrm{~L} / \mathrm{min}$ of oxidation air prior to the catalyst, the background-corrected absorbance readings from the analyzer (even without $\mathrm{Hg}$ in the gas stream) were too erratic to get meaningful $\mathrm{Hg}$ signals. A variety of possibilities could account for this observation. One possibility is that flow fluctuations in the gasifier/air blends were causing rapid fluctuations in the $\mathrm{SO}_{2}$ concentration downstream from the catalyst. The $\mathrm{Hg}$ analyzer may not be able to accurately perform background corrections in such cases. If so, design modifications in the analyzer would eliminate or alleviate this problem. Another possibility is that the decreased residence time in the catalyst zone (due to the increased volumetric flow rate resulting from the large volumes of steam from the added water) is resulting in incomplete conversion of $\mathrm{H}_{2} \mathrm{~S}$ to $\mathrm{SO}_{2}$. In this case, the ratio of $\mathrm{H}_{2} \mathrm{~S}$ to $\mathrm{SO}_{2}$ could well be fluctuating. In that event, it would throw the background-corrected absorbance readings off since the analyzer was set up specifically to correct for $\mathrm{SO}_{2}$ interferences, and some of the numerical factors entered into the analyzer (i.e., the $\mathrm{D}_{2}$ correction factor) for this purpose could be substantially in error if $\mathrm{H}_{2} \mathrm{~S}$ is present. Finally, it was noted that the red-hot portion of the catalyst system (where most of the gas stream oxidation was occurring) was pulsing every few seconds. Since this only happened when water was being added (via a peristaltic pump) to the sample stream, the water addition probably has something to do with the pulsing catalyst zone. It is believed that the pulsing was due to water flashing to steam in the sample line. Although the water was preheated prior to entering the main sample line, better preheating of the water and simple refinements in the plumbing for the water injection system would probably solve this problem (assuming that water flashing to steam is indeed the cause of the pulsing in the catalyst zone).

After using the simulated gasifier stream, the gas stream passing through the conditioner was switched back to only $\mathrm{N}_{2}$ (no oxidation air) and $\mathrm{Hg}$. However, the $\mathrm{Hg}$ signals were much lower than previously observed when using only $\mathrm{N}_{2}$ to transport the $\mathrm{Hg}$ through the conditioner. Thus, something apparently "poisoned" part of the sample transport and/or gas conditioning system. No aerosols or deposits were observed in the catalyst tube or in the oven containing the Nafion dryer (although heat tracing precluded immediate observation of the sample line connecting the catalyst tube to the dryer). However, it was suspected that the problem may still be related to traces of sulfur-containing gases in the system. Such gases may be interacting with the $\mathrm{Hg}$ in such a manner that the $\mathrm{Hg}$ is either combined with sulfur-containing vapors in the gas stream (in which case it would not be detectable by AA), or else is reacting with steel components with the aid of the sulfur-containing gases. After passing simulated gasifier streams through the entire system and then returning to a $\mathrm{N}_{2}$ flow of $1 \mathrm{~L} / \mathrm{min}$, traces of $\mathrm{SO}_{2}$ could still be smelled at the outlet of the gas conditioner an hour or more later. Over that time period, mAU readings from both the $\mathrm{Hg}$ and $\mathrm{D}_{2}$ channels of the analyzer exhibited a major downward drift, and absorbance readings were much higher (10 mAU or more) than those obtained for $\mathrm{N}_{2}$ streams that bypassed the conditioner. Since the $\mathrm{D}_{2}$ channel is not sensitive to $\mathrm{Hg}$, this is most likely due to the desorption of sulfur-containing gases, indicating that those gases have severe 
sorption/desorption effects in the gas conditioner. Similar results were obtained while bypassing the Nafion dryer, indicating that major sorption/desorption effects were occurring in other components of the sampling and/or gas conditioning system. Improvements are required to reduce those effects in the gas conditioner.

At the completion of the tests, the heat tracing was taken off the Teflon sample line connecting the catalyst tube to the Nafion dryer. The tube contained numerous spots on the interior walls and was heavily fogged in regions of the tubing. It was determined that a temperature of $200-220^{\circ} \mathrm{C}$ was needed to vaporize those deposits. The downstream end of the catalyst tube is always maintained at roughly $200^{\circ} \mathrm{C}$, while the line connecting the catalyst tube to the Nafion dryer is only maintained at $110^{\circ} \mathrm{C}$ in order to avoid excessive temperatures in the dryer (which would substantially reduce drying efficiency). Chemical and morphological analyses on the deposits by SEM-EDX indicated that the spots were crystalline and were highly enriched in oxygen and sulfur, and possibly lesser amounts of nitrogen. Thus, the spots are apparently some type of sulfate compounds, such as ammonium sulfates and/or ammonium thiosulfates. The presence of the latter compounds was previously shown to exist if $\mathrm{NH}_{3}$ was not completely removed from the gasifier stream. Improper operating conditions (excess air percentage, temperatures, etc.) over just a few minutes could have resulted in those deposits that, once formed, may adversely affect sample transport even during proper operation of the gas conditioner. It is very likely that the sulfur-containing deposits in the sample line were responsible for much of the $\mathrm{Hg}$ losses observed during sample transport. However, this work is complex, and additional work would be required to elucidate the precise mechanisms responsible for the Hg losses.

\section{HYDROGEN CHLORIDE STUDIES}

\section{SELECTION OF METHODS TO EVALUATE}

At the start of this project, the literature was reviewed to acquire information on analytical methodologies that may be suitable for determining $\mathrm{HCl}$ in hot gases from coal gasification systems. A variety of techniques for monitoring $\mathrm{HCl}$ in gaseous streams were identified. One of those methods utilizes a hollow cathode plasma (HCP) detection system. The HCP technique has been used to detect $\mathrm{Cl}$ in commercial gas mixtures (6). Although that method looked attractive in some respects, it is not specific to $\mathrm{HCl}$, must operate at reduced pressures, and may have severe molecular interferences. On-line analysis of liquid streams by ion chromatography (IC) was also discussed in the literature (7) and could likely be adapted for gas stream analysis. However, its primary application is for analysis of liquids, and there are concerns regarding instrument complexity and durability. That method has not yet been used for gas stream analysis. Mass spectrometry (MS) has been applied to the analysis of gaseous effluents for $\mathrm{HCl}$ (8), but it is complex, expensive, and requires the use of a vacuum system. In view of these considerations, the HCP, IC, and MS methods were not considered further. 
Fourier transform infrared spectroscopy (FTIR) should be a good method for determining $\mathrm{HCl}$ in flue gases. Although there is an interference from methane at the fundamental vibration of $\mathrm{HCl}$, the interference would be avoided when using gas stream oxidation. FTIR has been used to look at gaseous $\mathrm{HCl}$ emitted during laboratory heating of coal (9) and for $\mathrm{HCl}$ analyses in emissions from a hazardous waste incinerator and a coal-fired power plant $(10,11)$. In the latter study, $\mathrm{HCl}$ was not detected, even though $\mathrm{HCl}$ concentrations were believed to be high enough to detect. The authors noted that they were using nickel coated stainless steel absorption cells and suspected that $\mathrm{HCl}$ was being "removed" through reactions with the cell walls.

Gas filter correlation IR (GFCIR) is an attractive non-dispersive IR absorption technique. In that method, an IR beam is modulated by two cells mounted on a rotating wheel. The first cell is filled with the gaseous component to be monitored (thus, gas filter correlation) and the second one is filled with a gas that does not absorb IR energy in the same spectral region as the sample gas. The absorption of the IR beam at specific wavelengths in the sample cell is proportional to the $\mathrm{HCl}$ concentration. That method has been used to determine $\mathrm{HCl}$ in waste incinerator gases (12) and appeared to be a method worthy of further consideration, even though interferences are of considerable concern for IR absorption methods. For $\mathrm{HCl}$, methane is an interference of particular concern. Based on an EPA report, one GFCIR system did not perform reliably in field tests at a hazardous waste incinerator (13). On the other hand, we spoke with personnel from several different companies who had both laboratory and field experience with a Thermo Environmental Instruments Model 15 GFCIR analyzer. They reported that the instrument generally worked well in the field. However, several of the instrument users noted that the analytical uncertainty was significant in the 1-10 ppm range and recommended "dampening" the signal by taking 60 -second averages. Base line drift was also reported to be significant, which sometimes made it difficult to differentiate between 1 and $10 \mathrm{ppm}$. GFCIR monitors which have heated $\left(180^{\circ} \mathrm{C}\right)$ sample cells are commercially available.

Determining $\mathrm{HCl}$ by continuous titration has also been discussed in the literature (14). In that study, continuous titration was used to determine $\mathrm{HCl}$ in laboratory-generated combustion gases. That approach is probably a viable alternative to monitoring $\mathrm{HCl}$ emissions in NETL power producing systems. However, it is probably not the method of choice since it is relatively complex and more prone to breakdowns in the field compared to other options that were being considered.

NETL employed a wet chemical technique using conductivity measurements to determine $\mathrm{HCl}$ in simulated gasifier streams (15). That procedure involved using a high boiling point alcohol in a conductivity cell. $\mathrm{HCl}$ protonated the alcohol, thereby changing the conductivity of the solution. Although it is an attractive method, considerable problems involving memory effects and slow equilibration were encountered in the analyses. Despite the analytical problems, which may actually be due primarily to sample delivery issues, the method still appears to have promise for monitoring $\mathrm{HCl}$.

In addition to the above methods discussed in the literature, a number of commercially available analyzers were found after extensive interactions with vendors. These include methods based on colorimetry (dry), electrochemistry, electrolytic conductivity, ion mobility spectroscopy, ion selective electrodes, and semiconductor detection systems. Analyzers based 
on conductivity, electrochemical, and semiconductor detection are unsuitable for our application due to numerous chemical interferences from gaseous species anticipated to be present in gasifier streams. A dedicated monitor using an ion selective electrode for determining $\mathrm{HCl}$ in flue gas appeared promising. Although $\mathrm{H}_{2} \mathrm{~S}$ interferes with the analysis, this would not be a problem when using gas stream oxidation.

The methods found in the literature and from vendor contacts were screened to determine which methods had the most promise for our application (i.e., monitoring coal gasification streams). Criteria used to initially screen (no testing performed at this point) these methods for possible use in the $\mathrm{HCl}$ CEM included sensitivity, accuracy, interferences, cost, complexity, durability, mobility, and stage of development. Based on this initial screening, gas filter correlation IR (GFCIR), dry colorimetry, and ion mobility spectroscopy (IMS) were selected for evaluation in our laboratories. The laboratory evaluations of those three methods are discussed individually below. Based on those evaluations, IMS was ultimately selected as the method of choice for our $\mathrm{HCl} \mathrm{CEM}$.

\section{GAS FILTER CORRELATION IR}

A Thermo Environmental Instruments Model 15 GFCIR HCl Analyzer was evaluated in our laboratories. That unit is shown in Figure 21 below. The sample cell for this instrument (as designed at the time this work was performed) can operate up to about $50^{\circ} \mathrm{C}$. When using compressed gases for the $\mathrm{HCl}$ standard, instrument readings were very stable. For a $170 \mathrm{ppm}_{\mathrm{v}}$ $\mathrm{HCl}$ stream, the stability of the instrument reading and the signal rise and fall times observed when switching to span gases and then back to zero air are shown in Figure 22. In addition, the base line fluctuations were minimal (about $0.2 \mathrm{ppm} \mathrm{HCl}$ or less).

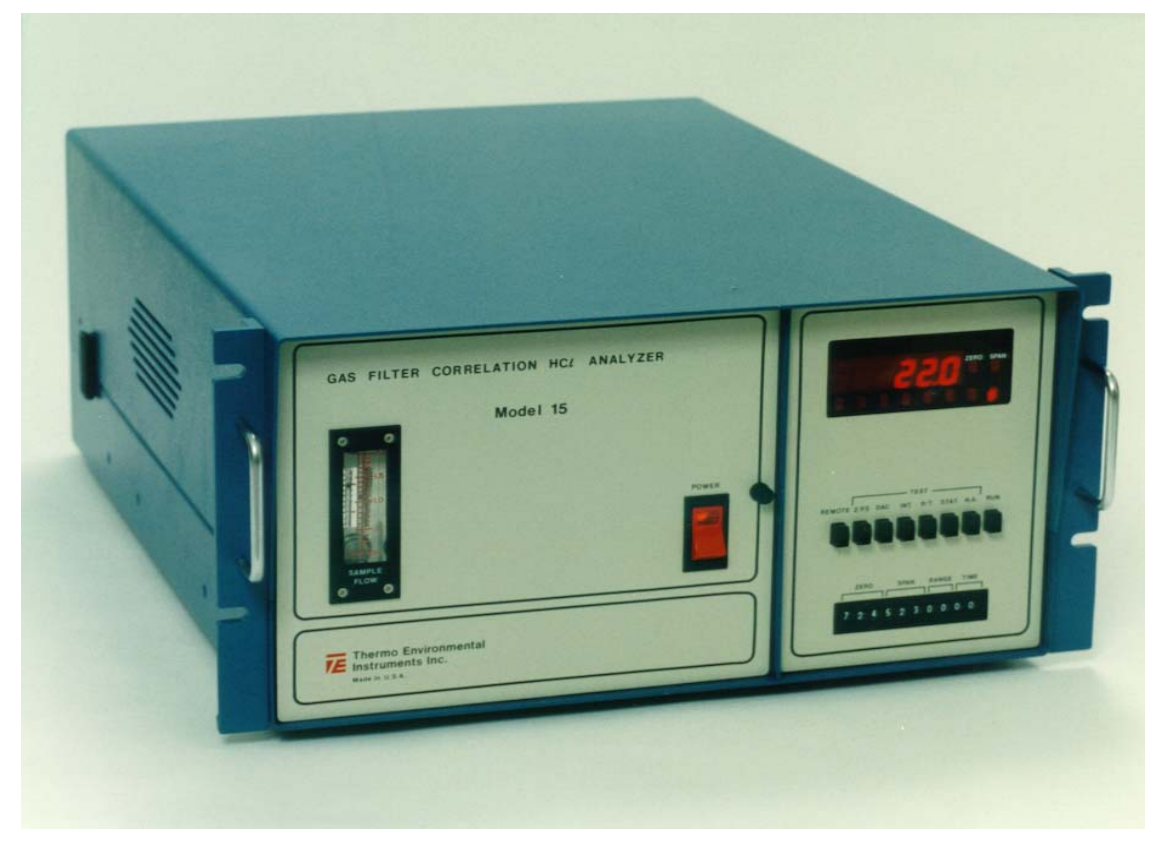


Figure 21. Thermo Environmental Instruments Model 15 GFCIR HCl Analyzer.

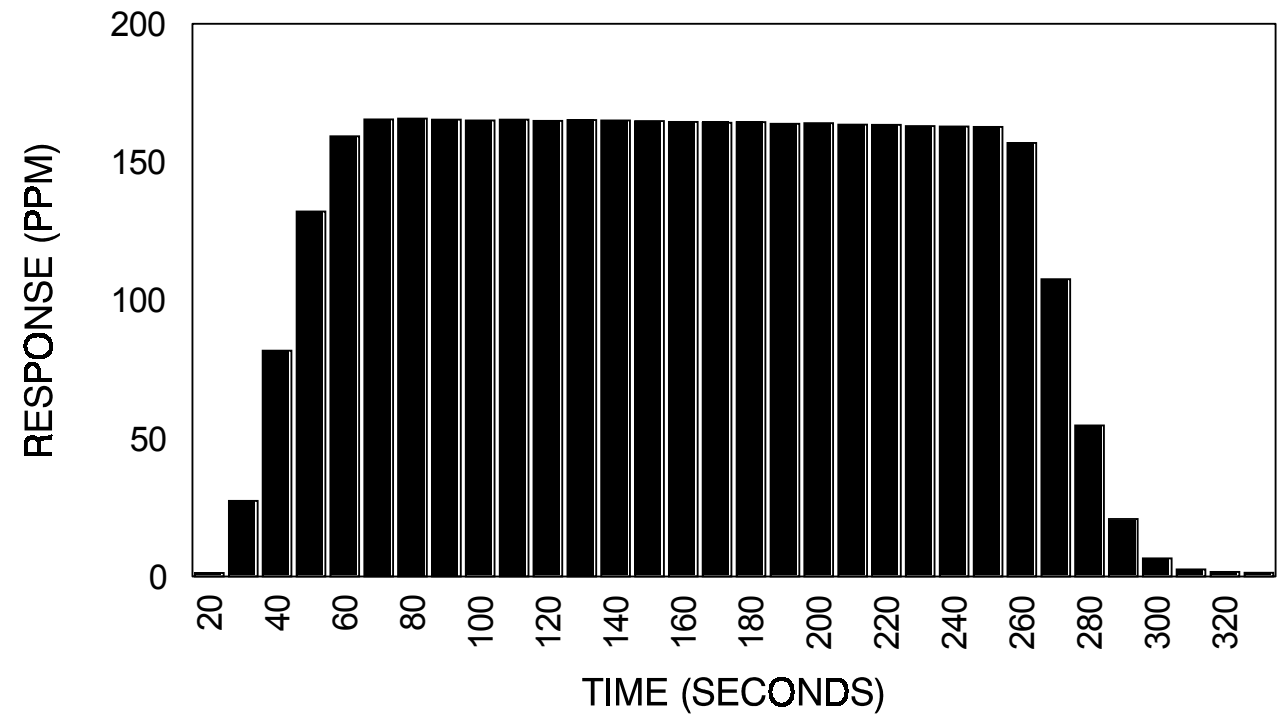

Figure 22. GFCIR Signal Observed for a 170 ppm HCl Stream.

Calibration curves were obtained by blending compressed gases containing $3000 \mathrm{ppm} \mathrm{HCl}$ with nitrogen to obtain the desired $\mathrm{HCl}$ concentrations. High concentrations of $\mathrm{HCl}$ were used to get a better feel for the dynamic range of the detector. The calibration curves were linear from 25-3000 $\mathrm{ppm}_{\mathrm{v}} \mathrm{HCl}$. In the range of 0 to $150 \mathrm{ppm} \mathrm{HCl}$ (see Figure 23), erratic responses were noted at concentrations below $25 \mathrm{ppm}$, but were fairly linear above that. The erratic responses observed for low $\mathrm{HCl}$ concentrations could be due to uncertainties in blending the calibration gases or to memory effects from $\mathrm{HCl}$ sorption/desorption with sample line walls. $\mathrm{HCl}$ permeation tubes containing aqueous $\mathrm{HCl}$ solutions (from VICI Metronics) were then used to provide gas stream concentrations of 0.2 to $2 \mathrm{ppm}_{\mathrm{v}} \mathrm{HCl}$. As shown in Figure 24, the instrument response showed good linearity from about 0.5 to $2 \mathrm{ppm}$. Long equilibration times and pronounced memory effects were noted when passing low concentrations of $\mathrm{HCl}$ through the sample lines (both Teflon and steel) and flow meters. This could explain why many users of GFCIR for $\mathrm{HCl}$ have reported problems in differentiating between different $\mathrm{HCl}$ concentrations below $10 \mathrm{ppm}$. In other words, those problems may be related more to sample transport issues than to instrumental issues.

Tests were also performed to study the severity of the known interference from $\mathrm{CH}_{4}$. For those experiments, $\mathrm{CH}_{4}$ was blended with a stream of $\mathrm{N}_{2}$ containing $100 \mathrm{ppm} \mathrm{HCl}$. The $\mathrm{CH}_{4}$ concentration in the gas stream was varied from 0 to $12 \%$ and the increase in the instrument reading (in ppm) was recorded for each $\mathrm{CH}_{4}$ concentration tested. Results of those tests are shown in Figure 25. From the ratio of $\mathrm{CH}_{4}$ concentration to the resulting increase in the instrument reading, it was calculated that $300-400 \mathrm{ppm} \mathrm{CH}_{4}$ gives a response equivalent to about 
$1 \mathrm{ppm} \mathrm{HCl}$. This has important implications regarding the use of this instrument for monitoring gasifier streams. Since $\mathrm{CH}_{4}$ concentrations can be as high as $15 \%$ in coal gasification effluents, the potential error in the $\mathrm{HCl}$ reading from $\mathrm{CH}_{4}$ is on the order of $400 \mathrm{ppm}$ if all the $\mathrm{CH}_{4}$ remains in the gas stream. Consequently, depending on the relative concentrations of $\mathrm{CH}_{4}$ and $\mathrm{HCl}$ in the gasifier effluent, $75 \%$ to nearly $100 \%$ of the $\mathrm{CH}_{4}$ will need to be removed prior to $\mathrm{HCl}$ determinations using this GFCIR instrument. However, since the intention is to use gas stream oxidation, the $\mathrm{CH}_{4}$ would not be an issue in that event since all of the $\mathrm{CH}_{4}$ should be quantitatively removed prior to $\mathrm{HCl}$ analysis.

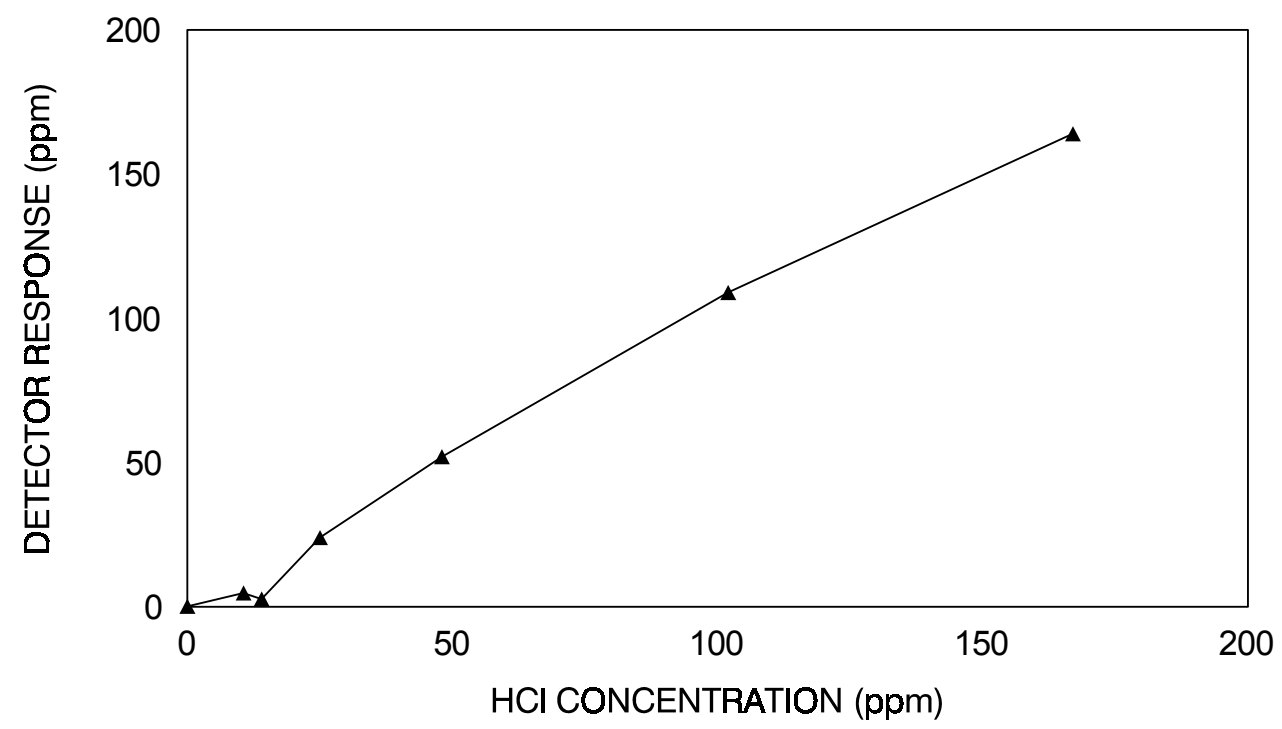

Figure 23. GFCIR Calibration Curve Obtained for $\mathrm{HCl}$ Concentrations of 0 to $150 \mathrm{ppm}$.

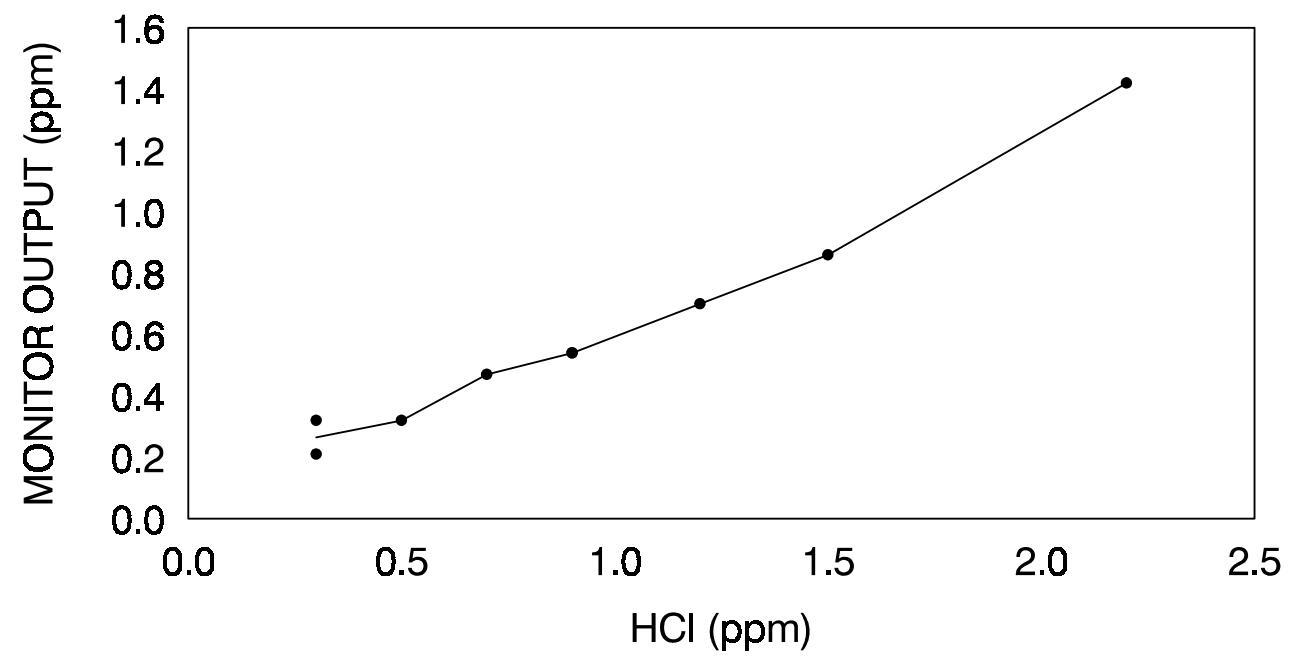


Figure 24. Calibration Curve Obtained Using Permeation Tubes to Provide Low HCl Concentrations.

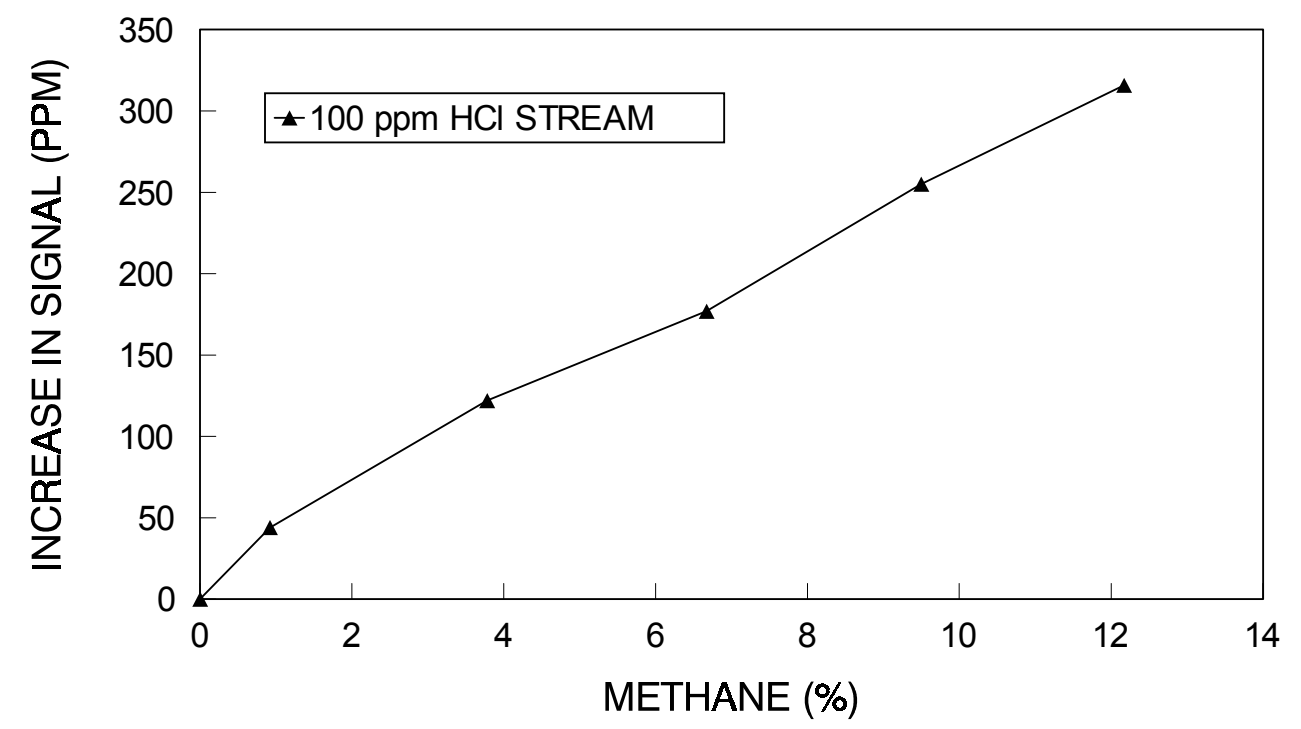

Figure 25. Effects of Methane on GFCIR Signal.

Humidity significantly affected results. When the humidity of the gas stream increased (not quantified), the reading observed for a $100 \mathrm{ppm} \mathrm{HCl}$ stream increased by $50 \%$, but returned to its original value after several minutes. These data reflect "flushing" effects due to the added moisture. In view of these results, it is apparent that a consistent humidity level should ideally be delivered to the detector. If the humidity level is fluctuating, equilibration times may not be adequate to provide accurate $\mathrm{HCl}$ analyses for the gas stream.

Potential interferences from butane and butene were also examined to ascertain whether hydrocarbons other than $\mathrm{CH}_{4}$ could result in analytical errors. For these tests, 5-mL volumes of each gas were injected into a stream of $\mathrm{N}_{2}$ carrier gas with and without $3000 \mathrm{ppm} \mathrm{HCl}$ present. When butane and butene were injected into $\mathrm{N}_{2}$ in the absence of $\mathrm{HCl}$, positive instrument responses equivalent to $10-30 \mathrm{ppm} \mathrm{HCl}$ were noted, but negative responses (decreases of $10 \%$ ) were noted when $\mathrm{HCl}$ was present. This suggests that chemical interactions may be occurring between the hydrocarbon gases and the $\mathrm{HCl}$, although these test results would require analytical verification. Thus, definitive conclusions regarding potential interferences from hydrocarbon gases other than $\mathrm{CH}_{4}$ can not be made from these data.

\section{COLORIMETRIC METHOD}


An analyzer using the MDA Scientific (now sold as a Zellweger Analytics analyzer) colorimetric "dot" method was tested previously in the field (MSW incinerator) by other researchers. Accuracy problems were encountered, which were thought to be due to different levels of humidity between sample and calibration gases. Technical experts with MDA Scientific informed us that the relative humidity (RH) of the gas delivered to the analyzer needs to be within the proper range for optimum operation. They believed that their instrument would work for our application and that sample delivery would be the most difficult part. In view of this, we decided to evaluate an MDA Scientific Model 7100 Toxic Gas Monitor (see Figure 26) in our laboratories.

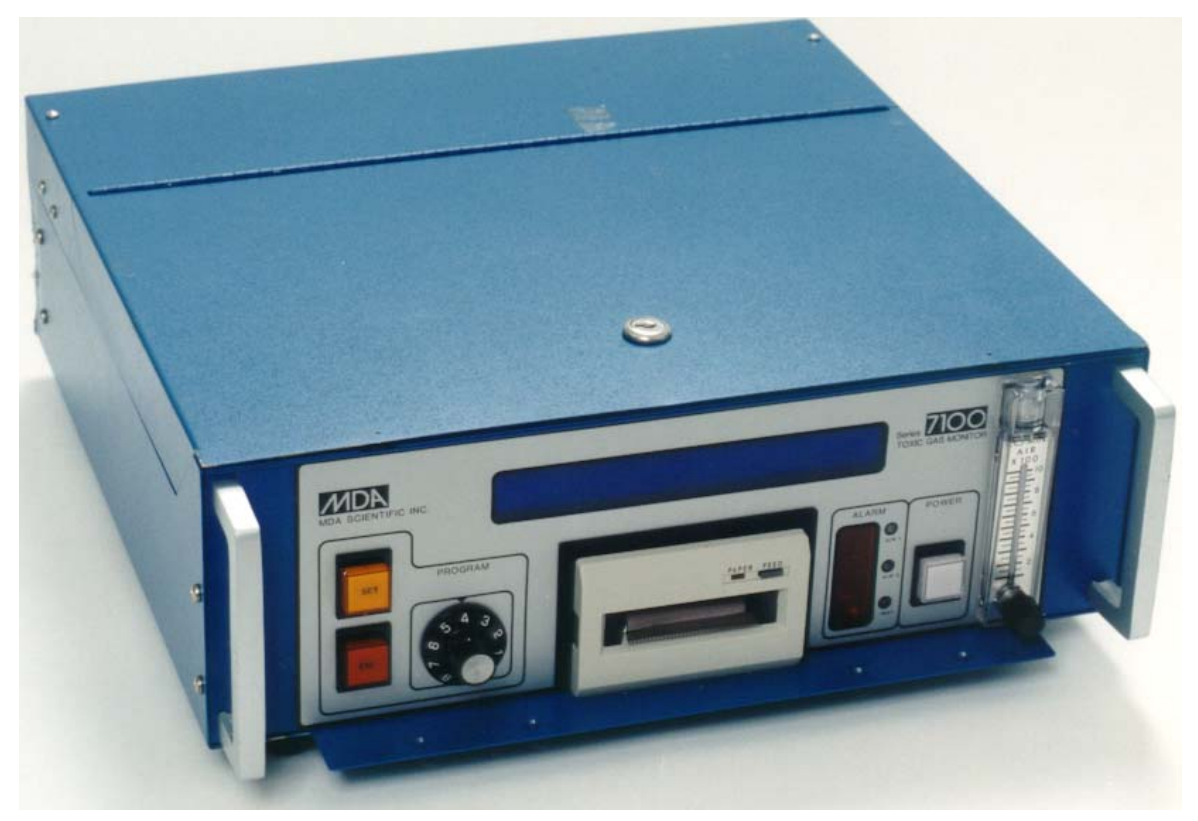

Figure 26. MDA Colorimetric Analyzer for $\mathrm{HCl}$.

The instrument is based on exposing a strip of color-indicating paper to a metered sample stream. Any $\mathrm{HCl}$ in the sample gas reacts with the paper to form a colored, circular (i.e., "dot") stain. The intensity of the stain is proportional to the $\mathrm{HCl}$ concentration and is quantified by using a photocell to detect the amount of reflected light from the dot. The color-indicating paper is in the form of a continuous strip and is mounted in a cassette cartridge, which is referred to as a chemcassette. This allows the monitor to provide continuous analysis of a gas stream. The standard chemcassette determines $\mathrm{HCl}$ in the range of about $0.2-50 \mathrm{ppm}_{\mathrm{v}}$. In addition, a lowlevel chemcassette is available for determining $\mathrm{HCl}$ down to about $50 \mathrm{ppb}_{\mathrm{v}}$. The low-level chemcassette employs different reaction chemistry than the standard chemcassette. Our tests were performed using both the standard and low-level tapes. A one-minute sampling period is used with the standard chemcassette, while a ten-minute sampling period is generally required for low-level $\mathrm{HCl}$ (sampling periods are factory set). 
The sample gas temperature at the detector inlet must be at or below $40^{\circ} \mathrm{C}$. Also, the manufacturer recommends humidifying the sample stream to about $25-75 \%$ relative humidity (RH) at ambient temperature. Significant errors can result if the RH is outside of this range. If dry gases are to be used, a special low-RH calibration should be performed. The instrument manufacturer reports that $\mathrm{HCN}$ and HF are possible interferences, but little information was available on the magnitude of those interferences. Both of those gases are expected to be present in coal gasifier streams. Consequently, the HF interference was investigated by using anhydrous HF from a permeation tube with room air as the carrier gas. The HCN interference was studied by using a compressed gas cylinder containing $1 \% \mathrm{HCN}$ in a nitrogen balance. Compressed gas cylinders containing $\mathrm{HCl}$ in a nitrogen balance were used for the tests with the standard chemcassette, while permeation tubes containing aqueous $\mathrm{HCl}$ were used for the tests with the low-level chemcassette. Results obtained with the standard and low-level $\mathrm{HCl}$ chemcassettes are discussed separately below. The relative standard deviations (RSDs) for all tests were typically $\pm 5 \%$ or less for a given set of conditions.

\section{STANDARD CHEMCASSETTE}

A calibration curve in the range of 0 to $25 \mathrm{ppm}_{\mathrm{v}}$ was obtained by blending $100 \mathrm{ppm} \mathrm{HCl}$ (in a nitrogen balance) with air and passing the blended gases into the analyzer. These results are shown in Figure 27. The measured detection limit for the standard chemcassette was several tenths of a ppm and the calibration curve was generally linear down to several ppm. At lower concentrations, the nonlinearity may be a result of dilution errors in the gas stream. When 25 ppm $\mathrm{HCl}$ in $\mathrm{N}_{2}$ was sent to the detector, results were about $50 \%$ higher when the gas stream was humidified. Although it was known that results could be affected by the relative humidity of the gas stream, these results demonstrate that the effects of humidity can be substantial.

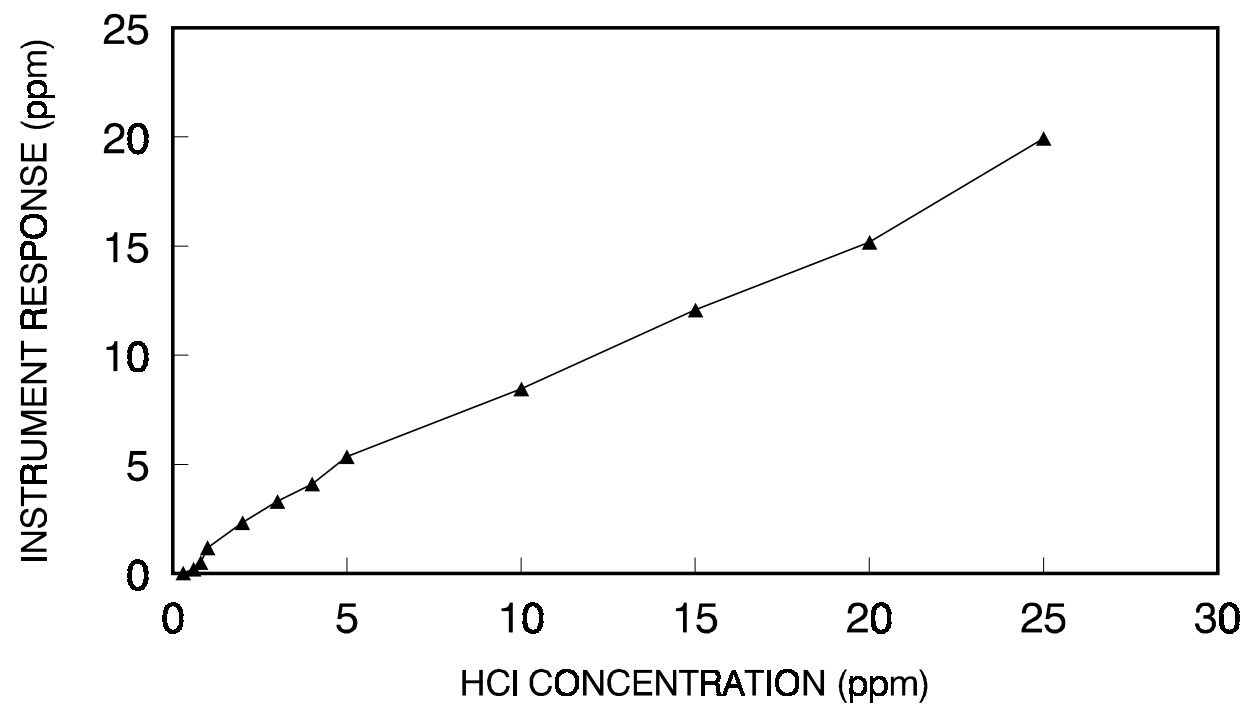

Figure 27. Calibration Curve Obtained with the Colorimetric Analyzer While Using Blended Gases. 
When $15 \mathrm{ppm}$ dry $\mathrm{HF}$ in air was sent to the $\mathrm{HCl}$ analyzer in the absence of $\mathrm{HCl}$, a reading corresponding to about $0.5 \mathrm{ppm} \mathrm{HCl}$ was obtained. For tests with $\mathrm{HF}$ in the presence of $\mathrm{HCl}$, the presence of $15 \mathrm{ppm}$ HF (the anticipated maximum concentration in coal gasification effluents) in a $1 \mathrm{ppm} \mathrm{HCl}$ stream had a negligible effect on the reported $\mathrm{HCl}$ concentration. When 100 to 2000 ppm $\mathrm{HCN}$ was sent to the analyzer in the absence of $\mathrm{HCl}$, a small positive response on the analyzer was noted. As the HCN concentration was varied, the ratio of the HCN concentration to the instrument response was fairly constant, with $1000 \mathrm{ppm} \mathrm{HCN}$ giving a reading corresponding to about $1 \mathrm{ppm} \mathrm{HCl}$. Results of the tests with $\mathrm{HCN}$ alone are shown in Figure 28. In gas streams containing $10 \mathrm{ppm} \mathrm{HCl}$, the $\mathrm{HCl}$ signal was not significantly affected by the presence of 150 ppm HCN. Based on these tests, it does not appear that HF or HCN will cause significant interferences for $\mathrm{HCl}$ determinations with the standard $\mathrm{HCl}$ tape.

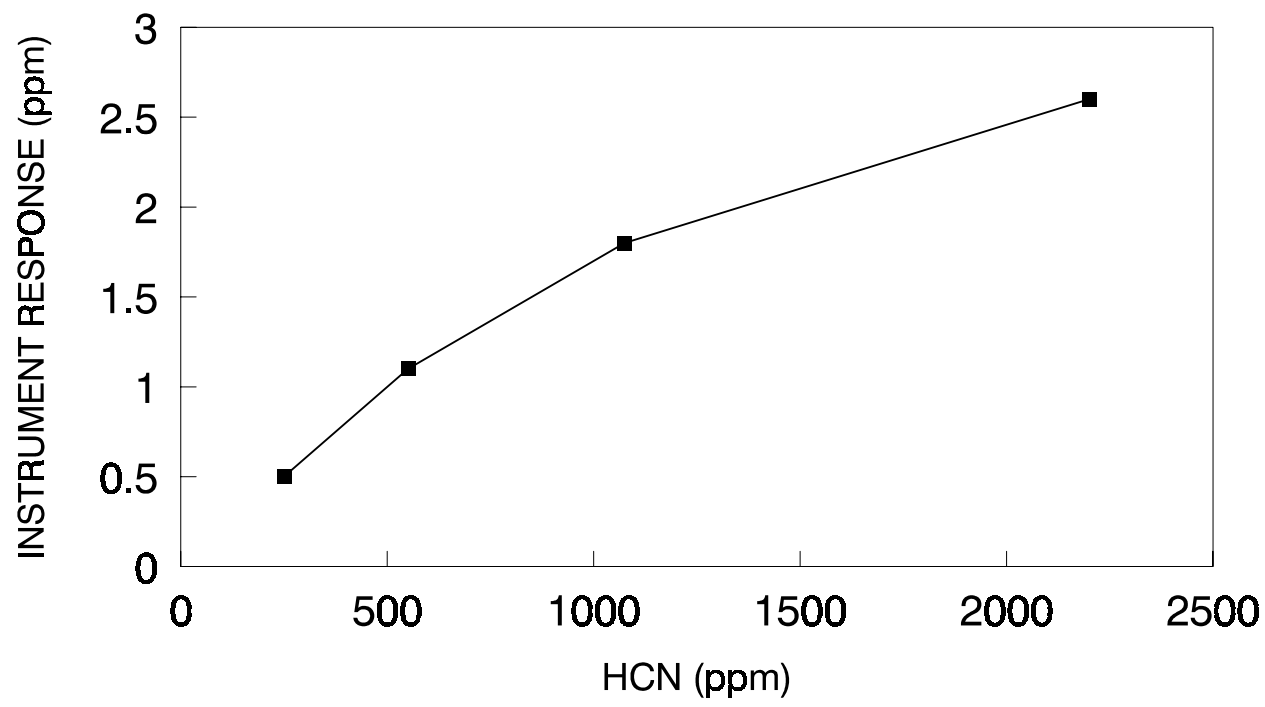

Figure 28. Results of HCN Tests with the Standard Chemcassette.

\section{LOW LEVEL CHEMCASSETTE}

For the tests with the low-level chemcassette, the $\mathrm{HCl}$ streams were produced using aqueous $\mathrm{HCl}$ permeation tubes in a VICI Metronics Model 340 Dynacalibrator. Based on calibration curves obtained when using the permeation tubes, the measured detection limit was about $50 \mathrm{ppb} \mathrm{HCl}$. As the $\mathrm{HCl}$ concentration was decreased from 400 to $75 \mathrm{ppb}$, good linearity in the calibration curve was obtained, as shown in Figure 29. However, as the $\mathrm{HCl}$ concentration decreased further, some anomalous readings indicative of desorption wall effects were observed. The permeation tube was removed from the permeation chamber $\left(\right.$ at $\left.100^{\circ} \mathrm{C}\right)$ in the Dynacalibrator, but significant $\mathrm{HCl}$ concentrations were still reported by the analyzer for more than two days when air passing through the empty permeation chamber was sent to the analyzer (see Figure 30). When the calibrator was set to send zero air to the $\mathrm{HCl}$ analyzer, the analyzer consistently reported "0 ppb". Since the gases from the calibrator passed through 
common sample lines in each case, and since the gas flow rate through the sample line was the same for each set of tests, the memory effects appear to be within the calibrator rather than in the analyzer or sample transport lines. After waiting until no $\mathrm{HCl}$ was being emitted from the empty calibrator during a constant gas purge, an $\mathrm{HCl}$ permeation tube was put back in and a calibration curve was obtained by increasing the $\mathrm{HCl}$ concentration $(\mathrm{HCl}$ concentration was decreased in the initial tests). Because of pronounced adsorption/desorption effects, the slopes and "x-axis" intercepts for the two calibration curves (one each from increasing and decreasing the $\mathrm{HCl}$ concentration) were much different. Those results are shown in Figure 31. This has important implications regarding field monitoring and calibration of analytical instruments, since wall effects can result in lengthy equilibration times (e.g., 24 hours or more).

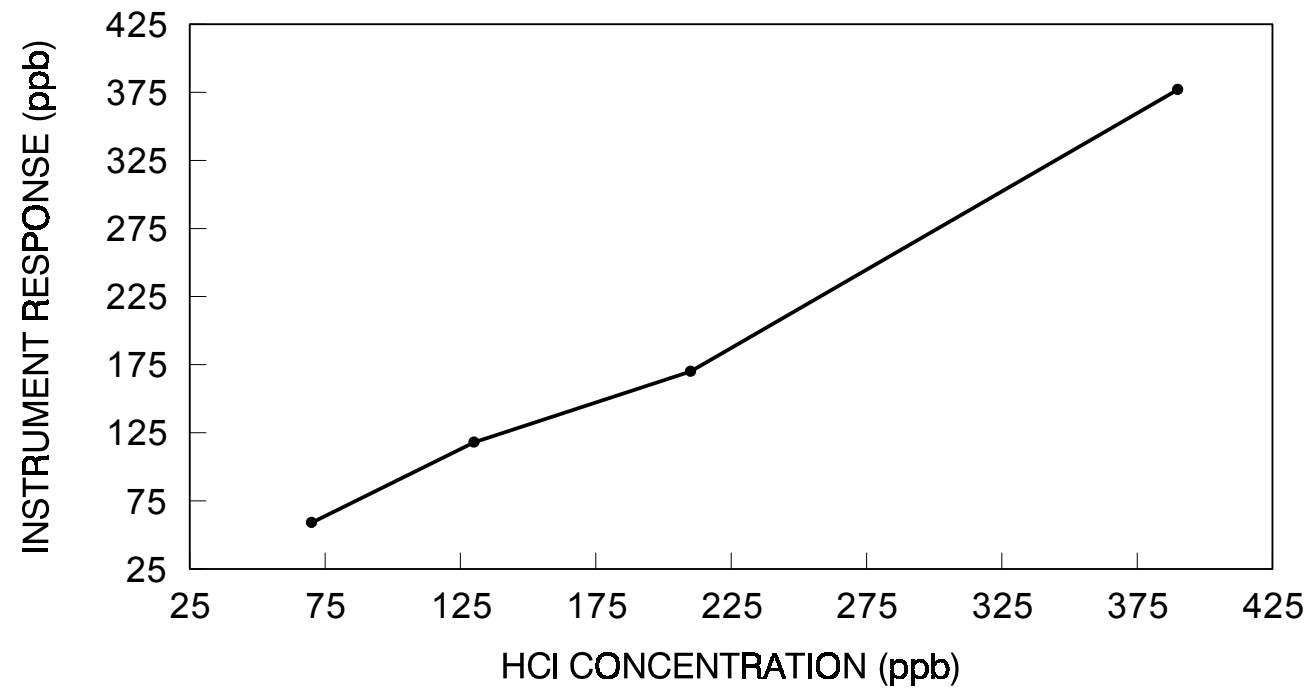

Figure 29. Calibration Curve Obtained with the Low-Level Chemcassette While Using HCl Permeation Tubes. 


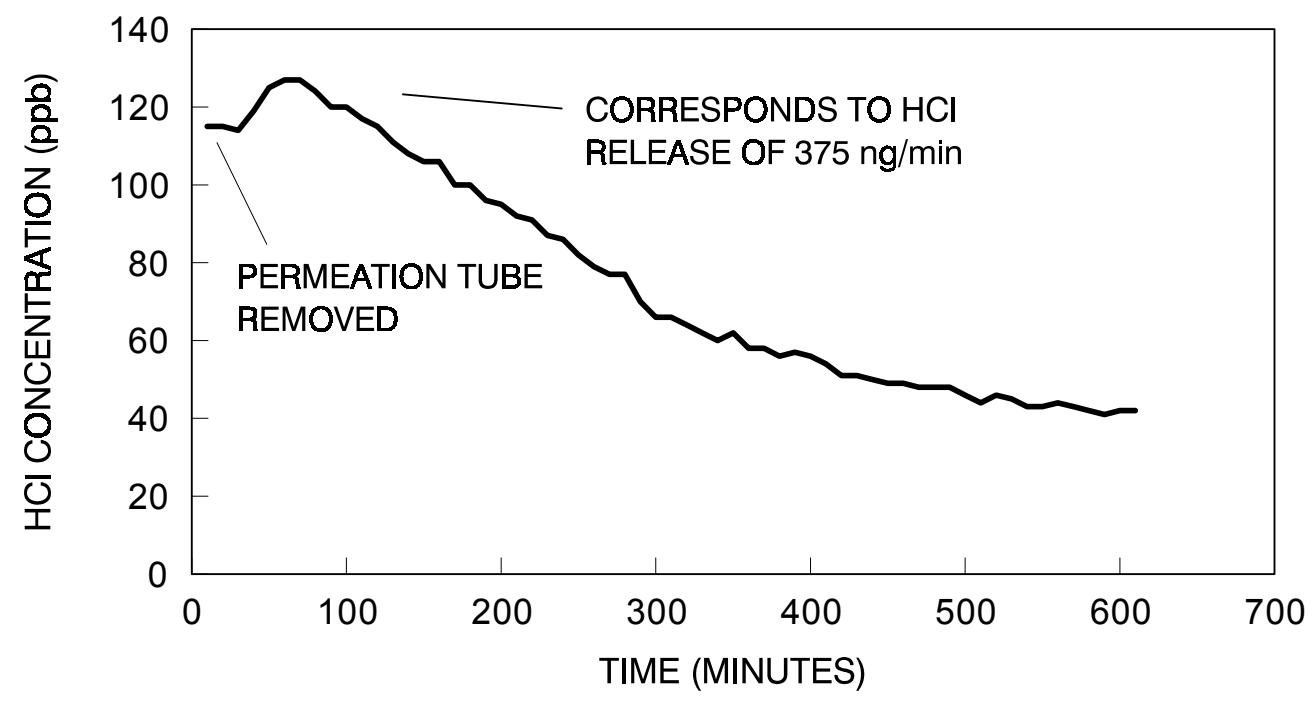

Figure 30. Apparent Memory Effects with the VICI Dynacalibrator.

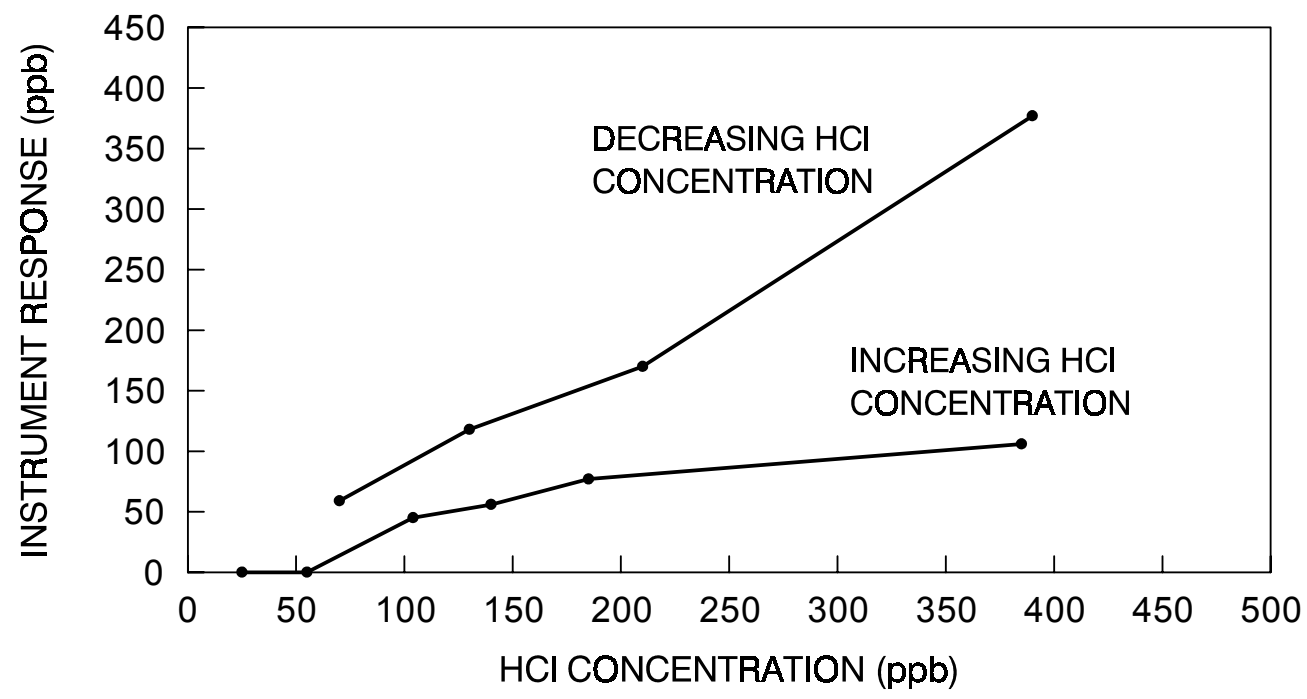

Figure 31. Calibration Curves Obtained with the Low-Level Chemcassette when Increasing and Decreasing the $\mathrm{HCl}$ Concentration.

Humidification of the nitrogen stream containing $\mathrm{HCl}$ had a more pronounced effect on the $\mathrm{HCl}$ reading when using the low-level chemcassette as opposed to the standard chemcassette. However, this is not necessarily due to differences in tape chemistry between the two chemcassettes. The humidity may have provided a "flushing" effect which minimized $\mathrm{HCl}$ sorption onto the sample lines. Such a flushing effect could be much more prominent (greater percent change in concentration reading) at the relatively low $\mathrm{HCl}$ concentrations used with the low-level chemcassettes. 
HF was a more prominent interference when using the low-level chemcassette. When the gas stream entering the analyzer contained only $1000 \mathrm{ppb}$ of $\mathrm{HF}$ (i.e., no $\mathrm{HCl}$ ), an $\mathrm{HCl}$ reading of roughly $130 \mathrm{ppb}$ was obtained. Thus, $15 \mathrm{ppm} \mathrm{HF}$ (the anticipated maximum concentration in gasifier streams) could cause a signal equivalent to that produced from several ppm $\mathrm{HCl}$. The $\mathrm{HF}$ interference should be negligible if the $\mathrm{HCl}$ concentration is significantly greater than the $\mathrm{HF}$ concentration. However, if the $\mathrm{HCl}$ concentrations are $1 \mathrm{ppm}$ or greater, if would be preferable to use the standard chemcassette since HF interferences with that chemcassette appear to be less prominent.

When $2800 \mathrm{ppm} \mathrm{HCN}$ was introduced to the analyzer in the absence of $\mathrm{HCl}$, a signal equivalent to only $100 \mathrm{ppb} \mathrm{HCl}$ was obtained, indicating that $\mathrm{HCN}$ is not a significant interference with the low-level chemcassette in low-humidity gases. When the tests were repeated in the presence of $150 \mathrm{ppb} \mathrm{HCl}$, the $\mathrm{HCN}$ again had little effect on the $\mathrm{HCl}$ reading.

\section{DISCUSSION}

By simply replacing a chemcassette, the colorimetric analyzer can be used to monitor other individual gas species of interest. Another potential advantage to the colorimetric monitor is the smaller amount of internal surface area, which could in turn reduce adsorption/desorption phenomena that can lead to memory effects. Disadvantages of the colorimetric monitor include the sensitivity of the technique to the relative humidity of the sample gases, the need for different chemcassettes employing different chemistry for different ranges of $\mathrm{HCl}$ concentrations, and possible complications regarding color formation in the complex gas matrices of a coal gasifier. If $\mathrm{CH}_{4}$ can be effectively removed from sample gases without affecting $\mathrm{HCl}$ concentrations, using the colorimetric monitor with the standard chemcassette does not appear to offer any significant advantages over the GFCIR unit that was investigated. Although the low-level chemcassette can detect lower levels of $\mathrm{HCl}$ than GFCIR, our results suggest that data should be viewed with caution when using that chemcassette in complex gas matrices. In view of these considerations, the dry colorimetric analyzer will not be employed for on-line analysis of coal gasifier streams.

\section{ION MOBILITY SPECTROSCOPY}

\section{OVERVIEW OF TECHNOLOGY}

Because ion mobility spectroscopy (IMS) was ultimately selected as the method of choice for monitoring $\mathrm{HCl}$ in coal gasifier streams, it is appropriate at this point to provide a brief overview of the IMS technology. IMS is an atmospheric, time-of-flight monitoring system. Although the IMS technology has existed for several decades, it is still considered by many to be in its infancy. Until the 1980s, work with IMS focused on fundamental studies rather than on specific applications (16). In recent years, the utility of IMS has been demonstrated in numerous practical applications, including monitoring environmental pollutants, measurement of trace 
contaminants in products from various manufacturing processes (including monitoring $\mathrm{HF}$ at oil refineries), and detection of drugs and explosives (16-18).

Advantages of IMS include minimal zero drift, high sensitivity, little sensitivity to relative humidity, few occurrences of false positives, and real time monitoring capability. Disadvantages include sensitivity to changes in temperature and pressure of the sample gas, matrix dependency, and narrow dynamic range (about 200). The issue of matrix dependency is addressed by using large gas stream dilutions, thereby providing a relatively consistent matrix. Additional areas to be careful of include overloading the IMS with analyte. Overloading can result in the disappearance of reactant ion peaks, the appearance of multiple analyte peaks, and peaks that persist for unusually long times. If severe overloading occurs, it can take several days to purge out the cell.

For $\mathrm{HCl}$, there are not anticipated to be any spectral interferences with the gas matrix for coal gasification streams. However, personnel with Molecular Analytics (the vendor for our IMS system) noted that ion clustering can occur in IMS, and that different chemical species can give byproduct ion clusters in the same spectral region, even if the masses of the original species are much different than that of $\mathrm{HCl}$. Also, $\mathrm{N}_{2} \mathrm{O}$ is a known problem due to its large electron affinity. However, it should not be present in gasifier streams. For applications where $\mathrm{N}_{2} \mathrm{O}$ may be present, Molecular Analytics has a preconditioner to reduce $\mathrm{N}_{2} \mathrm{O}$ to NO.

In the IMS technology, a porous membrane is used to provide some selectivity, filter particles, and reduce humidity effects (19). The membrane also restricts the amount of analyte that reaches the detector, and different porous membranes can be used to alter the analytical range of the analyzer. The compounds of interest pass through the membrane and are picked up by the carrier gas and transported to the reaction region of the IMS cell. In that region of the cell, the gases are ionized using beta particles from a suitable radiation source. Although ion formation has been accomplished by a variety of techniques, radioactive $\mathrm{Ni}^{63}$ foil is the most common ionization source (16). The detector requires a small amount of $\mathrm{O}_{2}$ (about $1 \%$ ) in order to properly ionize the analyte species. An electric field is used to attract the ions to a shutter, which opens and closes periodically to allow the ions to enter the "drift" portion of the cell. In the presence of a constant electric field, the ions drift down the tube and are separated because of differences in the size, shape, and mass of the individual ions. Drift time also depends on the electric field strength, length of the drift tube, temperature, and pressure (18). Because the time of transport is related to mass, the drift time in the tube is ion specific and therefore allows specific gaseous species of interest to be identified. The concentration of a specific ion is proportional to the height of the peak from the detector. A continuous flow of air or nitrogen at ambient pressure is usually used as the drift gas to sweep through the tube. IMS also requires a dopant gas to aid in the rejection of interferences, improve analyte ionization, improve sensitivity, and provide greater separation between the product and reactant ions $(16,20)$.

An air driven sampling probe using an eductor is usually used because sampling typically occurs at atmospheric pressure. Thus, the sample is diluted with dry air, which reduces the dew point of water in the sample stream to near or below room temperature. By using large dilutions with air or nitrogen, matrix effects can largely be avoided since the matrix will then be the gas used as a dilution stream. Without this dilution, matrix-specific calibrations would be required. 
Because of the extremely high sensitivity of IMS, a 100:1 dilution of a gasifier stream could theoretically still be used even with an initial (undiluted) $\mathrm{HCl}$ concentration of $10 \mathrm{ppm}$ or less.

\section{LABORATORY EVALUATIONS}

\section{$\underline{\text { Response to } \mathrm{HCl}}$}

We received a Model 20-HCl Stack Master IMS Analyzer (see Figure 32) on loan from Molecular Analytics for our evaluation. By changing a membrane in the analyzer, an analytical range of either 1-20 ppm or 1-200 ppb can be selected. For the initial tests, compressed gases were used to examine general instrument response and the linearity of calibration curves. Air was blended with a $100 \mathrm{ppm} \mathrm{HCl}$ gas stream (in a nitrogen balance) to give $\mathrm{HCl}$ concentrations ranging from 1 to $25 \mathrm{ppm}$. When the $\mathrm{HCl}$ flow was first sent to the detector, it took about 20 minutes for the $\mathrm{HCl}$ to equilibrate with the sample transport lines and portions of the IMS system. However, after this initial equilibration period, the unit responded rapidly (within 60 seconds) to changes in $\mathrm{HCl}$ concentration. The detector gave a linear response for $\mathrm{HCl}$ concentrations ranging from 1 to $25 \mathrm{ppm}$, as shown in Figure 33. The discrepancy between the $\mathrm{HCl}$ reading on the instrument and the nominal $\mathrm{HCl}$ concentrations may reflect gas metering uncertainties or calibration issues.

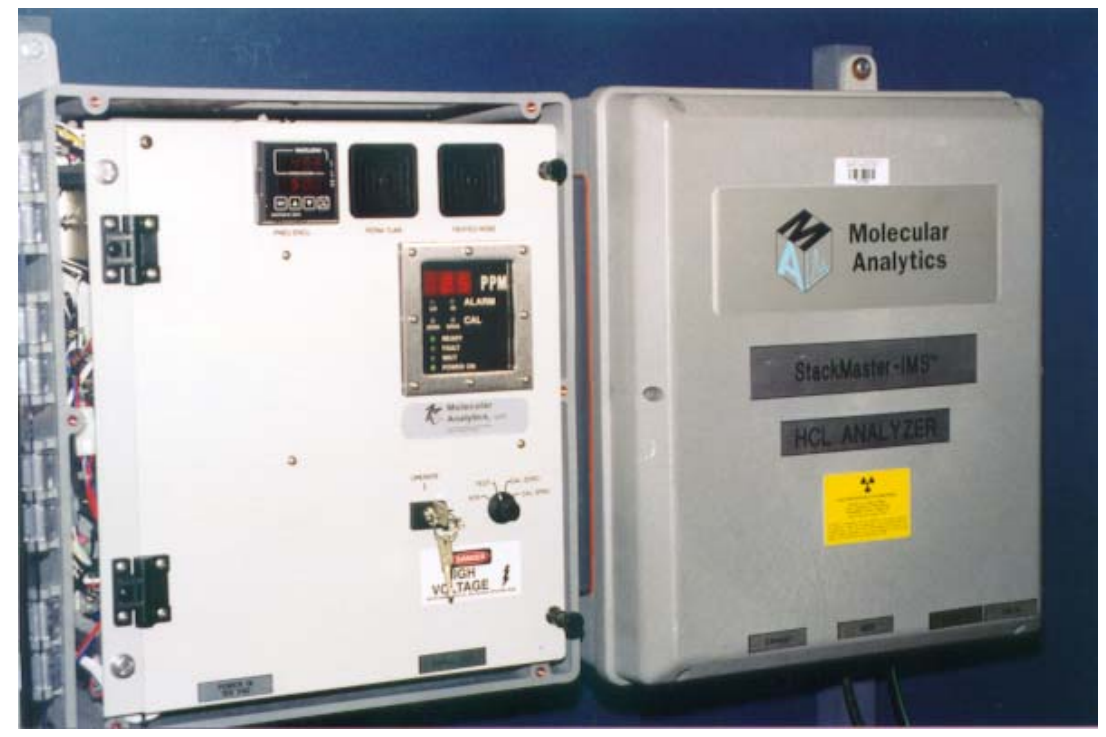

Figure 32. Ion Mobility Spectrometer for Monitoring $\mathrm{HCl}$. 


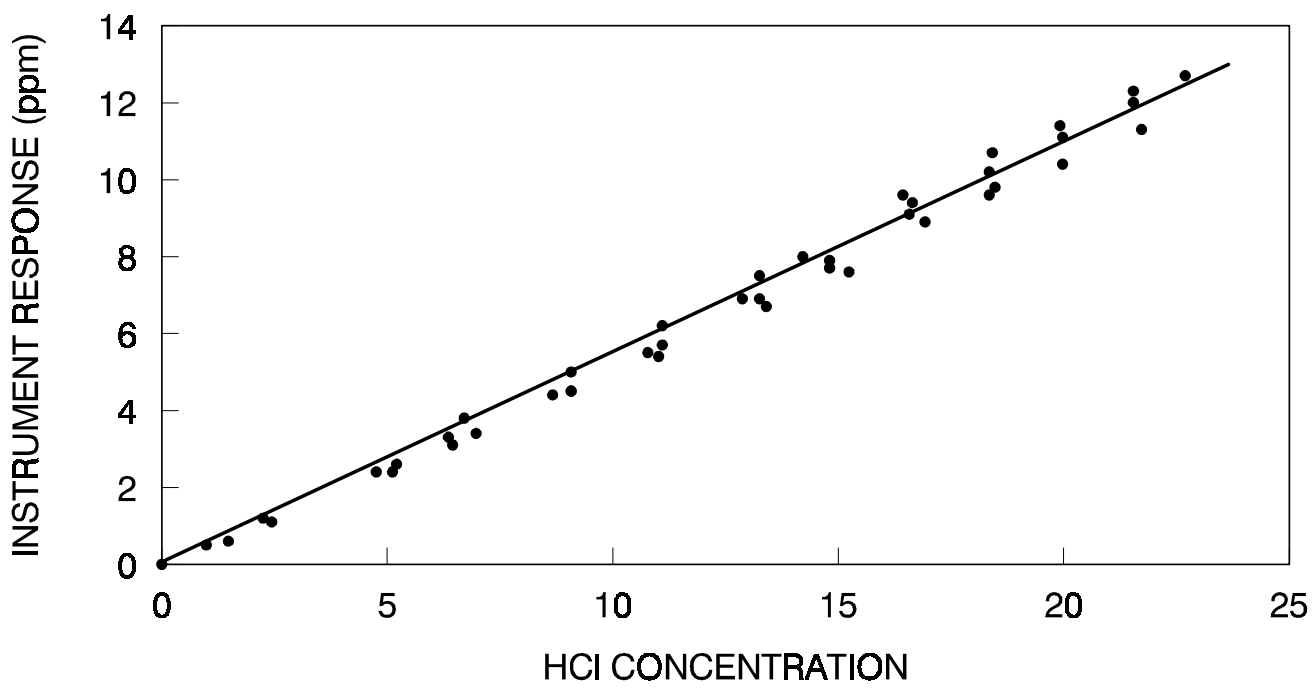

Figure 33. Calibration Curve Obtained for IMS Unit While Using Blended Gases.

After changing the membrane in the analyzer, studies were performed using an $\mathrm{HCl}$ permeation tube to assess instrument response in the 1-200 ppb range. The same permeation tube was used for all the tests, and the $\mathrm{HCl}$ concentration was adjusted to the desired level by either changing the tube temperature or the flow rate of the dilution air in the calibrator. The flow rate of the calibration gases ranged from 0.6 to $4.8 \mathrm{~L} / \mathrm{min}$. Prior to each reading, at least 2 hours were allowed for system equilibration. A detection limit of less than 5 ppb was observed in these tests. A typical calibration curve for $\mathrm{HCl}$ levels less than $50 \mathrm{ppb}$ is shown in Figure 34. An excellent calibration curve was obtained. The small amount of data scatter (deviation from linearity) that was observed is believed to be largely from variations in equilibration times.

Considerable memory effects were observed when using ppb levels of $\mathrm{HCl}$, which is one of the reasons why long equilibration times were used. The time necessary to reach equilibrium when switching from zero air to span gases (where $\mathrm{HCl}$ adsorption onto walls is occurring) was comparable to the time necessary for equilibration when switching from span gas to zero air (where $\mathrm{HCl}$ desorption from walls is occurring). Depending on the level of $\mathrm{HCl}$ present in the gas stream, it took 30 to 90 minutes to reach $90 \%$ of the final signal. However, the long equilibration times are believed to be largely due to the permeation tube calibrator (see page 71) and/or the connecting lines rather than due to the analyzer itself. Typical signal profiles when switching from zero air to span gas and then back to zero air again are shown in Figure 35. 


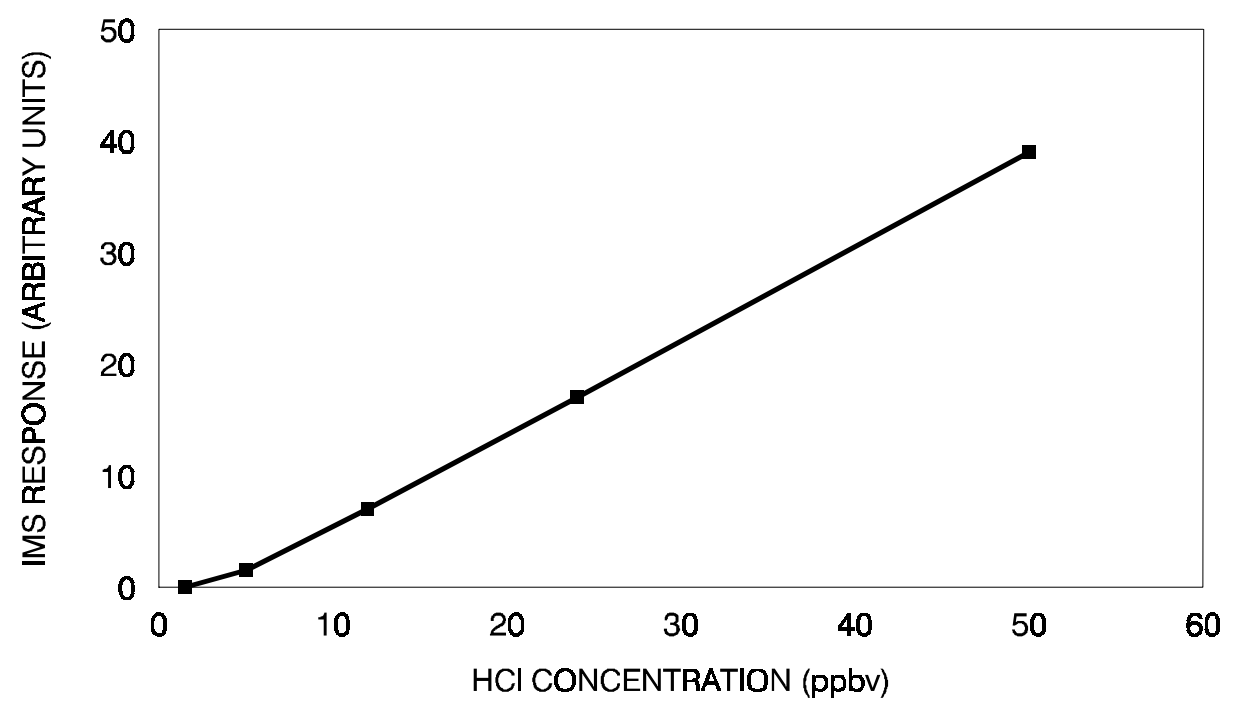

Figure 34. Calibration Curve Obtained Using Permeation Tubes with the IMS Analyzer.

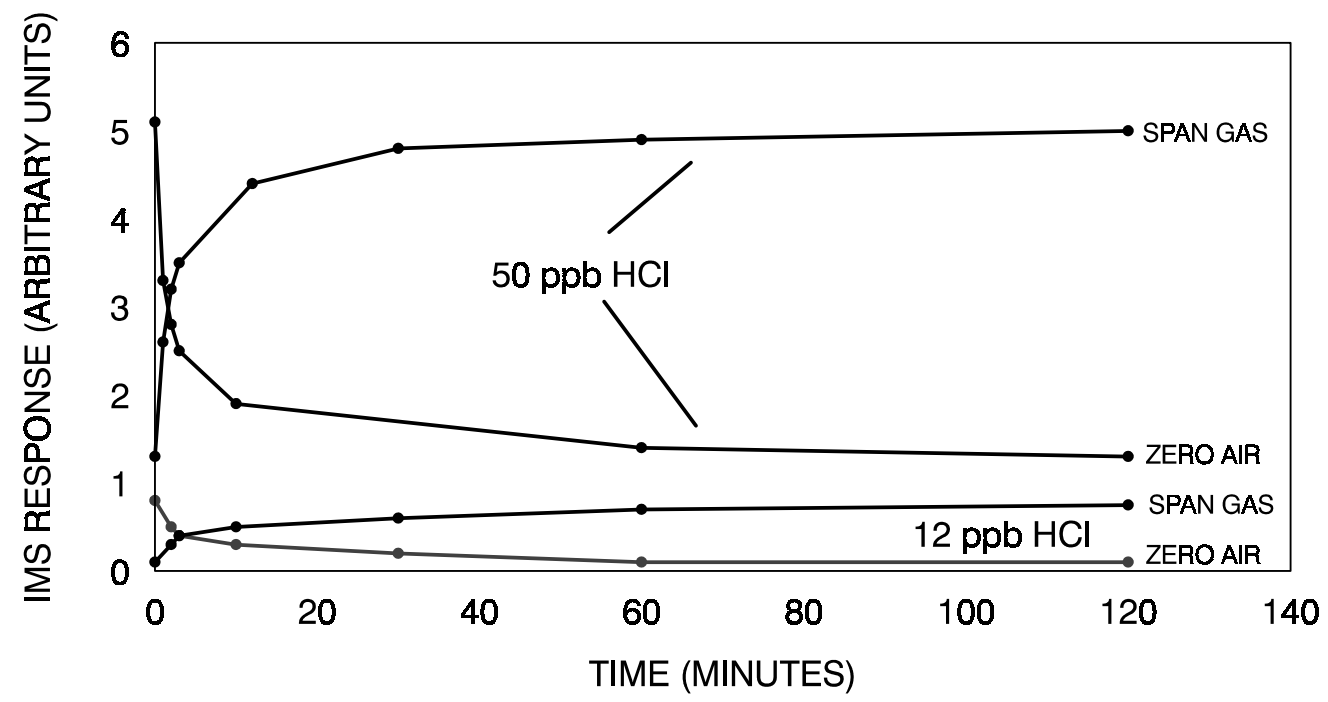

Figure 35. Signal Responses Vs. Time for 12 and $50 \mathrm{ppb} \mathrm{HCl} \mathrm{Streams.}$

\section{$\underline{\text { Response to Other Gases }}$}

The effects of moisture and other gases on the response of the IMS unit were investigated with the analyzer operating in the 1-20 ppm range. The relative humidity of the gases appeared to affect the IMS reading, but is likely due to the humidity altering wall effects (sorption of $\mathrm{HCl}$ ), which in turn affects the analyte concentration in the gas stream. Introducing $\mathrm{HCN}$ and $\mathrm{H}_{2} \mathrm{~S}$ increased the analyzer reading slightly, but those gases will probably not be present at high enough concentrations in real gasifier streams to appreciably affect the $\mathrm{HCl}$ signal. 
The presence of $\mathrm{HF}$ also appeared to affect the $\mathrm{HCl}$ reading while the instrument was operating in the 1-20 ppm range, but the procedure for introducing HF into the gas stream required refinement before definitive conclusions could be drawn. The possible interference from HF was of concern because of the possibility that significant amounts of HF may be present in coal gasification streams. Although HF is anticipated to be present at substantially lower concentrations than $\mathrm{HCl}$, the $\mathrm{HF}$ levels could still be sufficient to cause significant analytical errors. Consequently, additional tests with HF were performed after refining the HF delivery system in order to help quantify the severity of the HF interference. Results of those tests indicated that a given concentration of HF produced a signal similar in magnitude to that observed for the same concentration of $\mathrm{HCl}$. Next, the membrane inside the analyzer was changed to switch the unit to the 1-200 ppb range. While using the "low concentration" membrane, tests with HF were performed to see if the results supported or contradicted our results obtained at the higher concentration range. For these tests, air streams containing 0-200 ppb HF were sent to the IMS unit at a rate of $1 \mathrm{~L} / \mathrm{min}$. A linear instrument response was obtained for HF concentrations in this range. More importantly, a given concentration of HF gave a response equivalent to that observed for the same concentration of $\mathrm{HCl}$. Thus, these results agreed with earlier results obtained at higher concentrations using a different membrane.

Despite the observation that $\mathrm{HF}$ and $\mathrm{HCl}$ gave comparable responses for a given concentration, both in the ppm and ppb range, Molecular Analytics personnel believed that HF was not a major interference. They believed there is a 10:1 rejection ratio for HF, meaning that it takes $10 \mathrm{ppm} \mathrm{HF}$ to give the same response observed for $1 \mathrm{ppm} \mathrm{HCl}$. The possibility was considered that the HF permeation tube used for testing was defective. Consequently, a gravimetric determination on the rate of mass loss from the permeation tube over a 24 hour period was performed. In addition, the HF calibration gases were bubbled into a carbonate solution to collect the HF emissions. The solution was subsequently analyzed for fluoride ion by $\mathrm{IC}$, and the HF emission rate was calculated. The gravimetric analysis and the IC analyses both confirmed that the HF permeation tube was good. After a number of discussions with Molecular Analytics personnel, it was suspected that the dopant tube in the IMS analyzer was bad. Therefore, Molecular Analytics sent us a new dopant tube. After installing the new tube, the tests with HF were repeated. The instrument response to HF was about five times lower than previously observed, while the response to $\mathrm{HCl}$ was comparable to that observed previously. Thus, the "rejection ratio" for HF appears to be at least 5:1 rather than the 1:1 ratio observed previously. A research staff member at Molecular Analytics also believes that we previously saw small responses to $\mathrm{HCN}$ and $\mathrm{H}_{2} \mathrm{~S}$ because of the bad dopant tube. Because of the HF rejection ratio, as well as the fact that $\mathrm{HF}$ concentrations are expected to be substantially lower than $\mathrm{HCl}$ concentrations, the $\mathrm{HF}$ interference is not anticipated to be significant for our purposes.

\section{$\underline{\text { Discussion }}$}

After performing laboratory studies with IMS, GFCIR, and the dry colorimetric method, IMS was selected for use in the HCl CEM. The IMS analyzer which was loaned to us was then purchased for this project. IMS is the only technology we evaluated that can easily detect $\mathrm{HCl}$ at low ppb concentrations. This allows for a broader application of the HCl CEM. Also, the low detection limit allows for gas stream dilution as a method for lowering the moisture dew point without lowering the analyte concentration to levels at or below the detection limit of the 
analyzer. This would be important if the Nafion dryer proves to be unreliable for the application of interest. An added advantage is that there are few known interferences for $\mathrm{HCl}$.

\section{GENERAL HCl TRANSPORT STUDIES}

In the initial stages of the $\mathrm{HCl}$ studies, tests were performed to determine if known amounts of $\mathrm{HCl}$ could reliably be passed through the testing apparatus shown in Figure 1 (see page 3). This was done by flowing $\mathrm{HCl}$ gases through the apparatus and then bubbling the gases exiting that system into absorbing solutions. Because a suitable in-house method for rapidly determining chloride in liquids was not initially available, analyses of the liquids were performed using titrimetric procedures during the early stages of this project. The procedure involved bubbling gases into aqueous absorbing solutions containing $3 \mathrm{ml}$ of approximately $0.01 \mathrm{~N}$ $\mathrm{AgNO}_{3}$ solution. In that procedure, the $\mathrm{HCl}$ reacts with the $\mathrm{AgNO}_{3}$ to form $\mathrm{AgCl}$, which then precipitates from the solution. An Altex SelectIon 2000 Ion Analyzer was then used with a silver billet electrode and a glass reference electrode to perform argeneometric titrations with the $\mathrm{AgNO}_{3}$ solution. During the titration, $\mathrm{KCl}$ solution was slowly added and $\mathrm{mV}$ readings were taken for every $0.1-0.2 \mathrm{~mL}$ of the $\mathrm{KCl}$ solution used. That procedure was used to determine the amount of $\mathrm{AgNO}_{3}$ remaining in solution, which was in turn used to calculate (by difference) the amount of $\mathrm{AgNO}_{3}$ which reacted with the initial chloride (as $\mathrm{HCl}$ ) in the sample, and consequently the amount of chloride present in that sample. The procedure in essence measures the Ag ion activity. Ethanol was added to the analysis solutions to further decrease the solubility of $\mathrm{AgCl}$ that precipitates as $\mathrm{KCl}$ solution is added, thus improving the break in the titrimetric curve.

Initial tests were performed by adding liquid chloride standards to collection tubes containing the absorbing solution. The solutions were then analyzed as described above. Results indicated that chloride recoveries ranged from $97-103 \%$, thus confirming the validity of the sample analysis portion of the tests. Next, studies were performed to determine whether a known amount of $\mathrm{HCl}$ could be reliably delivered to a detector. As the first step in this evaluation, tests were performed to determine whether good $\mathrm{HCl}$ recovering could be obtained directly from a compressed gas cylinder containing $3000 \mathrm{ppm} \mathrm{HCl}$ in nitrogen. At low gas flow rates (e.g., $10 \mathrm{~mL} / \mathrm{min}$ ), the $\mathrm{HCl}$ recoveries were erratic (ranging from $40-105 \%$ ) and tended to be low, even when using Teflon lines directly from the gas cylinder. The erratic results did not appear to be caused by analytical errors, problems in collection efficiency, gas metering errors, or losses in the Teflon lines. Rather, there appeared to be erratic adsorption/desorption processes occurring upstream from the outlet of the regulator, despite the precautions taken to select a regulator with nonreactive components (internal parts constructed mostly of Monel, with Kel-F and Teflon for the critical sealing and seating surfaces). After increasing gas flow rates to $100 \mathrm{~mL} / \mathrm{min}$ or more, good precisions for $\mathrm{HCl}$ recoveries were obtained.

In other tests, the $\mathrm{HCl}$ gas mixture was passed through the testing apparatus. A total of about 25 tests were performed using gas flow rates ranging from 100-500 $\mathrm{mL} / \mathrm{min}$ and sample line temperatures of either 25 or $200^{\circ} \mathrm{C}$. At the elevated temperatures, tests were also performed with and without about 50\% water present in the gas stream. Overall, $\mathrm{HCl}$ recoveries averaged 
$85 \pm 5 \%$. The best precision and recoveries were observed for the tests where water vapor was present, in which case the $\mathrm{HCl}$ recovery averaged $92 \pm 3 \%$.

In subsequent work, tests were performed in which $\mathrm{HCl}$ gas was mixed with other gas components (including $\mathrm{CH}_{4}, \mathrm{CO}, \mathrm{CO}_{2}, \mathrm{COS}, \mathrm{H}_{2}, \mathrm{H}_{2} \mathrm{~S}, \mathrm{NH}_{3}$, and $\mathrm{HCN}$ ) and passed through the testing apparatus. The gases were heated to about $200^{\circ} \mathrm{C}$ and did not contain added moisture. Good $\mathrm{HCl}$ recoveries were obtained in the absence of $\mathrm{NH}_{3}$. However, difficulties were encountered in obtaining acceptable $\mathrm{HCl}$ recoveries in the presence of $\mathrm{NH}_{3}$ due to the formation and deposition of solid $\mathrm{NH}_{4} \mathrm{Cl}$ in sections of the sample line that were not heated (i.e., the connecting line between the testing apparatus and the collection solution).

\section{HCl TRANSPORT THROUGH CATALYST BEDS}

Tests were performed to determine whether $\mathrm{HCl}$ gases could be passed through a heated, commercially available Pt catalyst. The catalyst was the same as that discussed in the "Gas Conditioning" section of this report and was a beaded (1/8-inch) catalyst containing $1 \% \mathrm{Pt}$ on an alumina substrate (catalyst G-97B from United Catalysts). A nitrogen stream containing several hundred ppm $\mathrm{HCl}$ was passed through $100 \mathrm{~cm}^{3}$ of the catalyst while the catalyst temperature was slowly increased from 100 to $450^{\circ} \mathrm{C}$. Each intermediate temperature was held for 10 minutes, and the final temperature was held for one hour. Gases exiting the catalyst tube were bubbled into deionized water to collect the chloride, and the water was subsequently analyzed by IC to determine the amount of chloride exiting the catalyst tube. In those tests, results indicated that little or no $\mathrm{HCl}$ exited the catalyst tube, even after one hour at $450^{\circ} \mathrm{C}$. When the gases were bubbled directly (bypassing the catalyst) into water at room temperature and then analyzed by $\mathrm{IC}$, full $\mathrm{HCl}$ recoveries were obtained.

Follow-up tests were performed to determine whether the $\mathrm{HCl}$ losses were due to the $\mathrm{Pt}$ itself or to the catalyst substrate (alumina). As before, gases were bubbled into water and then analyzed by IC to determine the amount of $\mathrm{HCl}$ exiting the catalyst tube. Because of the possibility that the $\mathrm{HCl}$ losses could be partially attributable to the large surface area of the catalyst, the catalyst tube was greatly downsized to hold about $2 \mathrm{~cm}^{3}$ (instead of $100 \mathrm{~cm}^{3}$ ) of catalyst. Also, the heating system was redesigned to provide more uniform heating. Whereas a heating tape was used previously, the new heating method involved using a rod heater embedded in an aluminum block containing the catalyst tube.

For the tests with $2 \mathrm{~cm}^{3}$ of catalyst and catalyst substrate materials, a standard gas containing $100 \mathrm{ppm} \mathrm{HCl}$ in a nitrogen balance was used. When the gases were bubbled directly (bypassing the catalyst) into water at room temperature and then analyzed by $\mathrm{IC}$, full $\mathrm{HCl}$ recoveries were obtained. The $\mathrm{HCl}$ recoveries were about $90 \%$ when the gases passed through an empty catalyst tube at $475^{\circ} \mathrm{C}$ prior to bubbling the gases into water. This indicates that the walls of the catalyst tube and the associated hardware were not a significant source of $\mathrm{HCl}$ losses. Next, the $\mathrm{HCl}$ was passed over the Pt catalyst as well as just the catalyst substrate. The catalyst temperature was maintained at $475^{\circ} \mathrm{C}$. Results of the IC analyses indicated that the $\mathrm{HCl}$ recoveries were low when using the catalyst and catalyst substrate materials. The tests were 
repeated at $250^{\circ} \mathrm{C}$, with similar results. Therefore, this catalyst material was not considered further for the oxidation of gasifier streams prior to $\mathrm{HCl}$ analyses.

Because of the problems encountered in passing $\mathrm{HCl}$ through the commercially available $\mathrm{Pt}$ catalyst, tests were performed to determine if $\mathrm{HCl}$ could be effectively passed over a hot Pt wire. For those tests, about 60" of 0.01" diameter Pt wire was pressed into a 1-inch long section of a 1/4-inch OD quartz tube. The Pt bed was maintained at a temperature of either $250^{\circ}$ or $450^{\circ} \mathrm{C}$ using a small tube furnace. A stream of $100 \mathrm{ppm} \mathrm{HCl}$ in nitrogen was passed over the Pt bed and the gases exiting the tube were bubbled into water for subsequent chloride analyses by IC. The IC analyses indicated that nearly quantitative recovery of $\mathrm{HCl}$ was obtained at both temperatures. Thus, this type of Pt catalyst bed appears to be suitable for passing gas streams containing 100 ppm $\mathrm{HCl}$ without significant $\mathrm{HCl}$ losses.

Several revisions were made in the design of the catalyst module. In the current version of the catalyst system, Pt wire at $900^{\circ} \mathrm{C}$ was placed between two alumina beds at $900^{\circ} \mathrm{C}$. Tests were performed with that catalyst module to determine whether low levels of $\mathrm{HCl}$ in a simulated gasifier stream could be successfully passed through the oxidation catalyst. The simulated gasifier stream consisted of $50 \% \mathrm{CO}, 15 \% \mathrm{CO}_{2}, 25 \% \mathrm{H}_{2}, 8 \% \mathrm{CH}_{4}$, and $2 \% \mathrm{H}_{2} \mathrm{~S}$. For those tests, $500 \mathrm{~mL} / \mathrm{min}$ of simulated gasifier stream was blended with $1 \mathrm{~L} / \mathrm{min}$ of air and $50 \mathrm{~mL} / \mathrm{min}$ of 100 ppm $\mathrm{HCl}$. This gave an $\mathrm{HCl}$ concentration of $10 \mathrm{ppm}_{\mathrm{v}}$ in the simulated gasifier stream prior to blending it with air. Gases exiting the catalyst tube were bubbled into $100 \mathrm{~mL}$ of deionized water for 60 minutes to collect the $\mathrm{HCl}$, and the water samples were then analyzed for chloride using IC. Results of the IC analyses on the water used to collect $\mathrm{HCl}$ while bypassing the catalyst indicated that $100 \% \mathrm{HCl}$ recoveries were being obtained. Results of IC analyses on the solutions used to collect $\mathrm{HCl}$ passing through the heated catalyst bed indicated that $\mathrm{HCl}$ recoveries were $100-110 \%$. Thus, low levels of $\mathrm{HCl}$ were successfully passed through the heated catalyst while using a simulated gasifier stream.

\section{HCl TRANSPORT IN NAFION DRYERS}

Moisture removal is a critical gas conditioning step. Gasifier streams can contain up to $50 \%$ moisture by volume, but existing monitoring systems are not generally able to operate with such high moisture contents. This is often because the sample cells or other hardware components can not be heated to the temperatures necessary to prevent moisture from condensing. Thus, it was necessary to incorporate a drying system into the CEMs which would remove most of the moisture without affecting ppm levels of $\mathrm{HCl}$.

Common approaches for moisture removal prior to analysis of effluent gases include the use of condensers and desiccants. However, those approaches would not be suitable for this application because of the loss of analyte that would result from their use. As an alternative, the use of Nafion (a chemically selective membrane) was investigated for moisture removal. In that approach, the sample gas is transported with a Nafion tube, which is housed inside another tube. A countercurrent purge gas stream flows over the Nafion through the secondary (outer) tube and draws moisture through the walls of the Nafion while theoretically retaining $\mathrm{HCl}$ in the sample gas stream. 
The Nafion has a maximum operating temperature of $150^{\circ} \mathrm{C}$. Since the moisture content of gasifier streams can be very high, the gases will need to be heated to at least $110^{\circ} \mathrm{C}$ to ensure that no condensation occurs. Therefore, the maximum temperature of $150^{\circ} \mathrm{C}$ provides an adequate temperature range to work with. However, drying efficiency will decrease as the gas temperature into the drying system increases. Another consideration in using the Nafion dryer is that it does not necessarily have to remove all of the moisture from the gas stream. If Nafion is used to dry sample gases prior to analysis by IMS, the dryer only has to remove enough water to prevent condensation of water vapor in the sample stream at a temperature of about $50^{\circ} \mathrm{C}$, which is the maximum inlet gas temperature of the IMS system. However, the sample stream flowing into the IMS unit should have a fairly constant humidity in order to reduce analytical uncertainties.

Tests were performed with the gas drying system from Perma Pure (see Figure 3 on page 20) to see if $\mathrm{HCl}$ streams could be passed through the system. In order to simplify these initial tests and to reduce the number of experimental variables, only dry gases were used. Gas streams consisting of $100 \mathrm{ppm} \mathrm{HCl}$ in nitrogen were passed into the dryer and then bubbled into water (an $\mathrm{HCl}$ gas analyzer was not yet available). The sample gas flow rate was $100 \mathrm{ml} / \mathrm{min}$. The absorbing solutions (water) were subsequently analyzed by IC to determine the amount of chloride exiting the dryer over a given amount of time. After 10 minutes or less, $\mathrm{HCl}$ concentrations in the sample gas stream exiting the gas dryer were within $80-100 \%$ of the theoretical concentrations. Similar results were obtained when the tests were repeated using a sample gas flow rate of $1000 \mathrm{ml} / \mathrm{min}$. The countercurrent purge gas was also analyzed in the same manner. In the first few minutes of sampling, low concentrations of $\mathrm{HCl}$ were found in the purge gas. However, after 5 minutes, no $\mathrm{HCl}$ was detected in the purge gas stream. The initial low $\mathrm{HCl}$ readings are probably from sample line contamination during earlier experiments involving the transport of $\mathrm{HCl}$. More work on passing $\mathrm{HCl}$ through large-scale Nafion dryers is needed, including tests with humidified gas streams.

\section{CALIBRATION DEVICES}

\section{PRELIMINARY ASSESSMENT OF PERMEATION TUBES}

A variety of $\mathrm{HCl} \mathrm{CEMs} \mathrm{are} \mathrm{available} \mathrm{for} \mathrm{analyzing} \mathrm{gaseous} \mathrm{effluent} \mathrm{streams.} \mathrm{As} \mathrm{with} \mathrm{any}$ emission monitor, the accuracy of the instrument calibration is a crucial component in the accurate determination of the analyte in process streams. Verification of the $\mathrm{HCl}$ output from calibration systems is important for evaluating $\mathrm{HCl}$ analyzers and for performing accurate calibration of those analyzers. Consequently, numerous tests were performed with a VICI Metronics Model 340 Dynacalibrator (see Figure 36) using aqueous $\mathrm{HCl}$ (azeotropic 20.2\% solution) permeation tubes. Those tests were performed to check for the proper operation of the calibrator and to check the accuracy of $\mathrm{HCl}$ permeation tubes from that vendor. 


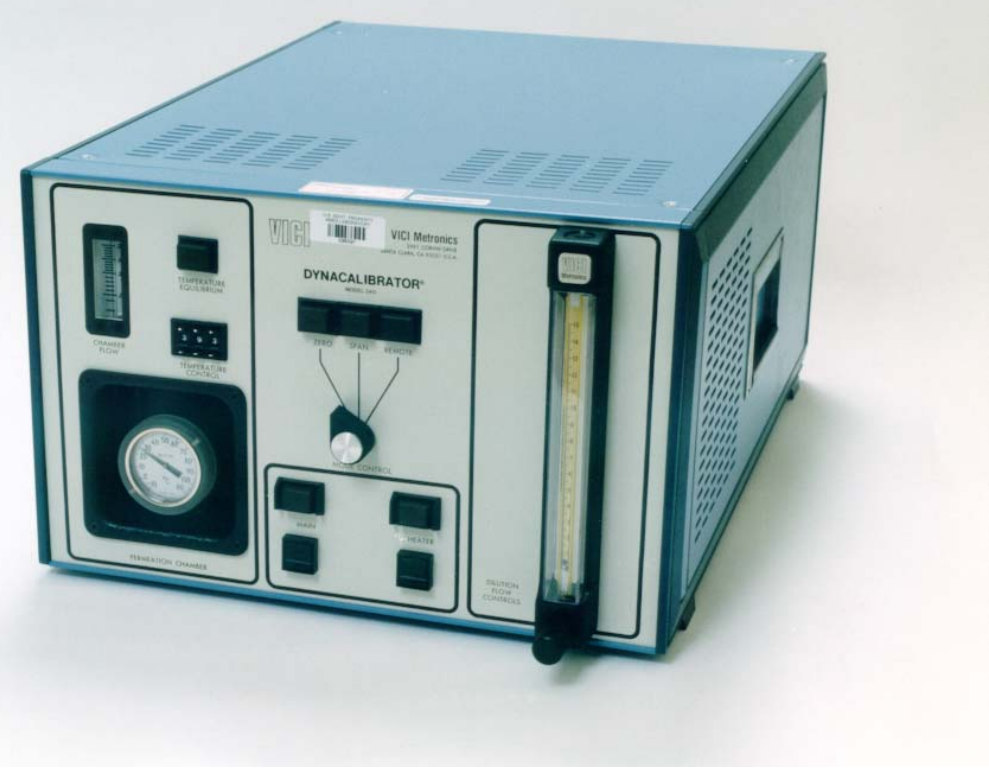

Figure 36. VICI Metronics Model 340 Dynacalibrator.

Two different $\mathrm{HCl}$ permeation tubes were used. The two different tubes had nominal emission rates of 510 and $1,200 \mathrm{ng} \mathrm{HCl} / \mathrm{min}( \pm 15 \%)$. The total mass loss rate from the permeation tubes was also checked to determine if it was within the range specified by the vendor. This was done by performing a gravimetric analysis on the tube after using the tube in the heated permeation chamber for several days. In addition, span gases from the calibrator were bubbled directly into a series of three water traps for several days, and the collection solutions were then analyzed titrimetrically and by IC to determine the amount of chloride collected. Additional tests were performed in which multiple collection solutions were used (in series) and then analyzed to ensure that $\mathrm{HCl}$ was not breaking through the first collector. Results of those tests indicated that essentially all (99\% or more) of the $\mathrm{HCl}$ was being collected using a single collection solution. By using the IC data, the actual $\mathrm{HCl}$ emission rates from the calibrator were calculated and then compared to the theoretical emission rates. In addition to bubbling gases into solutions, calibration gases from the permeation tube calibrator were passed directly into a Teflon gas sampling bag. The gas in the bag was analyzed directly for $\mathrm{HCl}$ using a Sensidyne gas sampling pump with color-indicating $\mathrm{HCl}$ detector tubes (accurate to within \pm $25 \%$ ). As a final test, the calibration gases were analyzed directly by inserting color-indicating $\mathrm{HCl}$ detector tubes directly into the permeation chamber containing the $\mathrm{HCl}$ permeation tube.

Results of the gravimetric analysis indicated that the total emission rates from the permeation tubes were within the uncertainty range listed for each tube. If the total mass emission rates determined experimentally are used as the actual tube emission rates, then the $\mathrm{HCl}$ concentration detected in the Teflon sampling bag (using direct gas analysis with colorindicating tubes) was about $55 \%$ of the theoretical value, while the concentrations detected by withdrawing gases directly from the permeation chamber were about $45 \%$ of the theoretical 
value. For the collection solutions, recoveries of about $15 \%$ and $25 \%$ were obtained by titration and $\mathrm{IC}$, respectively. Although the $\mathrm{HCl}$ recoveries obtained by analyzing the gases directly were significantly higher than those obtained by bubbling the calibration gases into a collection solution, the collective analytical uncertainties for the permeation tubes and analytical approaches still can not explain why such low $\mathrm{HCl}$ recoveries were obtained for all of the approaches used. It is unlikely that all the methods gave erroneous results with respect to the fact that measured $\mathrm{HCl}$ levels were much lower than theoretical levels in all cases.

The Teflon line from the calibrator, which is about a foot long, was considered as a possible source of $\mathrm{HCl}$ losses. To check that possibility, a test was performed in which an extra nine feet of Teflon line were added between the calibrator and the gas sampling bag. No detectable change in $\mathrm{HCl}$ concentration in the sampled gas was observed, indicating that the Teflon line is probably not a source of any $\mathrm{HCl}$ losses. Consequently, it was concluded that the $\mathrm{HCl}$ calibration gases actually contained lower concentrations of $\mathrm{HCl}$ than predicted. Although the vendor had confidence in the accuracy of their equipment at that time, it is worth noting that the vendor's experimental verification of accuracy is based only on gravimetric determinations on the permeation tubes to check total mass loss rates. Although the permeation tubes are filled with an azeotropic solution of $\mathrm{HCl}$, the emitted vapors from the tubes may have a lower $\mathrm{HCl}$ concentration for some unknown reason.

\section{STUDIES OF DIFFERENT CALIBRATION SYSTEMS}

In view of the accuracy concerns noted above for $\mathrm{HCl}$ permeation tubes, a variety of commercially available $\mathrm{HCl}$ calibration devices were investigated for possible use to calibrate our $\mathrm{HCl}$ emission monitor. The objective of this work was to assess the accuracy and response times associated with the overall calibration systems containing those devices. These evaluations were performed by using both direct gas analyses as well as analyses of collection solutions used to capture $\mathrm{HCl}$ emitted from the calibrators. Results of these tests are discussed below.

\section{$\underline{\text { Gas Calibration Equipment }}$}

A variety of $\mathrm{HCl}$ calibration devices were studied, including an aqueous $\mathrm{HCl}$ permeation tube, two anhydrous $\mathrm{HCl}$ permeation wafers, and an aqueous $\mathrm{HCl}$ diffusion vial from VICI Metronics. In addition, an anhydrous "ULED" $\mathrm{HCl}$ permeation tube from KIN-TEK Laboratories was examined. There are no specific operating temperatures recommended by the manufacturers for those devices. Instead, certified $\mathrm{HCl}$ emission rates are provided by the manufacturer for a given operating temperature. The calibration devices and operating temperatures were selected such that each had a certified output of about $1000 \mathrm{ng} / \mathrm{min}$ of $\mathrm{HCl}$. A summary of the $\mathrm{HCl}$ calibration devices, operating temperatures used in this study, nominal $\mathrm{HCl}$ emission rates, and nominal $\mathrm{HCl}$ concentrations in the gas stream exiting the calibrator are shown in Table 2. The reported accuracy of the certified emission values for the calibration devices ranged from $\pm 2 \%$ to $\pm 5 \%$. The certified values provided for the calibration devices from VICI Metronics were obtained using gravimetric determinations. That procedure involves taring the calibration device, heating it at a precise temperature for an amount of time sufficient to obtain an accurate weight loss, and then obtaining a final weight on the calibration device. 
The weight loss per unit time is then calculated. The VICI Metronics calibration devices containing aqueous $\mathrm{HCl}$ contain an azeotropic solution of $20.2 \% \mathrm{HCl}$. Therefore, $20.2 \%$ of the weight loss from the calibration devices using that solution should be $\mathrm{HCl}$. For the KIN-TEK system, the certified value was obtained by placing the permeation device in a vacuum and then measuring the pressure rise over time as anhydrous $\mathrm{HCl}$ was emitted at a specific temperature. The pressure rise is used to calculate the $\mathrm{HCl}$ emission rate.

Table 2. Summary of Calibration Devices from VICI Metronics and KIN-TEK Laboratories.

\begin{tabular}{|l|l|l|l|l|}
\hline Calibration Device & Contents & $\begin{array}{l}\text { Temp. } \\
(\mathrm{o} C)\end{array}$ & $\begin{array}{l}\text { Emission Rate } \\
(\mathrm{ng} \mathrm{HCl} / \mathrm{min})\end{array}$ & $\begin{array}{l}\mathrm{HCl} \mathrm{Conc.} \\
\left(\mathrm{ppm}_{\mathrm{v}}\right)\end{array}$ \\
\hline Permeation Wafer \#1 & Anhydrous HCl & 30 & 872 & 0.49 \\
\hline Permeation Wafer \#2 & Anhydrous HCl & 30 & 1314 & 0.73 \\
\hline Diffusion Vial & $\begin{array}{l}20.2 \% \text { Aqueous } \\
\mathrm{HCl}\end{array}$ & 30 & 1242 & 0.69 \\
\hline VICI Permeation Tube & $\begin{array}{l}20.2 \% \text { Aqueous } \\
\mathrm{HCl}\end{array}$ & 100 & 1121 & 0.63 \\
\hline ULED Permeation Tube & Anhydrous HCl & 30 & 1222 & 0.63 \\
\hline
\end{tabular}

All of the calibration devices were used in conjunction with a corresponding calibrator from the respective companies participating in this study. Specifically, a VICI Metronics Model 340 Dynacalibrator (see Figure 36) and a KIN-TEK Laboratories Model 491M Gas Standards Generator (see Figure 37) were used. The calibrators were each fitted with 3 feet of virgin 1/4" OD FEP Teflon tubing at the calibrator outlet. The VICI Metronics calibrator was operated with ambient air, while the KIN-TEK unit was operated with compressed dry air, as recommended by the manufacturer of that unit. With both the VICI Metronics and KIN-TEK systems, HCl is emitted from the calibration devices and swept away by a carrier gas stream, which is then blended inside the calibrator with a dilution gas. For our tests, a carrier gas flow of $170 \mathrm{~mL} / \mathrm{min}$ and a dilution flow of about $830 \mathrm{~mL} / \mathrm{min}$ were used. Thus, the total gas flow rate at the outlet of each calibrator was about $1000 \mathrm{~mL} / \mathrm{min}$. Nominal $\mathrm{HCl}$ concentrations in the span gases from the calibrators were on the order of $1 \mathrm{ppm}_{\mathrm{v}}$. For the VICI Metronics calibrator, the calibration devices (permeation tube, permeation wafer, or diffusion vial) are placed inside a chamber which has the carrier gas flowing through it. The KIN-TEK unit, on the other hand, does not involve the placement of a calibration device within a glass chamber that has a carrier gas flowing through it. Instead, $\mathrm{HCl}$ from the calibration device (ULED tube) enters directly from the permeation tube into the sample tubing (i.e., the $\mathrm{HCl}$ is not released into a chamber of any kind). 


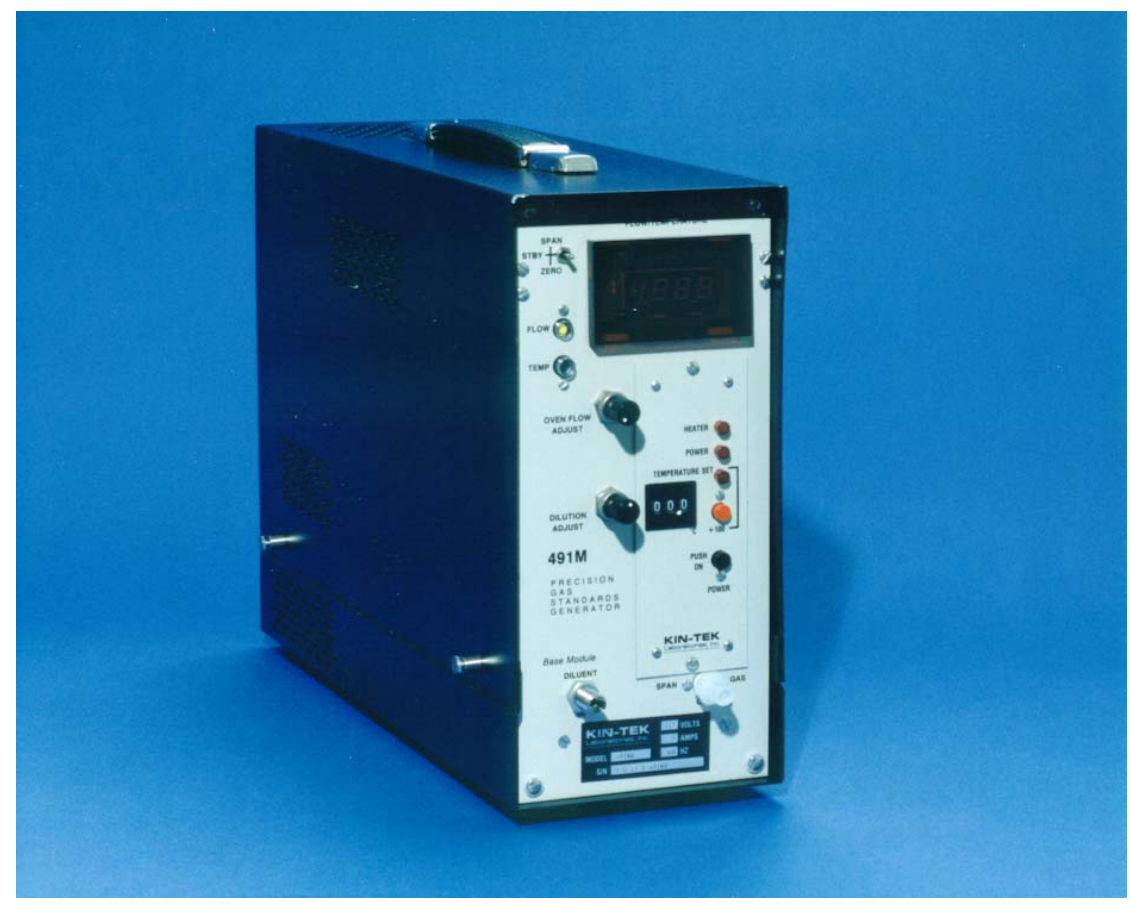

Figure 37. KIN-TEK Laboratories Model 491M Gas Standards Generator.

\section{Testing Approach}

Span gases from the calibrators were analyzed directly for $\mathrm{HCl}$ using the Molecular Analytics Model 20-HCl Stack Master IMS Analyzer discussed earlier in this report. $\mathrm{HCl}$ concentration profiles showing the IMS signal as a function of time were obtained. Also, the IMS readings were observed while switching back and forth between zero air (no $\mathrm{HCl}$ ) and span gases. Those analyses provided information on memory effects and response times associated with each calibration system.

In addition to the direct gas analyses, $\mathrm{HCl}$ in the span gases was collected by bubbling the gases into $100 \mathrm{~mL}$ of deionized water in a $125-\mathrm{mL}$ Erlenmeyer flask. For those tests, the 1/4" OD Teflon tubing at the calibrator outlet was connected to a short piece of $1 / 8$ " OD TFE Teflon tubing, which was inserted into the water in the flask. Sampling times ranged from 30-90 minutes. Before collecting $\mathrm{HCl}$ in the absorbing solutions, the IMS readings were used to help ensure that the calibrator was sufficiently equilibrated. Therefore, no samples were collected with the solutions until the IMS reading was constant (stable for at least several hours) for the calibration device being used. After constant IMS readings were obtained, span gases were bubbled into the absorbing solutions to collect $\mathrm{HCl}$ emitted from the calibrators. Three to five samples were collected for each calibration device.

As a check on the sample collection procedure with the Erlenmeyer flask, a series of tests were performed using a reduced flow rate to help ensure that the sampling procedure discussed above was valid. For those tests, gases were bubbled into $50 \mathrm{~mL}$ of deionized water in a $50-\mathrm{mL}$ graduated cylinder at flow rates of $1000 \mathrm{~mL} / \mathrm{min}$ and $170 \mathrm{~mL} / \mathrm{min}$. Using the graduated cylinder 
increased the bubble path length by about a factor of two compared to using the $125 \mathrm{~mL}$ Erlenmeyer flask. If higher chloride recoveries were obtained using a greater depth of absorbing solution or a lower gas flow rate $(170 \mathrm{~mL} / \mathrm{min}$ versus $1000 \mathrm{~mL} / \mathrm{min})$, this would suggest that quantitative collection of chloride was not being obtained using the normal sample collection procedure. A test was also performed in which a backup chloride trap was used to check for possible breakthrough from the collection solution when using a gas flow rate of $1000 \mathrm{~mL} / \mathrm{min}$. For that test, the first trap was a $125-\mathrm{mL}$ Erlenmeyer flask containing $100 \mathrm{~mL}$ of water and a 1/4" OD glass bubbler tube. The backup trap was an impinger containing $100 \mathrm{~mL}$ of deionized water and a fritted bubbler.

The water samples (absorbing solutions) for all of the tests discussed above were subsequently analyzed for chloride in duplicate or triplicate by IC at two different analytical laboratories. Analyses were performed in our own laboratories using a Dionex Model 2020i ion chromatograph system. In addition, samples were analyzed by IC at the Analytical Services Laboratory at Iowa State University using a Dionex DX 500 ion chromatograph system. Standards were prepared using either $\mathrm{NaCl}$ or $\mathrm{KCl}$ in water. Blanks and check samples were run routinely. Also, a $1.0 \mathrm{ppm}$ aqueous $\mathrm{HCl}$ standard was prepared and submitted to the IC analysts as an unknown sample. Results of the IC analyses on the absorbing solutions were used to calculate $\mathrm{HCl}$ emission rates from the calibrator. Those values were then compared to the certified emission rates for each calibration device and served as an indicator on the accuracy of the overall calibration systems under the conditions employed in this study.

Although Dynacalibrators currently sold by VICI Metronics do not have a dial thermometer in the chamber containing the calibration device, the instrument used for this study was equipped with a dial thermometer with a stainless steel probe that was situated in the chamber. Therefore, tests with the Dynacalibrator (both direct gas analyses and collection of chloride in absorbing solutions) were performed with and without the dial thermometer installed while using the permeation tube and wafer devices. The diffusion vial could not be situated in the chamber in an appropriate position with the dial thermometer installed. Therefore, the effects of the thermometer on $\mathrm{HCl}$ output from the calibrator were not investigated while using the diffusion vial. In addition, direct gas analyses and the analysis of absorbing solutions were used to study the effects of the orientation (pointed upstream or downstream) and location of various VICI Metronics calibration devices in the chamber on the $\mathrm{HCl}$ output in the span gases. Those tests were necessary since there were no recommended procedures for the location and orientation of the VICI Metronics calibration devices in the Dynacalibrator chamber.

\section{$\underline{\text { Results }}$}

For the IC analyses on the absorbing solutions, mean chloride values reported by each laboratory for a given solution were generally within $5 \%$ of each other. Similarly, for repeat analyses ( 2 to 3 injections per sample) of a given sample, the results were generally reproducible to within 5\% for a given laboratory. For the $1.0 \mathrm{ppm}$ aqueous $\mathrm{HCl}$ standard submitted as an unknown, each analyst reported a value within $10 \%$ of the theoretical concentration. Results of the IC analyses on the solutions used to determine the validity of the sample collection procedure (using absorbing solutions) indicated that the sample collection procedure was valid. In those tests, measured $\mathrm{HCl}$ emission rates from the calibrator (calculated from the IC results) at each 
flow rate investigated (170 and $1000 \mathrm{~mL} / \mathrm{min}$ ) were within $5 \%$ of each other. Similarly, increasing the depth of the absorbing solution by using a graduated cylinder had little effect on chloride recoveries. Results of the IC analyses on the solutions used to check for $\mathrm{HCl}$ breakthrough indicated that the first solution contained $99 \%$ or more of the total chloride collected. Therefore, a single collection solution appears to be adequate when using the normal collection procedure. These collective results indicate that the gas sampling approach was valid.

Typical response times (based on IMS readings) are shown in Figure 38 for each of the calibration devices as the calibrators were switched from zero air to span gases and then back to zero air. A time of zero minutes represents the time when the calibrator was switched from zero air to span gas. These data were obtained after an initial equilibration period of one to two days for each calibration device (permeation tubes, permeation wafers, or diffusion vial). The KINTEK system with the ULED tube exhibited the best performance in terms of response times after switching to either span gas or zero air. With the KIN-TEK unit, $90 \%$ of the maximum span gas signal (on the IMS analyzer) was reached within 20 seconds, and the signal generally reached a steady value in less than 45 seconds. When switching back to zero air, the signal decreased by $90 \%$ within 20 seconds and returned to the original base line level in less than 60 seconds. Response times for all of the VICI Metronics devices were much longer.

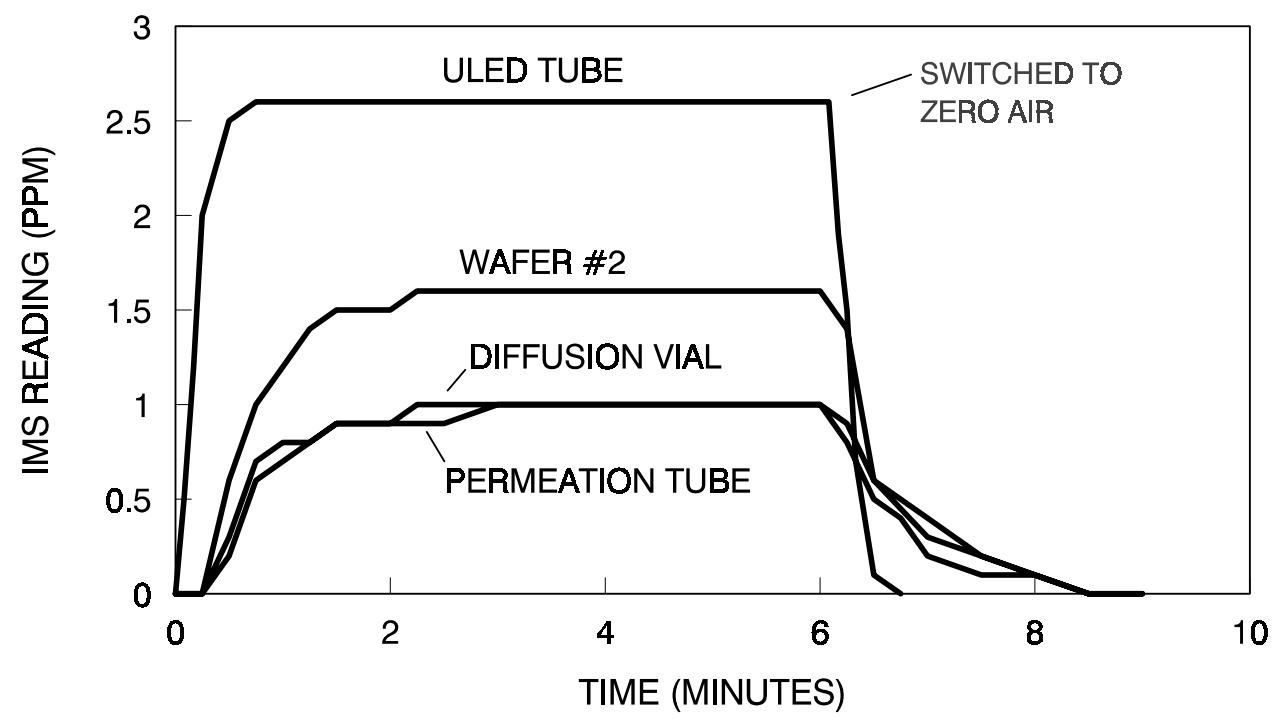

Figure 38. IMS Readings Versus Time for Different Calibration Devices.

When the dial thermometer was installed in the Dynacalibrator, results obtained by IMS and $\mathrm{IC}$ for the $\mathrm{HCl}$ permeation wafers were very low and indicated that $\mathrm{HCl}$ emissions from the calibrator were less than $25 \%$ of the expected values. This was true even after 60 hours or more of continuous operation. When the dial thermometer was removed from the Dynacalibrator chamber, the IMS reading and the $\mathrm{HCl}$ emission rate determined from the $\mathrm{IC}$ data increased by about a factor of two. Thus, when using wafers with anhydrous $\mathrm{HCl}$, the absence of the metal stem of the dial thermometer greatly improved results. When using the VICI Metronics 
permeation tube, the presence of the dial thermometer did not have a significant impact on the IMS signals.

To further demonstrate the effect of metal surfaces on $\mathrm{HCl}$ emission rates from the Dynacalibrator, it was experimentally determined that the location of the wafer in the Dynacalibrator chamber and the orientation (whether the membrane was pointed upstream or downstream) of the wafer both affected the IMS readings by as much as a factor or two. The highest $\mathrm{HCl}$ output from the calibrator was obtained when the wafer was centered in the chamber (see Figure 39) and when the wafer membrane pointed downstream (see Figure 40). When the wafer faced upstream, the stainless steel surrounding the permeation membrane became very greenish. Although this problem was also observed when the membrane was facing downstream, it appeared to be much less severe in that case. For the permeation tube, the location of the tube in the chamber affected the $\mathrm{HCl}$ output from the calibrator by $10 \%$ or less. Thus, the position of the calibration device was critical for the wafer, but not for the permeation tube.

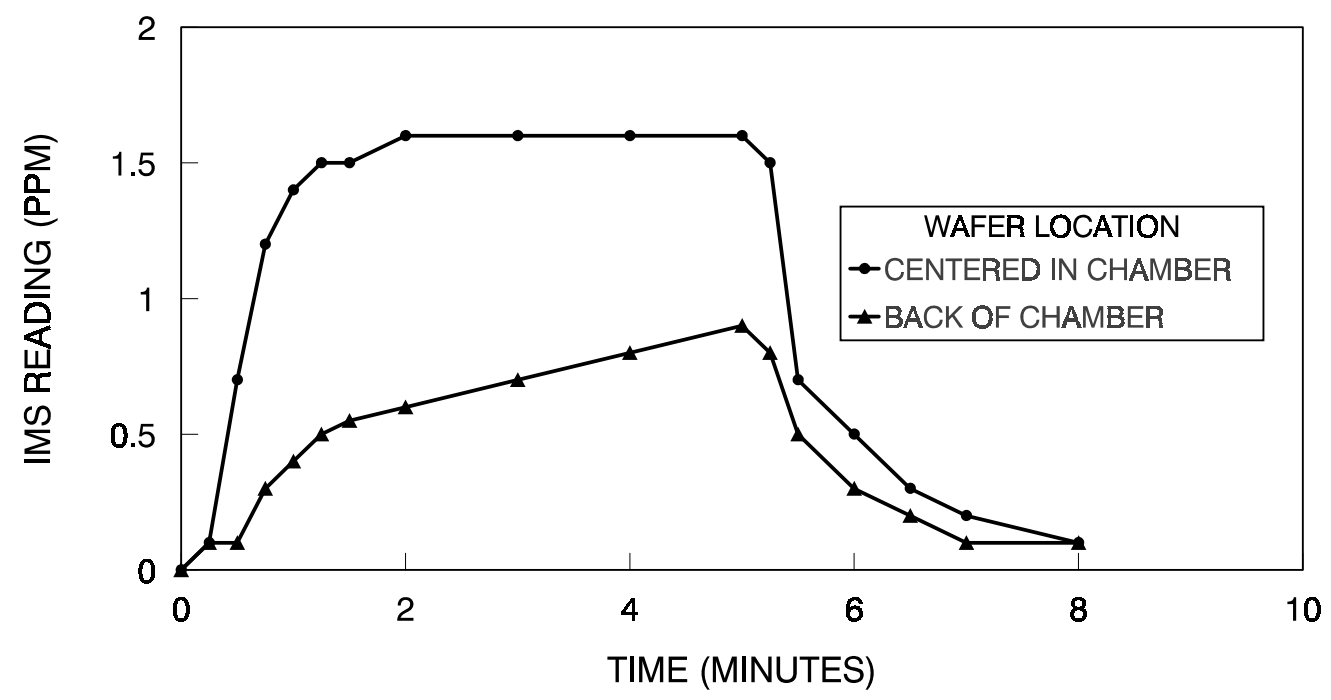

Figure 39. Effects of Wafer Location on $\mathrm{HCl}$ Output from the Calibrator.

Chloride emission rates determined from the IC data are shown in Table 3. As can be seen, the $\mathrm{HCl}$ outputs from all of the devices from VICI Metronics were found to be about 30-60\% too low. The measured $\mathrm{HCl}$ emission rates were generally reproducible to within $\pm 5 \%$ for each device. The second wafer device was one exception to this. Tests performed on different days with that device gave $\mathrm{HCl}$ emission values of 1094 and $763 \mathrm{ng} \mathrm{HCl} / \mathrm{min}$ (average of 928 $\mathrm{ng} / \mathrm{min}$ ), even though the results were very repeatable on a given day. The reason for this experimental anomaly is unclear. However, the wafer devices tended to behave in a more erratic fashion (based on IMS readings) than the other calibration devices tested, and were also more sensitive to experimental conditions (e.g., location and orientation of the wafer in the permeation chamber). 


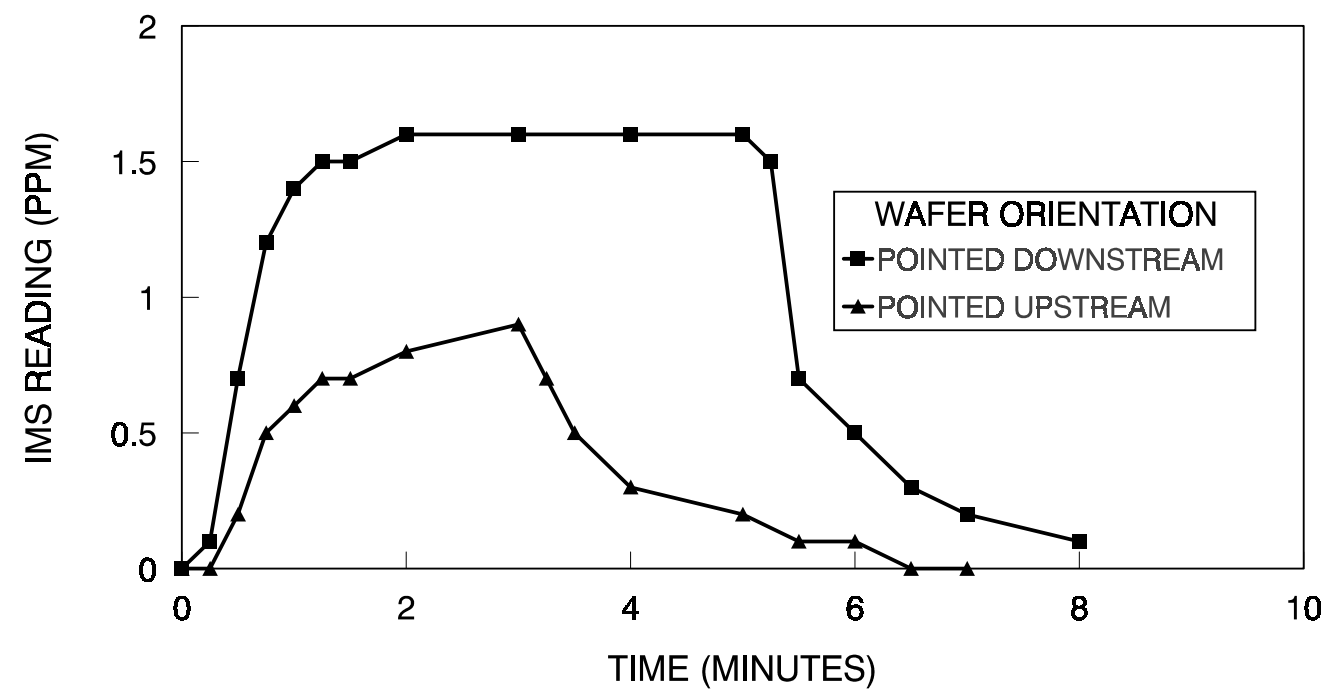

Figure 40. Effects of Wafer Orientation on $\mathrm{HCl}$ Output from the Calibrator.

Table 3. Measured and Certified (Provided by Manufacturer) $\mathrm{HCl}$ Emission Rates from the $\mathrm{HCl}$ Calibration Systems.

\begin{tabular}{|l|l|l|l|}
\hline Calibration Device & $\begin{array}{l}\text { Measured Emission Rate } \\
\text { (ng HCl/min) }\end{array}$ & $\begin{array}{l}\text { Certified Emission } \\
\text { Rate (ng HCl/min) }\end{array}$ & $\begin{array}{l}\text { Percent of } \\
\text { Certified Rate }\end{array}$ \\
\hline Permeation Wafer \#1 & 400 & 872 & 46 \\
\hline Permeation Wafer \#2 & $928 \pm 214$ & 1314 & 71 \\
\hline Diffusion Vial & 492 & 1242 & 40 \\
\hline VICI Permeation Tube & 550 & 1121 & 49 \\
\hline ULED Permeation Tube & $1884 \pm 45$ & 1222 & 154 \\
\hline
\end{tabular}

For the VICI Metronics calibration devices containing aqueous $\mathrm{HCl}$, the hydrochloric acidwater system $(20.2 \% \mathrm{HCl})$ is an azeotropic solution that has been used as a standard in quantitative analysis. As the solution is heated, the vapors should theoretically contain $20.2 \%$ $\mathrm{HCl}$. However, the low $\mathrm{HCl}$ recoveries observed with the aqueous $\mathrm{HCl}$ may reflect possible changes in the equilibrium of the solution as the aqueous $\mathrm{HCl}$ is calibrated and used at different temperatures.

The $\mathrm{HCl}$ output from the KIN-TEK system using the ULED tube was about $50 \%$ too high. Analyses with absorbing solutions were performed on six different days over a period of several weeks, and similar results were obtained in each case. The mean value and standard deviation for those six days of testing are given in Table 3. As can be seen, the relative standard deviation 
was about $2 \%$. The consistency in data obtained with absorbing solutions while using the ULED tube was also reflected in the IMS values obtained for that tube. The same IMS reading was observed when passing span gases continuously into the IMS analyzer for a period of several days, and that same reading was obtained repeatedly on numerous days over the course of the work, which covered a two-month period. Personnel at KIN-TEK identified a probable source of their certification bias with the ULED tube and have determined approaches that are likely to correct the problem.

As shown in Figure 41, chloride emission rates determined from the IC data tracked well with the $\mathrm{HCl}$ concentrations determined by IMS, indicating that the IMS readings were a good indicator of relative $\mathrm{HCl}$ concentrations in the gas stream. Consequently, those readings were a good indicator of when the $\mathrm{HCl}$ calibration systems could be considered to be equilibrated prior to collecting $\mathrm{HCl}$ with the absorbing solutions. The IMS readings were always somewhat higher than the $\mathrm{HCl}$ concentrations determined from the IC data, which may reflect difficulties in performing IMS instrument calibrations at low $\mathrm{HCl}$ levels. The IMS unit had been calibrated at the factory using blended gases from compressed gas cylinders, and a recalibration was not performed prior to these tests. Therefore, the IMS readings were used primarily to track changes in relative $\mathrm{HCl}$ concentrations.

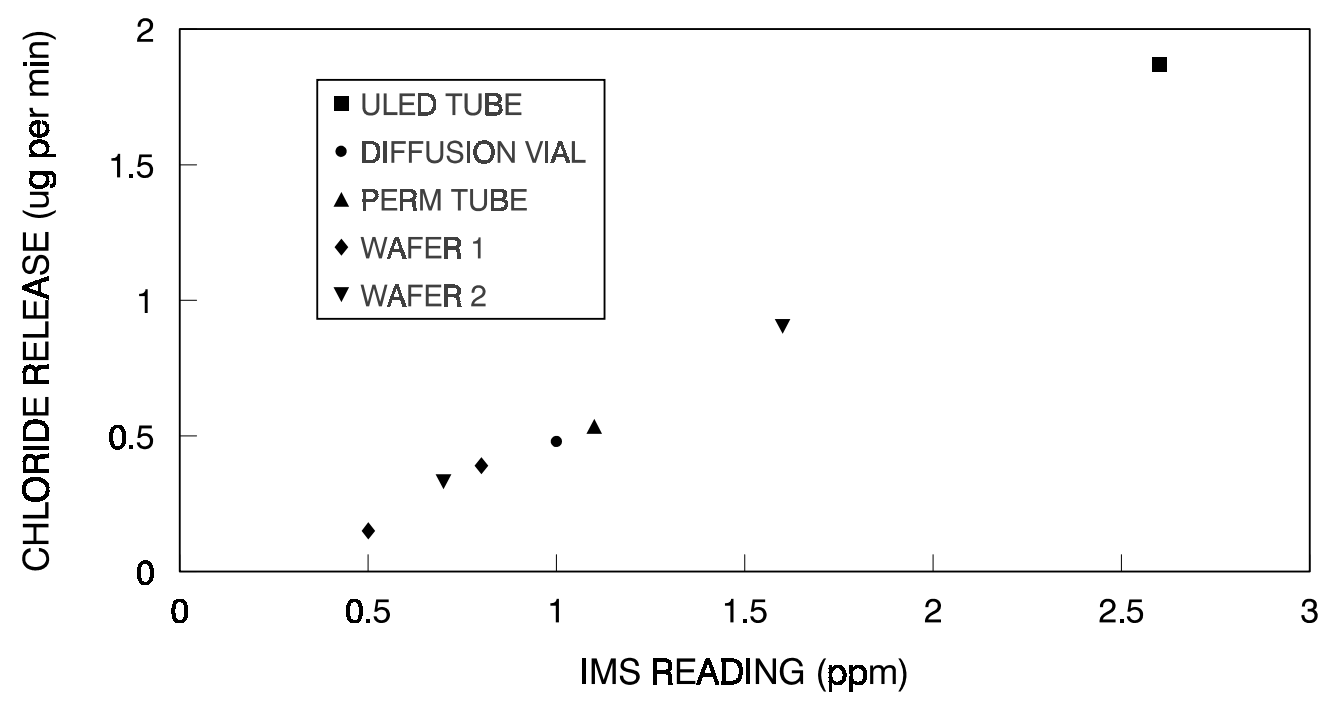

Figure 41. IMS Reading Vs. Calculated Chloride Release Rate from the Calibrators.

\section{$\underline{\text { Discussion }}$}

In the results noted above, it must be kept in mind that data were obtained under specific experimental conditions, and results may be substantially different as changes in the experimental design are made. In this regard, some of the more important considerations include the gas flow rates, temperatures, and nominal $\mathrm{HCl}$ concentrations used. The magnitude of the deviation in experimentally determined $\mathrm{HCl}$ emission rates from the certified emission rates is larger than can be accounted for through the combined analytical and experimental uncertainties 
involved. Also, it was observed that even minor procedural variations can significantly affect the $\mathrm{HCl}$ content of span gases from some calibration systems. It appears that additional work is needed in order to provide accurate calibration systems for trace levels of gaseous $\mathrm{HCl}$. Caution should be exercised when using certified $\mathrm{HCl}$ emission values for a given calibration device in order to calculate nominal $\mathrm{HCl}$ concentrations from a calibration system. Downstream analyses of the calibrator output should be performed to verify $\mathrm{HCl}$ concentrations in cases where calibration accuracy is of great importance.

\section{Follow-up Work with Diffusion Vial}

Some follow-up work was performed with the VICI Metronics diffusion vial. Although the results discussed for the permeation devices were not disputed by VICI Metronics, personnel at VICI Metronics were puzzled by the low emission values determined experimentally for the diffusion vial. This was based on the fact that another laboratory was routinely getting higher results $(85-98 \%$ of theoretical) with those vials, which was based on IC analyses of solutions used to collect the $\mathrm{HCl}$ emitted from their own Dynacalibrator. However, in their work, the vial was used at $70^{\circ} \mathrm{C}$ (as opposed to the $30^{\circ} \mathrm{C}$ we used) and the $\mathrm{HCl}$ concentrations were about $5-10$ ppm rather than the $1 \mathrm{ppm}$ levels used in our tests. In view of the discrepancy between their results and ours, we performed additional tests with the diffusion vial (containing aqueous $\mathrm{HCl}$ ) using the Model 340 Dynacalibrator. In order to see if comparable results were obtained using a different calibrator, similar tests were also performed using a VICI Metronics field calibrator. However, because of temperature instabilities in the field calibrator below $35^{\circ} \mathrm{C}$, the tests comparing the Model 340 Dynacalibrator with the field calibrator were performed at $35^{\circ} \mathrm{C}$ rather than the $30^{\circ} \mathrm{C}$ used previously.

In addition, a series of tests were performed under the conditions used by the other laboratory that was reporting higher $\mathrm{HCl}$ recoveries than we had observed. Specifically, a temperature of $70^{\circ} \mathrm{C}$ was used for the diffusion vial, which increased theoretical $\mathrm{HCl}$ emission rates by about a factor of ten. Those tests were performed to determine whether the differences in results obtained between us and the other laboratory could be explained by differences in experimental conditions used between the two laboratories. Before beginning our tests, proper gas flow rates were verified with a bubble flow meter, and chamber temperatures were verified using a reliable mercury thermometer. The calibrators were allowed to equilibrate with the span gases passing through the sample lines for a minimum of 24 hours before collecting samples (bubbling span gases into water). As before, absorbing solutions used to collect $\mathrm{HCl}$ were analyzed by IC. The IC data were then used to calculate actual $\mathrm{HCl}$ emission rates from the calibrators.

Comparable $\mathrm{HCl}$ emission results were obtained with the Dynacalibrator and the field calibrator at $35^{\circ} \mathrm{C}$, indicating that there probably was not a problem with the Dynacalibrator. However, the calculated $\mathrm{HCl}$ emission rates were about $80 \%$ of the theoretical rates, as opposed to the value of $40 \%$ which was observed previously when using a temperature of $30^{\circ} \mathrm{C}$. When the diffusion vial was used at $70^{\circ} \mathrm{C}$ in the Dynacalibrator, $\mathrm{HCl}$ emission rates calculated from the IC data were almost $95 \%$ of the theoretical emission rates. 
Next, the tests performed in the Dynacalibrator with the diffusion vial at both $30^{\circ} \mathrm{C}$ and $70^{\circ} \mathrm{C}$ were repeated to see if the results were reproducible. However, unlike the previous tests, fresh $20.2 \% \mathrm{HCl}$ was used at each of the temperatures studied. When the diffusion vial was at $30^{\circ} \mathrm{C}, \mathrm{HCl}$ emission rates were $43 \%$ of theoretical values, which was in excellent agreement with the value of $40 \%$ reported for previous tests at that temperature. For the tests performed at $70^{\circ} \mathrm{C}$, calculated $\mathrm{HCl}$ emission rates were $87 \%$ of the theoretical rates. Thus, it is clear that our results do not conflict with those from the other laboratory when similar conditions were used. It is also clear that the $\mathrm{HCl}$ output from the VICI Metronics Dynacalibrator is very low when using the diffusion vial at $30^{\circ} \mathrm{C}$. It is interesting to note that $\mathrm{HCl}$ recoveries were about $40 \%$, $80 \%$, and $90 \%$ of theoretical values when using temperatures of $30^{\circ}, 35^{\circ}$, and $70^{\circ} \mathrm{C}$, respectively. It is not known whether the increased recoveries at higher temperatures are truly related to temperature or whether the $\mathrm{HCl}$ concentration is the primary issue. At any rate, these data again reflect the uncertainties involved with $\mathrm{HCl}$ calibration systems.

In view of results obtained with the various calibration devices, we are not comfortable with any of the $\mathrm{HCl}$ calibration systems that are commercially available for our $\mathrm{HCl}$ range of interest. Instead of using diffusion vials, we intend to use either a permeation tube or a diluted stream of a certified $\mathrm{HCl}$ gas in a compressed gas cylinder. In the first case, it was shown that $\mathrm{HCl}$ permeation tubes are not very accurate in the low ppm range. However, the $\mathrm{HCl}$ output from the permeation tube appeared to be consistent, and they are easier to use than diffusion vials. Therefore, if permeation tubes are used, the $\mathrm{HCl}$ output will be experimentally determined by bubbling span gases into solutions and analyzing the solutions by IC to calculate the $\mathrm{HCl}$ emission rate. In the case of diluting $\mathrm{HCl}$ standard gases from a compressed gas cylinder, this is difficult to do at extremely low $\mathrm{HCl}$ concentrations, but may be the most reliable approach overall.

\section{ALTERNATE CALIBRATION APPROACHES}

Another common approach for performing $\mathrm{HCl}$ calibrations is to use compressed gas cylinders containing known concentrations of $\mathrm{HCl}$. Since $\mathrm{HCl}$ is generally believed to be unstable in gas cylinders at low concentrations (e.g., less than $10 \mathrm{ppm}$ ), higher starting concentrations are used and the gas is then blended to provide the desired final concentration. Some vendors believe this is an excellent way to perform calibrations at low $\mathrm{HCl}$ levels. However, the operator must be extremely careful of wall effects and the difficulties involved in accurately mixing gases to produce low $\mathrm{HCl}$ concentrations, as well as difficulties associated with $\mathrm{HCl}$ transport in general.

We briefly investigated an alternate approach for $\mathrm{HCl}$ calibrations whereby dilute aqueous solutions of hydrochloric acid were pumped at a known rate into a hot steam coil in our testing apparatus. The steam containing the $\mathrm{HCl}$ then entered the main carrier gas stream. This approach has the advantage of being able to accurately prepare the liquid $\mathrm{HCl}$ standard as well as the advantage of minimizing wall effects by pumping a liquid containing the $\mathrm{HCl}$ rather than using gases. By using this approach, good $\mathrm{HCl}$ recoveries at the exit of the testing apparatus were obtained in some cases. However, pumping problems were encountered when attempting to use the low flows necessary to attain both the desired moisture and $\mathrm{HCl}$ concentrations at the 
total gas flow rate (about $1000 \mathrm{~mL} / \mathrm{min}$ ) being tested. No further work in this area was performed.

\section{DESCRIPTION OF CEM}

As noted earlier, the analytical detection system for determining $\mathrm{HCl}$ is a Molecular Analytics Model 20-HCl Stack Master IMS Analyzer. Thus, unlike the Hg analyzer, this is a commercially available detection system. The unit has programmable high and low alarms, built-in diagnostics, and two analysis ranges $(0-20 \mathrm{ppm}$ and $0-200 \mathrm{ppb})$ which are obtained by changing an internal membrane.

As with the $\mathrm{Hg}$ analyses, operation of the overall $\mathrm{HCl} \mathrm{CEM}$ is based on the assumption that a properly filtered gas stream is available. Since filtering is not performed as part of the CEM operation, it should be performed upstream from the CEM using a suitable filtering device. Also, as with the Hg CEM, calibrations are nonautomated and are performed while bypassing the gas conditioning system. The issues discussed for calibrating the Hg CEM also apply to the calibration of this or any other $\mathrm{HCl} \mathrm{CEM}$. In addition, as discussed earlier in this report, commercially available $\mathrm{HCl}$ calibration systems tend to be unreliable at low $\mathrm{HCl}$ concentrations.

A picture of the overall gas conditioning and analytical system (all rack mounted) used for $\mathrm{HCl}$ is shown in Figure 42. The box on the floor next to the rack is the $\mathrm{Hg}$ analyzer, which uses the same gas conditioning system. The major components seen from the front of the equipment rack are 1) the control box at the top of the unit, which contains flow meters, temperature controllers, temperature displays, and Photohelic ${ }^{\circledR}$ pressure switch/gauges, 2) the IMS detection system for $\mathrm{HCl}$, which is located underneath the control box, 3) a catalyst module (long rectangular box below the IMS unit) for the oxidative decomposition of $\mathrm{NH}_{3}$ and tars, and 4) a large Nafion-based dryer for removing moisture from the sample stream prior to entering the detection system. The two Photohelic ${ }^{\circledR}$ pressure switch/gauges are used to monitor gas pressure as a safety feature in the event of a line plug. One of those switches has a relatively large range and is for positive pressures only. The other one has a relatively small range and is for both positive and negative pressures. The switch/gauge to be used depends on the specific monitoring application. The desired positive and negative pressure limits can be adjusted so that power to any of the analyzer components are automatically turned off if those limits are exceeded. This may be desirable if, for example, a line downstream from the catalyst plugs with ammonium chloride deposits because of problems with the catalyst module. Currently, the switch/gauges are for monitoring purposes only and have an automatic reset. However, by adding a manual reset switch, system components can be made to stay off until the problem causing abnormal pressure/vacuum conditions is corrected. Utility requirements for the overall CEM include two separate 20 -amp circuits. It may also be desirable to have filtered house air available at 60-100 psi. If the addition of another compressor is desired, an additional circuit would be required.

A schematic diagram of the overall system is shown in Figure 43. A compressor is used to provide air for the oxidation catalyst, the purge gas for the Nafion-based dryer, and the instrument air for the IMS analyzer. Air from the compressor is first passed into a small Perma Pure 12-inch heatless dryer in order to meet dew point requirements for the IMS analyzer and to improve drying efficiency of the Nafion dryer. After reviewing a variety of options for 
generating the necessary IMS instrument air (with a dew point requirement of at least $-40^{\circ} \mathrm{C}$ ), the 12 -inch heatless dryer from Perma Pure was selected since it provides a dew point of $-50^{\circ} \mathrm{C}$. For field use, the heatless dryer could be coupled to an air compressor if house air is not available.

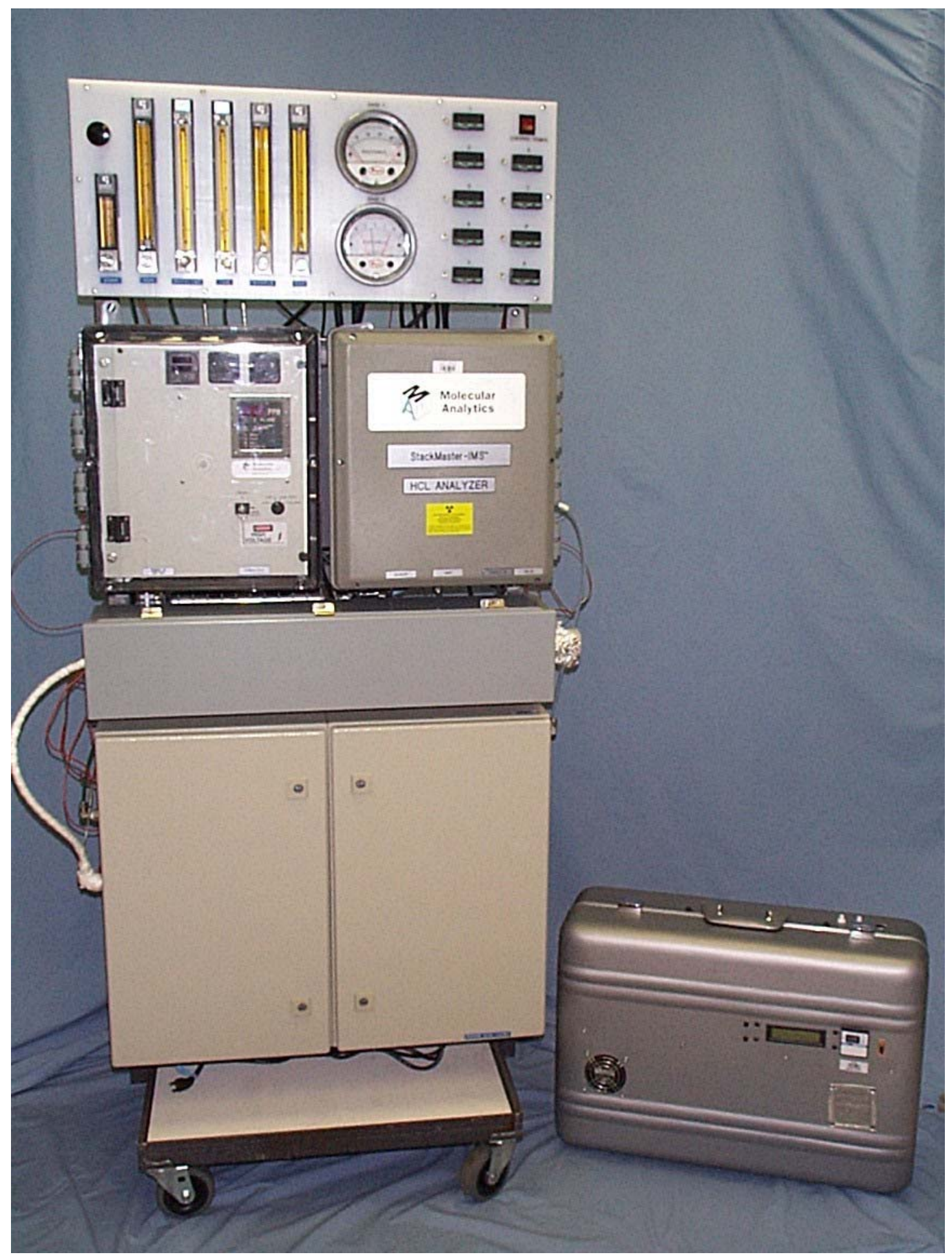


Figure 42. Gas Conditioning System and Analyzer for Monitoring $\mathrm{HCl}$ Emissions (Hg Analyzer Sitting on Floor Next to Rack).

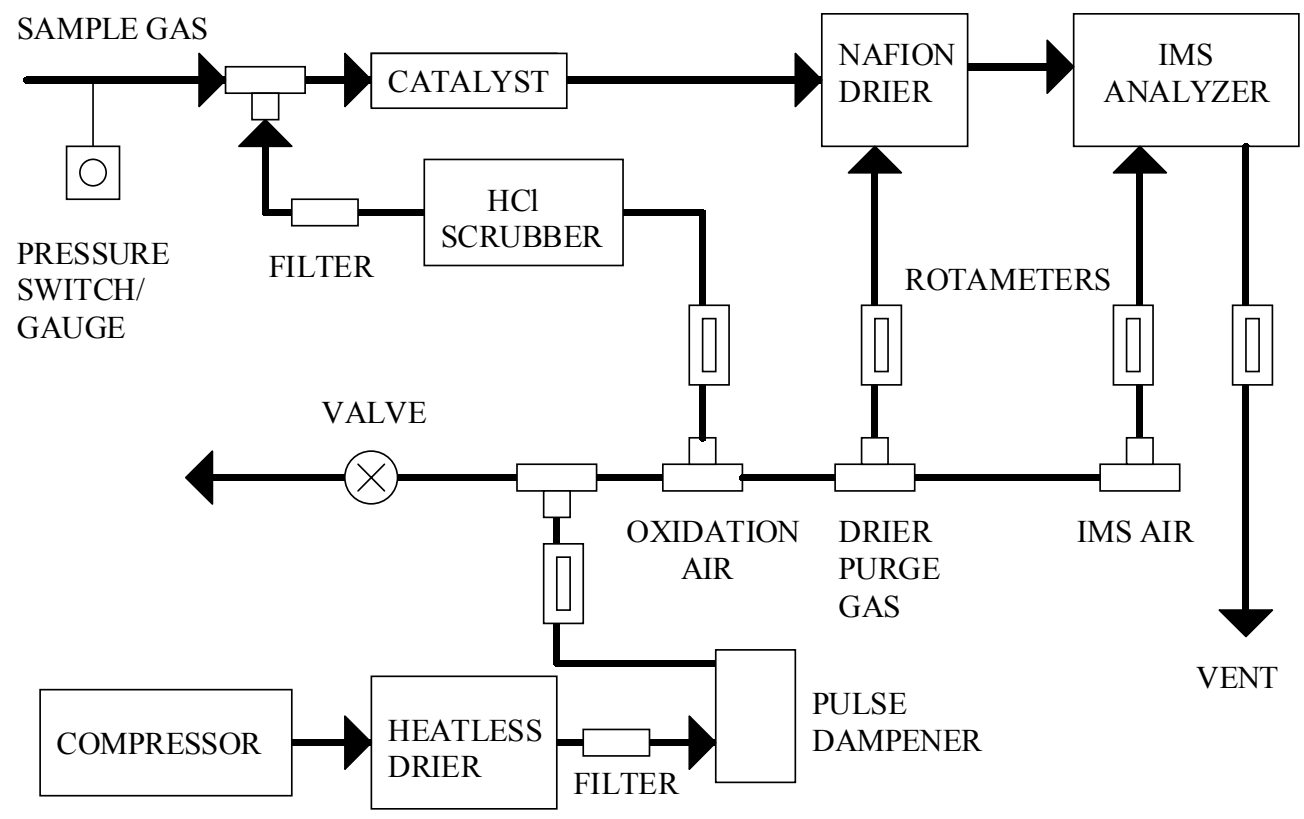

Figure 43. Schematic Diagram of Overall Gas Conditioning and Analysis System for HCl.

Pressure surges in the dried air from the heatless dryer were observed as the dryer cycled back and forth between two drying chambers. These pressure pulses caused fluctuations in the IMS instrument air (nominally $2 \mathrm{~L} / \mathrm{min}$ ) and the oxidation air (nominally $2 \mathrm{~L} / \mathrm{min}$ ) of up to about $0.5 \mathrm{~L} / \mathrm{min}$. Because of the pressure pulses, a pulse dampener was added to minimize downstream flow fluctuations resulting from the use of the heatless dryer. The pulse dampener, located immediately downstream from the heatless dryer, consists of a 1-gallon plastic jug fitted with Swagelock connectors. This reduced the magnitude of the flow fluctuations from $0.5 \mathrm{~L} / \mathrm{min}$ to only $0.05 \mathrm{~L} / \mathrm{min}$. Although this effectively dampened the flow fluctuations in the IMS instrument air and the oxidation air, the jug is only intended as a very temporary solution since the fittings in the jug can not be considered as being secure in view of the pressures of up to about 75 psi that are being used.

It should also be noted that the IMS unit is very sensitive to fluctuations in the sample gas flow. Pressure fluctuations were not a problem in our laboratory work using compressed gas cylinders. However, during actual field sampling, it may be necessary to put in a suitable Teflon chamber upstream from the analyzer in order to minimize pressure fluctuations in the sample gas flow into the IMS unit.

The oxidation air passes through a soda lime scrubber to remove $\mathrm{HCl}$ prior to being mixed with the sample gas upstream from the oxidation catalyst (the soda lime is replaced with 
activated carbon traps when $\mathrm{Hg}$ analyses are being performed). The sample gas is blended with the oxidation air using about $1 \mathrm{~L} / \mathrm{min}$ of sample gas and $2 \mathrm{~L} / \mathrm{min}$ of air. That stream then enters the oxidation catalyst for removal of $\mathrm{NH}_{3}$ and tars. Next, the gases enter a large Nafion-based dryer to remove moisture from the gas stream. The dryer is a Perma Pure GASS ${ }^{\text {TM }}$ (Gas Analysis Sampling System) designed to handle a 1-2 L/min gas flow with up to $50 \%$ (volumetric) moisture. That system contains two Perma Pure PD-1000-24AFS dryers with Nafion tubes as well as an internal Model FF-250-FG Filter Coalescer. After exiting the dryer, the gases enter the IMS analyzer for $\mathrm{HCl}$ determinations.

\section{TESTING OF ENTIRE CEM IN THE LABORATORY}

Laboratory testing was performed with the entire integrated (gas conditioner coupled to the analyzer) $\mathrm{HCl} \mathrm{CEM}$ using a simulated coal gasification stream. The simulated gasifier stream, on a dry basis, consisted of $22 \% \mathrm{H}_{2}, 13 \% \mathrm{CO}_{2}, 7 \% \mathrm{CH}_{4}, 1.7 \% \mathrm{H}_{2} \mathrm{~S}, 44 \% \mathrm{CO}, 0.25 \% \mathrm{NH}_{3}$, up to $100 \mathrm{ppm}_{\mathrm{v}} \mathrm{HCl}$, and a balance of $\mathrm{N}_{2}$. In addition, moisture was added to give a water content of 20\%. A single compressed gas cylinder containing blended $\mathrm{H}_{2}, \mathrm{CO}_{2}, \mathrm{CH}_{4}, \mathrm{H}_{2} \mathrm{~S}$, and $\mathrm{CO}$ was used. The $\mathrm{NH}_{3}, \mathrm{H}_{2} \mathrm{O}$, and $\mathrm{HCl}$ were each added separately to the sample line just prior to the inlet of the gas conditioning system. Compressed gas cylinders were used for the $\mathrm{NH}_{3}$ and $\mathrm{HCl}$, while known amounts of water were fed into the gas stream by using a peristaltic pump. The sample line (316 stainless steel) into the gas conditioner was heated and maintained at $600^{\circ} \mathrm{C}$, and the $\mathrm{NH}_{3}, \mathrm{H}_{2} \mathrm{O}$, and $\mathrm{HCl}$ were added to the gasifier stream via union tees in the $600^{\circ} \mathrm{C}$ sample line. Type 316 stainless steel would not be the preferred choice of materials for the sample line during prolonged testing, but it was used here because of its low cost relative to other options and because extended testing of the CEM was not to be performed. Sections (about 8 " each) of the $\mathrm{NH}_{3}, \mathrm{H}_{2} \mathrm{O}$, and $\mathrm{HCl}$ lines into the union tees were heavily insulated to provide preheating of those gas stream components prior to entering the gasifier stream.

Testing was performed using about $1 \mathrm{~L} / \mathrm{min}$ (dry basis) of gasifier stream blended with 2 $\mathrm{L} / \mathrm{min}$ of oxidation air, which was preheated to $600^{\circ} \mathrm{C}$ and added to the simulated gasifier stream just prior to the oxidation catalyst. For comparative purposes, $\mathrm{HCl}$ streams in air were passed directly (bypassing the gas conditioner) into the IMS analyzer. Similarly, tests were performed in which $\mathrm{HCl}$ in air alone was passed through the entire heated gas conditioning system.

In the tests where streams of $\mathrm{HCl}$ in air bypassed the gas conditioner and passed directly into the IMS analyzer, the nominal $\mathrm{HCl}$ concentration was varied from 2 to $10 \mathrm{ppm}$. The IMS analyzer exhibited rapid response, reaching $90 \%$ of the full reading within 30 seconds and reaching a steady reading within 60 seconds. Also, the IMS analyzer was very sensitive to small (1 ppm) changes in the $\mathrm{HCl}$ concentration.

Next, streams of $\mathrm{HCl}$ in air were passed through the entire heated gas conditioning system. A variety of minor problems were noted during these tests. For example, it became apparent that the compressor being used to provide the IMS instrument air, oxidation air, and purge gas for the

Nafion dryer was slightly undersized. Therefore, dry filtered house air was used instead of the 
compressor. Also, it was noted that the overall operation of the CEM could be improved by a variety of modifications in the CEM design, many of which related to plumbing considerations.

When passing a $10 \mathrm{ppm} \mathrm{HCl}$ stream (in air) through the gas conditioner, the $\mathrm{HCl}$ concentrations reported by the IMS analyzer were about $20 \%$ lower than those obtained while bypassing the conditioner. This could be due to a variety of reasons. One possibility is that there were $\mathrm{HCl}$ losses due to sorption onto the walls of the sample transport lines and other gas conditioner components. Another possibility is that the countercurrent purge gas flow rate in the Nafion-based dryer may have required fine tuning. In previous tests with the Nafion dryer, lowlevel $\mathrm{HCl}$ streams were successfully passed through the Nafion dryer and there did not appear to be any losses of analyte into the purge gas stream. However, for $\mathrm{HCl}$, the ratio of the purge gas flow rate to the sample gas flow rate is of great importance, and higher ratios are generally needed to prevent losses of $\mathrm{HCl}$ into the purge gas stream. Still a third possibility relates to the fact that the IMS analyzer requires sample gases to be at atmospheric pressure for proper operation. The pressure of the sample gases that bypassed the gas conditioner may have been slightly different than the sample gas pressure when going through the gas conditioner. If this is indeed the case, the problem can be easily corrected through minor design changes in the gas conditioning/sampling system. Additional work would be required to determine the reason for the $20 \%$ decrease in the IMS readout when going through the conditioner rather than bypassing the conditioner.

As expected, the signal lag times when switching back and forth between zero air (no $\mathrm{HCl}$ ) and span gases (containing $10 \mathrm{ppm} \mathrm{HCl}$ ) were substantially greater when going through the gas conditioner. Instead of reaching a steady signal within 60 seconds (as was the case when bypassing the conditioner), it took about 5 minutes when passing span gases through the conditioner. Similarly, due to apparent wall effects in the gas conditioner, it took a long time to purge residual $\mathrm{HCl}$ out of the system after turning off the $\mathrm{HCl}$ flow. Typically, it took several minutes just for a $50 \%$ signal reduction to be observed after switching from span gases to zero air. The response times can probably be improved considerably through a variety of improvements in the gas conditioning hardware.

In other tests with $\mathrm{HCl}$ streams (in air) passing through the gas conditioning system, $\mathrm{HCl}$ concentrations of $2,4,8$, and $10 \mathrm{ppm}$ in the span gases were used after first equilibrating the system with a $10 \mathrm{ppm} \mathrm{HCl}$ stream. The $\mathrm{HCl}$ concentration was then decreased sequentially to lower levels. In a relative sense, the IMS reading tracked well with the changing $\mathrm{HCl}$ concentrations. However, a specific percentage reduction in the nominal $\mathrm{HCl}$ concentration did not result in the same percentage reduction in the IMS reading. The decrease in the IMS reading was always somewhat less than expected based on the magnitude of the decrease in theoretical $\mathrm{HCl}$ concentrations in the gases entering the gas conditioning system. This could reflect a possible need for some routine maintenance of the IMS analyzer, or could reflect the extended lag times observed in the signal responses when passing sample gases through the conditioner. Another possibility is that some of the $\mathrm{HCl}$ was being removed from the gas stream due to wall losses. In that event, the magnitude of the changes in theoretical $\mathrm{HCl}$ concentrations could easily be greater than the magnitude of the changes in the IMS reading as the $\mathrm{HCl}$ concentration was varied. This is particularly true in view of the fact that sorption/desorption equilibrium may change with changing $\mathrm{HCl}$ concentration. 
Next, tests were performed in which a simulated gasifier stream (excluding $\mathrm{NH}_{3}$ ) containing $10 \mathrm{ppm} \mathrm{HCl}$ was passed through the gas conditioning system prior to the IMS analyzer. For these tests, $2 \mathrm{~L} / \mathrm{min}$ of air was blended with $1 \mathrm{~L} / \mathrm{min}$ of gasifier stream (dry basis) prior to entering the catalyst tube in the gas conditioner. This resulted in a nominal $\mathrm{HCl}$ concentration of about $3 \mathrm{ppm}$ in the final blended gas stream. The reading reported by the IMS analyzer for these tests was about $2.5 \mathrm{ppm}$. This is in excellent agreement with the theoretical value of $3 \mathrm{ppm}$ in view of the collective experimental uncertainties involved.

Unlike the tests using streams of only air and $\mathrm{HCl}$ through the conditioner, fairly rapid response times were observed with the simulated flue gas stream when going from zero air to span gases. Specifically, steady signals were obtained by the IMS analyzer within 60 seconds when passing the simulated gasifier stream through the conditioner. Although the signal rise time was short, it took five minutes or more to clear the $\mathrm{HCl}$ out of the system when returning to zero air. This shows that there are significant wall effects in the gas conditioner and/or steel sampling lines. The greatly improved signal rise times observed while using the simulated flue gas instead of the air $/ \mathrm{HCl}$ streams is probably related to the high moisture content of the simulated gasifier stream, as opposed to the dry gases used in the tests with only air and $\mathrm{HCl}$. The moisture probably resulted in a flushing effect which helped transport the analyte through the system. However, the added moisture did not seem to help purge $\mathrm{HCl}$ out of the system very quickly.

With the simulated gasifier stream, the IMS readings tracked well with changes in the $\mathrm{HCl}$ concentration as the $\mathrm{HCl}$ concentration (prior to blending with air for catalytic oxidation of the gas stream) was varied from 2 to $10 \mathrm{ppm}$. However, as was the case with passing air/ $\mathrm{HCl}$ streams through the conditioner, the magnitude of the changes in the IMS readings for different $\mathrm{HCl}$ concentrations was somewhat less than anticipated based on the magnitude of the changes in the nominal $\mathrm{HCl}$ concentrations entering the gas conditioner. Since signal lag times were not an issue in the tests with simulated gasifier streams (i.e., rapid responses were observed), the fact that the changes in IMS readings were somewhat less than expected may reflect $\mathrm{HCl}$ losses during sample transport. Alternatively, as noted earlier, the analyzer may require some routine maintenance in order to exhibit peak performance.

In the next series of tests, $\mathrm{NH}_{3}$ was added to the simulated gasifier stream after a steady IMS signal was obtained for a gasifier stream containing $10 \mathrm{ppm} \mathrm{HCl}$ (prior to dilution with oxidation air). When the $\mathrm{NH}_{3}$ was added, the IMS reading quickly decreased and most of the $\mathrm{HCl}$ signal on the IMS analyzer disappeared. When the $\mathrm{NH}_{3}$ flow was stopped, the IMS reading returned to nearly the same value that was observed before the $\mathrm{NH}_{3}$ addition. This implies that the oxidation catalyst was not effectively destroying all of the $\mathrm{NH}_{3}$, in which case the $\mathrm{NH}_{3}$ can easily combine with $\mathrm{HCl}$ to form ammonium chloride as the gases cool. Although laboratory tests indicated that the catalyst effectively destroys all of the $\mathrm{NH}_{3}$ at the gas flow rates being used, those tests were performed with dry gases. The added moisture in the simulated gasifier stream substantially increased the volumetric flow rate, which in turn decreased the gas residence time in the catalyst zone. This problem can easily be circumvented by simply increasing the size of the catalyst zone. 
The tests with $\mathrm{NH}_{3}$ were repeated after adjusting some of the temperatures in the gas conditioner. This time, the introduction of $\mathrm{NH}_{3}$ did not cause a decrease in the $\mathrm{HCl}$ signal. These results show how sensitive the critical $\mathrm{NH}_{3}$ removal step is to various parameters in the gas conditioner. The effects of those parameters on the IMS readings require more thorough investigation.

The tests with the $\mathrm{HCl}$ CEM were successful in that low-level $\mathrm{HCl}$ streams could be successfully passed through the entire system (even in a simulated gasifier stream), and small changes (e.g., $1 \mathrm{ppm}$ ) in the $\mathrm{HCl}$ concentration could be observed. The catalytic oxidation component of the CEM worked well (although more work on $\mathrm{NH}_{3}$ removal is needed), as did the Nafion-based dryer. However, additional work is required to minimize potential wall losses and to minimize residence times of residual $\mathrm{HCl}$ in the sample transport lines and the gas conditioning system.

\section{CONCLUSIONS}

The gas conditioning issues involved with coal gasification streams are very complex and do not have simple solutions. This is particularly true in view of the fact that the gas conditioning system must deal with tars, high moisture contents, and problems with $\mathrm{NH}_{3}$ without affecting low ppb levels of $\mathrm{Hg}$, low levels (low ppm or less) of $\mathrm{HCl}$, or the successful operation of conditioner components and analytical systems. Those issues are far from trivial. Trying to develop a non-chemical system for gas conditioning was very ambitious in view of the difficult sampling environment and unique problems associated with coal gasification streams. Although a great deal was learned regarding calibration, sample transport, instrumentation options, gas stream conditioning, and CEM design options, some challenging issues still remain. Sample transport is one area that is often not adequately considered. Because of the gas stream composition and elevated temperatures involved, special attention will need to be given to the choice of materials for the sample line and other plumbing components. When using gas stream oxidation, there will be sample transport regions under oxidizing as well as reducing conditions, and each of those regions will require different materials of construction for sample transport. The catalytic oxidation approach worked well for removal of tars and $\mathrm{NH}_{3}$ on a short term basis, but durability issues related to using the catalyst tube during extended testing periods still require study.

The $\mathrm{Hg}$ analysis system employing a $\mathrm{D}_{2}$ background correction approach is promising, but is not yet fully developed. The primary complicating factor at this time is the fact that the required correction factor on the $\mathrm{D}_{2}$ channel of the instrument changes slightly with changing levels of interfering gases. Additional work is required to resolve that issue. Since the analyzer is the first of its kind, it can probably be improved through modifications in the optical/electrical design as well as upgrades in the optical/electrical components. Such modifications should enhance base line stability, lower the detection limit, improve the accuracy of $\mathrm{Hg}$ readings in the presence of high levels of interfering gases, and minimize the importance of the $\mathrm{D}_{2}$ correction factor. Passing low levels of elemental $\mathrm{Hg}$ through the gas conditioning system is very complex. Additional work is required to address sample transport issues through the gas conditioner. 
Also, the formation and deposition of sulfate aerosols and the successful conversion of oxidized $\mathrm{Hg}$ (formed while passing over the oxidation catalyst) back to the elemental form (and keeping it in that form) are issues that still require further study. The overall gas conditioning system needs to be simplified to allow for more routine use.

The tests with $\mathrm{HCl}$ using simulated gasifier streams were generally successful, but it is clear that additional development is needed before it is ready for field use. Using the IMS analytical approach is attractive in view of its high sensitivity and lack of significant interferences. However, because of the low dynamic range, a dilution system would be needed to cover $\mathrm{HCl}$ concentrations in the range of 0 to $100 \mathrm{ppm}$. IMS is sensitive to pulsations in the sample gas flow and the sample gas must be at atmospheric pressure, but those issues are easily dealt with. As with $\mathrm{Hg}$, additional work on transporting $\mathrm{HCl}$ through the gas conditioning system is required. The complete removal of $\mathrm{NH}_{3}$ is critical to the successful operation of the $\mathrm{HCl} \mathrm{CEM}$, and more tests in that area should be performed using simulated gasifier streams.

\section{REFERENCES}

1. G. N. Krishnan, G. T. Tong, B. J. Wood, and N. Korens, "High Temperature Coal Gas Chloride Cleanup for Molten Carbonate Fuel Cell Applications," Final Report, DOE/MC/21167-2080 (DE87001041), November 1986, pp. 57-60.

2. G. L. Anderson, F. O. Berry, B. D. Harmon, R. M. Laurens, and R. Biljetina, "Development of a Hot Gas Cleanup System for Integrated Coal Gasification/Molten Carbonate Fuel Cell Power Plants," Final Report, DOE/MC/19403-1816 (DE86001589), October 1985, p. A-4.

3. T. Grindley and T. H. Gardner, "Trace Contaminants in Fixed-Bed Gasifier Gas," in Proc. Twelfth Annual Gasification and Gas Stream Cleanup Systems Contractors Review Meeting, DOE/METC-92/6128, Vol. 2 (DE93000229), September 1992, pp. 479-497.

4. D. Laudal, Personal Communication, December 1998.

5. N. B. French, S. J. Priebe, and W. J. Haas, Jr., "State-of-the-Art Mercury CEMs," Anal. Chem. (News \& Features), 71(13), 1999, 470A-475A.

6. L. Puig and R. Sacks, "Hollow Cathode Plasma Emission Determination of F, Cl, and $\mathrm{Br}$ in Gas Streams,” Appl. Spectrosc., 43(5), 1989, 801-810.

7. K. K. Haak, S. Carson, and G. Lee, "On-Line Process Monitoring Using Ion Chromatography,"” American Laboratory, 18(12), 1986, 50-55.

8. C. D. Bartman, J. H. Renfroe, Jr., H. L. Robards, Jr., and E. M. Connolly, "A Mass Spectrometer-Based Continuous Emissions Monitoring System for Hazardous Waste Stack Gas Measurements," International Patent Application No. PCT/US91/07449 (Publication No. WO 92/07242), April, 1992. 
9. D. Shao, W.-P. Pan, and C.-L. Chou, "Monitoring of Chlorine in Coal During Pyrolysis by Simultaneous TG/FTIR Technique," in Am. Chem. Soc. Div. Fuel Chem. Preprints, 37(1), 1992, 108-115.

10. M. Nelson, K. S. Knight, M. A. Serio, P. R. Solomon, and M. A. Halter, "On-Line FTIR Analysis of Fossil-Fuel Fired Power Plants," in Am. Chem. Soc. Div. Fuel Chem. Preprints, 38(4), 1993, 1159-1163.

11. G. M. Plummer, "Field and Laboratory Studies of Fourier Transform Infrared (FTIR) Spectroscopy in Continuous Emissions Monitoring Applications," in Proc. SPIE Int. Soc. Opt. Eng., 1434, 1991, 78-79.

12. B. Pandompatam, A. J. Liem, P. Hannak, and R. Frenette, "Continuous Emission Monitoring at a Hospital Waste Incinerator," in Proc. $79^{\text {th }}$ APCA Annual Meeting, 1986, 122 (abstract only).

13. S. A. Shanklin, J. R. Jernigan, and S. C. Steinsberger, "Evaluation of HCl Continuous Emissions Monitors," EPA/600/3-89/019, March 1989.

14. A. F. Grand, "Continuous Monitoring of Hydrogen Chloride in Combustion Atmospheres and in Air," J. Fire Sci., 6(1), 1988, 61-79.

15. G. C. Huston, Sr. and J. K. Wachter, "Development of an Extractive Continuous Monitor for Hydrogen Chloride ( $\mathrm{HCl})$ Analyses of Coal-Derived Process Streams," Anal. Letters, 22(1), 1989, 269-292.

16. H. H. Hill, Jr., W. F. Siems, R. H. St. Louis, and D. G. McMinn, "Ion Mobility Spectrometry," Anal. Chem., 62(23), 1990, 1201A-1209A.

17. V. Harris, "Field Validation of the Portable Ion Mobility Hydrogen Fluoride Continuous Emissions Monitoring Systems," presented at Stationary Source Sampling and Analysis for Air Pollutants, XIX, Engineering Foundation Conf., San Diego, CA, March 26-31, 1995.

18. G. E. Spangler and T. W. Carr, "Instrument Design and Description" in Plasma Chromatography, Plenum Press, New York, 1984.

19. A. T. Bacon, R. Getz, and J. Reategui, "Ion-Mobility Spectrometry Takles Tough Process Monitoring," Chem. Eng. Progress, 87(6), 1991, 61-64.

20. A. T. Bacon, Molecular Analytics, Personal Conversation, June, 1996. 